\title{
Unintended effects of anti-hyperglycaemic drugs studied in population-based cohorts
}

Citation for published version (APA):

Driessen, J. H. M. (2017). Unintended effects of anti-hyperglycaemic drugs studied in population-based cohorts. [Doctoral Thesis, Maastricht University]. Gildeprint Drukkerijen. https://doi.org/10.26481/dis.20170421ad

Document status and date:

Published: 01/01/2017

DOI:

10.26481/dis.20170421ad

Document Version:

Publisher's PDF, also known as Version of record

\section{Please check the document version of this publication:}

- A submitted manuscript is the version of the article upon submission and before peer-review. There can be important differences between the submitted version and the official published version of record.

People interested in the research are advised to contact the author for the final version of the publication, or visit the DOI to the publisher's website.

- The final author version and the galley proof are versions of the publication after peer review.

- The final published version features the final layout of the paper including the volume, issue and page numbers.

Link to publication

\footnotetext{
General rights rights.

- You may freely distribute the URL identifying the publication in the public portal. please follow below link for the End User Agreement:

www.umlib.nl/taverne-license

Take down policy

If you believe that this document breaches copyright please contact us at:

repository@maastrichtuniversity.nl

providing details and we will investigate your claim.
}

Copyright and moral rights for the publications made accessible in the public portal are retained by the authors and/or other copyright owners and it is a condition of accessing publications that users recognise and abide by the legal requirements associated with these

- Users may download and print one copy of any publication from the public portal for the purpose of private study or research.

- You may not further distribute the material or use it for any profit-making activity or commercial gain

If the publication is distributed under the terms of Article $25 \mathrm{fa}$ of the Dutch Copyright Act, indicated by the "Taverne" license above, 
Unintended effects of anti-hyperglycaemic drugs

studied in population-based cohorts

Annemariek Driessen 
(c) Annemariek Driessen, Maastricht, 2017

\section{Cover: Dorijn Otto}

Layout: Tiny Wouters

Printing: Gildeprint B.V.

ISBN: 978-90-9030183-9

Printing of this thesis was kindly supported by: het Nederlands Bijwerkingen Fonds. 


\title{
Unintended effects of anti-hyperglycaemic drugs
}

\author{
studied in population-based cohorts
}

\section{PROEFSCHRIFT}

ter verkrijging van de graad van doctor aan de Universiteit Maastricht,

op gezag van de Rector Magnificus, Prof. dr. Rianne M. Letschert, volgens het besluit van het College van Decanen,

in het openbaar te verdedigen

op vrijdag 21 april 2017, om 12.00 uur

door

Johanna Hendrika Maria Driessen 


\section{Promotor}

Prof. dr. J.P.W. van den Bergh

\section{Copromotoren}

Dr. F. de Vries

Dr. R.M.A. Henry

Dr. H.A.W. van Onzenoort (Radboudumc)

\section{Beoordelingscommissie}

Prof. dr. P.M.M. Geusens (voorzitter)

Prof. dr. G.J.P. van Breukelen

Prof. dr. G.J. Dinant

Prof. dr. M. den Heijer (VU medisch centrum Amsterdam)

Prof. dr. T.P. van Staa (University of Manchester, United Kingdom) 



\section{Contents}

List of Abbreviations

Chapter 1 General Introduction

Chapter 2 Fracture risk and use of anti-hyperglycaemic drugs

2.1 The epidemiology of fractures in Denmark in 2011

Osteoporos Int. 2016;27(6):2017-25

2.2 Use of dipeptidyl peptidase 4 inhibitors for type 2 diabetes mellitus and risk of fracture

Bone. 2014;68:124-30

2.3 Use of dipeptidyl peptidase 4 inhibitors and fracture risk compared to use of other anti-hyperglycaemic drugs

Pharmacoepidemiol Drug Saf. 2015;24(10):1017-25

2.4 Bone fracture risk is not associated with the use of glucagon-like peptide 1 receptor agonists: A population-based cohort analysis Calcif Tissue Int. 2015;97(2):104-12

2.5 Use of glucagon-like peptide 1 receptor agonists and risk of fracture as compared to use of other anti-hyperglycaemic drugs Calcif Tissue Int. 2015;97(5):506-15

2.6 The use of incretins and fractures - a meta-analysis on 103 population-based real life data Br J Clin Pharmacol. 2016; in press. fracture; a retrospective population-based cohort study Diabetes Obes Metab. 2017;19(3):421-428 
Chapter 3 Anti-hyperglycaemic drug use within the Maastricht Study population and potential unintended effects

3.1 Drug utilization in the Maastricht Study: a comparison with nationwide data

3.2 The association between insulin use and volumetric bone mineral density, bone micro-architecture and bone strength of the distal radius in patients with T2DM - the Maastricht Study

3.3 Metformin dosage and duration is not associated with aortic stiffness - the Maastricht Study

Chapter 4 Methodological Aspects

4.1 Evaluation of different missing data strategies in propensity score analyses

Chapter 5 General Discussion

Appendices Summary 


\section{List of Abbreviations}

AGE Advanced glycation end product

ATC Anatomical Therapeutic Chemical

BMD Bone mineral density

BMI Body mass index

CEL $\quad \mathrm{N}(\varepsilon)$-(carboxyethyl)lysine

cfPWV Carotid-femoral pulse wave velocity

$\mathrm{Cl} \quad$ Confidence interval

CML $\quad \mathrm{N}(\varepsilon)$-(carboxymethyl)lysine

COPD Chronic obstructive pulmonary disease

CPRD Clinical Practice Research Datalink

CVD Cardiovascular disease

DDD Defined daily dose

DPP4-I Dipeptidyl peptidase 4 inhibitor

DXA Dual-energy X-ray absorptiometry

EGFR Estimated glomerular filtration rate

EHD Electronic healthcare database

FRAX Fracture risk assessment tool

GI Gastrointestinal

GIP Gastric inhibitory polypeptide

GIP Glucose dependent insulinotropic polypeptide

GLP-1 Glucagon-like peptide 1

GLP1-RA Glucagon-like peptide 1 receptor agonist

GP General practitioner

GPRD General practice research database

HbA1c Glycosylated hemoglobin type A1c

HR Hazard ratio

HR-pQCT High-resolution peripheral quantitative computed tomography

ICD International classification of diseases and related health problems

IOF International osteoporosis foundation

IQR Interquartile range

IR Incidence rate

IRR Incidence rate ratio

MAP Mean arterial pressure

MAR Missing at random

MCAR Missing completely at random

MI Multiple imputation

MPR Medication possession rate

NHDR National Hospital Discharge Register

NHSR National Health Services Register 


$\begin{array}{ll}\text { NIAD } & \text { Non-insulin anti-diabetic drug } \\ \text { NSAID } & \text { Non-steroidal anti-inflammatory drugs } \\ \text { OGTT } & \text { Oral glucose tolerance test } \\ \text { OR } & \text { Odds ratio } \\ \text { PS } & \text { Propensity score } \\ \text { PPAR- }- & \text { Peroxisome proliferator-activated receptor- } \gamma \\ \text { RAAS } & \text { Renin angiotensin aldosterone system } \\ \text { RCT } & \text { Randomised controlled trial } \\ \text { RR } & \text { Relative risk } \\ \text { SAF } & \text { Skin autofluorescence } \\ \text { SD } & \text { Standard deviation } \\ \text { SU } & \text { Sulfonylurea derivative } \\ \text { T1DM } & \text { Type } 1 \text { diabetes mellitus } \\ \text { T2DM } & \text { Type } 2 \text { diabetes mellitus } \\ \text { TBS } & \text { Trabecular bone score } \\ \text { TZD } & \text { Thiazolidinedione } \\ \text { UK } & \text { United Kingdom } \\ \text { VBMD } & \text { Volumetric bone mineral density }\end{array}$





\section{Chapter 1}

General Introduction 


\section{Pharmacoepidemiology}

Pharmacoepidemiology studies the use and effects of medications in large numbers of people. It frequently utilizes large "real-world" electronic healthcare databases (EHDs) that often include millions of patients and multiple years of observations. These EHDs contain longitudinal data on patient characteristics as well as medical diagnoses and sometimes also life-style variables, like body mass index (BMI), smoking status and alcohol use. More recently, longitudinal drug prescription history has also been added to these databases. With these databases populationbased cohorts can be created to study exposure - outcome associations.

Examples of EHDs include the Clinical Practice Research Datalink (CPRD) (www.cprd.com), which is representative for the United Kingdom (UK) population, and the Danish National Health Services Register (NHSR) ${ }^{1}$. The NHSR contains data on $98 \%$ of all Danish residents and can be linked to the national hospital register ${ }^{2}$ as well as to the national prescription registry ${ }^{3}$. The PHARMO Record Linkage System database (www.pharmo.nl) is a Dutch EHD, which holds drug dispensing data of more than four million Dutch residents, representing $25 \%$ of the Dutch population. This database is linked to different registers, including the national hospital discharge register.

EHDs are particularly useful when studying rare adverse events which cannot be detected in randomised controlled trials (RCTs), due to the restricted number of included patients. Consequently, with use of EHDs adverse effects with a low incidence rate can be detected. Moreover, the longer follow-up time in EHDs makes it possible to study long-term adverse effects. Another advantage of EHDs over RCTs is that when studying real-life data, adherence to treatment rates may better represent actual medication intake, while RCTs tend to overestimate adherence ${ }^{4}$. Additionally, RCTs often apply strong in- and exclusion criteria which consequently result in a selected population. This therefore not always reflects the real-life situation where patients have comorbidities and use other drugs concomitantly. With the use of EHDs this can be taken into account. One of the drawbacks of using observational data is the possibility for bias and confounding, which might seriously distort the effect estimates. RCTs suffer less from this problem as patients are randomised to one of the investigated treatment arms.

When interpreting the results from a pharmacoepidemiological study, one has to take the potential sources of bias and confounding into account as well as the proposed biological or pharmacological mechanism which underlies the studied effect. A study investigating statin use and risk of hip fracture found a $45 \%$ reduced risk of fracture already after 30 days of statin use ${ }^{5}$. The hypothesized mechanism included an increase in bone formation and inhibition of osteoclast activity. Bisphosphonates, drugs used to increase bone mineral density (BMD), inhibit the osteoclast activity as well. However, for bisphosphonates it is known to take 
$\geq 18$ months (for non-vertebral fractures) to reduce fracture risk ${ }^{6}$. Re-analysis of the data showed that the choices made in the study design had resulted in this artificial reduced risk of fractures with statin use ${ }^{7}$. To overcome this problem one first has to hypothesize how the slope of the hazard function will look like where after this can be studied in multiple ways taking the time of a possible biological effect into account. Methods to study this include analyses where the time since the most recent prescription is studied. Additionally, average, cumulative dose and continuous duration of use should be studied as well as ever versus never exposure.

\section{Osteoporosis and diabetes}

Osteoporosis is defined as a systematic bone disease characterized by low bone mass and deterioration of the microarchitecture of the bone, leading to bone fragility and propensity to fracture ${ }^{8}$. It has been estimated that about 22 million women and 3.5 million men suffered from osteoporosis in Europe in $2010^{9}$. Estimates for the Netherlands showed a prevalence of 16.1 per 1000 women and 1.9 per 1000 men in $2007^{10}$. Osteoporosis can occur without a known underlying cause, and is diagnosed in clinical practice by the presence of a fragility fracture or using BMD criteria. BMD is the amount of bone mass per unit area (areal density, $\mathrm{g} / \mathrm{cm}^{2}$ ), and can be measured in vivo by densitometry techniques ${ }^{11}$. Dual-energy X-ray absorptiometry (DXA) provides a two-dimensional areal value and is influenced by bone size as well as the true density ${ }^{11,12}$.

The BMD criteria for diagnosis were developed by the WHO on the basis of epidemiological data that describe the normal distribution of BMD in a reference population comprising healthy young adults ${ }^{13}$. According to these criteria, a spine, total hip or femoral neck BMD of 2.5 standard deviations (SDs) or more below the reference mean (T-score $\leq-2.5$ ) defines osteoporosis. Osteopenia-low bone density or mass-is diagnosed by a T-score between -1.0 and -2.5 and a normal BMD by a Tscore $\geq-1$.

Diabetes is a chronic disease characterized by high blood glucose levels ${ }^{14}$. Diabetes is diagnosed based on a fasting glucose $\geq 7.0 \mathrm{mmol} / \mathrm{l}$ or a 2 -h plasma glucose $\geq 11.1 \mathrm{mmol} / \mathrm{I}^{15}$. The estimated total number of patients with diabetes world-wide was 171 million in $2000^{16}$. Projections indicate that the number of patients will increase to 366 million in 2030. The estimated prevalence of diabetes in the Netherlands was 61.8 per 1000 women and 66.1 per 1000 men in $2014^{17}$. About $90 \%$ of the patients with diabetes have type 2 diabetes mellitus (T2DM) which is characterized by insulin resistance and/or abnormal insulin secretion. Patients with T2DM need oral anti-hyperglycaemic drugs and/or insulin to control their blood glucose levels ${ }^{18}$. 


\section{T2DM and fracture risk}

T2DM has been associated with an increased risk of fracture despite the fact that patients with $\mathrm{T} 2 \mathrm{DM}$ often have a normal or even increased $\mathrm{BMD}^{19}$. It is hypothesized that this increased fracture risk is the consequence of an increased falling risk and reduced bone quality and bone strength ${ }^{20,21}$.

Older patients with T2DM have shown to fall more often than age members without $\mathrm{T}_{2} \mathrm{DM}^{22}$. In contrast, younger patients with T2DM did not show a difference in the fall frequency as compared to patients without $\mathrm{T}_{2} \mathrm{DM}^{23}$. Nevertheless, younger patients with T2DM showed a worse performance of a functional mobility test as compared to people of the same age without T2DM, which suggests that the fall risk in young patients with T2DM might be increased as well. Complications of T2DM, like neuropathy ${ }^{24}$ and retinopathy ${ }^{25}$ have been associated with and may attribute to an increased risk of falling. In addition, patients with T2DM use on average nine different medications concomitantly ${ }^{22}$. Concomitant use of four medications has been associated with an increased risk of falling ${ }^{26}$.

DXA measurements have extensively been used to measure BMD in persons with and without T2DM. High resolution peripheral quantitative computed tomography (HR-pQCT) is a relatively new technique which can be used to measure 3D bone density of the distal radius and tibia ${ }^{27}$. In addition, HR-pQCT allows the in vivo assessment of bone microarchitecture as well as calculation of biomechanical properties of the distal radius and tibia using microfinite element analysis ${ }^{27}$. Up to date, the HR-pQCT analyses in patients with T2DM are not uniform. An increased cortical porosity has been reported when comparing persons with and without $\mathrm{T}_{2} \mathrm{DM}^{28,29}$. However, other studies reported no differences when comparing HR-pQCT parameters between persons with and without $\mathrm{T}_{2} \mathrm{DM}^{30-32}$. In other studies, an increased cortical porosity was found only for patients with T2DM and microvascular complications $^{33}$ or in patients with T2DM and a fragility fracture compared to patients with T2DM without a fragility fracture ${ }^{34}$.

Anti-hyperglycaemic drugs might also affect bone metabolism. For instance, use of thiazolidinediones (TZDs) has been associated with an 1.3 times increased risk of osteoporotic fracture as compared to patients using other anti-hyperglycaemic drugs $^{35}$. TZDs are peroxisome proliferator-activated receptor (PPAR) $-\nu$ agonists and they improve glycemic control via the activation of PPAR- $\gamma$. However, they also activate PPAR- $\gamma$ on mesenchymal stem cells and consequently the differentiation of osteoblasts is shifted towards adipocytes ${ }^{36,37}$. This might then result in a lower BMD and hence increased fracture risk.

The use of insulin has also been associated with fracture risk. In vitro studies have suggested an anabolic effect of insulin on bone. However, an increased fracture risk was seen in observational studies ${ }^{38}$. One of the suggested explanations is that use of insulin is associated with an increased risk of hypoglycaemia and thereby an 
increased risk of falling, which then might increase fracture risk ${ }^{20}$. Another explanation is the fact that patients who use insulin for T2DM often have a longer disease duration and therefore also a longer hyperglycaemic exposure. Hyperglycaemic exposure has been associated with advanced glycation end products (AGEs) which can bind to collagen, and thereby might increase bone fragility and potentially increase fracture risk ${ }^{39}$.

Incretin agents, including dipeptidyl peptidase 4 inhibitors (DPP4-Is) and glucagonlike peptide 1 receptor agonists (GLP1-RAs), are a relatively new class of antihyperglycaemic drugs. Both GLP1-RAs and DPP4-Is prolong the short half-life of the incretin hormone glucagon-like peptide 1 (GLP-1). GLP1-RAs do this directly as they have an increased resistance to the degradation by the enzyme dipeptidyl peptidase 4 (DPP4), whereas DPP4-Is increase GLP-1 indirectly via the inhibition of DPP4 ${ }^{38}$.

In vitro studies have suggested that these agents might have a beneficial effect on fracture risk. GLP-1 receptors have been found on osteocytes and osteoblasts, and different mechanisms have been proposed how an increased level of GLP-1 might result in a decreased fracture risk $^{40-42}$. A first meta-analysis of adverse effects data of clinical trials indeed showed a $40 \%$ reduced risk of fractures ${ }^{43}$. However, observational data from population-based cohorts is lacking.

\section{The Maastricht Study}

The Maastricht Study is an observational prospective population-based cohort study which is currently collecting data from participants who live in the southern part of the Netherlands ${ }^{44}$. The Maastricht Study focuses on the aetiology, pathophysiology, complications and comorbidities of T2DM and is characterized by an extensive phenotyping approach. This includes extensive measurements on cardiovascular risk factors, diabetic complications, other chronic diseases, lifestyle, (psycho-) social factors as well as extensive biobanking. Additional to the current cross-sectional data, longitudinal drug dispensing data are available within the Maastricht Study, which makes it possible to perform pharmacoepidemiological studies.

\section{Missing data and confounding}

Missing data is an issue in almost every research, including observational research using EHDs or Maastricht Study data. Standard statistical techniques, such as regression, cannot handle missing data and as a consequence all observations with 
at least one missing variable are deleted during the analysis (a so called "complete-case analysis"). This is inefficient and might also result in biased estimates when the data are not missing completely at random (MCAR) ${ }^{45}$.

When data are missing due to an ill employee or a broken machine data are classified as $M_{C A R}{ }^{46}$. The missing data are completely independent from other measured or unmeasured data ${ }^{46}$. When the missingness is conditional on other measured data, data are classified as missing at random (MAR). The probability of missingness does then not depend on the true values for the missing observations but only on other observed variables ${ }^{46}$. For example, patients with a high BMI might be less able to perform a physical test. Their data might therefore be more likely to be missing. Additionally, it might be assumed that patients with a higher BMI score less on a performance test. Therefore the missing data, from the patients with a high $\mathrm{BMI}$, might be lower than the observed values. If $\mathrm{BMI}$ can then be used to fully explain the missingness of the physical test data, the data are said to be MAR. When missing data are neither MCAR nor MAR, missing data are classified as missing not at random ${ }^{46}$.

Multiple imputation ( $\mathrm{MI}$ ) is a statistical technique which can be used to deal with missing data by replacing the missing data with imputed values, creating multiple complete datasets. The observed data are used to impute the missing data taking into account the correlations between all variables used in the imputation model ${ }^{45}$. The different complete datasets are then analysed and the results combined to get valid inferences. If data are MCAR, a complete-case analysis will not result in biased estimates, it will only be inefficient. However, MCAR is not very likely in practice. When data are MAR, a complete-case analysis might result in biased estimates, whereas the estimates based on $\mathrm{Ml}$ are unbiased and more efficient ${ }^{45}$.

Another important aspect to occur in observational research is confounding. When analyses are not adjusted for confounding factors, it might result in distorted treatment effects. There are different techniques to deal with confounding. Propensity scores (PSs) are one of them. PSs were introduced by Rosenbaum and Rubin $^{47}$ in the eighties. However, they have not been widely used until $2000^{48}$. A PS is the probability of being exposed given the values of the measured confounding variables ${ }^{47}$. The use of a PS creates a balance based on the measured confounders between the groups under study ${ }^{49}$. Not much research has evaluated the effects of using PSs in combination with $\mathrm{MI}$ on estimated treatment effects in time-fixed analyses. 


\section{Objectives of this thesis}

The overall objective of this thesis was to study the unintended effects of antihyperglycaemic drugs in population-based cohorts. This thesis consists of three main parts: 1) evaluation of the association between use of incretin agents, both DPP4-Is and GLP1-RAs, and risk of fracture; 2) an assessment of the usefulness of Maastricht Study data to evaluate unintended effects of diabetes medication, in particular of bone strength parameters; and 3) to investigate the effect on treatment estimates when combining different techniques to handle missing data with propensity score analyses.

\section{Outline}

Chapter 2 comprises seven studies assessing fracture incidence rates and the risk of fractures when using incretin agents. It starts with a study on the incidence of fractures in Denmark in 2011 using data from the Danish NHSR. In this study we aimed to estimate fracture site specific incidence rates and to compare those to earlier reported imputed incidence rates. In Chapter 2.2 and 2.3 the association of DPP4-Is and fracture risk was studied using CPRD and Danish NHSR data, respectively. The association of GLP1-RAs and risk of fracture was evaluated using CPRD and the Danish NHSR data in Chapter 2.4 and 2.5. In addition the results of Chapter 2.2-2.5 have been meta-analysed, to further study the association between use of DPP4-Is and GLP1-RAs. This is presented in Chapter 2.6. To overcome the limitation of a restricted duration of follow-up of the data, Chapter 2.7 describes a sensitivity analysis of updated data from Chapter 2.2. In this chapter we extended the follow-up period from 2007-2012 to 2007-2015 in order to better evaluate the effects of prolonged DPP4-I use on fracture risk.

Chapter 3 consists of three studies which are performed using data from the Maastricht Study. It starts with a study investigating the representativeness of the Maastricht Study with respect to prescription data when compared to the national population. In Chapter 3.2 and 3.3, we studied the relationship of antihyperglycaemic drugs, as measured by longitudinal prescription data, and specific outcomes measured in the Maastricht Study. In Chapter 3.2 we examined whether use of insulin as compared to non-insulin use was associated with different bone architectural and strength parameters, as measured by HR-pQCT. In Chapter 3.3 we studied whether metformin has beneficial effects on arterial stiffness measured by carotid-femoral pulse wave velocity and what the role of AGEs was in this potential association. 
Chapter 4 consists of a study that evaluated what the effect on treatment estimates is when different techniques to deal with missing data are combined with propensity score analysis in time-fixed time-to-event data. This thesis concludes with a general discussion of the results, prospects for future research and some methodological considerations. 


\section{References}

1. Andersen TF, Madsen M, Jørgensen J, Mellemkjoer L, Olsen JH. The Danish National Hospital Register. A valuable source of data for modern health sciences. Dan Med Bull. 1999;46(3):263-8.

2. Andersen JS, Olivarius Nde F, Krasnik A. The Danish National Health Service Register. Scand J Public Health. 2011;39(7 Suppl):34-7.

3. Kildemoes HW, Sørensen HT, Hallas J. The Danish National Prescription Registry. Scand J Public Health. 2011;39(7Suppl):38-41.

4. Hannan EL. Randomized clinical trials and observational studies: guidelines for assessing respective strengths and limitations. JACC Cardiovasc Interv. 2008;1(3):211-7.

5. Meier $C R$, Schlienger $R G$, Kraenzlin $M E$, Schlegel B, Jick H. HMG-CoA reductase inhibitors and the risk of fractures. JAMA. 2000;283(24):3205-10.

6. McClung MR, Geusens P, Miller PD, Zippel H, Bensen WG, Roux $C$, et al. Effect of risedronate on the risk of hip fracture in elderly women. Hip Intervention Program Study Group. N Engl J Med. 2001;344(5): 333-40.

7. de Vries F, de Vries C, Cooper C, Leufkens B, van Staa TP. Reanalysis of two studies with contrasting results on the association between statin use and fracture risk: the General Practice Research Database. Int J Epidemiol.2006;35(5):1301-8.

8. Doran PM, Khosla S. Osteoporosis. In: Hall JE, Nieman LK, editors. Contemporary Endocrinology: Handbook of Diagnostic Endocrinology. Totowa, NJ: Humana Press. 2003:257-75.

9. Svedbom $A$, Hernlund $E$, Ivergård $M$, Compston J, Cooper C, Stenmark J, et al. Osteoporosis in the European Union: a compendium of country-specific reports. Arch Osteoporos. 2013;8:137.

10. Poos MJJC, Gommer AM. Hoe vaak komt osteoporose voor en hoeveel mensen sterven eraan? http://www.nationaalkompas.nl/gezon dheid-en-ziekte/ziekten-en-aandoeningen/bex wegingsstelsel-en-bindweefsel/osteoporose/o mvang/. Assessed: 27-6-2016.

11. E. Hernlund, A. Svedbom, M. Ivergård, J. Compston, C. Cooper, J. Stenmark, et al. A report prepared in collaboration with the International Osteoporosis Foundation (IOF) and the European Federation of
Pharmaceutical Industry Associations (EFPIA) Arch Osteoporos (2013) 8:136.

12. WHO (1994) Assessment of fracture risk and its application to screening for postmenopausal osteoporosis. WHO Study Group. World Health Organ Tech Rep Ser 843:1-129.

13. Writing Group for the ISCD Position Development Conference. Position statement: executive summary. The Writing Group for the International Society for Clinical Densitometry (ISCD) Position Development Conference. J. Clin. Densitom. 2004:7(1), 7-12.

14. Yan W, Li X. Impact of diabetes and its treatments on skeletal diseases. Front Med. 2013;7(1):81-90.

15. WHO. Definition and Diagnosis of diabetes mellitus and intermediate hyperglycemia. 2006. www.whoint/diabetes/publications/Defi nition\%20and\%20diagnosis\%20of\%20diabetes _newpdf. Assessed: 27-6-2016.

16. Wild S, Roglic G, Green A, Sicree R, King $H$. Global prevalence of diabetes: estimates for the year 2000 and projections for 2030. Diabetes Care. 2004;27(5):1047-53.

17. Diabetes prevalence Netherlands https://www. volksgezondheidenzorg.info/onderwerp/diabe tes-mellitus/cijfers-context/huidige-situatie\#n ode-prevalentie-diabeteshuisartsenpraktijk. Assessed: 27-6-2016.

18. Zimmet P, Alberti KG, Shaw J. Global and societal implications of the diabetes epidemic. Nature. 2001;414(6865):782-7.

19. Vestergaard P. Discrepancies in bone mineral density and fracture risk in patients with type 1 and type 2 diabetes--a meta-analysis. Osteoporos Int. 2007;18(4):427-44.

20. de Waard EA, van Geel TA, Savelberg $H H$, Koster A, Geusens PP, van den Bergh JP. Increased fracture risk in patients with type 2 diabetes mellitus: an overview of the underlying mechanisms and the usefulness of imaging modalities and fracture risk assessment tools. Maturitas. 2014;79(3):26574.

21. Carnevale V, Romagnoli E, D'Erasmo E. Skeletal involvement in patients with diabetes mellitus. Diabetes Metab Res Rev 2004;20:196-204.

22. Roman de Mettelinge T,Cambier D, Calders $P$, Van den Noortgate $\mathrm{N}$, Del-Baere K. Understanding the relationship between type 2 Diabetes mellitus and falls in older adults: a 
prospective cohort study. Plos One 2013;8(6):e67055.

23. Oliveira PP, Fachin SM, Tozatti J, Ferreira MC, Marinheiro LP. Comparative analysis of risk for falls in patients with and without type 2 diabetes mellitus. Rev Assoc Med Bras 2012;58(2):234-9.

24. Patel S, Hyer S, Tweed K, Kerry S, Allan K, Rodin $A$, et al. Risk factors for fractures and falls in older women with type 2 diabetes mellitus. Calcif Tissue Int. 2008;82(2):87-91.

25. Agrawal Y, Carey JP, Della Santina CC, Schubert MC, Minor LB. Diabetes, vestibular dysfunction, and falls: analyses from the National Health and Nutrition Examination Survey. Otol Neurotol. 2010;31(9):1445-50.

26. Huang ES, Karter AJ, Danielson KK, Warton EM, Ahmed AT. The association between the number of prescription medications and incident falls in a multi-ethnic population of adult type- 2 diabetes patients: the diabetes and aging study.J Gen Intern Med 2010; 25(2):141-6.

27. Geusens P, Chapurlat R, Schett G, GhasemZadeh A, Seeman E, de Jong J, et al. Highresolution in vivo imaging of bone and joints: a window to microarchitecture. Nat Rev Rheumatol. 2014;10(5):304-13.

28. Yu EW, Putman MS, Derrico N, AbrishamanianGarcia G, Finkelstein JS, Bouxsein ML. Defects in cortical microarchitecture among AfricanAmerican women with type 2 diabetes. Osteoporos Int. 2015;26(2):673-9.

29. Paccou J, Ward KA, Jameson KA, Dennison EM, Cooper C, Edwards $\mathrm{MH}$. Bone Microarchitecture in Men and Women with Diabetes: The Importance of Cortical Porosity. Calcif Tissue Int. 2016;98(5):465-73.

30. Shu A, Yin MT, Stein E, Cremers S, Dworakowski $E$, Ives $R$, et al. Bone structure and turnover in type 2 diabetes mellitus. Osteoporos Int. 2012;23(2):635-41.

31. Burghardt AJ, Issever AS, Schwartz AV, Davis KA, Masharani U, Majumdar S, et al. Highresolution peripheral quantitative computed tomographic imaging of cortical and trabecular bone microarchitecture in patients with type 2 diabetes mellitus. J Clin Endocrinol Metab. 2010;95(11): 5045-55.

32. Farr JN, Drake MT, Amin S, Melton LJ 3rd, McCready LK, Khosla S. In vivo assessment of bone quality in postmenopausal women with type 2 diabetes. J Bone Miner Res. 2014;29(4):787-95.

33. Shanbhogue VV, Hansen S, Frost $M$, Jørgensen NR, Hermann AP, Henriksen JE, et al. Compromised cortical bone compartment in type 2 diabetes mellitus patients with microvascular disease. Eur J Endocrinol. 2016;174(2):115-24.

34. Patsch JM, Burghardt AJ, Yap SP, Baum T, Schwartz AV, Joseph GB, et al. Increased cortical porosity in type 2 diabetic postmenopausal women with fragility fractures. J Bone Miner Res. 2013;28(2):31324.

35. Bazelier MT, Vestergaard P, Gallagher AM, van Staa TP, Cooper C, Leufkens HG, et al. Risk of fracture with thiazolidinediones: disease or drugs? Calcif Tissue Int. 2012;26(9):2271-9.

36. Grey A. Skeletal consequences of thiazolidinedione therapy. Osteoporos Int. 2008;19(2):129-37.

37. Benvenuti S, Cellai I, Luciani P, Deledda C, Baglioni S, Giuliani C, et al. Rosiglitazone stimulates adipogenesis and decreases osteoblastogenesis in human mesenchymal stem cells. J Endocrinol Invest 2007;30(9):RC26RC30.

38. Mannucci E, Dicembrini I. Drugs for type 2 diabetes: role in the regulation of bone metabolism. Clin Cases Miner Bone Metab. 2015;12(2):130-4.

39. Vashishth $\mathrm{D}$. The role of the collagen matrix in skeletal fragility. Curr Osteoporos Rep. 2007;5(2):62-6.

40. Pacheco-Pantoja EL, Ranganath LR, Gallagher $J A$, et al. Receptors and effects of gut hormones in three osteoblastic cell lines. BMC Physiol. 2011;11:12.

41. Nuche-Berenguer B, Portal-Núñez $S$, Moreno $P$, et al. Presence of a functional receptor for GLP1 in osteoblastic cells, independent of the CAMP-linked GLP-1 receptor. J Cell Physiol. 2010;225:585-92.

42. Ceccarelli E, Guarino EG, Merlotti D, Patti A, Gennari L, Nuti R, et al. Beyond glycemic control in diabetes mellitus: effects of incretin-based therapies on bone metabolism. Front Endocrinol (Lausanne) 2013;18(4):73.

43. Monami M, Dicembrini I, Antenore A, Mannucci E. Dipeptidyl peptidase-4 inhibitors and bone fractures: a meta-analysis of 
randomized clinical trials. Diabetes Care. 2011;34(11):2474-6.

44. Schram MT, Sep SJ, van der Kallen CJ, Dagnelie PC, Koster A, Schaper N, et al. The Maastricht Study: an extensive phenotyping study on determinants of type 2 diabetes, its complications and its comorbidities. Eur J Epidemiol. 2014;29(6):439-51.

45. Sterne JA, White IR, Carlin JB, Spratt M, Royston P, Kenward MG, et al. Multiple imputation for missing data in epidemiological and clinical research: potential and pitfalls. BMJ. 2009:29;338:b2393.
46. Little RJ, Rubin DB. Statistical analysis with missing data. 2nd ed. New York: Wiley, 2002.

47. Rosenbaum PR, Rubin DB. The central role of the propensity score in observational studies for causal effects. Biometrika. 1983a;70:41-55.

48. Glynn RJ, Schneeweiss S, Stürmer T. Indications for propensity scores and review of their use in pharmacoepidemiology. Basic Clin Pharmacol Toxicol. 2006;98(3):253-9.

49. Williamson EJ, Forbes A. Introduction to propensity scores.

Respirology. 2014;19(5):625-35. 



\section{Chapter}

Fracture risk and use of anti-hyperglycaemic drugs 


\section{Chapter}

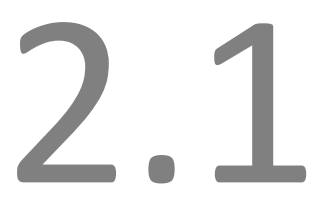

The epidemiology of fractures in Denmark in 2011

JHM Driessen, L Hansen, SA Eriksen, HAW van Onzenoort, RMA Henry, JPW van den Bergh, B Abrahamsen, P Vestergaard, F de Vries

Osteoporos Int. 2016;27(6):2017-25 


\section{Abstract}

\section{Introduction}

Osteoporosis is a major public health burden through associated (osteoporotic) fractures. In Denmark, incidence rates (IRs) of hip fracture are widely available. However, there is limited data about other fracture sites. A recent report could only provide imputed IRs, although nationwide data is readily available in electronic healthcare databases. Therefore our aim was to estimate fracture site specific IRs for Denmark in 2011 and to compare those to the previously reported imputed data.

\section{Methods}

Data from the Danish National Hospital Discharge Register was used to estimate age- and genderspecific IRs for any fracture as well as for different fracture sites in the Danish population aged 20 years and older in 2011. Hip fracture IRs were stratified to sub-sites and IRs were determined for all hip fractures which were confirmed by surgery.

\section{Results}

The total number of incident fractures in 2011 was 80,760 (IR: 191, 95\% confidence interval (CI): 190-192 (per 10,000 person-years), of which 35,398 (43.8\%, IR: 171, 95\% CI: 169-173) occurred in men and 45,362 (56.2\%, IR: $211,95 \% \mathrm{Cl}: 209-213)$ ) in women. The majority of the fractures occurred in the population aged 50 years and older ( $n=50,470$, IR: $249,95 \% \mathrm{Cl}: 247-251)$. The numbers of any and hip fracture were lower than the previously imputed estimates, whereas the number of forearm fractures was higher.

\section{Conclusion}

We showed age- and gender- specific fracture rates for any fracture as well as for different fracture sites. The IRs of most fracture sites increased with age. Estimating the number of fractures for Denmark based on imputation of data from other countries led to both over- and underestimation. Future research should therefore focus on how to improve those imputations as not all countries have nationwide registry data. 


\section{Introduction}

Osteoporosis is a major public health burden through associated (osteoporotic) fractures. In 2010, an estimated number of 66,000 incident fractures (12,000 hip fractures) occurred in the Danish population aged 50 years and older ${ }^{1}$. The associated costs of osteoporosis were estimated at $€ 1,055$ million for Denmark, 2010 ${ }^{1}$. Estimated costs of osteoporotic fractures have been projected to increase by about $50 \%$ in 2025 due to ageing of the population ${ }^{2}$.

An increasing number of studies have shown that secular trends in the incidence of hip fractures have levelled off or started to decline ${ }^{3,4}$. A call to update the data for as many countries as possible has been made ${ }^{3}$. Hip fracture incidence rates (IRs) have been estimated in different periods for the Danish population ${ }^{5,6}$ and IRs of distal forearm fracture are available for the period $1976-1984^{7}$, and for $2010^{8}$.

The International Osteoporosis Foundation (IOF) estimated the country-specific burden of osteoporosis and the number of incident fractures in 2010 for individuals aged $50+$ in Denmark ${ }^{1}$. Danish hip fracture IRs for 2004 were available from health registries which contain data on both in- and outpatient treatments ${ }^{9}$. IRs for other fracture sites were not available and therefore Swedish data from 1987-1994 were used $^{10}$. All radiography referrals that come to medical attention are recorded for Malmö, Sweden. Age- and sex- specific incidence rate ratios (IRRs) were calculated for the different fracture sites as compared to hip fracture in this population ${ }^{10}$. The estimated IRRs were then applied to the Danish hip fracture IRs, assuming that the ageand sex- specific IRRs were equal in Sweden and Denmark ${ }^{1}$. The IRs of forearm fractures in 2010 have recently been estimated for Denmark $^{8}$ using health registry data, which has shown a high validity ${ }^{11}$, and these IRs were somewhat higher than the imputed IRs by the IOF ${ }^{1}$.

Danish IRs are available for hip ${ }^{5,6}$ and forearm fractures ${ }^{7,8}$. However, there are no data on IRs of other fracture types. It has been shown for forearm fractures that imputation based on data from other countries might underestimate the real $I R^{8}$, but this has not been examined for other fracture types. Therefore the objective of our study was to estimate fracture site specific IRs for Denmark in 2011 and to compare those to the previously reported imputed data.

\section{Methods}

\section{Source population}

In Denmark, the extensive nature of registers, covering contacts to the health sector, offers good possibilities for studies on the occurrence of fractures ${ }^{11}$. Using the unique 10-digit civil registry number that is assigned to all Danish citizens shortly after birth, a 
complete hospital discharge history can be established for each individual, and valid linkage between population-based registries can be obtained ${ }^{12}$. Data on all changes in vital status, including change of address and date of death for the entire Danish population has been registered since 1968 in the Civil Registration System. The Danish National Hospital Discharge Register (NHDR) ${ }^{13}$ was founded in 1977 and covers all inpatient contacts from 1977 to 1994, and from 1995 furthermore includes all outpatient visits to hospitals, outpatient clinics, and emergency rooms. The reliability of Danish national fracture records has shown to be high, with a concordance of $94 \%$ for hip, $84 \%$ for forearm and $83 \%$ for humerus fractures between self-reported and registered fractures in female health professionals ${ }^{11}$. This was not a clinical trial and ethics committee approval was not required.

\section{Study design}

Patients were included when they were diagnosed with a fracture, high- or low trauma, in 2011 and aged 20 years or older. Any fracture was determined by the following International Classification of Diseases and Related Health Problems (ICD) 10 codes: S02, S12, S22, S32, S42, S52, S62, S72, S82, S92, T02, T08, T10 and T12. We investigated the following fracture sites: skull (S02), clinical symptomatic vertebral (S12, S22.0, S22.1, S32.0, T08), ribs (S22.2-S22.9), pelvis (S32), clavicle (S42.0), scapula (S42.1), humerus (S42.2-S42.4), forearm (S52), carpal (S62.0, S62.1), hip (S72.0-S72.2), femur unspecified (S72.3-S72.9), patella (S82.0), tibia/fibula (S82.1-S82.4), ankle (S82.5, S82.6, S82.8), and foot (S92). Unspecified fracture consisted of all other fracture ICD10 codes. Major osteoporotic fracture was determined as a hip, humerus, forearm or clinical symptomatic vertebral fracture according to the WHO definition ${ }^{14}$. Hip fracture was further stratified by the location of the fracture: neck, pertrochanteric or subtrochanteric (ICD-10: S72.0, S72.1 and S72.2, respectively). Surgery codes "KNFB" and "KNFJ4- 9 "15 were used to determine which hip fractures were confirmed by surgery within 10 days after the date of fracture.

The population demographics of the background population in 2011 were obtained online from Statistics Denmark (www.statistikbanken.dst.dk). IRs (number of fractures / 10,000 person-years) were calculated by dividing all cases of a first recorded fracture during 2011 over the total number of persons alive at July 1, 2011 and aged 20 or older. To overcome the potential problem of counting the same fracture twice, all fractures with a record of a previous fracture (of the same type or coded as unspecified) in the six months before the fracture date in 2011 were excluded. Age- and gender- specific IRs were estimated as well as IRs for the above defined fracture sites. Women-to-men IRRs were determined by dividing the women IR over the men IR. For the different fracture types the first fracture in that specific category was used to calculate the IR. 


\section{Results}

The total number of incident fractures in people aged 20 years and older in 2011 was 80,760 (IR: 191, 95\% confidence interval (CI): 190-193 per 10,000 person-years (py)), of which 45,362 (56.2 \%, IR: 211, 95\% Cl: 209-213) occurred in women and 35,398 (43.8\%, IR: $171,95 \% \mathrm{Cl}: 169-173)$ in men, Table 2.1.1. The majority of the fractures occurred in the population aged 50 years and older ( $n=50,470, I R: 249,95 \% \mathrm{Cl}: 247-251)$, Table 2.1.1. When patients with a history of a fracture in the six months before were not excluded, the total number of incident fractures in people aged 50 years and older was $4.5 \%$ higher $(n=52,745)$. Until the age of 50 , fractures occurred more often in men than in women (women to men IRR: $0.60,95 \% \mathrm{Cl}$ : 0.59-0.62). Whereas after the age of 50 , the majority of the fractures occurred in women (IRR: $1.89,95 \% \mathrm{Cl}: 1.85-1.92$ ). Figure 2.1.1 shows that the IRs strongly increased in both men and women after age 75 .

The total number of incident major osteoporotic fractures was 35,102 of which $82 \%$ occurred in the population aged 50 years and older. Women accounted for two-third of the major osteoporotic fractures and their IR was 2.5 times higher than the IR for men aged 50+, Table 2.1.2. Men and women showed a comparable IR until the age of 50, thereafter the IRs started to diverge until the age of 75, Figure 2.1.2.

The following sites showed homogeneous patterns of fracture IRs with age: femur, hip, humerus, pelvis, clinical symptomatic vertebral, rib, major osteoporotic fracture and any. There was an exponential increase starting at the 50-54 age category, Figure 2.1.2. The IR of forearm fractures yielded a strong increase from the age of 45 years. IRs of tibia and clavicle fracture started to rise at age 75. IRs of carpal, skull and foot fracture (men only) declined with age, whereas IRs of foot fractures rose in women aged 45-59 years and decreased thereafter. The IR of ankle fractures in men was steady, in contrast to the IR for women, which rose until age 60 and then stabilized. Rib and patella fracture showed a continuous increase for both men and women. Table 2.1.2 shows the IRs and total number of fractures in the population aged 50 and older. The women-to-men IRR was highest for forearm fracture (IRR: 3.8).

Stratification to hip fracture sites did not result in different patterns, Table 2.1.3. The hip fracture IRs strongly increased from age 75 . The IR was higher in women than in men and the majority (53.5\%) of the hip fractures occurred in the neck of the hip. Table 2.1.4 shows the IRs of hip fractures which were confirmed by a surgery in the 10 days after the date of fracture, those IRs were about 15 to $20 \%$ lower than the total hip fracture IRs. The same IR pattern was visible as with hip fracture and hip fracture stratified by fracture location. 


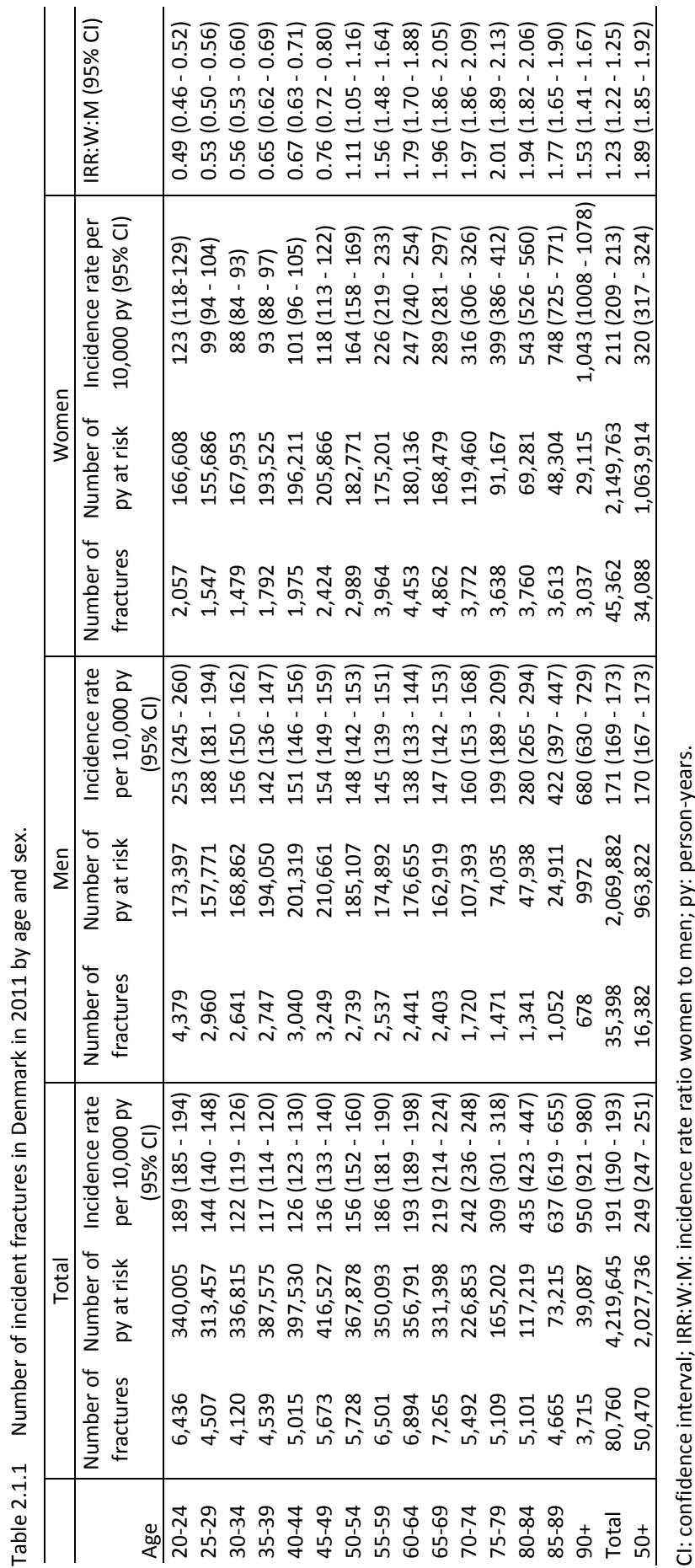




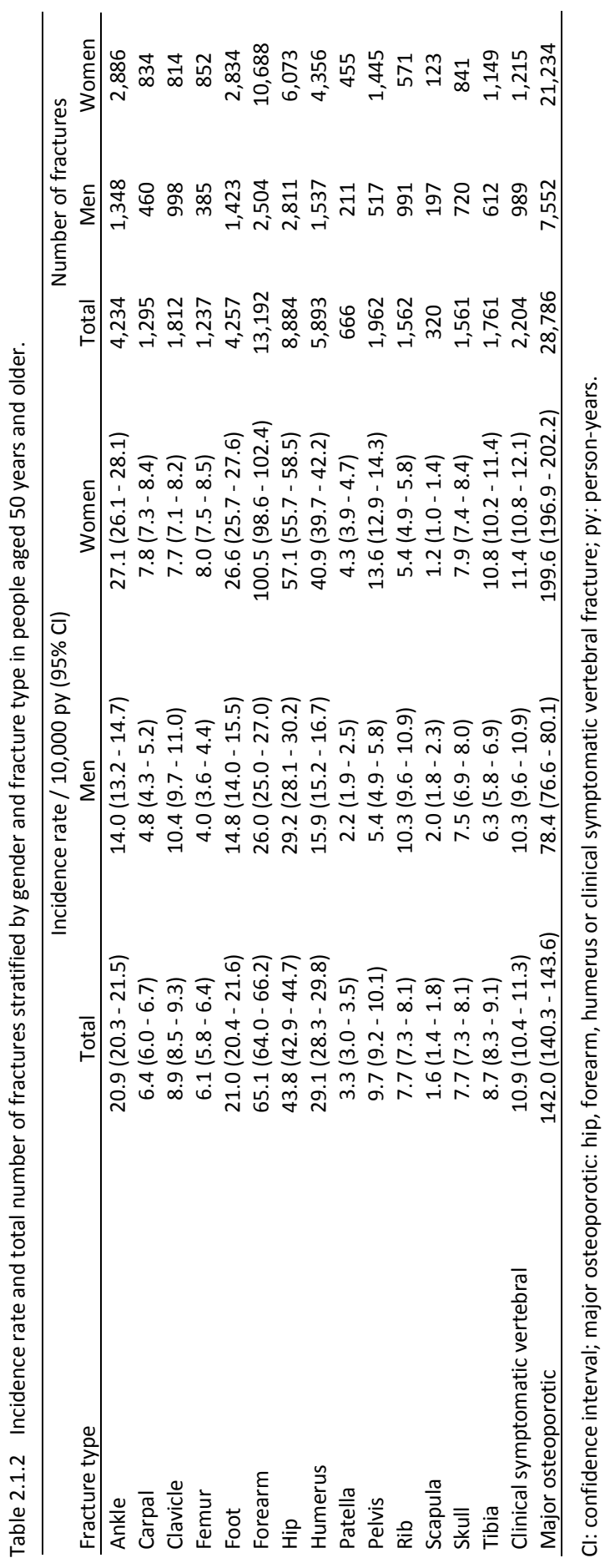



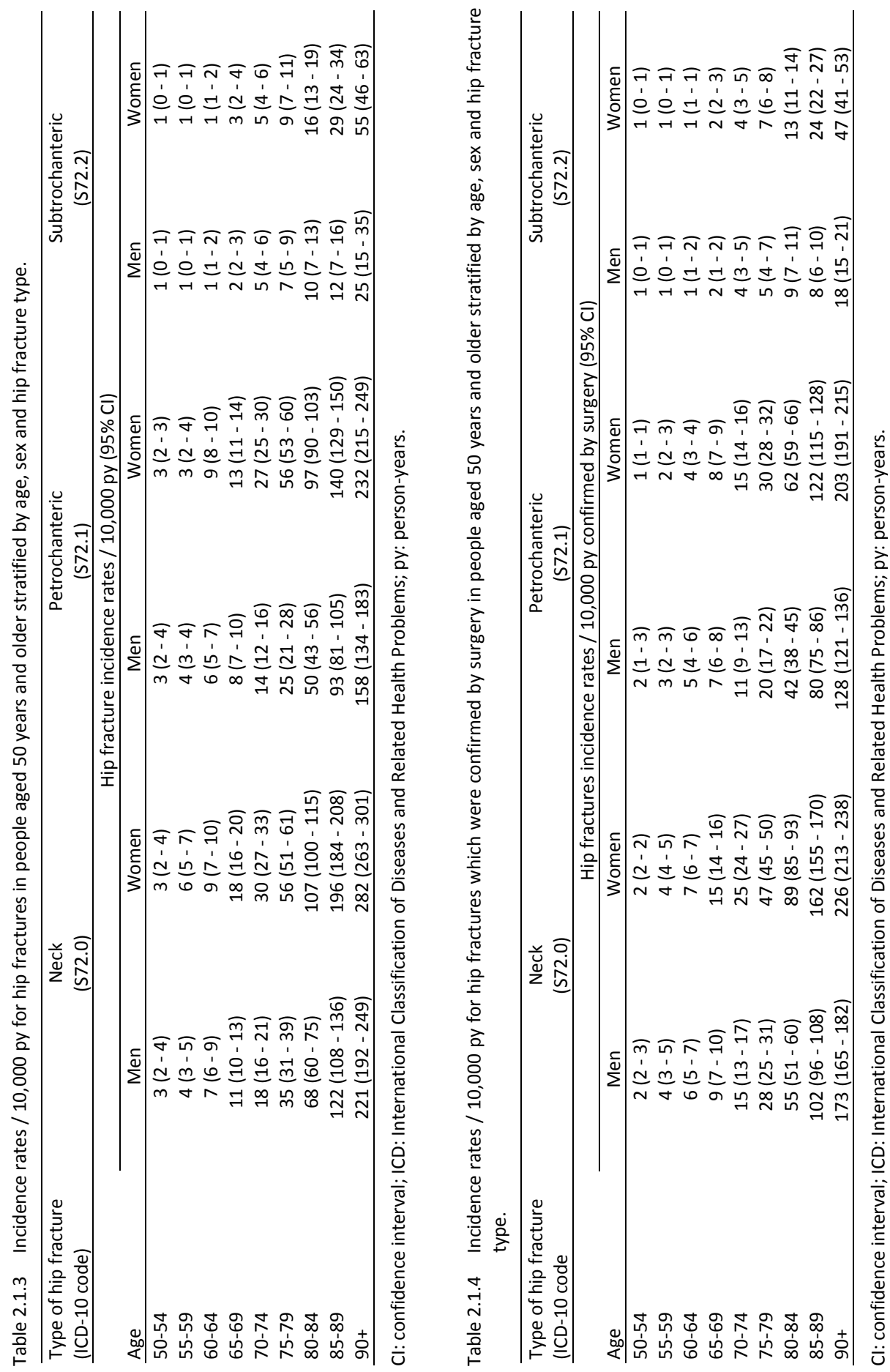
Our estimated number of fractures for various sites was considerably different to the estimates from the IOF. The number of incident fractures in patients aged 50 years and older (including people with a history of a fracture in the 6 months before) was $52,745,10,488,13,746$, and 2,299 in the present study for any, hip, forearm and clinical symptomatic vertebral fracture, respectively. The IOF estimate was $25 \%$ higher for any fracture $(n=66,000), 14 \%$ higher for hip fracture $(n=12,000)$ and $27 \%$ lower for forearm fracture $(n=10,000)^{1}$. The IOF estimate for clinical symptomatic vertebral fracture was 4.3 times higher $(n=10,000)$ as compared to our results ${ }^{1}$.

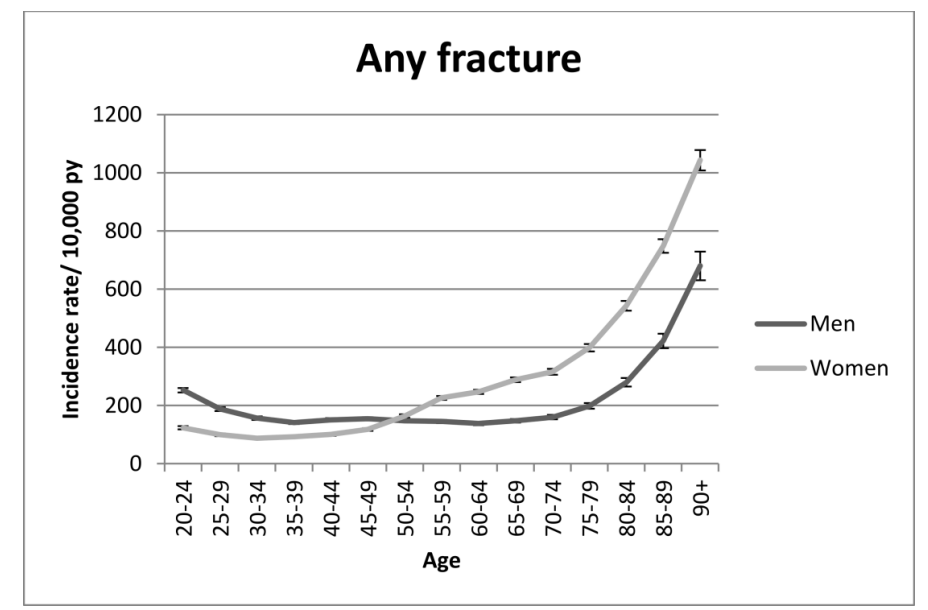

Figure 2.1.1 Incidence rates of first fracture in 2011 stratified by age and sex. py: person-years.

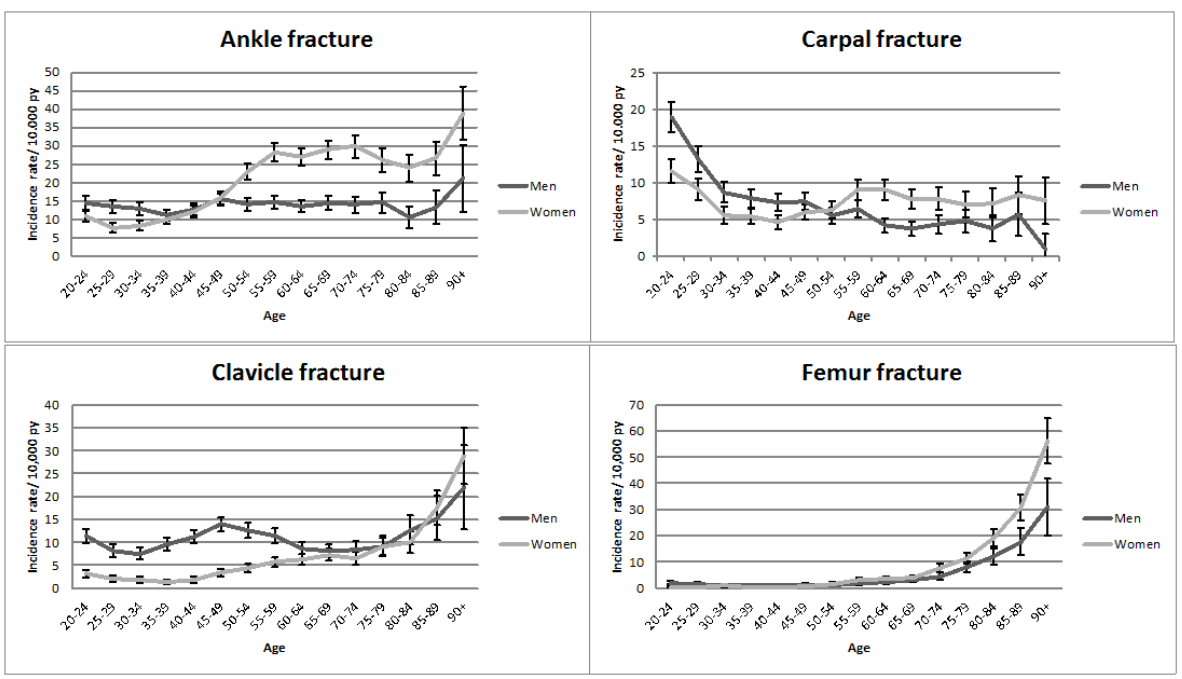




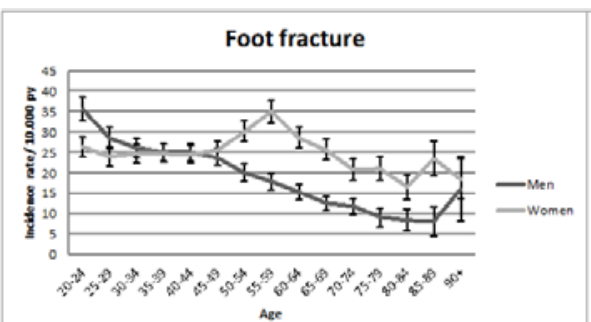

Hip fracture

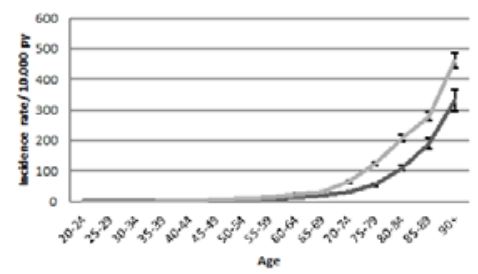

Patella fracture

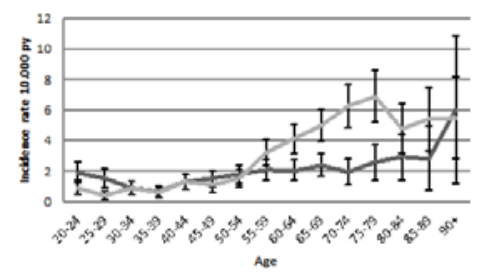

Rib fracture

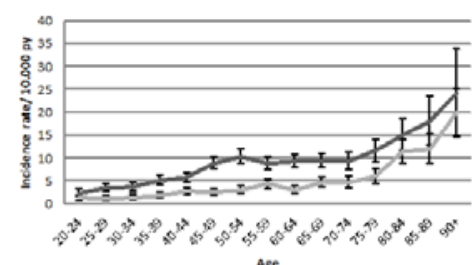

Ase

Skull fracture

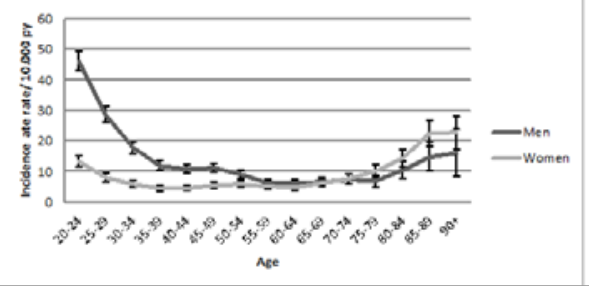

Forearm fracture

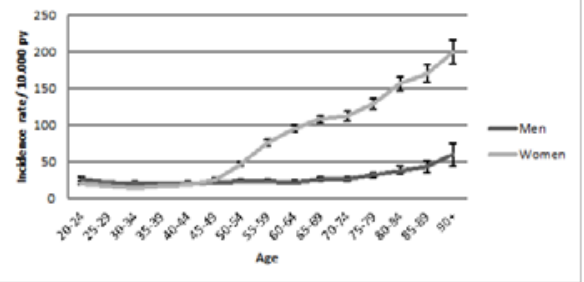

Humerus fracture

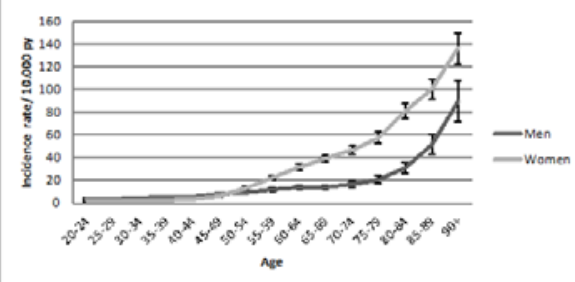

Pelvis fracture

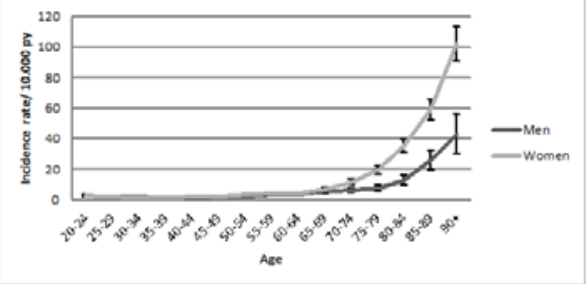

Scapula fracture

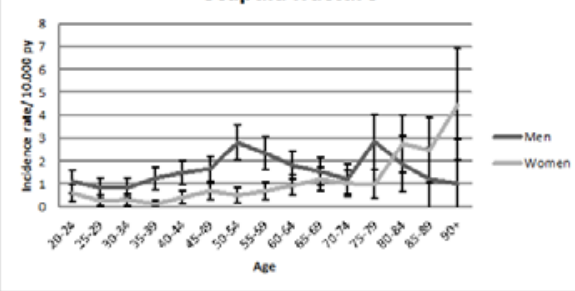

Tibia fracture

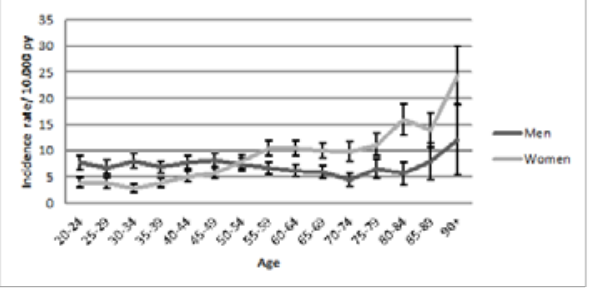




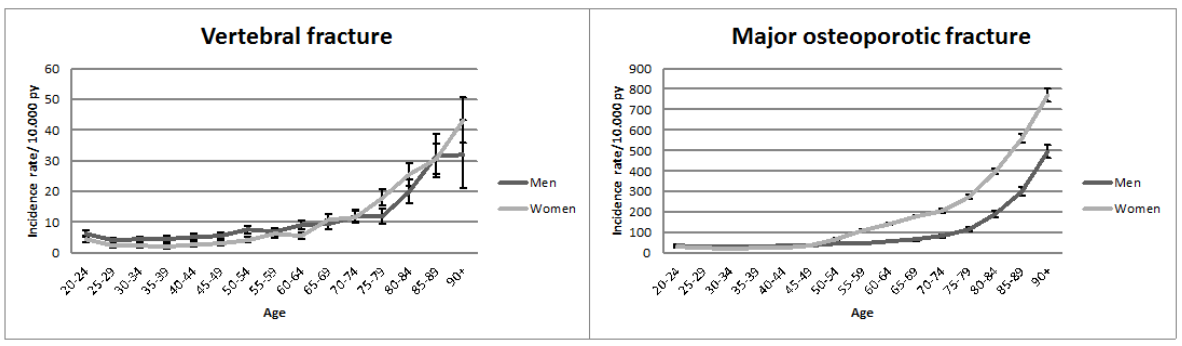

Figure 2.1.2 Incidence rates of first fracture in 2011 stratified by fracture type, age and sex. Major osteoporotic: hip, forearm, humerus or clinical symptomatic vertebral fracture.

\section{Discussion}

We have reported age- and gender- specific IRs for different fracture sites in the Danish population aged 20 years and older in 2011. The total number of incident fractures was 80,760 . The IRs for any, hip, femur, humerus, pelvis, clinical symptomatic vertebral, rib, and major osteoporotic fracture increased with age, in contrast to fractures of the carpus, foot or skull, which declined with age. Until the age of 50, fractures occurred more frequently in men than in women, while this was reversed after the age of 50.

The pattern of IRs of forearm fractures of the present study are in line with the results of a study that investigated the IRs of forearm fractures in Denmark in $2010^{6}$. Both studies showed a steady IR up to age categories of 44 years and a rise thereafter, especially in women. However, the IRs of forearm fractures in women aged 50 to 79 year were lower (8-21 fractures / 10000 py) in the present study than in the 2010 study, which is might be due to random variation and the fact that we excluded patients with an unspecified fracture in the six months before the date of fracture in $2011^{6}$. The results for hip fracture are comparable with earlier results from Denmark, $2008^{4}$. Our results are in keeping with results for the Dutch population ${ }^{16}$, when considering a threefold difference in hip fracture IRs as shown earlier ${ }^{17}$. As compared to IRs for Norway ${ }^{18}$, our results are similar below the age of 80 , whereas our results are lower than the Norwegian IRs for age groups of $\geq 80$. Based on a study which estimated standardized hip fracture rates for different European countries a higher hip fracture IR for Denmark was expected as compared to Norway ${ }^{17}$. The Norwegian study used data from 19942008 of a particular city to estimate IRs, while we used data from the whole country of Denmark for 2011 and this might partly explain the differences. Previous studies have demonstrated higher IRs of osteoporotic fractures in urban as compared to rural regions in Norway although this is believed principally to be with regard to forearm fractures ${ }^{19,20}$. 
The same pattern of IRs (stable until the age of 50 years, and a strong rise thereafter) was visible for any fracture, as compared to the results of a study investigating the IRs of different fracture sites in the United Kingdom, between 1988 and $1998^{21}$. Both studies investigated different fracture sites and those were comparable as well, except for patella and clinical symptomatic vertebral fracture, which showed a different pattern in people aged 80 and over. The IR was about 1.5-2 times higher in Denmark than in the UK, except for rib fracture which showed an equal IR. This may be explained by various reasons, such as differences in the definition of incident fracture between the studies, differences in the studied time period and differences in the used data source. Additionally, it is known from literature that IRs in Scandinavia are about 1.5-2 times higher than those in the rest of Europe ${ }^{4,22,23}$.

The IOF recently estimated numbers of fractures in 2010 for 27 different EU countries, including Denmark ${ }^{1}$. This is of course helpful for an appraisal of the societal burden and the report relied on the official statistics as available. Hence, for Denmark, the IOF had only data available on hip fractures, and imputed numbers of other fracture sites using the ratios of hip to other fracture types using Swedish data of Malmo (1987$1994)^{10}$. The IOF estimates were $25 \%$ higher for any fracture and $14 \%$ for hip fractures as compared to the numbers estimated in the current study. In contrast, the IOF estimate for forearm fractures was $27 \%$ lower than the present number of fractures. This is in line with recent incidence rates of forearm fractures in Denmark in 2010 which used the same data source as in this study.

The number of clinical symptomatic vertebral fractures estimated by the IOF is about 4.3 times higher as the number of clinical symptomatic vertebral fractures in the present study. The IOF used Swedish age- and gender- specific IRRs from vertebral to hip fracture IRs based on radiography referrals. In the present study we used register data which especially for clinical vertebral fractures might be less accurate than the radiographic data. As far as we know there is no data available on how well clinical vertebral fractures are captured in the Danish registry and therefore it is difficult to compare the IOF estimate to the estimate of the present study. When comparing the present data to the data from the IOF one has to take into account that there are some differences between the studies. The IOF estimated the number of fractures for 2010 , based on data from 2004 including repeat admissions ${ }^{1}$, while we used data from 2011 and applied a washout period of six months. Hip fracture IRs have shown to decline in Denmark $^{4,6}$. This decline in hip fracture incidence rates and the repeat admissions might explain the overestimation of the number of hip fractures. Imputation of fracture incidence rates might be improved by taking secular trends of fracture incidence rates into account.

This study has several strengths. We were able to estimate the number of fractures in 2011 for the full country of Denmark. Moreover, we were able to stratify to different fracture sites, without imputation based on data from other fracture sites or other countries. This made it also possible to compare our data to estimated IRs based on 
imputed data. The reliability of Danish national fracture records has previously been addressed in the Danish Nurses Cohort Study $(n=18,800)$, where $94 \%$ concordance was found between self-reported hip fracture in female health professionals and registered hip fracture, $84 \%$ concordance for forearm fractures, and $83 \%$ for humerus fractures ${ }^{11}$.

Furthermore, the present results provide more accurate estimates of the number of fractures and thereby these data will assist to the planning of health services and to the estimation of fracture associated costs. And the present estimates could also be used to update the Danish algorithms for fracture risk assessment tool (FRAX). At present, the Danish version of FRAX, includes in the major osteoporotic fracture risk estimate a vertebral fracture probability that is imputed from Danish official hip fracture rates using Malmö conversion ratios, while forearm and humerus fractures are those reported by the Danish National Board of Health at the time. The present study has the advantage of using a conservative approach to reduce the risk of multiple counting of the same fracture, or including hip fracture repair and it is also used the most up to date incidence rate report.

We are aware of some limitations of this study. Our IR estimates might be somewhat conservative, because we excluded all fractures with a history of fracture of the same type in the six months before, to overcome the problem of double counting of the same fracture. Additionally, we were only able to estimate the number of vertebral fractures that came to clinical attention. This of course reflects the immediate societal burden and use of the healthcare system but patients with vertebral fractures who do not receive the diagnostic work-up including $x$-rays are also subject to increased morbidity and mortality ${ }^{24}$.

In summary, we have shown age- and gender- specific fracture rates for any fracture as well as for different fracture sites. The IRs of most fracture sites increased with age. Until the age of 50 fractures occurred more in men than in women, while this was reversed in older age groups. Estimating the number of fractures for Denmark based on imputation of data from other countries led to both over- and underestimation. Future research should therefore focus on how to improve those imputations as not all countries have nationwide registry data. 
1. Svedbom $A$, Hernlund $E$, Ivergård $M$, Compston J, Cooper C, Stenmark J, et al. Epidemiology and economic burden of osteoporosis in Denmark. Arch Osteoporos. 2013;8:137.

2. Burge $R$, Dawson-Hughes $B$, Solomon $D H$, Wong JB, King A, Tosteson A. Incidence and economic burden of osteoporosis-related fractures in the United States, 2005-2025. J Bone Miner Res. 2007;22(3):465-75.

3. Cooper C, Cole ZA, Holroyd CR, Earl SC, Harvey NC, Dennison EM, et al. Secular trends in the incidence of hip and other osteoporotic fractures. Osteoporos Int. 2011;22(5):127788.

4. Requena G, Abbing-Karahagopian V, Huerta C, De Bruin ML, Alvarez $Y$, Miret $M$, et al. Incidence rates and trends of hip/femur fractures in five European countries: comparison using e-healthcare records databases. Calcif Tissue Int. 2014;94(6):580-9.

5. Giversen IM. Time trends of age-adjusted incidence rates of first hip fractures: a register-based study among older people in Viborg County, Denmark, 1987-1997. Osteoporos Int. 2006;17(4):552-64.

6. Abrahamsen B, Vestergaard P. Declining incidence of hip fractures and the extent of use of anti-osteoporotic therapy in Denmark 1997-2006. Osteoporos Int. 2010;21(3):37380.

7. Lauritzen JB, Schwarz P, Lund B, McNair P, Transbø| I. Changing incidence and residual lifetime risk of common osteoporosis-related fractures. Osteoporos Int. 1993;3(3):127-32.

8. Abrahamsen B, Jørgensen NR, Schwarz P. Epidemiology of forearm fractures in adults in Denmark: national age- and gender-specific incidence rates, ratio of forearm to hip fractures, and extent of surgical fracture repair in inpatients and outpatients. Osteoporos Int. 2015;26(1):67-76.

9. Andersen TF, Madsen $M$, Jørgensen J, Mellemkjoer L, Olsen JH. The Danish National Hospital Register. A valuable source of data for modern health sciences. Dan Med Bull. 1999;46(3):263-8.

10. Kanis JA, Johnell O, Oden A, Sembo I, RedlundJohnell I, Dawson A, et al. Long-term risk of osteoporotic fracture in Malmö. Osteoporos Int. 2000;11(8):669-74.
11. Hundrup YA, Høidrup S, Obel EB, Rasmussen NK. The validity of self-reported fractures among Danish female nurses: comparison with fractures registered in the Danish National Hospital Register. Scand J Public Health. 2004;32(2):136-43.

12. Frank L. Epidemiology. When an entire country is a cohort. Science. 2000;287:23989.

13. Andersen $T$, Madsen $M$, Jørgensen J, Mellemkjær L, Olsen J. The Danish National Hospital Register. Dan Med Bull 1999;46:2638.

14. FRAX. WHO Fracture Risk Assessment Tool. 2001. shef.ac.uk. www.shef.ac.uk/FRAX/index .aspx.

15. http://www.nip.dk/files/Subsites/NIP/Hoften \%C3\%A6re\%20frakturer/2010_Datadefinition er_g\%C3\%A61010310.pdf. Assessed: 1-7-2015.

16. Lalmohamed A, Welsing PM, Lems WF, Jacobs JW, Kanis JA, Johansson $\mathrm{H}$, et al. Calibration of FRAX ${ }^{\circledR} 3.1$ to the Dutch population with data on the epidemiology of hip fractures. Osteoporos Int. 2012;23(3):861-9.

17. Kanis JA, Odén A, McCloskey EV, Johansson $H$, Wahl DA, Cooper C, et al. A systematic review of hip fracture incidence and probability of fracture worldwide. Osteoporos Int. 2012;23(9):2239-56.

18. Emaus N, Olsen LR, Ahmed LA, Balteskard L, Jacobsen BK, Magnus T, et al. Hip fractures in a city in Northern Norway over 15 years: time trends, seasonal variation and mortality : the Harstad Injury Prevention Study. Osteoporos Int. 2011;22(10):2603-10.

19. Omsland TK, Ahmed LA, Grønskag A, Schei B, Emaus N, Langhammer A, et al. More forearm fractures among urban than rural women: the NOREPOS study based on the Troms $\varnothing$ study and the HUNT study. J Bone Miner Res. 2011;26(4):850-6.

20. Diamantopoulos AP, Rohde G, Johnsrud I, Skoie IM, Johnsen V, Hochberg $M$, et al. Incidence rates of fragility hip fracture in middle-aged and elderly men and women in southern Norway. Age Ageing. 2012;41(1):8692.

21. van Staa TP, Dennison EM, Leufkens HG, Cooper C. Epidemiology of fractures in England and Wales. Bone. 2001;29(6):517-22. 
22. Wade SW, Strader C, Fitzpatrick LA, Anthony MS. Sex- and age-specific incidence of nontraumatic fractures in selected industrialized countries. Arch Osteoporos. 2012;7:219-27.

23. Hernlund $E$, Svedbom $A$, Ivergård $M$, Compston J, Cooper C, Stenmark J, et al. Osteoporosis in the European Union: medical management, epidemiology and economic burden. A report prepared in collaboration with the International Osteoporosis Foundation (IOF) and the European Federation of Pharmaceutical Industry Associations (EFPIA). Arch Osteoporos. 2013;8:136.
24. Hasserius $\mathrm{R}$, Karlsson MK, Nilsson BE, Redlund-Johnell I, Johnell O; European Vertebral Osteoporosis Study. Prevalent vertebral deformities predict increased mortality and increased fracture rate in both men and women: a 10-year population-based study of 598 individuals from the Swedish cohort in the European Vertebral Osteoporosis Study. Osteoporos Int. 2003;14(1):61-8. 


\section{Chapter}

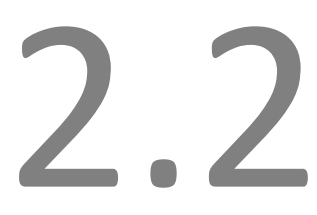

\section{Use of dipeptidyl peptidase 4 inhibitors for type 2 diabetes mellitus and risk of fracture}

JHM Driessen, HAW van Onzenoort, RMA Henry, A Lalmohamed, JPW van den Bergh, C Neef, HGM Leufkens, F de Vries

Bone 2014;68:124-130 


\section{Abstract}

\section{Introduction}

Although patients with type 2 diabetes mellitus have an increased bone mineral density as compared to healthy patients, their risk of fracture is elevated. Incretins, new anti-diabetic drugs, may have a protective effect on bone mineral density. However, data on the effect of incretins on fracture risk are limited. Therefore the aim of this study was to investigate the association between the use of dipeptidyl peptidase 4 inhibitors (DPP4-Is) and the risk of fracture.

\section{Methods}

A retrospective population-based cohort study, using data from the Clinical Practice Research Datalink (CPRD) database (2007-2012), was conducted. Patients $(n=216,816)$ with at least one prescription for a non-insulin anti-diabetic drug (NIAD), aged 18+ during data collection, were matched to one control patient. Cox proportional hazards models were used to estimate the hazard ratio of any fracture in DPP4-I users versus controls and versus other NIAD patients. Timedependent adjustments were made for age, sex, life style, comorbidity and drug use.

\section{Results}

The actual duration of DPP4-I use was 1.3 years. There was no different risk of fracture comparing current DPP4-I users to controls (adjusted hazard ratio (adj. HR) 0.89, 95\% confidence interval (Cl): 0.71-1.13). There was also no increased risk comparing current DPP4-I users to other NIAD users, adj. HR 1.03 (95\% Cl: 0.92-1.15).

\section{Conclusion}

DPP4-I use was not associated with fracture risk fracture compared to controls and to other NIAD users. However, the duration of DPP4-I use in our database might have been too short to show an association with fracture risk. 


\section{Introduction}

Osteoporosis is a common disease and a major public health burden through associated fractures. In 2010, an estimated 2.7 million hip fractures occurred worldwide, of which about 1.8 million were in women ${ }^{1}$. As the incidence of hip fracture continues to increase worldwide, projections indicate that the number of hip fractures occurring in the world each year will rise to 6.26 million by $2050^{2}$. Although patients with type 2 diabetes mellitus (T2DM) have an increased bone mineral density (BMD) as compared to controls, their risk of fracture is elevated ${ }^{3}$. This suggests that this elevated risk is due to reduced bone strength or quality. However, some of the anti-T2DM drugs also have been associated with an increased fracture risk, for example thiazolidinediones (TZDs) ${ }^{4-6}$ and human insulins ${ }^{7}$, while others, like metformin have been associated with a reduced fracture risk ${ }^{8}$.

In vivo research has shown that glucagon-like peptide 1 receptor agonists (GLP1-RAs), a new class of anti-diabetic drugs, might have a beneficial effect on bone ${ }^{9-}$ ${ }^{11}$. This effect might be established by increasing the level of glucagon-like peptide 1 (GLP-1) directly (via GLP1-RAs) or indirectly (via dipeptidyl peptidase 4 inhibitors (DPP4Is) and the GLP-1 receptor which might be present on osteocytes and osteoblasts, as shown in in vitro studies ${ }^{12,13}$. Finally this might lead to an increase in BMD.

Data on the effects of GLP1-RAs and DPP4-Is on fracture risk are limited to a small number of patients and conflicting. A meta-analysis of randomised controlled trials (RCTs) that compared DPP4-Is with a comparator group or placebo confirmed a $40 \%$ significant reduction in the risk of fracture ${ }^{14}$. However, this meta-analysis had several limitations: the total number of patients were small $(n=21,055)$, there were heterogeneous comparator groups. In contrast, a study investigating the effect of vildagliptin, a DPP4-I, on bone markers in humans did not show a change in markers representing bone resorption and calcium homeostasis ${ }^{15}$. The possible protective effect of DPP4-Is on risk of fracture in humans is not been well established. Therefore the aim of this study was to investigate the association between the use of DPP4-Is and the risk of fracture.

\section{Methods}

Data for this study were obtained from the Clinical Practice Research Datalink (CPRD) in the United Kingdom, previously known as the General Practice Research Database (GPRD) [www.CPRD.com]. The CPRD contains computerized medical records of 625 primary care practices in the United Kingdom, representing $8 \%$ of the population. The data recorded in the CPRD include demographic information, prescription details, clinical events, preventive care provided, specialist referrals, hospital admissions, and major outcomes since 1987. Previous studies using CPRD data have shown to be highly valid, with for example for hip fractures over $90 \%$ confirmed diagnoses ${ }^{16}$. 
We conducted a retrospective population-based cohort study. The case population consisted of all patients with at least one prescription for a non-insulin anti-diabetic drug (NIAD) and who were aged 18+ during the period of valid CPRD data collection. For this study, data collection started on June $13^{\text {th }} 2007$, the date of the first ever prescription of a DPP4-I in CPRD, and ended in August 2012. The index date was defined as the date of the first NIAD prescription since the start of the study period (i.e. the study population was a mix of incident and prevalent NIAD users).

After start of valid data collection a NIAD user was matched by sex, year of birth (within 5 years), and practice to one control. Control patients were patients who never had a prescription of a NIAD or insulin during the entire study period. The index date of the controls was set to the index date of the matched NIAD user and their period of follow-up was divided into intervals of 90 days. Each patient was followed from his or her index date to the end of data collection, the date of transfer out of the practice area, or the patient's death, whichever came first.

The follow-up time of the NIAD users was divided into intervals based on the NIAD and insulin prescriptions, i.e. for every prescription a new interval was created. When there was a washout period of 90 days, an interval was classified as "past NIAD use", until end of follow-up, or a new prescription of an anti-diabetic drug, whichever came first. Otherwise an interval was classified as "current NIAD use".

All DPP4-I exposed intervals were classified, according to the time since the most recent prescription, as current (1-90 days), recent (91-180 days), or past (over 180 days) use. At every DPP4-I current use interval, the cumulative prescribed DPP4-I dosage, in sitagliptin dose equivalents, was reviewed and divided by the DPP4-I treatment time (difference in time between the start of the first and last DPP4-I prescription) to estimate the average daily DPP4-I dose. Defined daily doses were used to calculate the sitagliptin dose equivalents ${ }^{17}$. For all current DPP4-I users, a half-year medication possession rate (MPR) was estimated at the date of their latest DPP4-I prescription. The prescribed quantity and the written dosage instruction were used to estimate the duration of treatment. The MPR was determined as the estimated duration of treatment divided by the actual duration (i.e. 182 days). When prescriptions were overlapping, the overlapping days were added to the estimated duration of treatment. A MPR of $80 \%$ or more was used as cut-off to categorize patients as compliant (MPR $\geq 80 \%$ ) or not compliant (MPR $<80 \%$ ).

Patients were followed up from the index date to either the end of data collection, the date of transfer of the patient out of the practice area, the patient's death, or the fracture type of interest, whichever came first. Fractures were classified by use of read codes. We used the following categories to classify fractures: any, hip, radius/ulna, vertebral, and major osteoporotic fracture. A major osteoporotic fracture was defined as a fracture of the hip, vertebrae, radius/ulna or humerus according to the WHO definition $^{18}$. 
The presence of risk factors was assessed by reviewing the computerized medical records for any record of a risk factor prior to the start of an interval. The following potential confounders were determined at baseline: sex, body mass index (BMI), smoking status and alcohol use. All other risk factors that were considered in this study were determined time-dependently (i.e. at the start of each interval). We considered the following potential confounders: age, glycosylated hemoglobin type A1c (HbA1c), falls in 7-12 months before the start of an interval, a history of chronic obstructive pulmonary disease, previous fracture, rheumatoid arthritis, hypothyroidism, hyperthyroidism, cancer, retinopathy, neuropathy, congestive heart failure and secondary osteoporosis (hypogonadism or premature menopause (<45 year)). In addition, the following drug prescriptions in the 6 months prior to the start of an interval were considered as a potential confounder: oral glucocorticoids, cholesterol lowering drugs, antidepressants, anxiolytics or hypnotics, antipsychotics, anti-Parkinson drugs, antihypertensives (beta-blockers, thiazide diuretics, renin angiotensin aldosterone system inhibitors, calcium channel blockers, loop diuretics), antiarrhythmics, opposed hormone replacement therapy, calcium, bisphosphonates, vitamin $\mathrm{D}$, raloxifene, strontium ranelate, calcitonin, parathyroid hormone, insulin and TZDs.

Regression analysis with Cox proportional hazards models (SAS 9.2, PHREG procedure) was used to estimate the fracture rate of current DPP4-I users compared to control patients (non-NIAD users). This analysis was stratified by major osteoporotic, hip, radius/ulna and clinically symptomatic vertebral fracture, as well as sex and different age categories. As a second analysis the fracture risk of current DPP4-I users was compared to other current NIAD users. The analysis was stratified by major osteoporotic, hip, radius/ulna, and vertebral clinically symptomatic fracture, as well as sex and different age categories. In different analyses we stratified current DPP4-I use by average daily dose, cumulative DPP4-I use and the estimated half-year MPR (low MPR $<80 \%$ and high MPR $\geq 80 \%$ ). In all analyses potential confounders were included if they independently changed the beta-coefficient for current DPP4-I exposure by at least $5 \%$, or when consensus about inclusion existed within the team of researchers, supported by clinical evidence from literature.

\section{Results}

Table 2.2.1 shows the baseline characteristics of the DPP4-I users, the NIAD users, and their matched controls. In total we included 216,816 NIAD users and the same number of controls. The mean age of NIAD users and the controls was 61 years in both groups (standard deviation (SD) 21.0 for both groups). The DPP4-I users were slightly younger at baseline, i.e. 59 years (SD 16.0). The percentage of women was $47.3 \%$ within the NIAD user group and the matched controls and $43.0 \%$ in the DPP4-I user group. The 
median follow-up time (from start of follow-up to end of data collection) was 3.7 years (Inter quartile range (IQR), 1.61-5.22) and 3.95 years (IQR, 1.79-5.22) for the NIAD users and controls, respectively. The DPP4-I users had a median follow-up time (from the first NIAD prescription until the end of data collection) of 5.0 years (IQR, 2.95-5.16) and a median duration of actual use (from the first DPP4-I prescription until the last DPP4-I prescription) of 1.04 years (IQR, 0.48-1.92).

Table 2.2.1 Baseline characteristics of DPP4-I users, NIAD users and their matched controls ${ }^{\mathrm{a}}$.

\begin{tabular}{|c|c|c|c|}
\hline Characteristic & $\begin{array}{c}\text { DPP4-I } \text { users }^{b} \\
N=22,510\end{array}$ & $\begin{array}{l}\text { NIAD users }{ }^{c} \\
N=216,816\end{array}$ & $\begin{array}{l}\text { Controls }^{d} \\
N=216,816\end{array}$ \\
\hline Median follow-up time, years [IQR] & $5.0[2.95-5.16]$ & $3.7[1.61-5.22]$ & $3.95[1.79-5.22]$ \\
\hline Actual duration of DPP4-I use, years [IQR] & $1.04[0.48-1.92]$ & $\mathrm{n} / \mathrm{a}$ & $\mathrm{n} / \mathrm{a}$ \\
\hline Number of women & $9,955(43.0)$ & $102,518(47.3)$ & $102,518(47.3)$ \\
\hline \multicolumn{4}{|l|}{ Age } \\
\hline Mean age at index date (years, SD) & $59(16.0)$ & $61(21.0)$ & $61(21.0)$ \\
\hline 18 - 49 years & $5,022(21.7)$ & $46,551(21.5)$ & $46,909(21.6)$ \\
\hline $50-59$ years & $6,563(28.3)$ & $44,634(20.6)$ & $45,132(20.8)$ \\
\hline $60-69$ years & $7,061(30.5)$ & $56,830(26.2)$ & $56,760(26.2)$ \\
\hline 70 - 79 years & $3,721(16.1)$ & $47,376(21.9)$ & $47,025(21.7)$ \\
\hline $80+$ years & $785(3.4)$ & 21,425 (9.9) & $20,990(9.7)$ \\
\hline \multicolumn{4}{|l|}{ BMI } \\
\hline Mean $\mathrm{BMI}$ at index date $\left(\mathrm{kg} / \mathrm{m}^{2}, \mathrm{SD}\right)$ & $33(6.6)$ & $31(6.6)$ & $27(5.1)$ \\
\hline$<20.0 \mathrm{~kg} / \mathrm{m}^{2}$ & $137(0.6)$ & $2,762(1.3)$ & $10,104(4.7)$ \\
\hline $20.0-24.9 \mathrm{~kg} / \mathrm{m}^{2}$ & $2,008(8.7)$ & $27,053(12.5)$ & $64,626(29.8)$ \\
\hline $25.0-29.9 \mathrm{~kg} / \mathrm{m}^{2}$ & $6,754(29.2)$ & $68,486(31.6)$ & 75,756 (34.9) \\
\hline $30.0-34.9 \mathrm{~kg} / \mathrm{m}^{2}$ & $7,029(30.4)$ & $60,195(27.8)$ & $30,681(14.2)$ \\
\hline$\geq 35.0 \mathrm{~kg} / \mathrm{m}^{2}$ & $7,063(30.5)$ & $52,937(24.4)$ & $12,466(5.7)$ \\
\hline Missing & $161(0.7)$ & $5,383(2.5)$ & $23,183(10.7)$ \\
\hline \multicolumn{4}{|l|}{ Smoking status } \\
\hline Never & $11,428(49.4)$ & $107,919(49.8)$ & $114,195(52.7)$ \\
\hline Current & $4,677(20.2)$ & 43,055 (19.9) & $45,187(20.8)$ \\
\hline Ex & $7,015(30.3)$ & 64,745 (29.9) & $51,686(23.8)$ \\
\hline Missing & $32(0.1)$ & $1,097(0.5)$ & $5,748(2.7)$ \\
\hline \multicolumn{4}{|l|}{ Alcohol use } \\
\hline No & $6,511(28.1)$ & 62,695 (28.9) & $39,364(18.2)$ \\
\hline Yes & $15,898(68.7)$ & $142,011(65.5)$ & $152,802(70.5)$ \\
\hline Missing & $743(3.2)$ & $12,110(5.6)$ & $24,650(11.4)$ \\
\hline Mean HbA1c $(\%, S D)$ & $8.3(1.8)$ & $8.0(1.8)$ & $6.3(1.2)$ \\
\hline Missing & $7,603(32.8)$ & $92,169(42.5)$ & 211,402 (97.5) \\
\hline Falls (7 - 12 months before) & $175(0.8)$ & $2,176(1.0)$ & $1,755(0.8)$ \\
\hline \multicolumn{4}{|l|}{ History of disease ever before } \\
\hline Fracture & 4,838 (20.9) & $44,957(20.7)$ & $45,197(20.8)$ \\
\hline Hyperthyroidism & $210(0.9)$ & $2,078(1.0)$ & $1,729(0.8)$ \\
\hline Hypothyroidism & $1,794(7.7)$ & $17,123(7.9)$ & $11,280(5.2)$ \\
\hline COPD & $1,006(4.3)$ & $11,922(5.5)$ & $9,898(4.6)$ \\
\hline Congestive heart failure & $620(2.7)$ & $9,088(4.2)$ & 4,064 (1.9) \\
\hline Cancer & $4,793(20.7)$ & $47,244(21.8)$ & $50,047(23.1)$ \\
\hline Rheumatoid arthritis & $357(1.5)$ & $3,741(1.7)$ & $3,406(1.6)$ \\
\hline Retinopathy & $2,947(12.7)$ & $26,202(12.1)$ & $1,365(0.6)$ \\
\hline Secondary osteoporosis & $1,501(6.5)$ & 19,447 (9.0) & 7,866 (3.6) \\
\hline Neuropathy & $1,645(7.1)$ & $16,404(7.6)$ & $2,747(1.3)$ \\
\hline
\end{tabular}


Table 2.2.1 (continued)

\begin{tabular}{lccc}
\hline & DPP4-I users & NIAD users & Controls $^{\mathrm{d}}$ \\
Characteristic & $\mathrm{N}=22,510$ & $\mathrm{~N}=216,816$ & $\mathrm{~N}=216,816$ \\
\hline Drug use within six months before & & & \\
$\quad$ Metformine & $20,428(88.2)$ & $179,104(82.6)$ & $\mathrm{n} / \mathrm{a}$ \\
Sulfonylurea derivatives & $8,939(38.6)$ & $58,024(26.8)$ & $\mathrm{n} / \mathrm{a}$ \\
TZDs & $4,749(20.5)$ & $22,561(10.4)$ & $\mathrm{n} / \mathrm{a}$ \\
Insulins & $1,023(4.4)$ & $24,276(11.2)$ & $\mathrm{n} / \mathrm{a}$ \\
Oral glucocorticoids & $1,090(4.7)$ & $12,512(5.8)$ & $8,602(4.0)$ \\
Statins & $15,790(68.2)$ & $118,531(54.7)$ & $45,338(20.9)$ \\
Antiarrhythmics & $362(1.6)$ & $3,453(1.6)$ & $2,904(1.3)$ \\
Antidepressants & $3,849(16.6)$ & $34,930(16.1)$ & $22,874(10.5)$ \\
Anti-Parkinson & $82(0.4)$ & $1,061(0.5)$ & $1,197(0.6)$ \\
Antipsychotics & $367(1.6)$ & $4,493(2.1)$ & $2,617(1.2)$ \\
Anxiolytics & $1,486(6.4)$ & $15,376(7.1)$ & $12,645(5.8)$ \\
Hypnotics & $1,010(4.4)$ & $10,661(4.9)$ & $9,050(4.2)$ \\
Antihypertensives & $14,895(64.3)$ & $125,397(57.8)$ & $70,861(32.7)$ \\
Bisphosphonates & $391(1.7)$ & $5,646(2.6)$ & $7,006(3.2)$ \\
Raloxifene & $16(0.1)$ & $303(0.1)$ & $172(0.1)$ \\
Vitamin D & $79(0.3)$ & $1,198(0.6)$ & $748(0.3)$ \\
Calcium & $646(2.8)$ & $8,399(3.9)$ & $9,545(4.4)$ \\
Strontium ranelate & $10(0.0)$ & $124(0.1)$ & $256(0.1)$ \\
PTH/calcitonin & $0(-)$ & $0(-)$ & $2(0.0)$ \\
Hormone replacement therapy & $158(0.7)$ & $904(0.4)$ & $1,618(0.7)$ \\
\hline
\end{tabular}

BMI: body mass index; COPD: chronic obstructive pulmonary disease; DPP4-I: dipeptidyl peptidase 4 inhibitor; IQR: inter quartile range; n/a: not applicable; NIAD: non-insulin anti-diabetic drug; PTH: parathyroid hormone; SD: standard deviation; TZD: thiazolidinedione; secondary osteoporosis; hypogonadism or premature menopause ( $<45$ year). ${ }^{a}$ Data are number (\%) of patients, unless stated otherwise. ${ }^{b}$ DPP4-I users are patients who have at least 1 prescription of a DPP4-I during follow-up. ${ }^{\mathrm{C}}$ NIAD users are patients who have at least 1 NIAD prescription during follow-up. ${ }^{d}$ Controls are patients who do not have a NIAD prescription during the entire study period.

Table 2.2.2 shows that the risk of fracture is similar when comparing the estimated hazard ratio of current DPP4-I use to that of the controls (adjusted hazard ratio (adj. $\mathrm{HR})$ 0.89, 95\% confidence interval (Cl): 0.71-1.13). Recent DPP4-I users had a significantly increased risk of fracture compared to the controls, adj. HR $1.54(95 \% \mathrm{Cl}$ : (1.08-2.18)). The adj. HR of past DPP4-I users was 1.01 (95\% Cl: 0.91-1.13) compared to the controls.

Current DPP4-I use was further stratified according to current exposure to insulin and TZDs because these drugs are known to increase fracture risk ${ }^{4-6}$. Current DPP4-I users who were not exposed to TZDs showed an adj. HR of 0.89 (95\% Cl: 0.79-1.02) as compared to controls. The adj. HR for current DPP4-I users who were also current TZD user was 1.77 (95\% Cl: 1.42-2.20). Current DPP4-I users who were not exposed to current insulin use showed an adj. HR of 0.99 (95\% Cl: 0.88-1.11), for current DPP4-I users exposed to insulin it was 1.36 (95\% Cl: 0.97-1.90), as compared to controls, Table 2.2.2. The risk of fracture among current DPP4-I users was comparable to the risk of other current NIAD users, Table 2.2.3. The adj. HR for current DPP4-I use was 1.03 (95\% $\mathrm{Cl}$ : 0.92-1.15). The adj. HR of recent DPP4-I use was significantly increased, adj. HR 1.49 
(95\% Cl: 1.05-2.11), and the HR of past DPP4-I use was 0.86 (95\% Cl: 0.68-1.08) all compared to other NIAD users. The stratified analysis for the different outcome types, sex and age categories are shown in Table 2.2.3.

Table 2.2.2 Risk of fracture in DPP4-I users compared with controls, by type of fracture, age, and sex ${ }^{\mathrm{a}}$.

\begin{tabular}{|c|c|c|c|c|}
\hline & $\begin{array}{c}\text { No of } \\
\text { fractures } \\
\mathrm{N}=18,445\end{array}$ & $\begin{array}{l}\text { Fracture IR } \\
\text { (/1000 PY) }\end{array}$ & $\begin{array}{c}\text { Age/sex adjusted HR } \\
(95 \% \mathrm{Cl})\end{array}$ & $\begin{array}{l}\text { Adjusted HR } \\
(95 \% \mathrm{Cl})\end{array}$ \\
\hline No NIAD use & 9,105 & 12.4 & Reference & Reference \\
\hline Past NIAD use & 711 & 6.4 & $0.56(0.52-0.61)^{*}$ & $0.55(0.51-0.60)^{*, c}$ \\
\hline Current NIAD use & 8,629 & 14.0 & $1.16(1.12 \text { - } 1.19)^{*}$ & $1.04(1.01-1.08)^{*, c}$ \\
\hline \multicolumn{5}{|l|}{ By type of NIAD ${ }^{b}$} \\
\hline Past DPP4-I use & 75 & 11.6 & $1.11(0.99-1.23)$ & $1.01(0.91-1.13)^{c}$ \\
\hline Recent DPP4-I use & 32 & 19.2 & $1.70(1.20-2.42)^{*}$ & $1.54(1.08-2.18)^{*, c}$ \\
\hline Current DPP4-I use & 347 & 11.8 & $0.99(0.79-1.25)$ & $0.89(0.71-1.13)^{\mathrm{c}}$ \\
\hline \multicolumn{5}{|l|}{ By current TZD use } \\
\hline Yes & 83 & 19.7 & $1.95(1.57-2.43)^{*}$ & $1.77(1.42-2.20)^{*, c}$ \\
\hline No & 264 & 10.4 & $0.97(0.86-1.10)$ & $0.89(0.79-1.02)^{c}$ \\
\hline \multicolumn{5}{|l|}{ By current insulin use } \\
\hline Yes & 35 & 18.6 & $1.71(1.22-2.39)^{*}$ & $1.36(0.97-1.90)^{c}$ \\
\hline No & 312 & 11.3 & 1.07 (0.95 - 1.19) & $0.99(0.88-1.11)^{c}$ \\
\hline \multicolumn{5}{|l|}{ By sex ${ }^{d}$} \\
\hline Males & 130 & 7.5 & $1.01(0.85-1.21)$ & $0.87(0.72-1.04)^{c}$ \\
\hline Females & 217 & 18.0 & $1.16(1.02-1.33)^{*}$ & $1.11(0.96-1.27)^{c}$ \\
\hline \multicolumn{5}{|l|}{ By age $e^{e}$} \\
\hline$<50$ years & 26 & 5.9 & $0.81(0.55-1.20)$ & $0.65(0.43-0.97)^{*, c}$ \\
\hline 50 - 59 years & 73 & 9.8 & $1.20(0.95-1.53)$ & $1.06(0.82-1.37)^{c}$ \\
\hline $60-69$ years & 99 & 10.1 & $1.05(0.86-1.29)$ & $0.88(0.71-1.09)^{c}$ \\
\hline $70-79$ years & 103 & 16.7 & $1.25(1.02-1.52)^{*}$ & $1.16(0.95-1.42)^{c}$ \\
\hline $80+$ years & 46 & 27.0 & $1.15(0.85-1.54)$ & $1.08(0.80-1.45)^{c}$ \\
\hline \multicolumn{5}{|l|}{ By type of fracture } \\
\hline Major Osteoporotic & 160 & 5.3 & $1.16(0.99-1.37)$ & $1.10(0.93-1.29)^{f}$ \\
\hline Hip fracture & 37 & 1.2 & $1.15(0.82-1.59)$ & $1.10(0.79-1.54)^{\mathrm{g}}$ \\
\hline Radius Ulna & 64 & 2.1 & $1.20(0.94-1.55)$ & $1.16(0.89-1.50)^{h}$ \\
\hline Vertebral fracture & 17 & 0.6 & $0.84(0.52-1.36)$ & $0.76(0.46-1.24)^{i}$ \\
\hline
\end{tabular}

$\mathrm{Cl}$ : confidence interval; DPP4-I: dipeptidyl peptidase 4 inhibitor: HR: hazard ratio; IR: incidence rate; NIAD: non-insulin anti-diabetic drug; PY: person years; TZD: thiazolidinedione. Current NIAD use: most recent NIAD prescription within 90 days before start of an interval. Past NIAD use: most recent prescription over 90 days before start of an interval. Current DPP4-I use: most recent prescription within 90 days before start of an interval. Recent DPP4-I use: most recent prescription within 91-180 days before start of an interval. Past DPP4-I use: most recent prescription over 180 days before start of an interval. * Statistical significant, $(\mathrm{P}<0.05) .{ }^{a}$ All models are statistically adjusted for glucagon-like peptide 1 receptor agonist use. ${ }^{b}$ Other NIAD types not shown. ${ }^{\mathrm{c}}$ Adjusted for ( $\mathrm{j}$ ) and the use of statins, hypnotic/anxiolytic drugs, anti-osteoporotic drugs ${ }^{\mathrm{k}}$, anti-depressants, and anti-psychotics. ${ }^{d}$ Model not statistically adjusted for gender. ${ }^{\mathrm{e}}$ Model not statistically adjusted for age. ${ }^{f}$ Adjusted for (j) and history of chronic obstructive pulmonary disease, use of statins, alcohol, anti-depressants, anti-psychotics, hypnotic/anxiolytic drugs, vitamin d, and calcium. ${ }^{\mathrm{g}}$ Adjusted for (j) and the use of anti-psychotics and anti-depressants. ${ }^{\mathrm{h}}$ Adjusted for (j) and the use of hypnotics/anxiolytic drugs, anti-osteoporotic drugs ${ }^{k}$ and anti-psychotics. ${ }^{i}$ Adjusted for (j) and the use of anti-osteoporotic drugs ${ }^{k}$, and anti-pshychotics. ${ }^{j}$ Sex, age, bmi, smoking status, history of neuropathy, retinopathy and secondary osteoporosis. ${ }^{k}$ Use of bisphosphonates, raloxifene, strontium ranelate or parathyroid hormone/calcitonin. 
Table 2.2.3 Risk of fracture in DPP4-I users compared with NIAD users, by type of fracture, age, and sex ${ }^{\mathrm{a}}$.

\begin{tabular}{|c|c|c|c|c|}
\hline & $\begin{array}{c}\text { No of } \\
\text { fractures } \\
N=9,340\end{array}$ & $\begin{array}{l}\text { Fracture IR } \\
\text { (/1000 PY) }\end{array}$ & $\begin{array}{c}\text { Age/sex adjusted HR } \\
(95 \% \mathrm{Cl})\end{array}$ & $\begin{array}{l}\text { Adjusted HR } \\
(95 \% \mathrm{Cl})\end{array}$ \\
\hline No DPP4-I use & 8,886 & 12.9 & Reference & Reference \\
\hline Past DPP4-I use & 75 & 11.6 & $0.98(0.70-1.12)$ & $0.86(0.68-1.08)^{c}$ \\
\hline Recent DPP4-I use & 32 & 19.2 & $1.51(1.07-2.14)^{*}$ & $1.49(1.05-2.11)^{*, c}$ \\
\hline \multicolumn{4}{|l|}{ By $\operatorname{sex}^{d}$} & $1.03(0.92-1.15)^{c}$ \\
\hline Males & 130 & 7.5 & $0.88(0.74-1.05)$ & $0.96(0.80-1.14)^{c}$ \\
\hline Females & 217 & 18.0 & $1.01(0.88-1.16)$ & $1.08(0.94-1.24)^{c}$ \\
\hline \multicolumn{5}{|l|}{ By age $e^{e}$} \\
\hline$<50$ years & 26 & 5.9 & $0.68(0.45-1.00)$ & $0.73(0.49-1.09)^{c}$ \\
\hline 50 - 59 years & 73 & 9.8 & $1.08(0.85-1.38)$ & $1.22(0.95-1.56)^{c}$ \\
\hline $60-69$ years & 99 & 10.1 & $0.95(0.77-1.16)$ & $1.02(0.83-1.25)^{c}$ \\
\hline $70-79$ years & 103 & 16.7 & $1.10(0.90-1.35)$ & $1.16(0.95-1.42)^{c}$ \\
\hline $80+$ years & 46 & 27.0 & $0.95(0.70-1.27)$ & $1.00(0.74-1.34)^{c}$ \\
\hline \multicolumn{5}{|l|}{ By type of fracture } \\
\hline Major osteoporotic & 160 & 5.3 & $1.00(0.85-1.17)$ & $1.07(0.91-1.25)^{f}$ \\
\hline Vertebral fracture & 17 & 0.6 & $0.84(0.51-1.37)$ & $0.96(0.58-1.57)^{\mathrm{g}}$ \\
\hline Hip fracture & 37 & 1.2 & $0.89(0.64-1.24)$ & $0.97(0.69-1.35)^{h}$ \\
\hline Radius Ulna & 64 & 2.1 & $1.14(0.88-1.47)$ & $1.19(0.92-1.55)^{i}$ \\
\hline
\end{tabular}

$\mathrm{Cl}$ : confidence interval; DPP4-I: dipeptidyl peptidase 4 inhibitor; HR: hazard ratio; IR: incidence rate; PY: person years. Current DPP4-I use: most recent prescription within 90 days before start of an interval. Recent DPP4-I use: Most recent prescription within 91-180 days before start of an interval. Past DPP4-I use: most recent prescription more than 180 days before start of an interval. * Statistically significant, $(P<0.05) .{ }^{a}$ All models are statistically adjusted for glucagon-like peptide 1 receptor agonist use. ${ }^{b}$ NIAD past use not shown. ${ }^{c}$ Adjusted for (j) and the use of statins, hypnotic/anxiolytic drugs, anti-osteoporotic drugs ${ }^{k}$, anti-depressants, and anti-psychotics. ${ }^{d}$ Model not statistically adjusted for gender. ${ }^{e}$ Model not statistically adjusted for age. ${ }^{f}$ Adjusted for (j) and history of chronic obstructive pulmonary disease, use of statins, alcohol, anti-depressants, anti-psychotics, hypnotic/anxiolytic drugs, vitamin $d$, and calcium. ${ }^{g}$ Adjusted for (j) and the use of antipsychotics and anti-depressants. ${ }^{h}$ Adjusted for ( $\mathrm{j}$ ) and the use of hypnotics/anxiolytic drugs, anti-osteoporotic drugs $^{k}$ and anti-psychotics. ${ }^{\mathrm{i}}$ Adjusted for $(\mathrm{j})$ and the use of anti-osteoporotic drugs ${ }^{\mathrm{k}}$, and anti-pshychotics. ${ }^{\mathrm{j}}$ sex, age, body mass index, smoking status, history of neuropathy, retinopathy and secondary osteoporosis, glycosylated hemoglobin type A1c and the use of insulin and thiazolidinediones. ${ }^{k}$ Use of bisphosphonates, raloxifene, strontium ranelate or parathyroid hormone /calcitonin.

Table 2.2.4 shows that the HRs were comparable for the different stratified groups of current DPP4-I use (i.e. by average daily dose and cumulative daily dose). The adj. HR for the highest average daily dose was $1.34(95 \% \mathrm{Cl}: 0.83-2.17)$ and the adj. HR for the highest cumulative dose was 1.02 (95\% Cl: 0.82-1.26). The adj. HR for the low MPR (MPR <80\%) was 1.04 (95\% Cl: 0.93-1.17) and the adj. HR of the high group (MPR $\geq 80 \%$ ) was 0.86 (95\% Cl: 0.59-1.24). After correction for TZD users the adj. HR for current DPP4-I users was 1.04 (95\% Cl: 0.93-1.16). 
Table 2.2.4 Risk of fracture in current DPP4-I users stratified by average and cumulative dose ${ }^{a}$.

\begin{tabular}{|c|c|c|c|c|}
\hline & $\begin{array}{c}\text { No of fractures } \\
N=9,340\end{array}$ & $\begin{array}{l}\text { Fracture IR } \\
\text { (/1000 PY) }\end{array}$ & $\begin{array}{c}\text { Age/sex adjusted } \\
\text { HR }(95 \% \mathrm{Cl})\end{array}$ & $\begin{array}{l}\text { Adjusted HR } \\
(95 \% \mathrm{Cl})^{c}\end{array}$ \\
\hline No DPP4-I use ${ }^{b}$ & 8,886 & 12.9 & Reference & Reference \\
\hline Current DPP4-I use & 347 & 11.8 & $0.96(0.86-1.07)$ & $1.03(0.92-1.15)$ \\
\hline \multicolumn{5}{|l|}{ By average dose exposure } \\
\hline 0 - $49 \mathrm{mg}$ sitagliptin equivalents & 172 & 11.0 & $0.91(0.78-1.06)$ & $0.97(0.84-1.13)$ \\
\hline 50 - 99 mg sitagliptin equivalents & 119 & 11.6 & $0.93(0.77-1.11)$ & $1.00(0.83-1.20)$ \\
\hline$\geq 100 \mathrm{mg}$ sitagliptin equivalents & 17 & 16.1 & $1.29(0.80-2.07)$ & $1.34(0.83-2.17)$ \\
\hline No dose & 39 & 15.4 & $1.26(0.92-1.73)$ & $1.34(0.98-1.84)$ \\
\hline \multicolumn{5}{|l|}{ By cumulative dose exposure } \\
\hline 0 - $18.2 \mathrm{~g}$ sitagliptin equivalents & 128 & 12.8 & $1.04(0.87-1.24)$ & $1.10(0.92-1.31)$ \\
\hline 18.3 - 36.5 g sitagliptin equivalents & 75 & 10.0 & $0.82(0.65-1.03)$ & $0.89(0.71-1.12)$ \\
\hline 36.6 - 54.7 g sitagliptin equivalents & 57 & 12.5 & $1.02(0.79-1.33)$ & $1.11(0.86-1.44)$ \\
\hline$>54.7$ g sitagliptin equivalents & 87 & 11.6 & $0.95(0.77-1.17)$ & $1.02(0.82-1.26)$ \\
\hline
\end{tabular}

$\mathrm{Cl}$ : confidence interval; HR: hazard ratio; IR: incidence rate; PY: person years; DPP4-I: dipeptidyl peptidase 4 inhibitor. ${ }^{a}$ Also corrected for glucagon-like peptide 1 receptor agonist use. ${ }^{b}$ NIAD past use, DPP4-I recent and DPP4-I past use not shown. ${ }^{c}$ Adjusted for sex, age, body mass index, smoking status, glycosylated hemoglobin type A1c, history of secondary osteoporosis, retinopathy and neuropathy, use of statins, hypnotic/anxiolytic drugs, anti-osteoporotic drugs ${ }^{d}$, anti-depressants, anti-psychotics, insulin and thiazolidinediones. ${ }^{d}$ Use of bisphosphonates, raloxifene, strontium ranelate or parathyroid hormone /calcitonin.

\section{Discussion}

The present study showed that there was no significant association with current DPP4-I use and fracture risk as compared to controls. Additionally, we showed that there was no association with DPP4-I use and fracture risk as compared to other NIAD users. Moreover, when stratifying current DPP4-I use by cumulative and average daily dose there was no association with fracture risk as compared to other NIAD users. The risk of hip, major osteoporotic and vertebral fracture was also not different between the DPP4-I and the NIAD users.

Our results are not in line with the main result found in a meta-analysis of RCTs by Monami et al. ${ }^{14}$. That study showed a $40 \%$ reduction of fracture risk for DPP4-I users compared to patients taking other anti-hyperglycaemic drugs or placebo ${ }^{14}$. Differences between the meta-analysis and our study could be explained by several factors. First, in the meta-analysis fractures were not routinely collected, they were only considered when reported as a severe adverse event. The present study used CPRD data which, for hip fracture has shown to be highly valid with over $90 \%$ confirmed routinely collected diagnoses ${ }^{16}$. Second, the mean duration of follow-up was rather short (35 weeks). It might be expected that due to the short follow-up and the low number of fractures the potential beneficial effect of DPP4-I on fracture risk was attenuated.

The results of our study are in keeping with a recently published large RCT $(n=16,492)$ that compared saxagliptin, a DPP4-I, to placebo ${ }^{19}$. That study showed that 
there was no significant difference in the number of bone fractures between saxagliptin and placebo users ${ }^{19}$. The results of the present study are in line with, to our knowledge, the only two clinical trials that investigated the effect of incretin (i.e. exenatide and vildagliptin) treatment on markers of bone remodelling and calcium homeostasis ${ }^{15,20}$. Both studies did not show an effect on calcium homeostasis and other markers reflecting bone resorption after one year and 44 weeks of treatment, respectively, which suggests that the risk of fracture is not altered after treatment with incretin mimetics.

The observation of a significantly 1.5-fold increased risk of fracture for recent DPP4-I users compared to controls and to other NIAD users was unexpected. It is difficult to explain this increased risk of fracture, which was only found in the recent user group, by an plausible underlying mechanism and we cannot rule out the play of chance. Users of both TZDs and DPP4-Is had a 1.8-fold increased fracture risk compared to controls without diabetes. TZDs have shown to increase fracture risk ${ }^{4-6}$ and this effect was still present in our study despite the potential protective effect of the DPP4-Is. Different mechanisms have been hypothesized by which GLP-1 might have a beneficial effect on bone. The enzyme dipetidyl peptidase 4 is involved in the degradation of GLP-1. DPP4-Is are able to inhibit this process and thereby prolonging the half-life of GLP-1. In vitro research has shown that different cell types have a GLP-1 receptor, including osteoblasts and osteocytes ${ }^{12,13}$. Besides, it has been shown that binding of GLP-1 to osteoblasts resulted in an increase of calcitonin which ultimately might lead to decreased bone resorption ${ }^{10}$. Another study showed that after binding of a GLP1-RA, Exendin-4, to osteocytes, the production of sclerostin was decreased ${ }^{21}$. This might in the end result in increased bone formation. Thyroid C cells express a GLP-1 receptor as well ${ }^{22}$. Another in vitro study showed that binding of GLP-1 resulted in increased secretion of calcitonin which could inhibit bone resorption ${ }^{22}$. However, more research is needed to elucidate whether DPP4-Is indeed are able, via the prolonging of the half-life of GLP-1, to increase bone formation and inhibit bone resorption and whether this effect is sufficient to reduce fracture risk in humans.

Our study had several strengths. We were able to statistically adjust in a timedependent way for several potentially important confounders, including, age, HbA1c, different comorbidities, such as retinopathy and neuropathy, and drug use. Besides, we had information at baseline about gender, smoking, and BMI for almost all patients. By adjusting our analyses for neuropathy, retinopathy and $\mathrm{HbA1C}$, we tried to adjust for the disease severity, which is a potential confounder. Additionally, because CPRD data is collected prospectively recall bias was probably not an issue in the present study. Finally, a substantial amount of data representing the general population of the United Kingdom was available. Our main limitation was the mean duration of actual DPP4-I use (time from the first DPP4-I prescription until the last DPP4-I prescription) which was, despite the mean duration of follow-up of 4.0 years, 1.3 years. Drugs used for the treatment of osteoporosis, such as bisphosphonates, have shown a diminishing effect 
on the risk of fracture after 1-1.5 years of use ${ }^{23,24}$. This suggests that our follow-up time might be too short to have enough power to detect an effect of the use of DPP4-Is on the risk of fracture.

It is possible that there is still some residual confounding present. For instance, we were not able to correct for the amount of exercise. Exercise has been shown to reduce the risk of fracture ${ }^{25}$. DPP4-I users might perform less exercise compared to non-DPP4-I users, which could lead to an overestimation of our effect. Another potential source of bias is a selective prescribing of DPP4-Is to patients who are known to use more than the average amount of alcohol. Alcohol use has been associated with hypoglycaemic events $^{26}$ and with an increased risk of fracture ${ }^{27}$. DPP4-Is have been associated with a lower risk of hypoglycaemic events compared to, for example, sulfonylurea derivatives ${ }^{28}$. The selective prescribing could therefore mask the potential beneficial effect of DPP4-Is on fracture risk. Although, we statistically adjusted our main analysis for alcohol use (yes, no or missing), this did not change our results (data not shown), but underreporting of the amount of alcohol patients use might be an issue.

In summary, we showed that DPP4-I use is not associated with fracture risk compared to controls and to other NIAD users. However, our duration of DPP4-I use was probably too short to show an association with fracture risk. Therefore, a longer duration of DPP4-I use is needed to further investigate the potential protective effect of DPP4-Is on fracture risk. 


\section{References}

1. Odén A, McCloskey EV, Johansson H, Kanis JA. Assessing the impact of osteoporosis on the burden of hip fractures. Calcif Tissue Int. 2013;92(1):42-9.

2. Cooper C, Campion G, Melton LJ 3rd. Hip fractures in the elderly: a world-wide projection. Osteoporos Int. 1992;2:285-9.

3. Vestergaard P. Discrepancies in bone mineral density and fracture risk in patients with type 1 and type 2 diabetes - a meta-analysis. Osteoporos Int. 2007;18(4):427-44.

4. Bazelier MT, Gallagher AM, van Staa TP, Cooper C, Leufkens HG, Vestergaard P, et al. Use of Thiazolidinediones and risk of osteoporotic fracture: Disease or drugs? Pharmacoepidemiol Drug Saf. 2012;21(5):50714.

5. Bazelier MT, Vestergaard P, Gallagher AM, van Staa TP, Cooper C, Leufkens HG, et al. Risk of fracture with thiazolidinediones: disease or drugs? Calcif Tissue Int. 2012;26(9):2271-9.

6. Betteridge DJ. Thiazolidinediones and fracture risk in patients with Type 2 diabetes. Diabet Med. 2011;28(7):759-71.

7. Schwartz AV, Vittinghoff E, Bauer DC, Hillier TA, Strotmeyer ES, Ensrud KE, et al. Association of BMD and FRAX score with risk of fracture in older adults with type 2 diabetes. JAMA. 2011;305(21):2184-92.

8. Cooper C, Melton LJ, 3rd. Epidemiology of osteoporosis. Trends Endocrinol Metab. 1992;3(6):224-9.

9. Nuche-Berenguer $B$, Moreno $P$, Esbrit $P$, Dapía S, Caeiro JR, Cancelas J, et al. Effect of GLP-1 treatment on bone turnover in normal, type 2 diabetic, and insulin-resistant states. Calcif Tissue Int. 2009;84:453-61.

10. Nuche-Berenguer B, Moreno P, Portal-Nuñez $S$, Dapía $S$, Esbrit $P$, Villanueva-Peñacarrillo $M L$. Exendin-4 exerts osteogenic actions in insulinresistant and type 2 diabetic states. Regul Pept. 2010;159(1-3):61-6.

11. Moreno P, Nuche-Berenguer B, GutiérrezRojas I, Acitores A, Sancho V, Valverde I, et al. Normalizing action of exendin-4 and GLP-1 in the glucose metabolism of extrapancreatic tissues in insulin-resistant and type 2 diabetic states. Journal of Molecular Endocrinology. 2012;48:37-47.

12. Nuche-Berenguer $B$, Portal-Núñez $S$, Moreno P, González N, Acitores A, López-Herradón A, et al. Presence of a functional receptor for GLP-1 in osteoblastic cells, independent of the CAMP-linked GLP-1 receptor. J Cell Physiol. 2010;225(2):585-92.

13. Kim JY, Lee SK, Jo KJ, Song DY, Lim DM, Park $K Y$, et al. Exendin-4 increases bone mineral density in type 2 diabetic OLETF rats potentially through the down-regulation of SOST/sclerostin in osteocytes. Life Sciences. 2013;92:533-40.

14. Monami M, Dicembrini I, Antenore A, Mannucci E. Dipeptidyl peptidase-4 inhibitors and bone fractures: a meta-analysis of randomized clinical trials. Diabetes Care. 2011;34(11):2474-6.

15. Bunck MC, Poelma M, Eekhoff EM, Schweizer A, Heine RJ, Nijpels G, et al. Effects of vildagliptin on postprandial markers of bone resorption and calcium homeostasis in recently diagnosed, well-controlled type 2 diabetes patients. J. Diabetes. 2012;4(2):181-5.

16. Van Staa TP, Abenhaim L, Cooper C, Zhang B, Leufkens HG. The use of a large pharmacoepidemiological database to study exposure to oral corticosteroids and risk of fractures: validation of study population and results. Pharmacoepidemiol Drug Saf. 2000;9(5):359-66.

17. Anonymous. ATC classification index with DDDs 2002. Nydalen, WHO Collaborating Centre for Drug Statistics Methodology, Norwegian Institute of Public Health, 2002.

18. FRAX. WHO Fracture Risk Assessment Tool. 2001. shef.ac.uk. www.shef.ac.uk/FRAX/ index.aspx.

19. Scirica BM, Bhatt DL, Braunwald E, Steg PG, Davidson J, Hirshberg B, et al. Saxagliptin and cardiovascular outcomes in patients with type 2 diabetes mellitus. N Engl J Med. 2013; epub ahead of print.

20. Bunck MC, Eliasson B, Corner A, Heine RJ, Shaginian RM, Taskinen MR, et al. Exenatide treatment did not affect bone mineral density despite body weight reduction in patients with type 2 diabetes. Diabetes Obes Metab. 2011;13:374-7.

21. Kim JY, Lee SK, Jo KJ, Song DY, Lim DM, Park $K Y$, et al. Exendin-4 increases bone mineral density in type 2 diabetic OLETF rats potentially through the down-regulation of 
SOST/sclerostin in osteocytes. Life Sci. 2013;21;92(10):533-40.

22. Lamari $Y$, Boissard C, Moukhtar MS, Jullienne A, Rosselin G, Garel JM. Expression of glucagon-like peptide 1 receptor in a murine $C$ cell line: Regulation of calcitonin gene by glucagon-like peptide 1 . FEBS Letters. 1996;393(2-3):248-52.

23. Cummings SR, Black DM, Thompson DE, Applegate WB, Barrett-Connor E, Musliner TA, et al. Effect of alendronate on risk of fracture in women with low bone density but without vertebral fractures: results from the Fracture Intervention Trial. J Am Med Assoc. 1998;280:2077-82.

24. McClung MR, Geusens P, Miller PD, Zippel H, Bensen WG, Roux C, et al. Hip Intervention Program Study Group. Effect of risedronate on the risk of hip fracture in elderly women. Hip Intervention Program Study Group. N Engl J Med. 2001;344:333-40.
25. Kemmler W, Häberle L, von Stengel S. Effects of exercise on fracture reduction in older adults: a systematic review and meta-analysis. Osteoporos Int. 2013;24(7):937-50.

26. Ahrén B. Avoiding hypoglycemia: a key to success for glucose-lowering therapy in type 2 diabetes.Vasc Health and Risk Manag. 2013;9:155-63.

27. Kanis JA, Johnell $O$, Oden $A$, Johansson $H$, McCloskey E. FRAX and the assessment of fracture probability in men and women from the uk. Osteoporos Int. 2008;19(4):385-97.

28. Rathmann W, Kostev K, Gruenberger JB, Dworak M, Bader G, Giani G. Treatment persistence, hypoglycaemia and clinical outcomes in type 2 diabetes patients with dipeptidyl peptidase-4 inhibitors and sulphonylureas: a primary care database analysis. Diabet Obes Metab. 2013;15(1):5561. 


\section{Chapter}

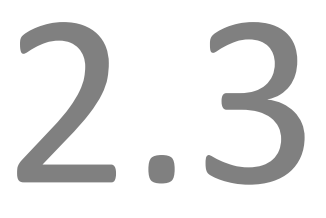

\section{Use of dipeptidyl peptidase 4 inhibitors and}

fracture risk compared to use of other antihyperglycaemic drugs

JHM Driessen, HAW van Onzenoort, J Starup-Linde, RMA Henry, C Neef, JPW van den Bergh, $P$ Vestergaard, $F$ de Vries, AM Burden

Pharmacoepidemiol Drug Saf 2015;24(10):1017-25 


\section{Abstract}

\section{Introduction}

Dipeptidyl peptidase 4 inhibitors (DPP4-Is) are a new class of anti-hyperglycaemic drugs which might have a potential beneficial effect on bone metabolism. Data on the effect of DPP4-I use and fracture risk is limited and conflicting. The aim of the present study was to investigate the association between use of DPP4-Is and fracture risk.

\section{Methods}

A case-control study was conducted using data from the Danish National Health Service. Cases were those who sustained a fracture and controls were those without a fracture during the study period (2007-2011), all aged 18 years and older. Conditional logistic regression estimated the odds ratios of fracture with current use of DPP4-Is. Analyses were adjusted for comorbidities and recent drug use.

\section{Results}

Among the cases there were 6,993 current non-insulin anti-diabetic drug (NIAD) users (excluding incretin users) and 643 DPP4-I users. There were 7,209 NIAD users (excluding incretin users) among the controls and 707 DPP4-I users. Current DPP4-I use was not associated with risk of any fracture (adjusted [adj.] OR: $0.97,95 \% \mathrm{Cl}: 0.79-1.18$ ) or major osteoporotic fracture (adj. OR: $0.96,95 \% \mathrm{Cl}: 0.72-1.28)$. Stratification of current DPP4-I use to cumulative and average daily dose did not show an association.

\section{Conclusion}

In a population-based case-control study we identified that short-term use of DPP4-I was not associated with fracture risk as compared to users of other anti-hyperglycaemic drugs. Additionally, results suggest that increasing daily dose and cumulative DPP4-I exposure were not associated with fracture risk. However, more research is needed to assess the effect of long-term DPP4-I use on the risk of fracture. 


\section{Introduction}

Individuals with type 2 diabetes are at an excess risk of osteoporotic fractures ${ }^{1}$. Although the aetiology of this increased risk is largely unknown, it has been hypothesized that this might be due to the underlying disease and/or to the drugs used in the treatment of type 2 diabetes $^{2,3}$. For instance, thiazolidinediones have been associated with an increased fracture risk as compared to use of other antihyperglycaemic drugs ${ }^{4-6}$. Moreover, epidemiological studies have shown that insulin use is associated with an elevated risk of fracture ${ }^{7}$, whereas metformin has been associated with a decreased risk of fracture ${ }^{8}$.

Dipeptidyl peptidase 4 inhibitors (DPP4-Is), such as sitagliptin, vildagliptin and saxagliptin, are a new class of anti-hyperglycaemic drugs, which may positively affect bone metabolism ${ }^{3}$ and decrease fracture risk. DPP4-Is inhibit the degradation process of incretin hormones, such as glucose-dependent insulinotropic polypeptide (GIP) and glucagon-like peptide 1 (GLP-1), which are secreted shortly after food ingestion ${ }^{3}$. Thus, DPP4-Is prolong the half-life time of the incretin hormones. In vitro research has shown that there are GLP-1 receptors present on osteocytes ${ }^{9}$ and immature osteoblast cells ${ }^{10}$. Activation of this receptor leads to an increased bone formation and an inhibition of bone resorption ${ }^{5,11}$, which might result in a decreased fracture risk.

Prior evidence on the association between DPP4-I use and risk of fracture are conflicting and limited mostly to clinical trial data. A meta-analysis of clinical trials showed a $40 \%$ reduction in fracture risk associated with DPP4-I use $\mathrm{e}^{12}$. However, the study had several limitations: the total number of fractures was small, fracture was not a primary endpoint and fractures were not routinely collected, there were heterogeneous comparison groups and it might be that relatively healthy patients were included in the trials. A large clinical trial $(n=16,492$, with a median follow-up time of 2.1 years), comparing saxagliptin to placebo showed a relative risk of fracture around $1^{13}$. An observational study investigating the effect of DPP4-I use on fracture risk showed a hazard ratio of 1.03 (95\% confidence interval (CI): 0.92-1.15) as compared to use of other anti-hyperglycaemic drugs ${ }^{14}$.

With limited available data, the aim of the present study was to examine the association between use of DPP4-Is and fracture risk compared to use of other antihyperglycaemic drugs in a population-based case-control study.

\section{Methods}

\section{Data source}

In Denmark, the extensive nature of health registries, covering all contacts to the health sector, offers the possibility for large population-based studies on the occurrence of fractures ${ }^{15}$. Using the unique 10-digit civil registry number that is assigned to all Danish 
citizens shortly after birth, a complete hospital discharge and prescription history can be established for each individual, and permits valid linkage between population-based registries ${ }^{16}$. Data on all changes in vital status, including change of address and date of death for the entire Danish population are registered since 1968 in the Civil Registration System. The Danish National Hospital Discharge Registes ${ }^{17}$ was founded in 1977 and covers all inpatients contacts from 1977 to 1994. Additionally, all outpatient visits to hospitals, outpatient clinics, and emergency rooms have been collected since 1995.

In Denmark, pharmacies are equipped with a computerised accounting system through which data are sent directly to a Register of Medicinal Product Statistics (i.e. a prescription database) at the Danish Medicines Agency with key information on prescriptions for refundable drugs. The prescription database includes information on patient's civil registry number, the type and amount of drug prescribed according to the Anatomical Therapeutic Chemical (ATC) classification system and the date when the prescription was filled. The database was started on January 1, 1996 and updated hereafter.

The Danish population constituted approximately 5.2 million individuals in 1995 and 5.5 million in 2011. The study was subject to control by the National Board of Health and the Danish Data Protection Agency.

\section{Study design}

We conducted a population-based case-control study. Cases were all subjects, both genders and aged 18 years and older, who sustained a fracture (International Classification of Diseases and Related Health Problems [ICD]-10 codes: S02, S12, S22, S32, S42, S52, S62, S72, S82, S92, T02, T08, T10, and T12) between 9 May 2007 (the first ever prescription of a DPP4-I in Denmark) and 31 December 2011. Information on fractures was on based in- and outpatient hospital records. Controls were all subjects, both genders and aged 18 years and older, who did not sustain a fracture during the study period. We randomly selected one control for each case, matched by gender and year of birth by means of the incidence-density sampling technique ${ }^{18}$. The date of the first fracture was used as index date and controls were assigned the index date of their matched case. The following categories were used to further classify fractures: hip (S72.0-S72.2), radius/ulna (S52) and vertebrae (S12, S22.0-S22.1, S32.0-S32.2, S32.7, S32.8, T08). A major osteoporotic fracture was defined as a fracture of the hip, radius/ulna, vertebrae or humerus (S42.2-S42.4) according to the WHO definition ${ }^{19}$.

\section{Exposure of interest}

We explored all drugs bought during the observation period available in the database. The dose of the drug bought during the observation period was expressed as defined daily dose $(D D D)^{20}$. ATC code A10B was used to determine exposure to non-insulin anti- 
diabetic drugs (NIAD). Based on the time of the most recent prescription before the index date, patients were classified as current (1-91 days) or past (over 91 days) NIAD user. Current NIAD users were divided into two mutually exclusive categories: never (during the study period) incretin users and incretin users. As diabetes itself might act as a confounder ${ }^{2}$ we used never incretin users (i.e. patients using non-insulin antidiabetic drugs excluding incretins) as the reference category in our analysis. Incretin use was further divided into glucagon-like peptide 1 receptor agonists (GLP1-RAs) users and DPP4-I users. DPP4-I exposure was determined by use of ATC codes A10BD07-A10BD13 and A10BH. DPP4-I users were classified as current (1-91 days), recent (92-182), past (183-365 days) or distant (over 365 days) users based on the time since the most recent prescription before the index date.

The DDDs were used to estimate the cumulative dose of DPP4-Is for each current DPP4-I user, expressed as sitagliptin equivalents. The average daily dose was estimated by dividing the cumulative exposure by the treatment time (time between the first DPP4-I prescription and the index date).

\section{Potential confounders}

We considered the following potential confounders ever before the index date: a history of chronic obstructive pulmonary disease, previous fracture, rheumatoid arthritis, hypothyroidism, hyperthyroidism, cancer, alcoholism, retinopathy, secondary osteoporosis (diabetes type 1, hypogonadism or premature menopause) and congestive heart failure. The potential confounders were determined by use of the National Hospital Register based on ICD10 and ICD8 codes. Other potential confounders included a prescription in the six months before the index date of the following drugs: GLP1-RAs, oral glucocorticoids ${ }^{21}$, cholesterol lowering drugs, antidepressants ${ }^{22}$, anxiolytics, hypnotics ${ }^{23}$, antipsychotics, anti-Parkinson drugs ${ }^{24}$, antihypertensives (betablockers, thiazide diuretics, renin angiotensin aldosterone system inhibitors, calcium channel blockers and loop diuretics), and antiarrhythmics. The prescription database was used to explore the presence of a prescription of the above-mentioned drugs.

\section{Statistical analysis}

Conditional logistic regression was used to estimate the association between the use of DPP4-Is versus use of other anti-hyperglycaemic drugs and risk of fracture, using SAS 9.3 software. Analyses were stratified by age, gender, type of fracture and for current DPP4-I use also by average daily and cumulative exposure. As a sensitivity analysis the main analyses was also adjusted for current metformin use, because metformin use has been associated with a decreased risk of fracture ${ }^{8}$. Final regression models were determined by stepwise backward elimination using a significance level of 0.05 . All results are presented as odds ratios (ORs) with corresponding $95 \% \mathrm{Cls}$. 


\section{Results}

We identified 229,145 cases and the same number of controls. In both cases and controls, the mean age was 55 years old and $56 \%$ were females. Baseline characteristics are shown in Table 2.3.1. There were $643(0.3 \%)$ cases and $707(0.3 \%)$ controls that were DPP4-I users (current, recent, past or distant). The mean duration of DPP4-I use (time from first prescription till index fracture date) for current DPP4-I use was 47 weeks for both cases and controls.

Table 2.3.1 Baseline characteristics ${ }^{\mathrm{a}}$.

\begin{tabular}{|c|c|c|}
\hline Characteristic & Cases $(\mathrm{N}=229,145)$ & Controls $(\mathrm{N}=229,145)$ \\
\hline Women & $127,449(55.6)$ & $127,449(55.6)$ \\
\hline Mean age at index date (years, SD) & $55(20.6)$ & $55(20.6)$ \\
\hline $18-49$ years & $90,598(39.5)$ & $90,607(39.5)$ \\
\hline 50 - 59 years & $37,247(16.3)$ & $37,191(16.2)$ \\
\hline 60 - 69 years & $38,751(16.9)$ & 38,805 (16.9) \\
\hline 70 - 79 years & $28,950(12.6)$ & $28,931(12.6)$ \\
\hline $80+$ years & $33,599(14.7)$ & $33,611(14.7)$ \\
\hline \multicolumn{3}{|l|}{ History of comorbidities } \\
\hline Type 1 diabetes mellitus & $2,113(0.9)$ & $1,419(0.6)$ \\
\hline Alcoholism & $11,147(4.9)$ & $4,824(2.1)$ \\
\hline Fracture & $46,446(20.2)$ & $15,418(6.7)$ \\
\hline Hyperthyroidism & $3,715(1.6)$ & $3,688(1.6)$ \\
\hline Hypothyroidism & $2,887(1.3)$ & $2,496(1.1)$ \\
\hline COPD & $10,812(4.7)$ & $7,418(3.2)$ \\
\hline Congestive heart failure & $7,141(3.1)$ & $5,424(2.4)$ \\
\hline Cancer & $21,893(9.6)$ & $18,486(8.1)$ \\
\hline Rheumatoid arthritis & $3,912(1.7)$ & $2,795(1.2)$ \\
\hline Retinopathy & $3,105(1.4)$ & $2,314(1.0)$ \\
\hline Neuropathy & $7,915(3.5)$ & $6,093(2.7)$ \\
\hline Secondary osteoporosis & $5,284(2.3)$ & $3,352(1.5)$ \\
\hline \multicolumn{3}{|c|}{ Drug use within six months before index date } \\
\hline Diabetic Medication & $8,541(3.7)$ & $8,676(3.8)$ \\
\hline Biguanides & $6,223(2.7)$ & $6,678(2.9)$ \\
\hline Sulphonylurea derivatives & $3,900(1.7)$ & $3,809(1.7)$ \\
\hline Thiadolidinediones & $262(0.1)$ & $183(0.1)$ \\
\hline Glinides & $87(0.0)$ & $83(0.0)$ \\
\hline GLP1-RAs & $255(0.1)$ & $220(0.1)$ \\
\hline DPP4-Is & $643(0.3)$ & $707(0.3)$ \\
\hline Acarbose & $42(0.0)$ & $28(0.0)$ \\
\hline Insulins & $4,900(2.1)$ & $3,261(1.4)$ \\
\hline Short acting & $2,046(0.9)$ & $1,139(0.5)$ \\
\hline Intermediate acting & $2,049(0.9)$ & $1,411(0.6)$ \\
\hline Long acting & $1,444(0.6)$ & $869(0.4)$ \\
\hline Combinations & $1,679(0.7)$ & $1,200(0.5)$ \\
\hline
\end{tabular}


Table 2.3.1 (continued)

\begin{tabular}{lcr}
\hline Characteristic & Cases $(\mathrm{N}=229,145)$ & Controls $(\mathrm{N}=229,145)$ \\
\hline Statins & $31,874(13.9)$ & $32,064(14.0)$ \\
Antiarrhythmics & $818(0.4)$ & $522(0.2)$ \\
Beta-blockers & $23,281(10.2)$ & $23,592(10.3)$ \\
Thiazide diuretics & $20,425(8.9)$ & $21,547(9.4)$ \\
RAAS inhibitors & $37,555(16.4)$ & $39,379(17.2)$ \\
Calcium channel blockers & $22,942(10.0)$ & $22,816(10.0)$ \\
Loop diuretics & $16,905(7.4)$ & $12,766(5.6)$ \\
Antidepressants & $33,644(14.7)$ & $20,338(8.9)$ \\
Anti-Parkinson drugs & $3,174(1.4)$ & $1,814(0.8)$ \\
Antipsychotics & $8,032(3.5)$ & $4,867(2.1)$ \\
Anxiolytics & $14,668(6.4)$ & $10,431(4.6)$ \\
Hypnotics & $19,137(8.4)$ & $14,332(6.3)$ \\
Glucocorticoids & $9,390(4.1)$ & $6,858(3.0)$ \\
Bisphosphonates & $7,371(3.2)$ & $4,913(2.1)$ \\
Raloxifene & $214(0.1)$ & $148(0.1)$ \\
Vitamin D & $211(0.1)$ & $169(0.1)$ \\
Calcium & $1,885(0.8)$ & $1,375(0.6)$ \\
Strontium ranelate & $194(0.1)$ & $101(0.0)$ \\
Parathyroid hormone & $130(0.1)$ & $70(0.0)$ \\
Calcitonin & $2(0.0)$ & $1(0.0)$ \\
Hormone replacement therapy & $11,912(5.2)$ & $13,955(6.1)$ \\
Beta2-agonists & $10,436(4.6)$ & $8,130(3.6)$ \\
Inhaled anticholinergics & $4,569(2.0)$ & $3,277(1.4)$ \\
Inhaled corticosteroids & $5,265(2.3)$ & $4,657(2.0)$ \\
\hline
\end{tabular}

COPD: chronic obstructive pulmonary disease; DPP4-I: dipeptidyl peptidase 4 inhibitor; GLP1-RA: glucagonlike peptide 1 receptor agonist; RAAS: renin angiotensin aldosterone system; SD: standard deviation. ${ }^{a}$ Data are number (\%) of patients, unless stated otherwise.

We identified, 6,993 (3.1\%) cases and 7,209 (3.1\%) controls with current NIAD users (excluding incretin users), Table 2.3.2. Never NIAD use was associated with a slightly increased risk of fracture, adjusted (adj.) OR 1.10 (95\% Cl: 1.06-1.14) as well as past NIAD use, adj. OR 1.12 (95\% Cl: 1.05-1.20). The risk of any fracture was not associated with current DPP4-I use adj. OR 0.97 (95\% Cl: 0.79-1.18), whereas recent use showed a significantly decreased risk of fracture, adj. OR 0.76 (95\% Cl: 0.59-0.97). The risk associated with past and distant DPP4-I use was not significantly decreased: adj. OR 0.96 (95\% Cl: 0.77-1.20), and adj. OR 0.95 (95\% Cl: 0.72-1.25), respectively. There was no decreased risk of fracture after stratification by sex and age, Table 2.3.2.

Current DPP4-I use was not associated with major osteoporotic fracture risk, adj. OR 0.96 (95\% Cl: 0.72-1.28), Table 2.3.3. Recent DPP4-I use showed a significantly decreased risk of major osteoporotic fracture adj. OR 0.70 (95\% Cl: $0.49-1.00)$, while past and distant DPP4-I use were not associated with a decrease in risk adj. OR 0.95 (95\% Cl: 0.71-1.29; adj. OR 0.94 (95\% Cl: 0.63-1.38, respectively). DPP4-I use (current, recent, past or distant) was not associated with risk of hip fracture or radius/ulna fracture. Current DPP4-I use was not associated with vertebral fracture risk whereas 
recent DPP4-I use resulted in a decreased risk of vertebral fracture: adj. OR 0.27 (95\% $\mathrm{Cl}$ : 0.08-0.90). Past and distant use was not associated with a decreased risk of vertebral fracture: adj. OR 2.34 (95\% Cl: 0.87-6.32), adj. OR 1.01 (95\% Cl: 0.25-4.12), respectively. Stratification by gender did not result in a reduced fracture risk for women or men (data not shown).

Stratification of current DPP4-I use by cumulative and average daily dose did not show a significantly decreased risk of any fracture, Table 2.3.4. The adjusted OR for the highest cumulative dose was 1.08 (95\% Cl: 0.76-1.54) and for highest average daily dose was 0.83 (95\% Cl: 0.55-1.26). Stratification of current DPP4-I use by cumulative and average daily dose for the other fracture types did not result in a decreased risk of major osteoporotic, Table 2.3.4, hip, vertebral or radius/ulna fracture (data not shown).

Adjusting the main analysis for current metformin use did not substantially change the results. Adjusted OR with current DPP4-I use was 0.94 (95\% Cl: 0.77-1.15), recent DPP4-I use was 0.74 (95\% Cl: 0.58-0.95), past DPP4-I use was 0.93 (95\% Cl: 0.74-1.16) and distant DPP4-I use was 0.92 (95\% Cl: 0.70-1.22).

\section{Discussion}

The present study showed that current DPP4-I use was not associated with any fracture risk as compared to current use of other anti-hyperglycaemic drugs. We further identified that the risk of other fractures was not associated with current DPP4-I use. Stratification of current DPP4-I use to cumulative and average daily dose did not show an association with fracture risk. However, recent DPP4-I use was associated with a significantly decreased risk of any fracture.

Our results are in agreement with a large clinical trial $(n=16,492$, median follow-up 2.1 years) that compared saxagliptin (DPP4-I) to placebo and showed a non-significant relative fracture risk around $1.0^{13}$. However, fractures were not the primary endpoint. The results are also in keeping with a cohort study using data from the Clinical Practice Research Datalink (CPRD) reporting that fracture risk was not associated with DPP4-I use as compared to use of other anti-hyperglycaemic drugs ${ }^{14}$. Similarly, two metaanalyses of clinical trials on the effect of GLP1-RAs on fracture risk showed no association between GLP1-RAs and fracture risk ${ }^{25,26}$. As well as a retrospective cohort study comparing use of GLP1-RAs to use of other anti-hyperglycaemic drugs ${ }^{27}$. Although GLP1-RAs intervene on a different molecule than DPP4-Is, the final effect on bone metabolism might be similar ${ }^{3}$. Moreover, our results are supported by the results of a clinical trial investigating the effect of the DPP4-I vildagliptin on a bone resorption marker $^{28}$. Compared to placebo, 44 weeks of treatment with vildagliptin was not associated with a decrease in postprandial markers of resorption ${ }^{29}$, which indirectly supports our findings. 


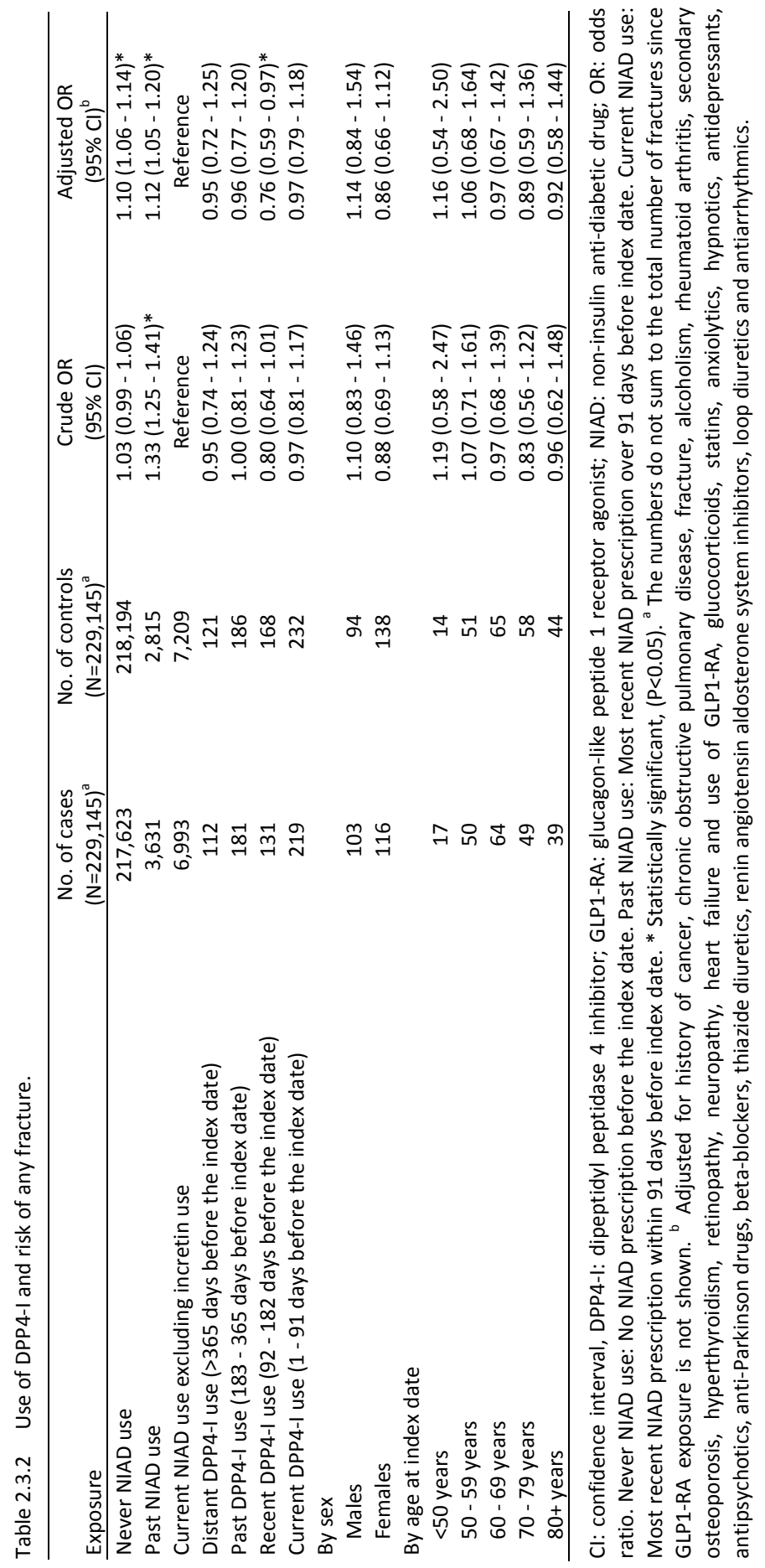




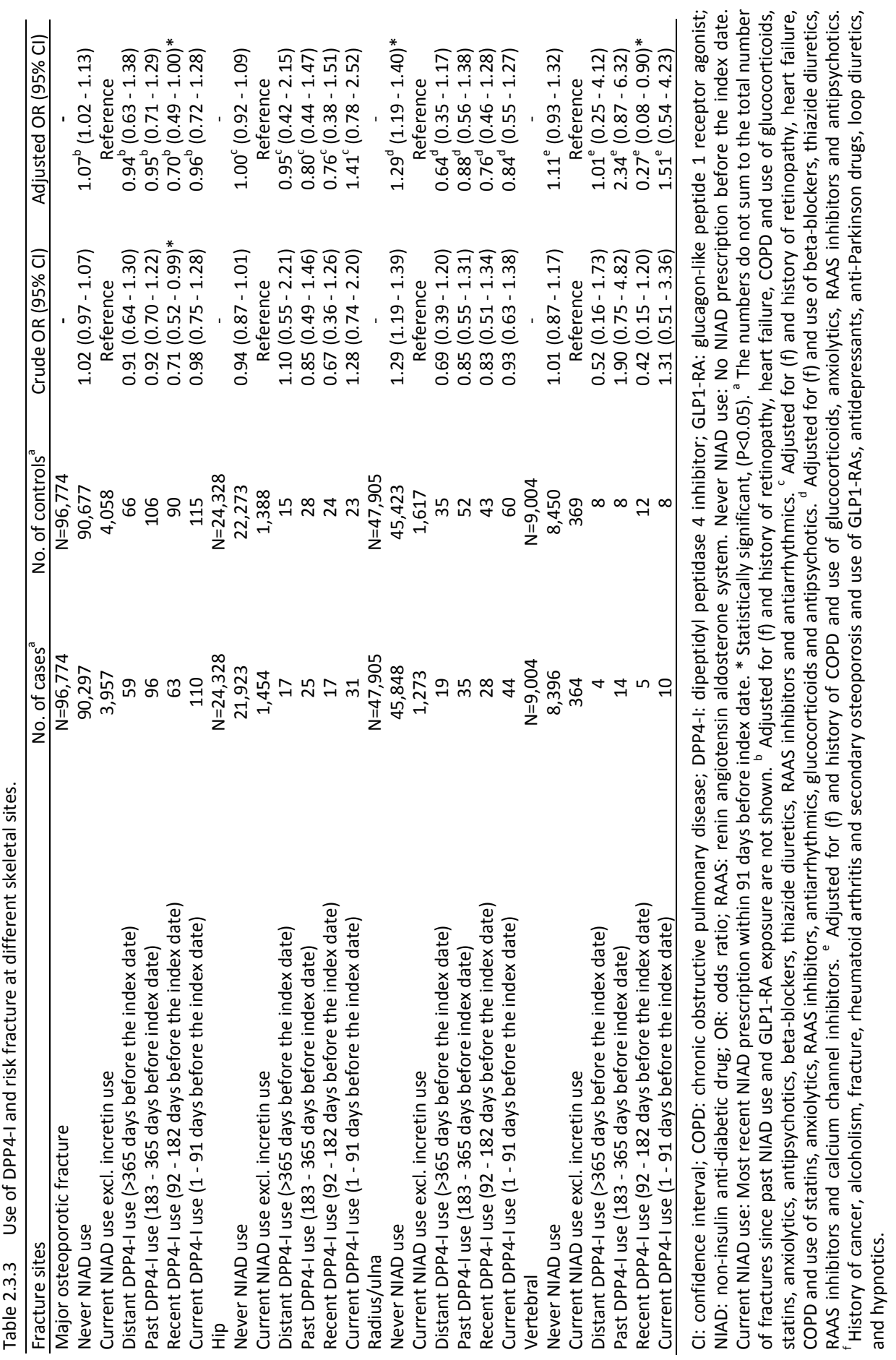




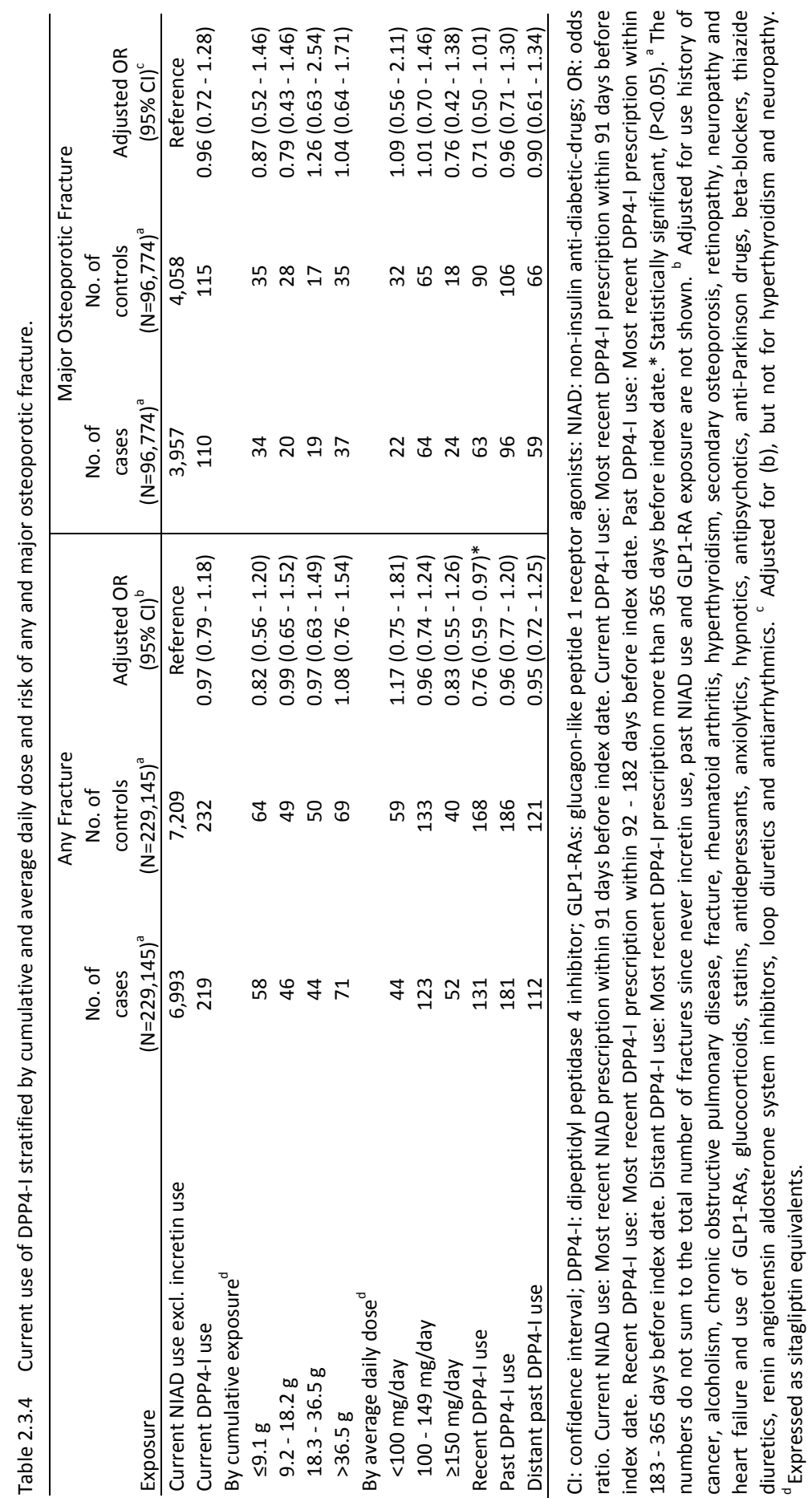


We note that our results are in contrast to a meta-analysis on the effect of DPP4-Is on fracture ${ }^{12}$ identifying that DPP4-I use was associated with a $40 \%$ reduction in fracture risk. However, this meta-analysis had several limitations, which may explain the discrepancies with our findings. Specifically, the mean duration of follow-up was only 35 weeks, the number of fractures was low $(n=63)$ and the outcome was not routinely collected. Based on the low number of fractures and the short duration an attenuation of the effect would be expected, nevertheless a $40 \%$ reduced fracture risk was found. In addition, 12 weeks of sitagliptin treatment was associated with a decreased bone resorption marker as compared to metformin use in postmenopausal diabetic women, which may support a beneficial effect of DPP4-Is ${ }^{29}$.

Different mechanisms by which GLP-1 might result in increased bone formation ${ }^{30-32}$ have been previously hypothesized. GLP-1 and glucose-dependent insulinotropic polypeptides (GIP) are incretin hormones that are secreted by the intestine after food ingestion, whereas DPP4 is an enzyme that degrades incretin hormones quickly after secretion $^{3}$. DPP4-Is inhibit the enzymal degradation process and thereby prolongs the half-life time of the incretin hormones.

In vitro studies have identified GLP-1 receptors on bone marrow stromal cells ${ }^{33}$, immature osteoblast ${ }^{10}$ and osteocytes ${ }^{9}$. Activation of the GLP-I receptor has shown to lead to increased osteoblast activity ${ }^{30}$ and inhibition of bone resorption ${ }^{34}$ that, theoretically, may lead to elevated bone formation and a reduced fracture risk. Similarly, GIP receptors have been identified on osteoblasts ${ }^{11}$, osteoclasts ${ }^{35}$, and bone marrow stromal cells ${ }^{36}$. Binding of GIP to its receptor stimulates osteoblast activity and inhibits osteoclast activity ${ }^{10,11}$, which may increase bone formation and reduce fracture risk. Decreased bone turnover has been associated with increased microdamage accumulation in animal studies ${ }^{37}$. This might result in an increased risk of fracture because the bones become more brittle. So, it might be hypothesized that use of DPP4-Is may result in an increased risk of fracture due to the decreased bone turnover. However, a study investigating the frequency of cancellous bone microcracks in patients who had used bisphosphonates for more than three years as compared to controls did not show a different frequency of microcracks ${ }^{38}$. In summary, more research is needed to better elucidate whether DPP4-Is are able to increase bone formation via the prolonging of the half-life of GLP-1 and GIP, and whether this effect is sufficient to alter osteoporotic fracture risk in humans.

Recent DPP4-I use showed a decreased association with risk of any fracture and risk of vertebral fracture. Surprisingly, this was not found for other DPP4-I users (current, past and distant), which would have been expected when an underlying mechanism is causing this decreased fracture risk. Consequently, we consider these results to likely be due to chance, and believe they require further replication. The total number of vertebral fractures with recent DPP4-I use was rather low and these results should therefore be interpreted with caution. Never and past NIAD use had an increased fracture risk as compared to current use of other anti-hyperglycaemic drugs, which was 
also unexpected. Unfortunately, we were unable to adjust our analysis for body mass index (BMI), which has been shown to decrease fracture risk ${ }^{39}$. Since an elevated BMI is a risk factor for diabetes, our finding that the increased risk associated with never NIAD use is a by-product of higher BMI among the current NIAD users. We also note that our past NIAD user group includes patients with type 2 diabetes mellitus receiving insulin therapy. Prior evidence has identified that fracture risk doubles for type 2 diabetes mellitus patients who use insulin compared to patients who receive strictly oral monotherapy ${ }^{2}$.

Strengths of this study include the nation-wide population-based design, large sample size, the validity of data, and the completeness of the Danish Health Registries. In addition, fractures are well captured in the hospital system of Denmark ${ }^{15}$. Another strength is the fact that data are prospectively collected, which circumvents any recall bias. Unfortunately, there was no data available about life style factors, such as BMI and smoking, or lab tests. For example, glycosylated hemoglobin A1c (HbA1c) values, which might be potential confounders, were not captured in our data. However, as a proxy for $\mathrm{HbA1C/poor} \mathrm{diabetes} \mathrm{control,} \mathrm{we} \mathrm{corrected} \mathrm{our} \mathrm{analyses} \mathrm{for} \mathrm{known}$ complications of diabetes, such as neuropathy and retinopathy, and we used current use of other anti-hyperglycaemic drugs (with the exception of insulin) as a proxy for diabetes. However, it is acknowledged that some residual confounding may still be present. For example, current NIAD use included current TZD and insulin use, which has been associated with an elevated fracture risk ${ }^{4-7}$. The result of this bias in the reference category may be an observed artificial inverse association between DPP4-I use and risk of fracture, which could have falsely supported our hypothesis. However, we did not observe an inverse association between DPP4-I use and risk of fracture. We might not have been able to fully adjust for diabetes severity which could have masked a true decreased risk of fracture with use of DPP4-Is. When studying a population with diabetes patient only, the adjusted diabetic complication severity index may be used to correct for diabetes severity ${ }^{40}$. We further note that metformin use has been associated with a reduced fracture risk. While our referent group included current metformin users, which may have limited our findings, we did not find a decreased risk of fracture associated with current use of DPP4-Is after adjusting for current metformin use. Another limitation of our study was the relatively short mean duration (47 weeks) of DPP4-I use (time from first to index date). However, a meta-analysis of clinical trials investigating the effect of DPP4-I use on risk of fracture showed a decreased effect on fracture risk with a mean duration of 35 weeks ${ }^{12}$.

In summary, we showed in a population-based case-control study that short-term DPP4-I use was not associated with fracture risk as compared to use of other antihyperglycaemic drugs. Additionally, increasing daily dose and cumulative DPP4-I exposure were also not associated with fracture risk. However, more research is needed to assess the effect of long-term DPP4-I use on the risk of fracture. 


\section{References}

1. Vestergaard P. Discrepancies in bone mineral density and fracture risk in patients with type 1 and type 2 diabetes - a meta-analysis. Osteoporos Int. 2007;18(4):427-44.

2. Carnevale V, Romagnoli E, D'Erasmo E. Skeletal involvement in patients with diabetes mellitus. Diabetes Metab Res Rev. 2004;20(3):196-204.

3. Montagnani A, Gonnelli S. Diabetes Obes Metab. Antidiabetic therapy effects on bone metabolism and fracture risk. 2013;15(9):78491.

4. Bazelier MT, Gallagher AM, van Staa TP, Cooper C, Leufkens HG, Vestergaard P, et al. Use of Thiazolidinediones and risk of osteoporotic fracture: Disease or drugs? Pharmacoepidemiol Drug Saf. 2012;21(5):50714.

5. Bazelier MT, Vestergaard P, Gallagher AM, van Staa TP, Cooper C, Leufkens HG, et al. Risk of fracture with thiazolidinediones: disease or drugs? Calcif Tissue Int. 2012;26(9):2271-9.

6. Betteridge DJ. Thiazolidinediones and fracture risk in patients with Type 2 diabetes. Diabet Med. 2011;28(7):759-71.

7. Schwartz AV, Vittinghoff E, Bauer DC, Hillier TA, Strotmeyer ES, Ensrud KE, et al. Association of BMD and FRAX score with risk of fracture in older adults with type 2 diabetes. JAMA. 2011;305(21):2184-92.

8. Vestergaard P, Rejnmark L, Mosekilde L. Relative fracture risk in patients with diabetes mellitus, and the impact of insulin and oral antidiabetic medication on relative fracture risk. Diabetologia. 2005;48(7):1292-9.

9. Kim JY, Lee SK, Jo KJ, Song DY, Lim DM, Park $K Y$, et al. Exendin-4 increases bone mineral density in type 2 diabetic OLETF rats potentially through the down-regulation of SOST/sclerostin in osteocytes. Life Sci. 2013;92(10):533-40.

10. Phillips LK, Prins JB. Update on incretin hormones. Ann N Y Acad Sci. 2011;1243:E5574.

11. Bollag RJ, Zhong Q, Phillips $P$, Min L, Zhong L, Cameron $\mathrm{R}$, et al. Osteoblast-derived cells express functional glucose-dependent insulinotropic peptide receptors. Endocrinology 2000;141(3);1228-35.

12. Monami M, Dicembrini I, Antenore A, Mannucci E. Dipeptidyl peptidase-4 inhibitors and bone fractures: a meta-analysis of randomized clinical trials. Diabetes Care. 2011;34(11):2474-6.

13. Scirica BM, Bhatt DL, Braunwald E, Steg PG, Davidson J, Hirshberg B, et al. Saxagliptin and cardiovascular outcomes in patients with type 2 diabetes mellitus. N Engl J Med. 2013;369(14):1317-26.

14. Driessen $\mathrm{JH}$, van Onzenoort HA, Henry RM, Lalmohamed A, van den Bergh JP, Neef $C$, et al. Use of dipeptidyl peptidase-4 inhibitors for type 2 diabetes mellitus and risk of fracture. Bone. 2014;68:124-30.

15. Vestergaard P, Mosekilde L. Fracture risk in patients with celiac Disease, Crohn's disease, and ulcerative colitis: a nationwide follow-up study of 16,416 patients in Denmark. Am J Epidemiol. 2002;156(1):1-10.

16. Frank L. Epidemiology. When an entire country is a cohort. Science. 2000;287:2398-9.

17. Andersen $T$, Madsen $M$, Jørgensen J, Mellemkjær L, Olsen J. The Danish National Hospital Register. Dan Med Bull. 1999:46:2638.

18. Wacholder S, McLaughlin J, Silverman D, Mandel J. Selection of controls in case-control studies. I. Principles. Am J Epidemiol. 1992;135:1019-28.

19. FRAX. WHO Fracture Risk Assessment Tool. 2001. shef.ac.uk. www.shef.ac.uk/FRAX/index. aspx.

20. Anonymous. ATC classification index with DDDs 2002. Nydalen, WHO Collaborating Centre for Drug Statistics Methodology, Norwegian Institute of Public Health, 2002.

21. Klop C, de Vries F, Vinks T, Kooij MJ, van Staa $\mathrm{TP}, \mathrm{Bijlsma} J W$, et al. Increase in prophylaxis of glucocorticoid-induced osteoporosis by pharmacist feedback: a randomised controlled trial. Osteoporos Int. 2014;25(1):385-92.

22. Prieto-Alhambra D, Petri $H$, Goldenberg JS, Khong TP, Klungel $\mathrm{OH}$, Robinson NJ, et al. Excess risk of hip fractures attributable to the use of antidepressants in five European countries and the USA. Osteoporos Int. 2014;25(3):847-55.

23. Khong TP, de Vries F, Goldenberg JS, Klungel $\mathrm{OH}$, Robinson NJ, Ibáñez L, et al. Potential impact of benzodiazepine use on the rate of hip fractures in five large European countries and the United States. Calcif Tissue Int. 2012;91(1):24-31. 
24. Pouwels S, Bazelier MT, de Boer A, Weber WE, Neef C, Cooper C, et al. Risk of fracture in patients with Parkinson's disease. Osteoporos Int. 2013;24(8):2283-90.

25. Mabilleau G, Mieczkowska A, Chappard D. Use of glucagon-like peptide-1 receptor agonists and bone fractures: a meta-analysis of randomized clinical trials. J Diabetes. 2014;6(3):260-6.

26. Su B, Sheng $H$, Zhang $M, B u L$, Yang $P$, Li L, et al. Risk of bone fractures associated with glucagon-like peptide-1 receptor agonists' treatment: a meta-analysis of randomized controlled trials. Endocrine. 2014; Epub ahead of print.

27. Driessen $\mathrm{JH}$, Henry RM, van Onzenoort $H A$, Lalmohamed A, Burden AM, Prieto-Alhambra $D$, et al. Bone fracture risk is not associated with the use of glucagon-like peptide-1 receptor agonists: a population-based cohort analysis. Calcif Tissue Int. 2015;97(2):104-12.

28. Bunck MC, Poelma M, Eekhoff EM, Schweizer A, Heine RJ, Nijpels $G$, et al. Effects of vildagliptin on postprandial markers of bone resorption and calcium homeostasis in recently diagnosed, well-controlled type 2 diabetes patients. J. Diabetes. 2012;4(2):181-5.

29. Hegazy SK. Evaluation of the anti-osteoporotic effects of metformin and sitagliptin in postmenopausal diabetic women. J Bone Miner Metab.2014;33(2):207-12.

30. Nuche-Berenguer $B$, Moreno $P$, Esbrit $P$, Dapía S, Caeiro JR, Cancelas J, et al. Effect of GLP-1 treatment on bone turnover in normal, type 2 diabetic, and insulin-resistant states. Calcif Tissue Int. 2009;84:453-61.

31. Nuche-Berenguer B, Moreno P, Portal-Nuñez $S$, Dapía S, Esbrit $P$, Villanueva-Peñacarrillo ML. Exendin-4 exerts osteogenic actions in insulinresistant and type 2 diabetic states. Regul Pept. 2010;159(1-3):61-6.

32. Moreno $\mathrm{P}$, Nuche-Berenguer $\mathrm{B}$, GutiérrezRojas I, Acitores A, Sancho V, Valverde I, et al. Normalizing action of exendin- 4 and GLP-1 in the glucose metabolism of extrapancreatic tissues in insulin-resistant and type 2 diabetic states. J Mol Endocrinol. 2012;48:37-47.
33. Sanz $C$, Vázquez $P$, Blázquez $C$, Barrio PA, Alvarez Mdel M, Blázquez $E$. Signaling and biological effects of glucagon-like peptide 1 on the differentiation of mesenchymal stem cells from human bone marrow. Am J Physiol Endocrinol Metab. 2010;298(3):E634-43.

34. Lamari $Y$, Boissard C, Moukhtar MS, Jullienne A, Rosselin G, Garel JM. Expression of glucagon-like peptide 1 receptor in a murine $C$ cell line: Regulation of calcitonin gene by glucagon-like peptide 1. FEBS Letters. 1996;393(2-3):248-52.

35. Zhong, Q, Itokawa T, Sridhar S, Ding KH, Xie D, Kang $B$, et al. Effects of glucose-dependent insulinotropic peptide on osteoclast function. Am. J. Physiol. Endocrinol. Metab. 2007 292(2);E543-8.

36. Ding KH, Shi XM, Zhong Q, Kang B, Xie D, Bollag $W B$, et al. Impact of glucose-dependent insulinotropic peptide on age-induced bone loss. J. Bone Miner. Res. 2008;23(4);536-43.

37. Johnston CC, Burr DB. Suppressed bone turnover by bisphosphonates increases microdamage accumulation and reduces some biomechanical properties in dog rib. J Bone Miner Res 2000;15:613-20.

38. Chapurlat RD, Arlot $M$, Burt-Pichat $B$, Chavassieux P, Roux JP, Portero-Muzy N, et al. Microcrack frequency and bone remodeling in postmenopausal osteoporotic women on longterm bisphosphonates: a bone biopsy study. J Bone Miner Res. 2007;22(10):1502-9.

39. Cummings SR, Nevitt MC, Browner WS, Stone $\mathrm{K}$, Fox KM, Ensrud KE, et al. Risk factors for hip fracture in white women. Study of Osteoporotic Fractures Research Group. N Engl J Med. 1995;332(12):767-73.

40. Chang HY, Weiner JP, Richards TM, Bleich SN, Segal JB. Validating the adapted Diabetes Complications Severity Index in claims data. Am J Manag Care. 2012;18(11):721-6. 


\section{Chapter}

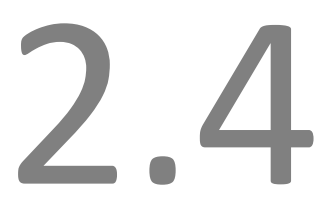

Bone fracture risk is not associated with the use of glucagon-like peptide 1 receptor agonists: a population-based cohort analysis

JHM Driessen, RMA Henry, HAW van Onzenoort, A Lalmohamed, AM Burden, D Prieto-Alhambra, C Neef, HGM Leufkens, F de Vries

Calcif Tissue Int. 2015;97(2):104-112 


\section{Abstract}

\section{Introduction}

Glucagon-like peptide 1 receptor agonists (GLP1-RAs) are a relatively new class of antihyperglycaemic drugs which may positively affect bone metabolism and thereby decrease (osteoporotic) bone fracture risk. Data on the effect of GLP1-RAs on fracture risk are scarce and limited to clinical trial data only. The aim of this study was to investigate, in a population-based cohort, the association between the use of GLP1-RAs and bone fracture risk.

\section{Methods}

We conducted a population-based cohort study, with the use of data from the Clinical Practice Research Datalink (CPRD) database (2007-2012). The study population $(n=216,816)$ consisted of all individuals with type 2 diabetes mellitus patients with at least one prescription for a noninsulin anti-diabetic drug (NIAD) and were over 18 years of age. Cox proportional hazards models were used to estimate the hazard ratio of fracture in GLP1-RA users versus never-GLP1-RA users. Time-dependent adjustments were made for age, sex, lifestyle, comorbidity and the use of other drugs.

\section{Results}

There was no decreased risk of fracture with current use of GLP1-RAs as compared to neverGLP1-RA use (adjusted hazard ratio (HR) 0.99, 95\% Cl: 0.82-1.19). Osteoporotic fracture risk was also not decreased by current GLP1-RA use (adjusted HR 0.97, 95\% Cl: 0.72-1.32). In addition, stratification according to cumulative dose did not show a decreased bone fracture risk with increasing cumulative GLP1-RA dose.

\section{Conclusion}

We showed in a population-based cohort study that GLP1-RA use is not associated with a decreased bone fracture risk as compared to users of other anti-hyperglycaemic drugs. Future research is needed to elucidate the potential working mechanisms of GLP1-RAs on bone. 


\section{Introduction}

In individuals with type 2 diabetes mellitus (T2DM), the risk of bone fracture is increased as compared to individuals without $\mathrm{T}_{2} \mathrm{DM}^{1}$. This increased risk might be associated with the pathobiology of T2DM itself, although the underlying mechanisms remain largely unknown ${ }^{2}$. Alternatively, it has been suggested that this increased bone fracture risk is a consequence of the kind of therapeutic regimen initiated to combat hyperglycaemia ${ }^{3}$. For instance, thiazolidinediones ${ }^{4-6}$ have shown to increase fracture risk. It has been suggested that human recombinant insulins ${ }^{7}$ also increase bone fracture risk, whereas metformin might actually decrease it ${ }^{8}$.

Glucagon-like peptide 1 receptor agonists (GLP1-RAs) are a relative new class of anti-hyperglycaemic drugs, which may positively affect bone metabolism ${ }^{9-11}$ and decrease bone fracture risk. However, a recent meta-analysis, based upon randomised clinical trial data, in which bone fractures were not a primary outcome, did not show a decreased bone fracture risk ${ }^{12}$. Thus, the aim of the present study was to investigate, in a large population-based cohort study, the association between GLP1-RA use and the risk of bone fractures in individuals with T2DM.

\section{Methods}

\section{Data source}

Data were obtained from the British Clinical Practice Research Datalink (CPRD; previously the General Practice Research Database [GPRD]; see [www.CPRD.com]). The CPRD contains computerized medical records of 625 primary care practices in the United Kingdom (UK), and patients represent $8 \%$ of the UK population. Data have been collected since 1987 and include, amongst others; demographic information, prescription details, data on morbidity and mortality, preventive care provided and specialist referrals. Data in the CPRD has been shown to be accurate and valid ${ }^{13}$. Particularly, with regard to the main outcome of the present study, fractures have been validated in over $90 \%$ of all cases ${ }^{14}$.

\section{Study population}

We conducted a population-based cohort study. The population consisted of all patients with at least one prescription for a non-insulin anti-hyperglycaemic drug (NIAD) and who were aged 18+ during the period of valid CPRD data collection ${ }^{15}$. Cohort entry was defined as the date of first prescription for GLP1-RA, identified between June $13^{\text {th }}, 2007$ and August 31, 2012. The index date was defined as the date of the first NIAD prescription; thereby the study population was a mix of incident and prevalent NIAD users. Patients were followed from the index date to the end of data 
collection, date of transfer of the patient out of the practice area, patient's death, or fracture types of interest, whichever came first.

\section{Exposure}

Follow-up time was divided into intervals based on NIAD and insulin prescriptions. Thus a new interval was created for every prescription. When there was a washout period of 90 days, an interval was classified as "past use", until end of follow-up, or a new antihyperglycaemic drug prescription, whichever came first. In all other circumstances an interval was classified as "current use". If no GLP1-RA was prescribed during follow-up person-time was classified as never use of GLP1-RA.

All GLP1-RA exposed intervals were classified, according to the time since the most recent prescription, as current (1-90 days), recent (91-180 days), or past (over 180 days) GLP1-RA use. At every current use interval, the cumulative prescribed GLP1-RA dosage, in exenatide dose equivalents, was reviewed and divided by the GLP1-RA treatment time (difference in time between the start of the first and last GLP1-RA prescription) to estimate the average daily GLP1-RA dose. Defined daily doses were used to calculate the exenatide dose equivalents ${ }^{16}$.

\section{Outcomes}

Patients were followed from the index date to the end of data collection, date of transfer of the patient out of the practice area, patient's death, or fracture types of interest, whichever came first. Fractures were classified with the use of READ codes $^{17}$ into hip, radius and (or) ulna, vertebral, humerus and other fractures. A major osteoporotic fracture was defined according to the WHO definition as a fracture of the hip, humerus, vertebral or radius/ulna ${ }^{18}$.

\section{Other variables}

The presence of risk factors for bone fractures was assessed by reviewing the computerized medical records for any record of any risk factors for bone fractures prior to the start of an interval. The following potential confounders were determined at baseline: sex, body mass index (BMI), smoking status, and alcohol use. All other potential confounders that were considered in this study were determined timedependent (i.e. at the start of each interval): age, falls in 7 to 12 months before the start of an interval, a history of chronic obstructive pulmonary disease, a previous fracture, rheumatoid arthritis, hypothyroidism, hyperthyroidism, cancer, retinopathy, neuropathy, secondary osteoporosis (hypogonadism or early menopause), and congestive heart failure. The most recent glycosylated hemoglobin type A1c (HbA1c) value up to one year prior to the start of an interval was determined. The following drug prescriptions, in the 6 months prior to the start of an interval, were considered 
potential confounders; oral glucocorticoids ${ }^{19}$, cholesterol lowering drugs, antidepressants $^{20}$, anxiolytics or hypnotics ${ }^{21}$, antipsychotics, anti-Parkinson drugs ${ }^{22}$, antihypertensives (beta-blockers, thiazide diuretics, renin angiotensin aldosterone system inhibitors, calcium channel blockers, loop diuretics), antiarrhythmics, hormone replacement therapy, calcium, bisphosphonates, vitamin $D$, raloxifene, strontium ranelate, calcitonin, and parathyroid hormone.

\section{Statistical analyses}

Regression analysis with Cox proportional hazards models (SAS 9.2, PHREG procedure) was used to estimate bone fracture risk of GLP1-RA users (current, recent or past) compared to never-GLP1-RA users. Current GLP1-RA use was further stratified to age and gender and the main analyses was repeated for major osteoporotic bone fracture risk. In a series of further analyses, current GLP1-RA use was stratified according to type of GLP1-RA (i.e. exenatide and liraglutide), daily and cumulative dose. As a sensitivity analysis the person-time for thiazolidinediones (TZD) was excluded from the reference group and analysed as a separate group.

In all analyses potential confounders were included if they independently changed the beta-coefficient for current GLP1-RA exposure by at least $5 \%$, or when consensus about inclusion existed within the team of researchers, supported by clinical evidence from literature.

\section{Results}

\section{Study population and follow-up}

In total, 216,816 individuals were included in the present study, of which 8,354 used GLP1-RAs (either current, recent or past). The characteristics of the study population are presented in Table 2.4.1. On average, GLP1-RA users were younger than neverGLP1-RA users (53.5 vs. 61.0 years), and had a higher BMI (37.5 vs. 31.0). The median duration of follow-up time (from start of follow-up to end of data collection) was 5.1 years (Inter Quartile Range [IQR]: 3.6-5.2 years for GLP1-RA users and 3.6 years (IQR: 1.6-5.2 years) for never-GLP1-RA users.

After adjusting for confounders, the risk for bone fractures with current GLP1-RA, as compared to never-GLP1-RA users, was (hazard ratio [HR] and $[95 \% \mathrm{CI}]$ ): $0.99(95 \% \mathrm{Cl}$ : 0.82-1.19), with recent GLP1-RA use: 1.19 (95\% Cl: 0.66-2.14) and with past GLP1-RA use: 1.38 (95\% Cl: 1.03-1.84), Table 2.4.2. Stratification of current GLP1-RA by GLP1-RA type resulted in an adjusted (adj.) HR of 0.90 (95\% Cl: 0.69-1.17) with use of liraglitude and an adj. HR of 1.08 (95\% Cl: 0.84-1.38) with exenatide use. 
Table 2.4.1 Baseline characteristics of GLP1-RA users and never-GLP1-RA users ${ }^{a}$.

\begin{tabular}{|c|c|c|}
\hline & GLP1-RA users $^{\mathrm{b}}$ & Never-GLP1-RA users ${ }^{c}$ \\
\hline Characteristic & $\mathrm{N}=8,354$ & $\mathrm{~N}=208,462$ \\
\hline Median [IQR] follow-up time, years & $5.1[3.6-5.2]$ & $3.6[1.6-5.2]$ \\
\hline Median [IQR] duration of actual GLP1-RA use, years & $1.7[0.8-2.7]$ & $\mathrm{n} / \mathrm{a}$ \\
\hline Women & $3,904(46.7)$ & $98,614(47.3)$ \\
\hline \multicolumn{3}{|l|}{ Age } \\
\hline Mean age at index date (years, SD) & $53.5(10.5)$ & $61.0(15.1)$ \\
\hline 18 - 49 years & $2,952(35.3)$ & $43,574(20.9)$ \\
\hline $50-59$ years & $2,909(34.8)$ & $41,717(20.0)$ \\
\hline $60-69$ years & $1,986(23.8)$ & $54,865(26.3)$ \\
\hline $70-79$ years & $481(5.8)$ & $46,907(22.5)$ \\
\hline $80+$ years & $26(0.3)$ & $21,399(10.3)$ \\
\hline \multicolumn{3}{|l|}{ BMI } \\
\hline Mean $\mathrm{BMI}$ at index date $\left(\mathrm{kg} / \mathrm{m}^{2}, \mathrm{SD}\right)$ & $37.5(7.1)$ & $31.0(6.5)$ \\
\hline$<20.0 \mathrm{~kg} / \mathrm{m}^{2}$ & $3(0.0)$ & $2,759(1.3)$ \\
\hline $20.0-24.9 \mathrm{~kg} / \mathrm{m}^{2}$ & $84(1.0)$ & $26,969(12.9)$ \\
\hline $25.0-29.9 \mathrm{~kg} / \mathrm{m}^{2}$ & $936(11.2)$ & $67,550(32.4)$ \\
\hline $30.0-34.9 \mathrm{~kg} / \mathrm{m}^{2}$ & $2,369(28.4)$ & $57,826(27.7)$ \\
\hline $35.0 \mathrm{~kg} / \mathrm{m}^{2}$ & $4,921(58.9)$ & $48,016(23.0)$ \\
\hline Missing & $41(0.5)$ & $5,342(2.6)$ \\
\hline \multicolumn{3}{|l|}{ HbA1c \% } \\
\hline Mean (SD) & $8.6(1.9)$ & $8.0(1.8)$ \\
\hline Missing & 2,915 (34.9) & $88,937(42.7)$ \\
\hline \multicolumn{3}{|l|}{ Smoking status } \\
\hline Never & $3,949(47.3)$ & 103,970 (49.9) \\
\hline Current & $1,945(23.3)$ & $41,110(19.7)$ \\
\hline Ex & $2,458(29.4)$ & $62,287(29.9)$ \\
\hline Missing & $2(0.0)$ & $1,095(0.5)$ \\
\hline \multicolumn{3}{|l|}{ Alcohol use } \\
\hline No & 2,417 (28.9) & $60,278(28.9)$ \\
\hline Yes & $5,638(67.5)$ & $136,373(65.4)$ \\
\hline Missing & $299(3.6)$ & $11,811(5.7)$ \\
\hline Falls (7 - 12 months before) & $52(0.6)$ & $2,141(1.0)$ \\
\hline \multicolumn{3}{|l|}{ History of diseases } \\
\hline Fracture & $52(0.6)$ & $1,342(0.6)$ \\
\hline Hyperthyroidism & $64(0.8)$ & $2,014(1.0)$ \\
\hline Hypothyroidism & $719(8.6)$ & $16,413(7.9)$ \\
\hline COPD & $345(4.1)$ & $11,585(5.6)$ \\
\hline Congestive heart failure & $244(2.9)$ & $8,846(4.2)$ \\
\hline Cancer & $1,626(19.5)$ & $45,626(21.9)$ \\
\hline Rheumatoid arthritis & $109(1.3)$ & $3,633(1.7)$ \\
\hline Retinopathy & $1,284(15.4)$ & $24,954(12.0)$ \\
\hline Secondary osteoporosis & $895(10.7)$ & $18,571(8.9)$ \\
\hline Neuropathy & $768(9.2)$ & $15,652(7.5)$ \\
\hline \multicolumn{3}{|l|}{ Drug use within six months before index date } \\
\hline Metformin & $7,367(88.2)$ & $171,699(82.4)$ \\
\hline Sulfonylurea derivatives & $4,589(54.9)$ & $54,874(26.3)$ \\
\hline Thiazolidinediones & $2,108(25.2)$ & $20,293(9.7)$ \\
\hline Insulin & $2,238(26.8)$ & $22,556(10.8)$ \\
\hline DPP4-Is & $144(1.7)$ & $1,374(0.7)$ \\
\hline Glucocorticoids & $439(5.3)$ & $12,077(5.8)$ \\
\hline
\end{tabular}


Table 2.4.1 (continued)

\begin{tabular}{lcc}
\hline & GLP1-RA users & Never-GLP1-RA users $^{\mathrm{c}}$ \\
Characteristic & $\mathrm{N}=8,354$ & $\mathrm{~N}=208,462$ \\
\hline Statins & $5,803(69.5)$ & $113,343(54.4)$ \\
Antiarrhythmics & $125(1.5)$ & $3,336(1.6)$ \\
Antidepressants & $2,075(24.8)$ & $32,995(15.8)$ \\
Anti-Parkinson drugs & $24(0.3)$ & $1,040(0.5)$ \\
Antipsychotics & $157(1.9)$ & $4,343(2.1)$ \\
Anxiolytics & $658(7.9)$ & $14,752(7.1)$ \\
Hypnotics & $437(5.2)$ & $10,242(4.9)$ \\
Antihypertensives & $5,651(67.6)$ & $120,188(57.7)$ \\
Bisphosphonates & $87(1.0)$ & $5,569(2.7)$ \\
Raloxifene & $5(0.1)$ & $298(0.1)$ \\
Vitamin D & $42(0.5)$ & $1,161(0.6)$ \\
Calcium & $145(1.7)$ & $8,263(3.9)$ \\
Strontium & $0(-)$ & $124(0.1)$ \\
PTH/calcitonin & $0(-)$ & $0(-)$ \\
Hormone replacement therapy & $71(0.8)$ & $835(0.4)$ \\
\hline
\end{tabular}

BMI: body mass index; COPD: chronic obstructive pulmonary disease; DPP4-I: dipeptidyl peptidase 4 inhibitor; GLP1-RA: glucagon-like peptide 1 receptor agonist; IQR: inter quartile range; NIAD: non-insulin anti-diabetic drug, PTH: parathyroid hormone; SD: standard deviation. ${ }^{a}$ Data are number (\%) of patients, unless stated otherwise. ${ }^{b}$ GLP1-RA users are patients who had at least 1 GLP1-RA prescription during follow-up. ${ }^{\mathrm{C}}$ NeverGLP1-RA users are patients who had at least 1 NIAD prescription other than GLP1-RA, during follow-up.

When stratified by sex, bone fracture risk for current male GLP1-RA users was 1.01 (95\% Cl: 0.76-1.33) and for current female GLP1-RA users was 0.96 (95\% Cl: 0.75-1.22), Table 2.4.2. After stratification by age group (i.e., 18-49, 50-59, 60-69 and $\geq 70$ years), the risk for bone fractures among patients with current GLP1-RA use aged 18-49 was 0.80 (95\% Cl: $0.52-1.25)$, aged 50-59 was 0.80 (95\% Cl: 0.56-1.15), aged 60-69 was 1.38 (95\% Cl: $1.04-1.83)$, and aged 70 years or older was 0.68 (95\% Cl: $0.39-1.18)$, Table 2.4.2.

As compared to never-GLP1-RA use, the risk for major osteoporotic fractures with current GLP1-RA use was 0.97 (95\% Cl: 0.72-1.32), with recent GLP1-RA use; 1.13 (95\% $\mathrm{Cl}: 0.42-3.02)$ and with past GLP1-RA use; 1.04 (95\% Cl: 0.61-1.76), Table 2.4 .3 (detailed data not shown). Current GLP1-RA use was not associated with a decreased bone fracture risk for other fracture types, Table 2.4.3.

If current GLP1-RA use was stratified according to cumulative dose (i.e., 0-2.7 mg, 2.8-5.4 $\mathrm{mg}, 5.5-8.2 \mathrm{mg}$ and $\geq 8.3 \mathrm{mg}$ exenatide dose equivalents) the results showed that, as compared to never-GLP1-RA users, bone fracture risk for 0-2.7 mg was 1.02 (95\% Cl: 0.75-1.40), for 2.7-5.5 mg; 0.89 (95\% Cl: 0.60-1.34), for 5.5-8.2 mg; 0.94 (95\% $\mathrm{Cl}: 0.58-1.52)$ and for $\geq 8.3 \mathrm{mg} ; 1.03$ (95\% Cl: $0.75-1.41)$. When stratified according to current GLP1-RA average daily dose use (i.e., missing, 0-15 mcg, 16-20 mcg and $>20 \mathrm{mcg}$ exenatide dose equivalents) the results were not substantially altered, Table 2.4.4. 
Table 2.4.2 Risk of bone fracture in GLP1-RA users compared with never-GLP1-RA users ${ }^{\mathrm{a}}$.

\begin{tabular}{|c|c|c|c|c|}
\hline & $\begin{array}{c}\text { No. of } \\
\text { fractures } \\
\mathrm{N}=9,340^{\mathrm{b}}\end{array}$ & $\begin{array}{l}\text { Fracture IR } \\
\text { (/1000 PY) }\end{array}$ & $\begin{array}{l}\text { Age/sex adjusted HR } \\
(95 \% \mathrm{Cl})\end{array}$ & $\begin{array}{l}\text { Adjusted } \mathrm{HR}^{\mathrm{d}} \\
(95 \% \mathrm{Cl})\end{array}$ \\
\hline \multicolumn{5}{|c|}{ GLP1-RA exposure } \\
\hline Never use ${ }^{c}$ & 8,449 & 12.9 & Reference & Reference \\
\hline Past use & 47 & 16.1 & $1.48(1.11-1.95)^{*}$ & $1.38(1.03-1.84)^{*}$ \\
\hline Recent use & 11 & 13.4 & $1.22(0.69-2.14)$ & $1.19(0.66-2.14)$ \\
\hline Current use & 122 & 10.6 & $1.00(0.83-1.20)$ & 0.99 (0.82 - 1.19) \\
\hline \multicolumn{5}{|c|}{ By GLP1-RA type } \\
\hline Liraglutide & 57 & 9.5 & $0.91(0.70-1.18)$ & $0.90(0.69-1.17)$ \\
\hline Exenatide & 65 & 11.8 & $1.09(0.85-1.40)$ & $1.08(0.84-1.38)$ \\
\hline \multicolumn{5}{|l|}{ By $\operatorname{sex}^{e}$} \\
\hline Men & 53 & 8.5 & $1.02(0.78-1.35)$ & $1.01(0.76-1.33)$ \\
\hline Women & 69 & 13.1 & $0.98(0.77-1.25)$ & $0.96(0.75-1.22)$ \\
\hline \multicolumn{5}{|l|}{ By age $^{f}$} \\
\hline $18-49$ & 22 & 7.6 & $0.88(0.57-1.35)$ & $0.80(0.52-1.25)$ \\
\hline $50-59$ & 33 & 8.5 & $0.83(0.58-1.19)$ & $0.80(0.56-1.15)$ \\
\hline $60-69$ & 54 & 15.0 & $1.48(1.12-1.95)^{*}$ & $1.38(1.04-1.83)^{*}$ \\
\hline $70+$ & 13 & 11.3 & $0.60(0.35-1.04)$ & $0.68(0.39-1.18)$ \\
\hline
\end{tabular}

$\mathrm{Cl}$ : confidence interval; DPP4-I: dipeptidyl peptidase 4 inhibitor; GLP1-RA: glucagon-like peptide 1 receptor agonist; HR: hazard ratio; IR: incidence rate; NIAD: non-insulin anti-diabetic drug. Current GLP1-ra use: most recent prescription within 90 before start of an interval. Recent GLP1-ra use: most recent prescription within 91-180 before start of an interval. Past GLP1-ra use: most recent prescription over 180 days before start of an interval. * Statistically significant, $(\mathrm{P}<0.05)$. ${ }^{\text {a }}$ All models are corrected for DPP4-I use. ${ }^{\text {b }}$ Past NIAD use not shown, therefore the total number of fractures do not add up. ${ }^{c}$ Never GLP1-RA use does not include use of DPP4-I. 'Adjusted for sex, age, body mass index, smoking status, glycosylated hemoglobin type A1c, retinopathy, neuropathy, secondary osteoporosis, and the use of glucocorticoids, cholesterol lowering drugs, hypnotic/anxiolytic drugs and antidepressants. ${ }^{e}$ Models not statistically adjusted for sex. ${ }^{f}$ Models not statistically adjusted for age.

As TZD use has been associated with an increased risk of fracture we additionally excluded for the main analysis all TZD exposed person-time from the reference group and analysed it as a separate group. This did not substantially change the results of GLP1-RA use (adj. HR with current GLP1-RA use; 1.03 (95\% Cl: 0.86-1.24), with recent GLP1-RA use; 1.19 (95\% Cl: 0.66-2.15) and with past GLP1-RA use; 1.38 (95\% Cl: 1.03-1.84)). 
Table 2.4.3 Risk of bone fracture in current GLP1-RA users stratified to fracture type ${ }^{a}$.

\begin{tabular}{|c|c|c|c|c|}
\hline Fracture sites & $\begin{array}{c}\text { No. of } \\
\text { fractures }\end{array}$ & $\begin{array}{l}\text { Fracture IR } \\
\text { (/1000 PY) }\end{array}$ & $\begin{array}{c}\text { Age/sex adjusted HR } \\
(95 \% \mathrm{Cl})\end{array}$ & $\begin{array}{c}\text { Adjusted HR } \\
(95 \% \mathrm{Cl})\end{array}$ \\
\hline \multicolumn{5}{|c|}{ Major osteoporotic fracture } \\
\hline Never-GLP1-RA use ${ }^{b}$ & 4,373 & 6.1 & Reference & Reference \\
\hline Current GLP1-RA use & 44 & 3.7 & $0.97(0.71-1.31)$ & $0.97(0.72-1.32)^{c}$ \\
\hline \multicolumn{5}{|l|}{ Hip fracture } \\
\hline Never-GLP1-RA use ${ }^{b}$ & 1,383 & 1.9 & Reference & Reference \\
\hline Current GLP1-RA use & 2 & 0.2 & $0.26(0.06-1.03)$ & $0.27(0.07-1.08)^{d}$ \\
\hline \multicolumn{5}{|l|}{ Radius/ulna fracture } \\
\hline Never-GLP1-RA use $^{\mathrm{b}}$ & 1,442 & 2.0 & Reference & Reference \\
\hline Current GLP1-RA use & 15 & 1.3 & $1.78(0.47-1.32)$ & $0.82(0.48-1.37)^{\mathrm{e}}$ \\
\hline \multicolumn{5}{|l|}{ Vertebral fracture } \\
\hline Never-GLP1-RA use ${ }^{\mathrm{b}}$ & 513 & 0.7 & Reference & Reference \\
\hline Current GLP1-RA use & 8 & 0.7 & $1.59(0.78-3.24)$ & $1.64(0.80-3.37)^{f}$ \\
\hline
\end{tabular}

$\mathrm{Cl}$, confidence interval; DPP4-I, dipeptidyl peptidase 4 inhibitor; GLP1-RA, glucagon-like peptide 1 receptor agonist; HR: hazard ratio; IR: incidence rate. Current GLP1-ra use: most recent prescription within 90 before start of an interval. * Statistically significant, $(\mathrm{P}<0.05)$. ${ }^{\text {a }}$ All models are corrected for DPP4-I use. ${ }^{\mathrm{b}}$ Never-GLP1RA use does not include use of DPP4-I. ' Adjusted for (g), and history of congestive heart failure, use of cholesterol lowering drugs, antidepressants, hypnotics/anxiolytics, calcium, and anti-osteoporotic drugs ${ }^{\mathrm{g}}{ }^{\mathrm{d}}$ Adjusted for (g), and the use of glucocorticoids, antidepressants, and falls 7-12 months before index date. ${ }^{\mathrm{e}}$ Adjusted for (g), and the use of cholesterol lowering drugs, antidepressants, hypnotics/anxiolytics, antiosteoporotic drugs ${ }^{h}$, and glucocorticoids. ${ }^{f}$ Adjusted for $(\mathrm{g})$, and history of congestive heart failure, use of cholesterol lowering drugs, antidepressants, hypnotics/anxiolytics, and glucocorticoids. ${ }^{\mathrm{g}}$ Sex, age, body mass index, glycosylated hemoglobin type A1c, smoking status, $\mathrm{HbA1c}$, retinopathy, neuropathy and secondary osteoporosis. ${ }^{\mathrm{h}}$ Use of bisphosphonates, raloxifene, strontium ranelate or parathyroid hormone/calcitonin.

Table 2.4.4 Risk of bone fracture in current GLP1-RA users compared to never-GLP1-RA users, stratified by average and cumulative DDD exposure ${ }^{\mathrm{a}}$.

\begin{tabular}{|c|c|c|c|c|}
\hline & $\begin{array}{c}\text { No. of } \\
\text { fractures }\end{array}$ & $\begin{array}{l}\text { Fracture IR } \\
\text { (/1000 PY) }\end{array}$ & $\begin{array}{c}\text { Age/sex adjusted } \\
\text { HR }(95 \% \mathrm{Cl})\end{array}$ & $\begin{array}{l}\text { Adjusted HR } \\
(95 \% \mathrm{Cl})^{\mathrm{c}}\end{array}$ \\
\hline Never-GLP1-RA use ${ }^{b}$ & 8,449 & 12.9 & Reference & Reference \\
\hline \multicolumn{5}{|l|}{ Current GLP1-RA use } \\
\hline \multicolumn{5}{|c|}{$\begin{array}{l}\text { By average DDD exposure } \\
\text { (in exenatide equivalents) }\end{array}$} \\
\hline $0-15 \mathrm{mcg}$ & 48 & 16.9 & $1.05(0.79-1.40)$ & $1.03(0.78-1.38)$ \\
\hline $16-20 \mathrm{mcg}$ & 37 & 8.7 & $0.82(0.59-1.14)$ & $0.82(0.59-1.13)$ \\
\hline$\geq 21 \mathrm{mcg}$ & 28 & 14.3 & $1.29(0.89-1.88)$ & $1.27(0.88-1.85)$ \\
\hline No dose & 9 & 9.8 & $0.91(0.48-1.76)$ & $0.90(0.47-1.73)$ \\
\hline \multicolumn{5}{|c|}{$\begin{array}{l}\text { By cumulative DDD exposure } \\
\text { (in exenatide equivalents) }\end{array}$} \\
\hline $0-2.7 \mathrm{mg}$ & 41 & 11.3 & $1.03(0.76-1.41)$ & $1.02(0.75-1.40)$ \\
\hline $2.8-5.4 \mathrm{mg}$ & 24 & 9.4 & $0.90(0.60-1.35)$ & $0.89(0.60-1.34)$ \\
\hline $5.5-8.2 \mathrm{mg}$ & 17 & 9.9 & $0.95(0.59-1.53)$ & $0.94(0.58-1.52)$ \\
\hline
\end{tabular}

$\mathrm{Cl}$ : confidence interval; DDD: defined daily dose; DPP4-I: dipeptidyl peptidase 4 inhibitor, GLP1-RA: glucagonlike peptide 1 receptor agonist; HR: hazard ratio; IR: incidence rate, NIAD: non-insulin anti-diabetic drug. ${ }^{a}$ Also corrected for DPP4-I use. ${ }^{b}$ NIAD past use, GLP1-RA recent and GLP1-RA past use not shown. NeverGLP1-RA use does not include use of DPP4-I. ' Adjusted for sex, age, body mass index, smoking status, glycosylated hemoglobin type A1c, history of secondary osteoporosis, retinopathy and neuropathy, use of glucocorticoids, cholesterol lowering drugs, hypnotic/anxiolytic drugs and antidepressants. 


\section{Discussion}

The results of the present population-based study show that (osteoporotic) bone fracture risk was not decreased by GLP1-RA use. In addition, stratification according to cumulative dose did not show a decreased risk of bone fracture with increasing cumulative GLP1-RA dose. The results of the present study thereby do not support the hypothesis that GLP1-RA use may reduce bone fracture risk in individuals with T2DM. The results of our study add to the field population-based data and are indirectly supported by a clinical trial on the effect of exenatide on markers of bone remodelling and calcium homeostasis, which failed to show a positive effect ${ }^{23}$. Our study is thereby in line with a recent meta-analysis ${ }^{12}$ done on randomised clinical trial data. Another more recent meta-analysis also showed no association between use of GLP1-RAS and fracture risk ${ }^{24}$. However, after stratification to GLP1-RA type they found a decreased risk of fracture with use of liraglutide and an increased risk of fracture with use of exenatide. The results of our study did not show a decreased or increased risk after stratification by GLP1-RA type. It has to be taken into account, however, that the included studies of these meta-analyses were not designed to investigate fracture risk and that fractures were not routinely registered. The results of our study are also in keeping with the results of a large cohort study on the use of dipeptidyl peptidase 4 inhibitors (DPP4-Is) and fracture risk which also did not show a decreased fracture risk $^{25}$.

The pathways through which GLP1-RAs may act on bone metabolism are not fully elucidated, but it has been suggested that GLP1-RAs may, either directly or indirectly, shift the balance in bone homeostasis towards bone formation ${ }^{26}$, via receptor coupling on osteoblasts ${ }^{27}$ and (or) thyroid C cells ${ }^{28,29}$. Alternatively, it has been suggested that GLP1-RA may increase calcitonin concentration ${ }^{29,30}$ and decreases sclerostin which both may inhibit bone formation ${ }^{31}$. Nevertheless, it remains to be determined whether such mechanisms may also be operative in humans. Interestingly, a recent meta-analysis of clinical trial data on the use of DPP4-Is did show a $40 \%$ reduction in the risk of bone fracture $^{32}$. The latter brings forward the hypothesis that any effects on bone metabolism by DPP4-I might be independent from the direct effect of GLP1 on bone, despite the pharmacodynamics through which they are linked ${ }^{3}$. However, the underlying mechanisms between anti-hyperglycaemic drug use along the GLP1/DPP4 axis and bone fracture risk in T2DM in humans remain complex.

Unexpectedly, our results showed a 1.4-fold increase in bone fracture risk for past GLP1-RA users (GLP1-RA use had discontinued $\geq 180$ days) and for patients aged 60-69 compared to never-GLP1-RA users. As any plausible underlying mechanism seems missing, we consider these results as a play of chance.

Our study had several strengths. Firstly, the results were based upon populationbased data that may have prevented, at least partially, selection bias as compared to randomised clinical trials in which only patients meeting specific inclusion criteria are 
able to participate. Secondly, bone fractures are often not primary end-points in clinical trials, thus their registration may be inadequate. The current study, however, was able to partially circumvent this potential bias, as over $90 \%$ of all fractures have been clinically validated in the CPRD ${ }^{14}$. Finally, all participants were extensively clinically characterized which allowed us to take a series of potential confounders, including prior medical history, into account. In addition we were able to adjust for neuropathy, retinopathy and $\mathrm{HbA1C}$ with which we tried to capture disease severity. In particular, $\mathrm{HbA1c}$ could act as a potential confounder of the association between GLP1-RA use and bone fracture risk in individuals with T2DM. However, it is acknowledged that some residual confounding may still be present.

When interpreting the results, a couple of limitations are worth mentioning. First, an important consideration, in light of the discussion on GLP1-RA use and bone fracture risk, in terms of time effect, is the average duration of GLP1-RA use. In our analysis the median duration of actual GLP1-RA use was 1.2 years (from first GLP1-RA prescription until last GLP1-RA prescription), and this might be relatively short. For bisphosphonate use it has been shown that bone fracture risk starts to decrease after 1 to 1.5 years of use $^{33,34}$. Even for the highest cumulative dose group (i.e., $\geq 8.3 \mathrm{mg}$ ), which could be equivalent to 1 DDD GLP1-RA per day during at least 1.5 years, we did not show a decrease in bone fracture risk. However, the time-window for GLP1-RA to exert an effect on bone fracture risk is not yet determined. Second, the risk of fracture is known to increase with age ${ }^{35}$, yet we identified that patients who used GLP1-RA were slightly younger at baseline, as compared to never-GLP1-RA users. Thus, this might have masked the protective effect of GLP1-RA on risk of bone fracture. Yet, our age-stratified analyses did not show a protective effect of GLP1-RA use on bone fracture risk. Third, GLP1-RAs are selectively prescribed to patients with a high BMI, which might have influenced the results. High BMI has been associated with a lower risk of fracture ${ }^{36}$, and this might even strengthen the protective effect of GLP1-RAs. However, we could not show a protective effect of GLP1-RAs on fracture risk. Fourth, after stratification of the analyses to specific fracture types the number of fractures within the current GLP1-RA group became low and therefore the results should be interpreted with caution.

In summary, we showed in a population-based cohort study that GLP1-RA use is not associated with a decreased risk of bone fracture as to users of other antihyperglycaemic drugs. Future research is needed to elucidate the working mechanisms of the complex GLP1/DPP4 axis and to investigate the time-window of GLP1-RA to exert an effect on bone fracture risk. 


\section{References}

1. Vestergaard P. Discrepancies in bone mineral density and fracture risk in patients with type 1 and type 2 diabetes - a meta-analysis. Osteoporos Int. 2007;18(4):427-44.

2. Carnevale V, Romagnoli E, D'Erasmo E. Skeletal involvement in patients with diabetes mellitus. Diabetes Metab Res Rev. 2004;20(3):196-204.

3. Montagnani A, Gonnelli S. Diabetes Obes Metab. Antidiabetic therapy effects on bone metabolism and fracture risk. 2013;15(9):78491.

4. Bazelier MT, Gallagher AM, van Staa TP, Cooper C, Leufkens HG, Vestergaard P, et al. Use of Thiazolidinediones and risk of osteoporotic fracture: Disease or drugs? Pharmacoepidemiol Drug Saf. 2012;21(5):50714.

5. Bazelier MT, Vestergaard P, Gallagher AM, van Staa TP, Cooper C, Leufkens HG, et al. Risk of fracture with thiazolidinediones: disease or drugs? Calcif Tissue Int. 2012;26(9):2271-9.

6. Betteridge DJ. Thiazolidinediones and fracture risk in patients with Type 2 diabetes. Diabet Med. 2011;28(7):759-71.

7. Schwartz AV, Vittinghoff E, Bauer DC, Hillier TA, Strotmeyer ES, Ensrud KE, et al. Association of BMD and FRAX score with risk of fracture in older adults with type 2 diabetes. JAMA. 2011;305(21):2184-92.

8. Vestergaard P, Rejnmark L, Mosekilde L. Relative fracture risk in patients with diabetes mellitus, and the impact of insulin and oral antidiabetic medication on relative fracture risk. Diabetologia. 2005;48(7):1292-9.

9. Nuche-Berenguer $B$, Moreno $P$, Esbrit $P$, Dapía S, Caeiro JR, Cancelas J, et al. Effect of GLP-1 treatment on bone turnover in normal, type 2 diabetic, and insulin-resistant states. Calcif Tissue Int. 2009;84:453-61.

10. Nuche-Berenguer B, Moreno P, Portal-Nuñez $S$, Dapía S, Esbrit P, Villanueva-Peñacarrillo ML. Exendin-4 exerts osteogenic actions in insulinresistant and type 2 diabetic states. Regul Pept. 2010;159(1-3):61-6.

11. Moreno $P$, Nuche-Berenguer $B$, GutiérrezRojas I, Acitores A, Sancho V, Valverde I, et al. Normalizing action of exendin-4 and GLP-1 in the glucose metabolism of extrapancreatic tissues in insulin-resistant and type 2 diabetic states. J Mol Endocrinol. 2012;48:37-47.
12. Mabilleau G, Mieczkowska A, Chappard D. Use of glucagon-like peptide-1 receptor agonists and bone fractures: a meta-analysis of randomized clinical trials. J Diabetes. 2014;6(3):260-6.

13. Herrett E, Thomas SL, Schoonen WM, Smeeth L, Hall AJ. Validation and validity of diagnoses in the General Practice Research Database: a systematic review. $\mathrm{Br} J$ Clin Pharmacol. 2010;69(1):4-14.

14. Van Staa TP, Abenhaim L, Cooper C, Zhang B, Leufkens HG. The use of a large pharmacoepidemiological database to study exposure to oral corticosteroids and risk of fractures: validation of study population and results. Pharmacoepidemiol Drug Saf. 2000;9(5):359-66.

15. Eppenga $W L$, Lalmohamed $A$, Geerts $A F$, Derijks HJ, Wensing M, Egberts A, et al. Risk of lactic acidosis or elevated lactate concentrations in metformin users with renal impairment: a population-based cohort study. Diabetes Care. 2014;37(8):2218-24.

16. Anonymous. ATC classification index with DDDs 2002. Nydalen, WHO Collaborating Centre for Drug Statistics Methodology, Norwegian Institute of Public Health, 2002.

17. Health and Social Care Information Centre: UK terminology centre-readcodes. http://systems. hscic.gov.uk/data/uktc/readcodes/index_html.

18. FRAX. WHO Fracture Risk Assessment Tool. 2001. shef.ac.uk. www.shef.ac.uk/FRAX/ index. aspx.

19. Klop C, de Vries F, Vinks T, Kooij MJ, van Staa TP, Bijlsma JW, et al. Increase in prophylaxis of glucocorticoid-induced osteoporosis by pharmacist feedback: a randomised controlled trial. Osteoporos Int. 2014;25(1):385-92.

20. Prieto-Alhambra D, Petri $H$, Goldenberg JS, Khong TP, Klungel $\mathrm{OH}$, Robinson $\mathrm{NJ}$, et al. Excess risk of hip fractures attributable to the use of antidepressants in five European countries and the USA. Osteoporos Int. 2014;25(3):847-55.

21. Khong TP, de Vries F, Goldenberg JS, Klungel $\mathrm{OH}$, Robinson NJ, Ibáñez L, et al. Potential impact of benzodiazepine use on the rate of hip fractures in five large European countries and the United States. Calcif Tissue Int. 2012;91(1):24-31. 
22. Pouwels S, Bazelier MT, de Boer A, Weber WE, Neef C, Cooper C, et al. Risk of fracture in patients with Parkinson's disease. Osteoporos Int. 2013;24(8):2283-90.

23. Bunck MC, Eliasson B, Corner A, Heine RJ, Shaginian RM, Taskinen MR, et al. Exenatide treatment did not affect bone mineral density despite body weight reduction in patients with type 2 diabetes. Diabetes Obes Metab. 2011;13:374-7.

24. Su B, Sheng $H$, Zhang $M, B u L$, Yang $P$, Li L, et al. Risk of bone fractures associated with glucagon-like peptide-1 receptor agonists' treatment: a meta-analysis of randomized controlled trials. Endocrine. 2015;48(1):10715.

25. Driessen $\mathrm{JH}$, van Onzenoort HA, Henry RM, Lalmohamed A, van den Bergh JP, Neef C, et al. Use of dipeptidyl peptidase-4 inhibitors for type 2 diabetes mellitus and risk of fracture. Bone. 2014;68:124-30.

26. Ceccarelli E, Guarino EG, Merlotti D, Patti A, Gennari L, Nuti R, et al. Beyond glycemic control in diabetes mellitus: effects of incretinbased therapies on bone metabolism. Front Endocrinol (Lausanne). 2013;18;4:73.

27. Nuche-Berenguer $B$, Portal-Núñez $S$, Moreno P, González N, Acitores A, López-Herradón A, et al. Presence of a functional receptor for GLP-1 in osteoblastic cells, independent of the cAMP-linked GLP-1 receptor. J Cell Physiol. 2010;225(2):585-92.

28. Crespel A, De Boisvilliers F, Gros L, Kervran A. Effects of glucagon and glucagon-like peptide1-(7-36) amide on $\mathrm{C}$ cells from rat thyroid and medullary thyroid carcinoma CA-77 cell line. Endocrinology. 1996;137(9):3674-80.

29. Lamari Y, Boissard C, Moukhtar MS, Jullienne A, Rosselin G, Garel JM. Expression of glucagon-like peptide 1 receptor in a murine $C$ cell line: regulation of calcitonin gene by glucagon-like peptide 1. FEBS Lett. 1996;393(23):248-52.

30. Yamada C, Yamada Y, Tsukiyama K, Yamada K, Udagawa N, Takahashi $\mathrm{N}$, et al. The murine glucagon-like peptide-1 receptor is essential for control of bone resorption.Endocrinology. 2008;149(2):547-9.

31. Kim JY, Lee SK, Jo KJ, Song DY, Lim DM, Park $K Y$, et al. Exendin-4 increases bone mineral density in type 2 diabetic OLETF rats potentially through the down-regulation of SOST/sclerostin in osteocytes. Life Sci. 2013;21;92(10):533-40.

32. Monami M, Dicembrini I, Antenore A, Mannucci E. Dipeptidyl peptidase-4 inhibitors and bone fractures: a meta-analysis of randomized clinical trials. Diabetes Care. 2011;34(11):2474-6.

33. Cummings SR, Black DM, Thompson DE, Applegate WB, Barrett-Connor E, Musliner TA, et al. Effect of alendronate on risk of fracture in women with low bone density but without vertebral fractures: results from the Fracture Intervention Trial. J Am Med Assoc. 1998;280:2077-82.

34. McClung MR, Geusens P, Miller PD, Zippel H, Bensen WG, Roux C, et al. Effect of risedronate on the risk of hip fracture in elderly women. Hip Intervention Program Study Group. N Engl J Med. 2001;344:333-40.

35. van Staa TP, Dennison EM, Leufkens HG, Cooper C. Epidemiology of fractures in England and Wales. Bone. 2001;29(6):517-22.

36. Cummings SR, Nevitt MC, Browner WS, Stone $\mathrm{K}$, Fox KM, Ensrud KE, et al. Risk factors for hip fracture in white women. Study of Osteoporotic Fractures Research Group. N Engl J Med. 1995;332(12):767-73. 


\section{Chapter

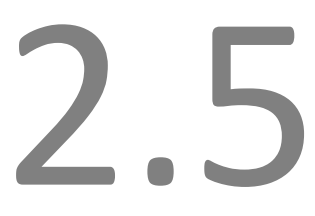

Use of glucagon-like peptide 1 receptor agonists and risk of fracture as compared to use of other anti-hyperglycaemic drugs

JHM Driessen, HAW van Onzenoort, J Starup-Linde, RMA Henry, AM Burden, C Neef, JPW van den Bergh, $P$ Vestergaard, $F$ de Vries

Calcif Tissue Int. 2015;97(5):506-515 


\section{Abstract}

\section{Introduction}

Glucagon-like peptide 1 receptor agonists (GLP1-RAs) are a new class of drugs that might have a potential beneficial effect on bone metabolism. Data on the effect of GLP1-RAs and fracture risk is lacking. The aim of the present study was to investigate the association between the use of GLP1-RAs and the risk of fracture.

\section{Methods}

A case-control study was performed using Danish National Health Service data. Cases were those who sustained a fracture and controls were those without a fracture during the study period (2007-2011), all aged 18 years and older. Conditional logistic regression estimated the odds ratios of fracture with current use of GLP1-RAs. Analyses were adjusted for comorbidities and recent drug use.

\section{Results}

Among cases $(n=229,114)$, there were 6,993 current non-insulin anti-diabetic drug (NIAD) users (excluding incretin users) and 255 GLP1-RA users. Similarly, among controls ( $n=229,114), 7,209$ were NIAD users (excluding incretin users) and 220 were GLP1-RA users. Current GLP1-RA use was not associated with a decreased risk of fracture (adjusted (adj.) odds ratio (OR): 1.16 (95\% Cl: 0.83-1.63)). Osteoporotic fracture risk was also not associated with current GLP1-RA use (adj. OR: 0.78 (95\% Cl: 0.44-1.39)).

\section{Conclusion}

In our nation-wide case-control study we identified that the use of GLP1-RA was not associated with fracture risk as compared to use of other anti-hyperglycaemic drugs. Additionally, current GLP1-RA use, stratified by cumulative or average daily dose, is not associated with fracture risk. Further research should focus on long-term use of GLP1-RAs and fracture risk. 


\section{Introduction}

The risk of fracture is significantly increased in patients with type 2 diabetes mellitus $(\mathrm{T} 2 \mathrm{DM})^{1}$. It has been hypothesized that a reduced bone strength or bone quality plays a role in patients with $\mathrm{T}_{2} \mathrm{DM}^{2}$. Alternatively, it has been suggested that antihyperglycaemic drugs might affect fracture risk. For instance, observational studies showed that use of thiazolidinediones is associated with a 1.3-1.9 fold ${ }^{3,4}$ increased risk of fracture, in particular in women, as compared to use of other anti-hyperglycaemic drugs. Insulin use has been associated with an elevated fracture risk $^{5}$ whereas metformin might be associated with a reduced fracture risk ${ }^{6}$.

Glucagon-like peptide 1 receptor agonists (GLP1-RAs), such as exenatide and liraglutide, are a new class of drugs in the treatment of T2DM. GLP1-RAs may have a potential beneficial effect on bone metabolism, established by binding of GLP1-RAs to a glucagon-like peptide 1 (GLP1) receptor on osteocytes and osteoblasts, as shown in in vitro studies ${ }^{7-9}$. Consequently, this may result in an increased bone formation and a decreased bone resorption ${ }^{10,11}$. As a result of this process, we hypothesize that this then may lead to a reduced risk of fracture.

However, current there is limited data, particularly epidemiologic, in the literature. A recent meta-analysis of randomised clinical trials $(n=4,255$, mean duration of included studies 67.4 weeks) did not show a reduced risk of fracture with use of GLP1-RAs ${ }^{12}$ as compared to use of other anti-hyperglycaemic drugs. To our knowledge there is only one observational study examining fracture risk with GLP1-RA use which showed no association $^{13}$. In particular, studies with longer durations of use or stratified to daily dose are required to best understand the association between GLP1-RA use and fracture risk. We therefore sought to examine the association between GLP1-RA use compared to other anti-hyperglycaemic drug use and fracture risk in a nation-wide case-control study.

\section{Methods}

\section{Data source}

We utilized data from the Danish National Health Service, which covers all contacts to the health sector, and includes approximately 5.2 million individuals in 1995 and 5.5 million in $2011^{14}$. The unique 10-digit civil registry number was used to link population-based registries and generate a complete hospital discharge and prescription history for each individual ${ }^{15}$. Data on vital status (e.g., change of address and date of death) for the entire Danish population have been collected since 1968 in the Civil Registration System. All inpatient contacts have been registered through the Danish National Hospital Discharge Register ${ }^{16}$ since 1977, and outpatient visits to hospitals, outpatient clinics, and emergency rooms have been included since 1995. In 
Denmark, prescription records are sent directly to a Register of Medicinal Product Statistics (i.e. a prescription database) at the Danish Medicines Agency. The prescription database includes information on patient's civil registry number, the type and amount of drug prescribed according to the Anatomical Therapeutic Chemical (ATC) classification system and the date when the prescription was filled. Pharmacy data have been collected since January 1,1996 . This study was subject to control by the National Board of Health and the Danish Data Protection Agency.

\section{Study design}

The study was designed as a case-control study. Cases were all subjects, both genders and aged 18 years and older, who sustained a fracture, low or high trauma, (International Classification of Diseases and Related Health Problems (ICD)-10 codes: S02, S12, S22, S32, S42, S52, S62, S72, S82, S92, T02, T08, T10, and T12) between 9 May 2007 (the first ever prescription of a GLP1-RA in Denmark) and 31 December 2011. Controls were all subjects, both genders and aged 18 years and older, who did not sustain a fracture during the study period. We randomly selected one control for each case, matched by gender and year of birth. The controls were selected using incidencedensity sampling ${ }^{17}$. The date of the first fracture was used as index date for cases, and controls were assigned the index date of their matched case.

Fractures were classified into the following categories using ICD-10 codes: hip (S72.0-S72.2), radius/ulna (S52) and vertebrae (S12, S22.0-S22.1, S32.0-S32.2, S32.7, S32.8, T08). A major osteoporotic fracture was defined as a fracture of the hip, radius/ulna, vertebrae or humerus (S42.2-S42.4) according to the WHO definition ${ }^{18}$.

\section{Exposure of interest}

We identified all drugs bought during the observation period using the Register of Medicinal Product Statistics. The dose of the drug was expressed as defined daily dose $(D D D)^{19}$. ATC code A10B was used to determine exposure to non-insulin anti-diabetic drugs (NIAD), and patients were classified as current (1-91 days) or past (over 91 days) NIAD users, based on the time of the most recent prescription before the index date. Current NIAD users were divided into two mutually exclusive categories: never incretin users and incretin users.

To control for the potential that diabetes might act as a confounder ${ }^{2}$, we used never incretin use (i.e. current NIAD use excluding incretin use) as the reference category in our analysis. ATC codes A10BX04 and A10BX07 were used to determine GLP1-RA exposure before the index date in the prescription database. Based on the time since the most recent prescription, cases and controls were classified as current (1-91 days), recent (92-182) or past (over 182 days) GLP1-RA users. The DDDs estimated the cumulative dose of GLP1-RAs for current GLP1-RA users, expressed as exenatide equivalents. The average daily dose was estimated by dividing the cumulative exposure 
by the treatment time (time between the first GLP1-RA prescription and the index date).

\section{Potential confounders}

A history of the following potential confounders ever before the index date were taken into account: chronic obstructive pulmonary disease, previous fracture, rheumatoid arthritis, hypothyroidism, hyperthyroidism, cancer, retinopathy, alcoholism, secondary osteoporosis (diabetes type 1, hypogonadism or premature menopause), and congestive heart failure. The potential confounders were identified from the National Hospital register using ICD-10 and ICD-8 codes. Additional potential confounders included a prescription in the six months before the index date of the following drugs: dipeptidyl peptidase 4 inhibitors (DPP4-Is), oral glucocorticoids ${ }^{20}$, lipid-modifying drugs, antidepressants $^{21}$, anxiolytics, hypnotics ${ }^{22}$, antipsychotics, anti-Parkinson drugs ${ }^{23}$, antihypertensives (beta-blockers, thiazide diuretics, renin angiotensin aldosterone system inhibitors, calcium channel blockers, and loop diuretics), and antiarrhythmics. The prescription database was used to explore the presence of a prescription of the above mentioned drugs.

\section{Statistical analysis}

Conditional logistic regression estimated the association between the use of GLP1-RAs versus use of other anti-hyperglycaemic drugs and risk of fracture, using SAS 9.3 software. Analyses were stratified by age, gender, type of fracture and for current GLP1-RA use also by average daily dose and cumulative exposure. The stratified analyses were determined a-priori, therefore no interaction analyses were performed. As a sensitivity analysis we adjusted for current metformin use, as it has been associated with a decreased risk of fracture ${ }^{6}$. As a second sensitivity analyses we adjusted the final model for insulin use, as insulin use has been associated with an increased fracture risk ${ }^{5}$. Final regression models were determined by stepwise backward elimination using a significance level of 0.05 . All results are presented as odds ratios (ORs) with corresponding $95 \%$ confidence intervals (Cls).

\section{Results}

The study population consisted of 229,145 cases and the same number of controls. The mean age was 55 years old, and $56 \%$ were women. Baseline characteristics are shown in Table 2.5.1. Among cases we identified 6,993 (3.1\%) current NIAD users (excluding incretin users) and 255 (0.1\%) GLP1-RA users (current, recent or past). Similarly, we identified 7,209 (3.1\%) NIAD users (excluding incretin users), and 220 (0.1\%) GLP1-RA 
users among controls. The mean duration of actual GLP1-RA use (from first GLP1-RA prescription till index date) was 36 weeks.

Table 2.5.1 Baseline characteristics ${ }^{\mathrm{a}}$.

\begin{tabular}{|c|c|c|}
\hline Characteristic & Cases $(\mathrm{N}=229,145)$ & Controls $(\mathrm{N}=229,145)$ \\
\hline Women & $127,449(55.6)$ & $127,449(55.6)$ \\
\hline Mean age at index date (years, SD) & $55(20.6)$ & $55(20.6)$ \\
\hline $18-49$ years & $90,598(39.5)$ & 90,607 (39.5) \\
\hline $50-59$ years & $37,247(16.3)$ & $37,191(16.2)$ \\
\hline $60-69$ years & 38,751 (16.9) & 38,805 (16.9) \\
\hline $70-79$ years & $28,950(12.6)$ & $28,931(12.6)$ \\
\hline $80+$ years & $33,599(14.7)$ & $33,611(14.7)$ \\
\hline \multicolumn{3}{|l|}{ History of comorbidities } \\
\hline Type 1 diabetes mellitus & $2,113(0.9)$ & $1,419(0.6)$ \\
\hline Alcoholism & 11,147 (4.9) & $4,824(2.1)$ \\
\hline Fracture & $46,446(20.2)$ & $15,418(6.7)$ \\
\hline Hyperthyroidism & $3,715(1.6)$ & $3,688(1.6)$ \\
\hline Hypothyroidism & $2,887(1.3)$ & $2,496(1.1)$ \\
\hline COPD & $10,812(4.7)$ & $7,418(3.2)$ \\
\hline Congestive heart failure & $7,141(3.1)$ & $5,424(2.4)$ \\
\hline Cancer & $21,893(9.6)$ & $18,486(8.1)$ \\
\hline Rheumatoid arthritis & $3,912(1.7)$ & $2,795(1.2)$ \\
\hline Retinopathy & $3,105(1.4)$ & $2,314(1.0)$ \\
\hline Neuropathy & $7,915(3.5)$ & $6,093(2.7)$ \\
\hline Secondary osteoporosis & $5,284(2.3)$ & $3,352(1.5)$ \\
\hline \multicolumn{3}{|c|}{ Drug use within six months before index date } \\
\hline Anti-hyperglycaemic drugs & $8,541(3.7)$ & $8,676(3.8)$ \\
\hline Biguanides & $6,223(2.7)$ & $6,678(2.9)$ \\
\hline Sulphonylurea derivatives & $3,900(1.7)$ & $3,809(1.7)$ \\
\hline Thiazolidinediones & $262(0.1)$ & $183(0.1)$ \\
\hline Glinides & $87(0.0)$ & $83(0.0)$ \\
\hline GLP1-RAs & $255(0.1)$ & $220(0.1)$ \\
\hline DPP4-Is & $643(0.3)$ & $707(0.3)$ \\
\hline Insulins & $4,900(2.1)$ & $3,261(1.4)$ \\
\hline Short acting & $2,046(0.9)$ & $1,139(0.5)$ \\
\hline Intermediate acting & $2,049(0.9)$ & $1,411(0.6)$ \\
\hline Long acting & $1,444(0.6)$ & $869(0.4)$ \\
\hline Combinations & $1,679(0.7)$ & $1,200(0.5)$ \\
\hline Statins & $31,874(13.9)$ & $32,064(14.0)$ \\
\hline Antiarrhythmics & $818(0.4)$ & $522(0.2)$ \\
\hline Beta blockers & $23,281(10.2)$ & $23,592(10.3)$ \\
\hline Thiazide diuretics & $20,425(8.9)$ & $21,547(9.4)$ \\
\hline RAAS inhibitors & $37,555(16.4)$ & $39,379(17.2)$ \\
\hline Calcium channel blockers & $22,942(10.0)$ & $22,816(10.0)$ \\
\hline Loop diuretics & $16,905(7.4)$ & $12,766(5.6)$ \\
\hline Antidepressants & $33,644(14.7)$ & $20,338(8.9)$ \\
\hline Anti-Parkinson drugs & $3,174(1.4)$ & $1,814(0.8)$ \\
\hline Antipsychotics & $8,032(3.5)$ & $4,867(2.1)$ \\
\hline Anxiolytics & $14,668(6.4)$ & $10,431(4.6)$ \\
\hline Hypnotics & $19,137(8.4)$ & $14,332(6.3)$ \\
\hline Glucocorticoids & $9,390(4.1)$ & $6,858(3.0)$ \\
\hline Bisphosphonates & $7,371(3.2)$ & $4,913(2.1)$ \\
\hline
\end{tabular}


Table 2.5.1 (continued)

\begin{tabular}{lrr}
\hline Characteristic & Cases $(\mathrm{N}=229,145)$ & Controls $(\mathrm{N}=229,145)$ \\
\hline Raloxifene & $214(0.1)$ & $148(0.1)$ \\
Vitamin D & $211(0.1)$ & $169(0.1)$ \\
Calcium & $1,885(0.8)$ & $1,375(0.6)$ \\
Strontium ranelate & $194(0.1)$ & $101(0.0)$ \\
Parathyroid hormone & $130(0.1)$ & $70(0.0)$ \\
Calcitonin & $2(0.0)$ & $1(0.0)$ \\
Hormone replacement therapy & $11,912(5.2)$ & $13,955(6.1)$ \\
Beta2-agonists & $10,436(4.6)$ & $8,130(3.6)$ \\
Inhaled anticholinergics & $4,569(2.0)$ & $3,277(1.4)$ \\
Inhaled corticosteroids & $5,265(2.3)$ & $4,657(2.0)$ \\
\hline
\end{tabular}

COPD: chronic obstructive pulmonary disease; DPP4-I: dipeptidyl peptidase 4 inhibitor; GLP1-RA: glucagonlike peptide 1 receptor-agonist; RAAS: renin angiotensin aldosterone system; SD: Standard deviation. ${ }^{\mathrm{a}}$ Data are number (\%) of patients, unless stated otherwise.

Current GLP1-RA use was not associated with a decrease in fracture risk: adjusted (adj.) OR: 1.16 (95\% Cl: 0.83-1.63). Similarly, no significant decrease was observed for recent use (adj. OR 1.03, 95\% $\mathrm{Cl}$ : 0.69-1.53), or for past use (adj. OR 1.09, 95\% Cl: $0.82-1.46$ ). Having no prior use of NIAD (never use) was associated with a significant increase in risk of fracture (adj. OR $1.10,95 \% \mathrm{Cl}$ : 1.06-1.14), as well as past NIAD use (adj. OR 1.12, 95\% Cl: 1.05-1.20). The risk of fracture was not reduced after stratification by sex or age, Table 2.5.2.

Table 2.5.3 shows that current GLP1-RA use was not associated with osteoporotic fracture risk (adj. OR 0.78, 95\% Cl: 0.44-1.39). We identified similar trends for recent GLP1-RA use (adj. OR 0.97, 95\% Cl: 0.52-1.79) and for past use (adj. OR 0.94, 95\% Cl: $0.60-1.48$ ). Stratification by sex and age did not substantially change the results (data not shown). There was no significant association with fracture risk of the radius/ulna for current GLP1-RA use (adj. OR 0.93, 95\% Cl: 0.48-1.80), recent GLP1-RA use (adj. OR 1.32, 95\% Cl: 0.55-3.17), or for past GLP1-RA use (adj. OR $0.93,95 \% \mathrm{Cl}: 0.48-1.80$ ). Stratification by gender and age did not show a decreased fracture risk (data not shown). Hip and vertebral fracture risk was not associated with GLP1-RA use (current, recent or past), Table 2.5.3.

The risk of any fracture was comparable, and not significantly reduced, among the cumulative and average daily dose groups, Table 2.5.4. The adj. OR for the highest cumulative dose ( $\geq 5.5 \mathrm{mg}$ exenatide equivalent) was $0.98(95 \% \mathrm{Cl}: 0.50-1.94)$ and the adj. OR for the highest average daily dose ( $\geq 22.5 \mathrm{mcg}$ exenatide equivalent per day) was 1.66 (95\% Cl: 0.86-3.19). When only osteoporotic fractures were considered, there was again, no association with a decreased risk of fracture. Adj. OR for the highest cumulative dose ( $\geq 5.5 \mathrm{mg}$ exenatide equivalent) was 0.93 (95\% Cl: $0.30-2.92)$ and the adj. OR for the highest average daily dose ( $\geq 22 \mathrm{mcg}$ exenatide equivalent per day) was 1.40 (95\% Cl: 0.47-4.13). 


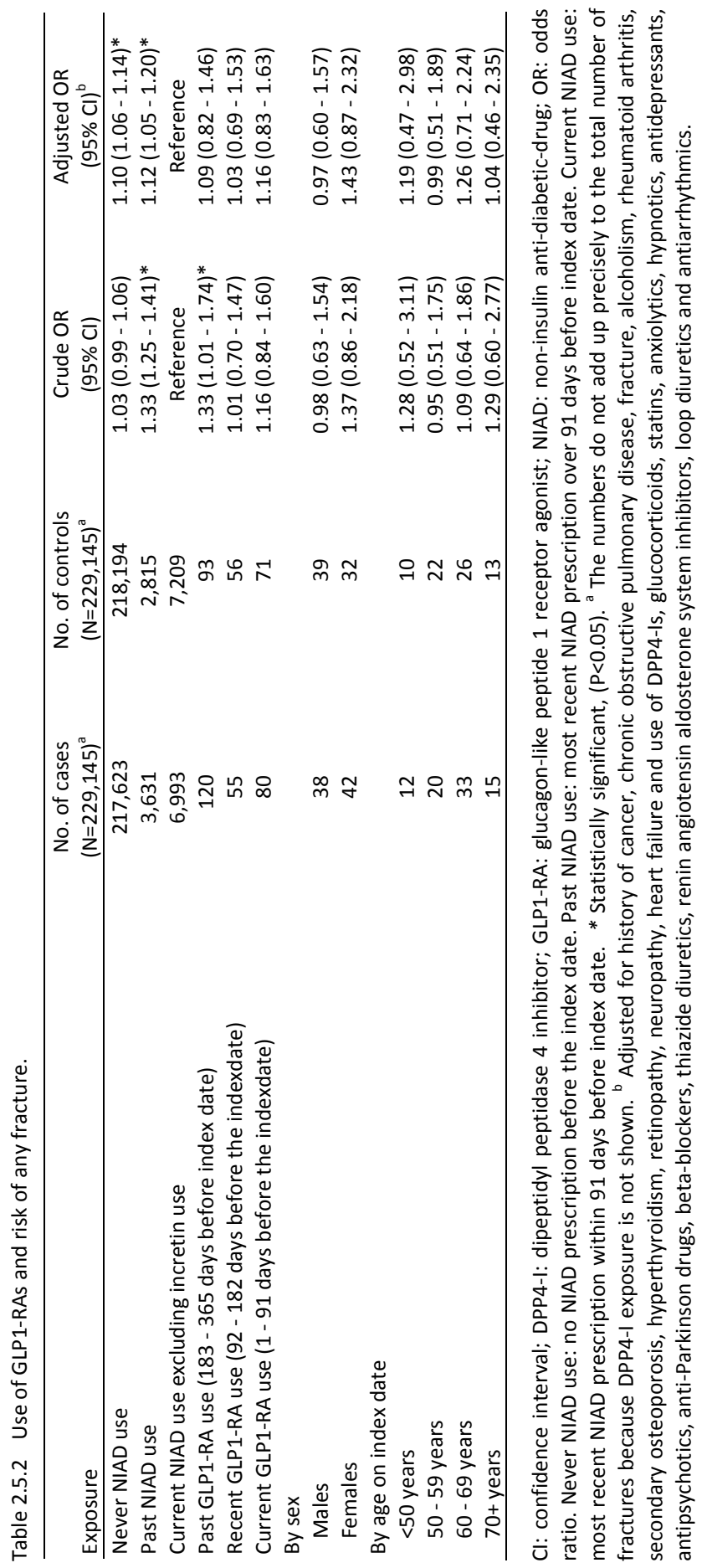




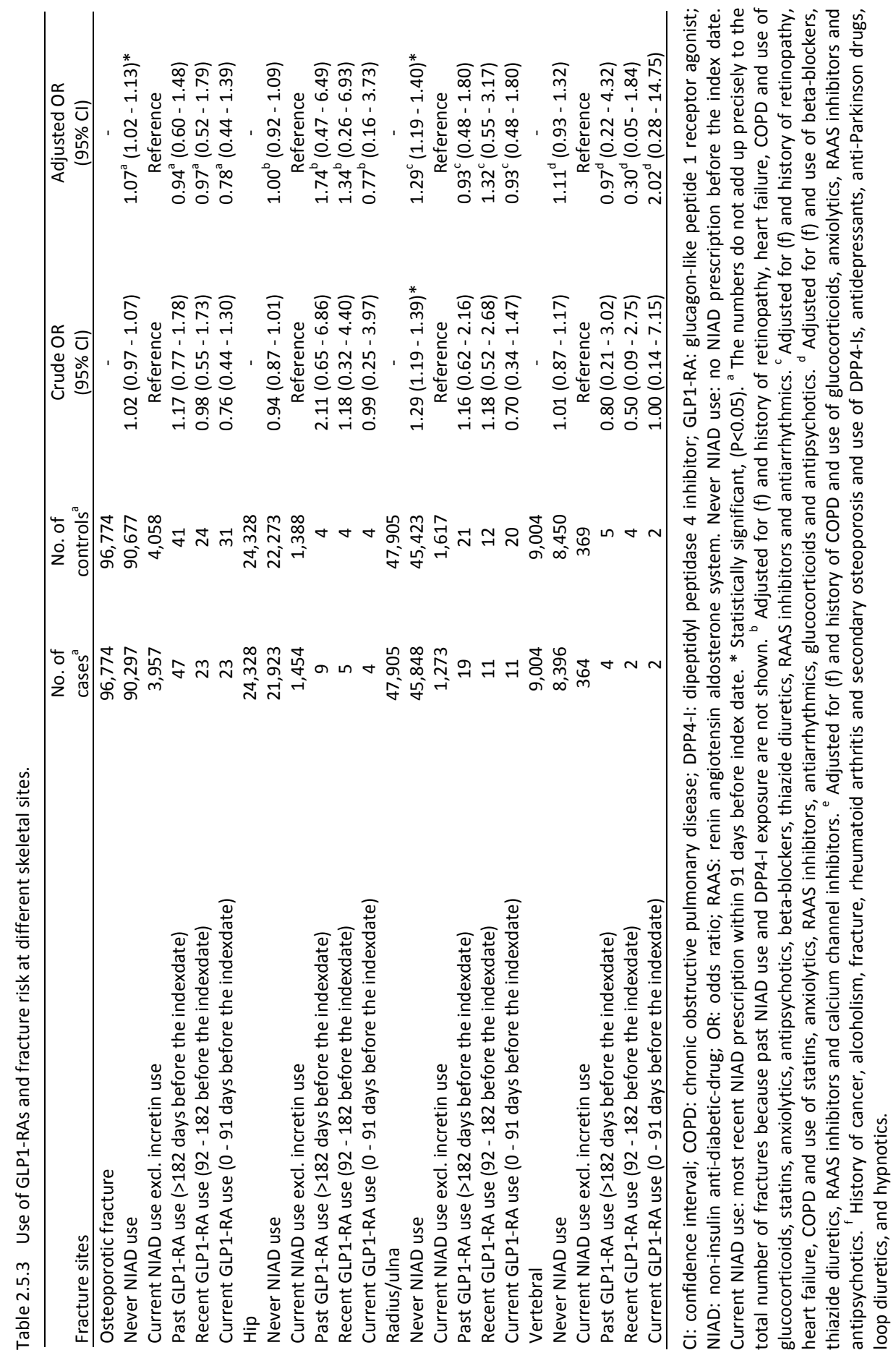




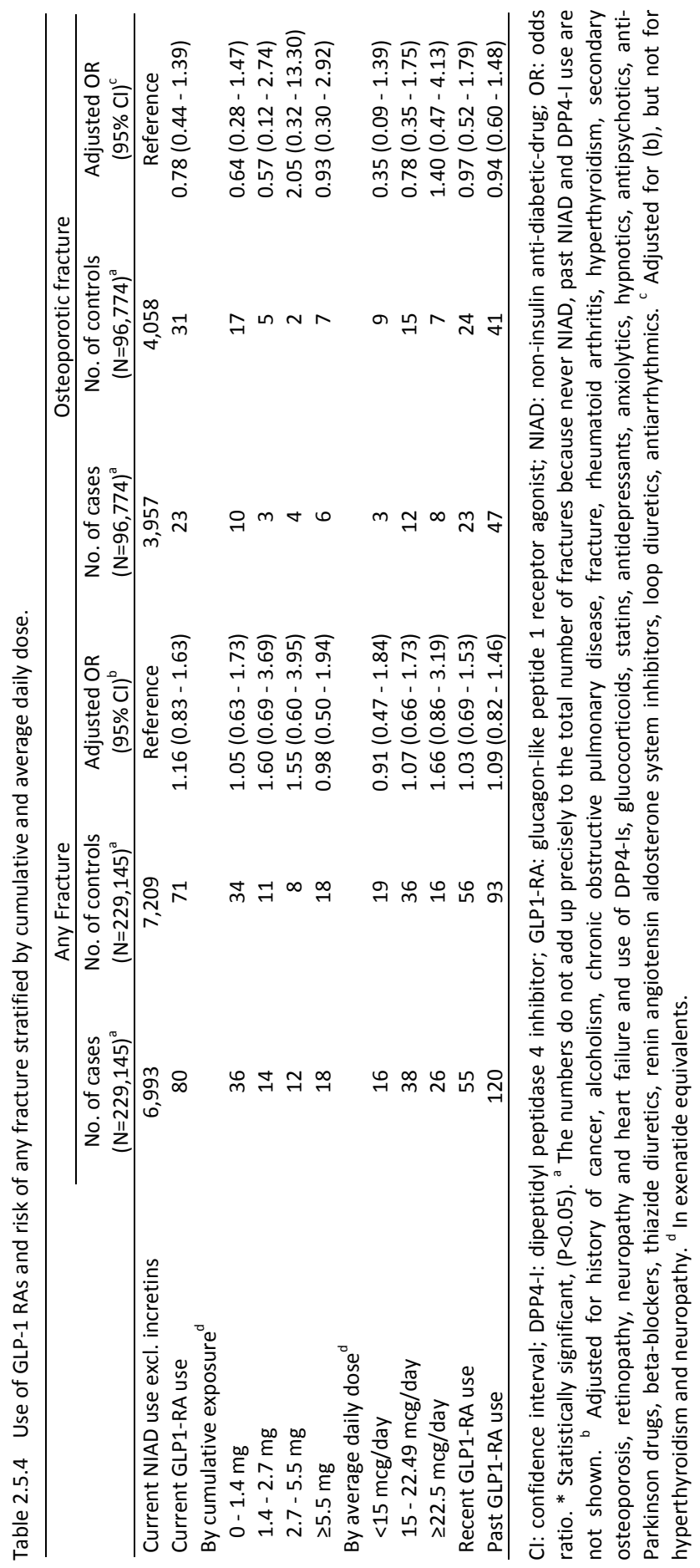


Adjusting the main analysis for current metformin use did not substantially change our results. The adj. OR for current GLP1-RA use was 1.17 (95\% Cl: 0.83-1.64), for recent GLP1-RA 1.03 (95\% Cl: 0.70-1.54) and for past GLP1-RA use 1.09 (95\% Cl: $0.82-1.46)$. As a second sensitivity analysis we additionally adjusted the main analysis for insulin use, this did not alter the results. The adj. OR for current GLP1-RA use was 1.13 (95\% Cl: 0.80-1.58), for recent use 1.00 (95\% Cl: 0.67-1.49) and for past use 1.05 (95\% Cl: 0.79-1.41).

\section{Discussion}

The present study showed that current GLP1-RA use was not associated with a decreased risk of any fracture, as compared to use of other anti-hyperglycaemic drugs, and current GLP1-RA use was not associated with a reduced risk of other fracture types. Moreover, stratification of current GLP1-RA by cumulative or average daily dose was not associated with a decreased risk of fracture.

The results of the present study are in line with the results of a meta-analysis of clinical trials on the effect of GLP1-RAs on fracture risk, which showed that fracture risk was not significantly reduced with use of GLP1-RAs ${ }^{12,24}$. Our results are also in keeping with a large clinical trial $(n=16,492)$ on the effect of a DPP4-I, saxagliptin, which showed no difference in risk of fracture with use of DPP4-I use and placebo ${ }^{25}$. Additionally, the present results are also supported by the results of a cohort study which was not able to show a decreased risk of fracture with use of GLP1-RAs as compared to use of other anti-hyperglycaemic drugs ${ }^{13}$ and a cohort study that compared use of DPP4-I to use of other anti-hyperglycaemic drugs ${ }^{26}$. The pathway by which DPP4-Is might affect bone metabolism may be the same as that of GLP1-RAs because DPP4-Is inhibit the degradation of $\mathrm{GLP} 1^{2}$. Moreover, our results are indirectly supported by a clinical trial on the effect of a GLP1-RA, exenatide, on markers of bone metabolism ${ }^{27}$, which reported that bone markers were unaffected after 44 weeks of exenatide treatment.

We acknowledge that our findings are in contrast to those of a meta-analysis of randomised clinical trials $(n=22,055)$ that showed a significant $40 \%$ reduction of fracture risk with the use of DPP4-Is ${ }^{28}$ as compared to active treatment or placebo. However, studies that were included in this meta-analysis did not routinely collect fractures as an outcome of interest, the number of fractures was low and different comparator groups had been used ${ }^{27}$. The results from this meta-analysis should likely be interpreted with caution as the low number of events in a meta-analysis of adverse events can give biased estimates ${ }^{28,29}$.

Results of in vitro studies have suggested that use of GLP1-RAs might have a beneficial effect on bone metabolism ${ }^{7-9}$, yet different mechanisms of effect have been hypothesized. In vitro studies have shown that GLP1 receptors are present on bone marrow stromal cells ${ }^{30}$, immature osteoblast ${ }^{31}$ and osteocytes ${ }^{10}$, and binding of GLP1 to 
its receptor on bone cells leads to increased osteoblast activity ${ }^{9}$, and decreased osteoclast activity ${ }^{10}$. This could then lead to increased bone formation and a reduced fracture risk. However, more research is needed to assess whether GLP1-RAs are also able to bind to GLP1 receptors on human bone cells and whether this could ultimately result in a reduced risk of fracture.

An unexpected finding was that never and past NIAD use showed an increased fracture risk as compared to current use of other anti-hyperglycaemic drugs. This may have been the result of residual confounding by high body mass index (BMI), which has been shown to decrease fracture risk ${ }^{32}$. T2DM has been associated with an increased $\mathrm{BMI}$ and therefore it might be that the increased risk of never NIAD use is a result of a higher BMI in the current NIAD use group which was used as a reference group. The past NIAD use group included patients with T2DM who use insulin only. Insulin use has been associated with a two-fold increased risk of fracture as compared to patients with T2DM who use NIADs².

There are several strengths to the current study. First the use of a nationwide population register permitted the examination of a large number of cases and controls. The data used were also collected longitudinally, and for prescriptions this permitted us to calculate a reliable cumulative and average daily dose. Second, the data used to identify fractures has been validated ${ }^{14}$. Third, we were able to adjust our analyses for many potential confounders. When interpreting our results, we are mindful of a couple of limitations. We were not able to adjust for potential confounders such as BMI, glycosylated hemoglobin type A1c (HbA1c), smoking, amount of exercise and serum vitamin D levels. A high BMI has been associated with a reduced risk of fracture ${ }^{32}$ and therefore a decreased risk of fracture with GLP1-RA use could have represented the association between high BMI and fracture risk. Nevertheless, we did not show a reduced fracture risk with GLP1-RA use. Smoking is a risk factor of fracture ${ }^{33}$, but there is no evidence that GLP1-RA users have different smoking behaviors than patients treated with other anti-hyperglycaemic drugs. Exercise has been associated with a decreased risk of fracture ${ }^{34}$, GLP1-RA users might perform less exercise which could result in an overestimation of the effect. Lower levels of serum vitamin $D$ have been associated with more severe T2DM complications and increased fracture risk ${ }^{35,36}$. Not adjusting for serum vitamin $D$ levels might lead to an overestimation of the effect when GLP1-RA users have lower serum vitamin D levels as compared to users of other antihyperglycaemic drugs. Thus, while we were able to identify a large number of confounders due to the completeness of the registry data, it is acknowledged that some residual confounding might still be present. In addition, we tried to capture severity of diabetes by correcting our analyses for known complications of diabetes, such as neuropathy and retinopathy. Moreover we used current NIAD use (excluding incretin use) as a reference group, because diabetes itself might act as a confounder. Current NIAD use included use of TZDs or insulins, which have been shown to increase fracture risk ${ }^{3,4}$. The result of this bias in the reference category may be an observed 
artificial inverse association between GLP1-RA use and risk of fracture which could have falsely supported our hypothesis. However, we did not observe an inverse association between GLP1-RA use and risk of fracture. Current NIAD use also included metformin use which has been associated with a reduced fracture risk and therefore it might mask a decreased association between GLP1-RA use and fracture risk. Nevertheless, statistical adjustment of the main analysis for current metformin use did not alter the results.

Although the total number of fractures was high, the number of some fracture types (i.e., hip and radius/ulna) was not high enough to stratify current GLP1-RA use by cumulative and average dose, and to keep adequate statistical power. In the analyses with hip and vertebral fracture as outcome the number of GLP1-RA users was quite small, therefore these results should be interpreted with caution. The average duration of actual GLP1-RA use (36 weeks) in the present study was rather short, which might be the reason that we were unable to observe an association between GLP1-RA use and fracture risk. However, after stratification of current GLP1-RA use by cumulative dose, risk of fracture was not decreased in the group with patients who had used on average 15 microgram exenatide equivalent per day for at least one year (cumulative dose: $\geq 5.5 \mathrm{mg}$ exenatide equivalent).

In conclusion, we showed in a population-based case-control study that the use of GLP1-RAs (current, recent or past) is not associated with fracture risk as compared to use of other anti-hyperglycaemic drugs. In addition, current GLP1-RA use stratified by cumulative and average daily dose was not associated with a decreased fracture risk. More research is needed, and in particular future studies should focus on the effect of long-term use of GLP1-RAs on fracture risk. 
1. Vestergaard P. Discrepancies in bone mineral density and fracture risk in patients with type 1 and type 2 diabetes - a meta-analysis. Osteoporos Int. 2007;18(4):427-44.

2. Montagnani A, Gonnelli S. Diabetes Obes Metab. Antidiabetic therapy effects on bone metabolism and fracture risk. 2013;15(9):78491.

3. Bazelier MT, Gallagher AM, van Staa TP, Cooper C, Leufkens HG, Vestergaard $P$, et al. Use of Thiazolidinediones and risk of osteoporotic fracture: Disease or drugs? Pharmacoepidemiol Drug Saf. 2012;21(5):507-14.

4. Betteridge DJ. Thiazolidinediones and fracture risk in patients with Type 2 diabetes. Diabet Med. 2011;28(7):759-71.

5. Schwartz AV, Vittinghoff E, Bauer DC, Hillier TA, Strotmeyer ES, Ensrud KE, et al. Association of $B M D$ and FRAX score with risk of fracture in older adults with type 2 diabetes. JAMA. 2011;305(21):2184-92.

6. Vestergaard P, Rejnmark L, Mosekilde L. Relative fracture risk in patients with diabetes mellitus, and the impact of insulin and oral antidiabetic medication on relative fracture risk. Diabetologia. 2005;48(7):1292-9.

7. Nuche-Berenguer $B$, Moreno $P$, Esbrit $P$, Dapía S, Caeiro JR, Cancelas J, et al. Effect of GLP-1 treatment on bone turnover in normal, type 2 diabetic, and insulin-resistant states. Calcif Tissue Int. 2009;84:453-461.

8. Nuche-Berenguer B, Moreno P, Portal-Nuñez $S$, Dapía $S$, Esbrit $P$, Villanueva-Peñacarrillo $\mathrm{ML}$. Exendin-4 exerts osteogenic actions in insulinresistant and type 2 diabetic states. Regul Pept. 2010;159(1-3):61-6.

9. Moreno P, Nuche-Berenguer B, Gutiérrez-Rojas I, Acitores A, Sancho V, Valverde I, et al. Normalizing action of exendin-4 and GLP-1 in the glucose metabolism of extrapancreatic tissues in insulin-resistant and type 2 diabetic states. J Mol Endocrinol. 2012;48:37-47.

10. Kim JY, Lee SK, Jo KJ, Song DY, Lim DM, Park KY, et al. Exendin-4 increases bone mineral density in type 2 diabetic OLETF rats potentially through the down-regulation of SOST/sclerostin in osteocytes. Life Sci. 2013;21;92(10):533-40.

11. Nuche-Berenguer B, Moreno P, Portal-Nuñez $S$, Dapía S, Esbrit P, Villanueva-Peñacarrillo ML. Exendin-4 exerts osteogenic actions in insulin- resistant and type 2 diabetic states. Regul Pept. 2010;159(1-3):61-6.

12. Mabilleau G, Mieczkowska A, Chappard D. Use of glucagon-like peptide-1 receptor agonists and bone fractures: a meta-analysis of randomized clinical trials. J Diabetes. 2014;6(3):260-6.

13. Driessen JH, Henry RM, van Onzenoort $H A$, Lalmohamed A, Burden AM, Prieto-Alhambra D et al. Bone Fracture Risk is Not Associated with the Use of Glucagon-Like Peptide-1 Receptor Agonists: A Population-Based Cohort Analysis. Calcif Tissue Int. 2015;97(2):104-12.

14. Vestergaard P,Mosekilde L. Fracture risk in patients with celiac Disease, Crohn's disease, and ulcerative colitis: a nationwide follow-up study of 16,416 patients in Denmark. Am J Epidemiol 2002;156(1):1-10.

15. Frank L. Epidemiology. When an entire country is a cohort. Science. 2000;287:2398-99.

16. Andersen $T$, Madsen $M$, Jørgensen J, Mellemkjær L, Olsen J. The Danish National Hospital Register. Dan Med Bull 1999;46:263-8.

17. Wacholder S, McLaughlin J, Silverman D, Mandel J (1992) Selection of controls in casecontrol studies. I. Principles. Am J Epidemiol 135:1019-28.

18. FRAX. WHO Fracture Risk Assessment Tool. 2001. shef.ac.uk.www.shef.ac.uk/FRAX/index.a spx.

19. Anonymous. ATC classification index with DDDs 2002. Nydalen, WHO Collaborating Centre for Drug Statistics Methodology, Norwegian Institute of Public Health, 2002.

20. Klop C, de Vries F, Vinks T, Kooij MJ, van Staa TP, Bijlsma JW, et al. Increase in prophylaxis of glucocorticoid-induced osteoporosis by pharmacist feedback: a randomised controlled trial. Osteoporos Int. 2014;25(1):385-92.

21. Prieto-Alhambra D, Petri H, Goldenberg JS, Khong TP, Klungel $\mathrm{OH}$, Robinson $\mathrm{NJ}$, et al. Excess risk of hip fractures attributable to the use of antidepressants in five European countries and the USA. Osteoporos Int. 2014;25(3):847-55.

22. Khong TP, de Vries F, Goldenberg JS, Klungel $\mathrm{OH}$, Robinson NJ, Ibáñez L, et al. Potential impact of benzodiazepine use on the rate of hip fractures in five large European countries and the United States. Calcif Tissue Int. 2012;91(1):24-31. 
23. Pouwels S, Bazelier MT, de Boer A, Weber WE, Neef C, Cooper C, et al. Risk of fracture in patients with Parkinson's disease. Osteoporos Int. 2013;24(8):2283-90.

24. Su B, Sheng H, Zhang M, Bu L, Yang P, Li L, et al. Risk of bone fractures associated with glucagon-like peptide-1 receptor agonists' treatment: a meta-analysis of randomized controlled trials. Endocrine. 2015;48(1):107-15.

25. Scirica BM, Bhatt DL, Braunwald E, Steg PG, Davidson J, Hirshberg B et al. Saxagliptin and cardiovascular outcomes in patients with type 2 diabetes mellitus. N Engl J Med. 2013;369(14):1317-26.

26. Bunck MC, Eliasson B, Corner A, Heine RJ, Shaginian RM, Taskinen MR, et al. Exenatide treatment did not affect bone mineral density despite body weight reduction in patients with type 2 diabetes. Diabetes Obes Metab. 2011;13:374-7.

27. Monami M, Dicembrini I, Antenore A, Mannucci E. Dipeptidyl peptidase-4 inhibitors and bone fractures: a meta-analysis of randomized clinical trials. Diabetes Care. 2011;34(11):2474-6.

28. Lane PW. Meta-analysis of incidence of rare events. Methods Med Res. 2013;22(2):117-32.

29. Bhaumik DK, Amatya A, Normand SL, Greenhouse J, Kaizar E, Neelon B et al. MetaAnalysis of Rare Binary Adverse Event Data. J Am Stat Assoc. 2012;107(498):555-67.

30. Sanz $C$, Vázquez $P$, Blázquez $C$, Barrio PA, Alvarez Mdel M, Blázquez E. Signaling and biological effects of glucagon-like peptide 1 on the differentiation of mesenchymal stem cells from human bone marrow. Am J Physiol Endocrinol Metab. 2010;298(3):E634-43.

31. Phillips LK, Prins JB. Update on incretin hormones. Ann N Y Acad Sci. 2011;1243:E5574.

32. Cummings SR, Nevitt MC, Browner WS, Stone K, Fox KM, Ensrud KE et al. Risk factors for hip fracture in white women. Study of Osteoporotic Fractures Research Group. N Engl J Med. 1995;332(12):767-73.

33. Kanis JA, Johnell $O$, Oden $A$, Johansson $H, D e$ Laet C, Eisman JA, et al. Smoking and fracture risk: a meta-analysis. Osteoporos Int. 2005;16(2):155-62.

34. Kemmler W, Häberle L, von Stengel S. Effects of exercise on fracture reduction in older adults: a systematic review and meta-analysis. Osteoporos Int. 2013;24(7):937-50.

35. Zoppini G, Galletti A, Targher G, Brangani C, Pichiri I, Trombetta M, et al. Lower levels of 25hydroxyvitamin D3 are associated with a higher prevalence of microvascular complications in patients with type 2 diabetes. BMJ Open Diabetes Res Care. 2015;24:3(1).

36. Bischoff-Ferrari HA, Willett WC, Wong JB, Stuck $A E$, Staehelin HB, Orav EJ, et al. Prevention of nonvertebral fractures with oral vitamin $D$ and dose dependency: a meta-analysis of randomized controlled trials. Arch Intern Med. 2009;169(6):551-61. 


\section{Chapter}

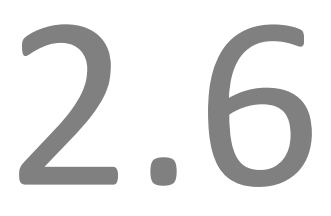

The use of incretins and fractures - a metaanalysis on population-based real life data

JHM Driessen, F de Vries, HAW van Onzenoort, NC Harvey, C Neef, JPW van den Bergh, P Vestergaard, RMA Henry

Br J Clin Pharmacol. 2016; in press. 


\section{Abstract}

\section{Introduction}

The aim of the present study was to estimate the effect of use of incretins on fracture risk in the real world situation by a meta-analysis of the available population-based cohort data.

\section{Methods}

Pubmed and Embase were searched for original articles investigating use of incretin agents, and fracture risk up to December 2015. Adjusted results were extracted and results were pooled by use of generic inverse variance methods, assuming a random-effects model.

\section{Results}

Neither current dipeptidyl peptidase 4 inhibitor use, nor current glucagon-like peptide 1 receptor agonist use was associated with a decreased risk of fracture: pooled relative risk [pooled RR (95\% Cl): $1.02(0.91-1.13)$ and $1.03(0.87-1.22)]$, respectively.

\section{Conclusion}

This meta-analysis demonstrated that current use of incretin agents, was not associated with decreased fracture risk. Our findings show the value of representative real-world populations, and the risks associated with suggesting benefits for medications on the basis of safety reporting in randomised controlled trials. 


\section{Introduction}

Fractures are associated with increased morbidity and mortality, and place a considerable economic burden upon health care systems ${ }^{1}$. Patients with type 2 diabetes mellitus (T2DM) are at increased fracture risk, both from the disease itself and potentially from associated medications ${ }^{2}$. Since 2007 , incretin agents, such as dipeptidyl peptidase 4 inhibitors (DPP4-Is) and glucagon-like peptide 1 receptor agonists (GLP1RAs), have been available for the treatment of T2DM.

Interestingly, a meta-analysis, solely based upon randomised controlled trial (RCT) data, showed that the use of DPP4-Is was associated with a $40 \%$ reduction in fracture risk $^{3}$. In contrast, two meta-analyses of RCT data comparing GLP1-RAs to active comparators and/or placebo showed no association between GLP1-RA use and fracture risk $^{4,5}$. Nevertheless, stratification by type of GLP1-RA resulted in a $62 \%$ reduced risk with a specific GLP1-RA, while another type showed a two-fold increased risk ${ }^{5}$.

We have recently investigated the association between incretin use and fracture risk, using real-life data from large population-based cohorts ${ }^{6-9}$. In contrast to the RCT meta-analyses ${ }^{3,5}$ we did not observe a reduced fracture risk with use of either of the incretins.

The aim of the present study was to obtain the highest quality estimate of the effect of incretins on fracture risk in the real world situation by meta-analysis of the available population-based cohort data.

\section{Methods}

Pubmed and Embase were searched for original published and peer-reviewed articles investigating incretin agents, either DPP4-Is or GLP1-RAs, and fracture risk up to 2015. The following search string was used: "(dpp-4 inhibitors or dipeptidyl peptidase-4 inhibitors or Sitagliptin or Vildagliptin or Saxagliptin or Linagliptin or Anagliptin or Teneligliptin or Alogliptin or Trelagliptin or Gemigliptin or Dutogliptin or Omarigliptin or exenatide or liraglutide or lixisenatide or albiglutide or dulaglutide or GLP1-analogues or glucagon-like peptide 1 or incretin) and fracture". Two authors (JD and FV) reviewed the titles and abstracts of the potential eligible articles. To be included, a study had to meet the following criteria: (1) the use of an observational study design; (2) a comparison of the use of at least one of the incretin agents (DPP4-I or GLP1-RA) to use of other non-insulin anti-diabetic drugs (NIADs); (3) report fracture as outcome; (4) reporting relative risks (RRs), odds ratios (ORs), or hazard ratios (HRs) including $95 \%$ confidence intervals (Cls); (5) reporting in English. References of included articles were searched to identify additional articles.

The name of first author, the year of publication, the study design, the number of patients per exposure group, the number of events, the duration of follow-up and the point estimates with corresponding $95 \% \mathrm{Cls}$ were extracted from the included studies. 
Data on specified fracture sites and results stratified by age and gender were extracted as well. Additionally, data on average daily dose en cumulative dose were extracted, if the average and cumulative daily dose categories were not similar between studies, authors were contacted to provide adjusted results.

Results were pooled by use of generic inverse variance methods, assuming a random effects model. Sub-analyses were performed for different fracture sites (hip, radius/ulna, clinical vertebral and major osteoporotic fracture), average daily dose, cumulative dose, different age categories and sex. Heterogeneity was assessed by the Cochrane Q-statistic and the 12 statistic. Publication bias could not be assessed due to the low number of included studies per exposure $(n=2)^{10}$. Analyses were performed using RevMan Version 5.3 (Cochrane Collaboration, Oxford, UK). A p-value $<0.05$ was considered to be statistically significant.

\section{Results}

The initial electronic search resulted in a total of 125 hits (Pubmed: 59; Embase 66), Figure 2.6.1. After screening of the abstracts and titles a total of four studies met our inclusion criteria. Two of them were cohort studies whereas the other two were casecontrol studies $^{6-9}$. These studies contained in total data on 22,961 current DPP4-I users (568 fractures) and 8,505 current GLP1-RA users (202 fractures), Table 2.6.1.

We found that neither current DPP4-I use, nor current GLP1-RA use was associated with a decreased risk of fracture (corresponding forest plots Figure 2.6.2 and Figure 2.6.3): pooled relative risk [pooled RR (95\% Cl): 1.02 (0.91-1.13) and 1.03 (0.87-1.22)] respectively, except for GLP1-RA use which was associated with an increased risk of vertebral fracture risk [pooled RR $(95 \% \mathrm{Cl}) 1.86$ (1.19-2.91)] (data not shown). For both DPP4-I use and GLP1-RA use no heterogeneity was found across studies (DPP4-I: Q-statistic: 0.28 (p-value=0.60), $I^{2}=0 \%$; GLP1-RA: 0.66 , Q-statistic: ( $p$-value 0.42 ), $I^{2}=0 \%$, Figure 2.6.2 and 2.6.3, respectively).

The results were similar if DPP4-I use was stratified according to cumulative exposure or average daily dose. When GLP1-RA use was stratified according to cumulative exposure or average daily dose there was no consistent increased or decreased fracture risk with cumulative dose, whereas fracture risk was increased if the average daily GLP1-RA dose exceeded $22.5 \mathrm{mcg} /$ day [pooled RR (95\% Cl) 1.63 (1.11-2.41)], all Table 2.6.2. 


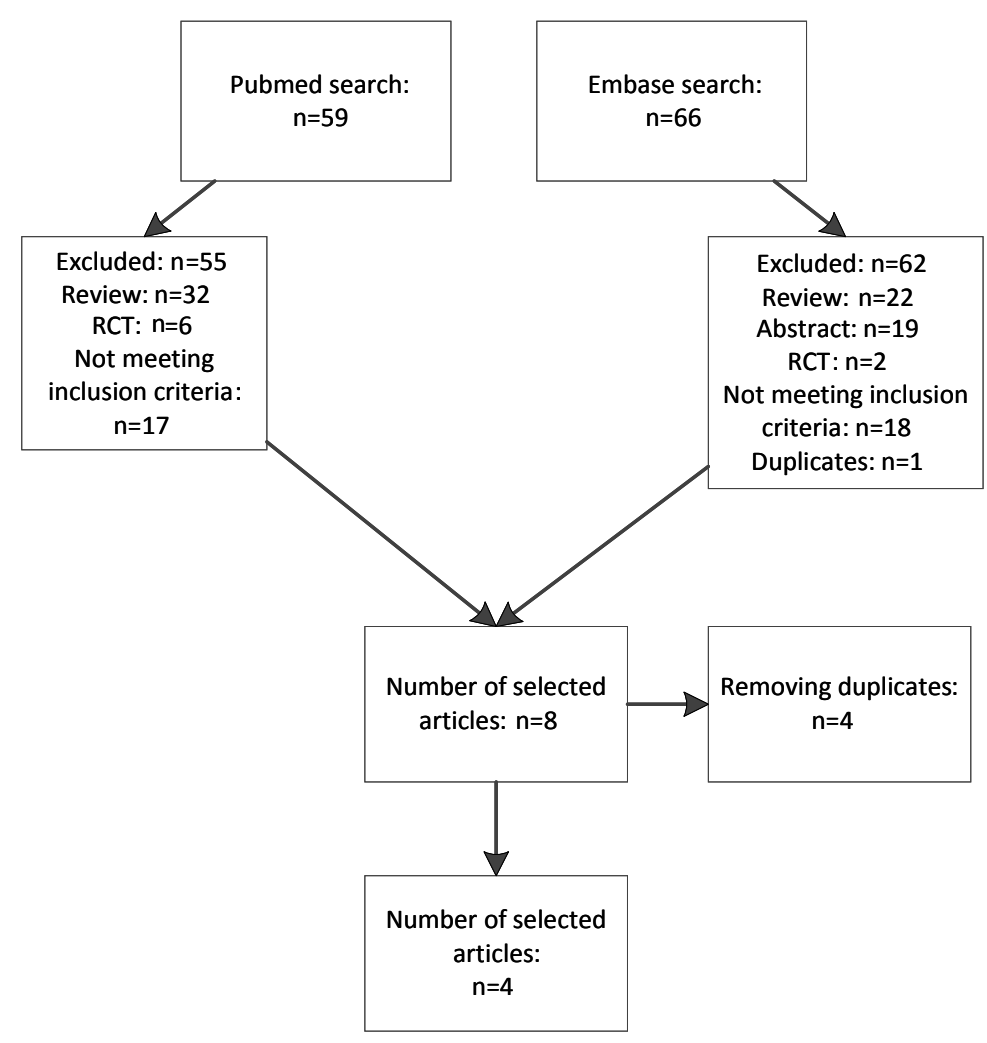

Figure 2.6.1 Flowchart of included studies. RCT: randomised controlled trial.

Table 2.6.1 Characteristics of included studies.

\begin{tabular}{|c|c|c|c|c|c|}
\hline $\begin{array}{l}\text { Author and year } \\
\text { [Reference] }\end{array}$ & $\begin{array}{l}\text { Investigated } \\
\text { exposure }\end{array}$ & Study design & $\begin{array}{l}\text { Number of } \\
\text { patients } \\
\text { exposed to } \\
\text { incretin agents }\end{array}$ & $\begin{array}{c}\text { Number of patients } \\
\text { in } \\
\text { the reference } \\
\text { group }\end{array}$ & $\begin{array}{c}\text { Characteristics at } \\
\text { baseline }\end{array}$ \\
\hline $\begin{array}{l}\text { Driessen et al. } \\
2014 \text { [6] }\end{array}$ & PP4-I & Coh & 22,510 & 194,306 & $\begin{array}{c}\text { Mean age: } 61 \\
\% \text { Women: } 47.3\end{array}$ \\
\hline $\begin{array}{l}\text { Driessen et al. } \\
2015 \text { [8] }\end{array}$ & DPP4-I & $\begin{array}{l}\text { Case-control } \\
\text { study }\end{array}$ & $\begin{array}{c}\text { Cases: } 219 \\
\text { Controls: } 232\end{array}$ & $\begin{array}{l}\text { Cases: } 6993 \\
\text { Controls: } 7209\end{array}$ & $\begin{array}{c}\text { Mean age: } 55 \\
\% \text { Women: } 55.6\end{array}$ \\
\hline $\begin{array}{l}\text { Driessen et al. } \\
2015 \text { [7] }\end{array}$ & GLP1-RA & Cohort study & 8,354 & 208,462 & $\begin{array}{c}\text { Mean age: } 61 \\
\text { \% Women: } 47.3\end{array}$ \\
\hline $\begin{array}{l}\text { Driessen et al. } \\
2015 \text { [9] }\end{array}$ & GLP1-RA & $\begin{array}{c}\text { Case-control } \\
\text { study }\end{array}$ & $\begin{array}{c}\text { Cases:80 } \\
\text { Controls:71 }\end{array}$ & $\begin{array}{c}\text { Cases:6993 } \\
\text { Controls:7209 }\end{array}$ & $\begin{array}{c}\text { Mean age: } 55 \\
\text { \% Women: } 55.6\end{array}$ \\
\hline
\end{tabular}

DPP4-I: dipeptidyl peptidase 4 inhibitor; GLP1-RA: glucagon-like peptide 1 receptor agonist. 


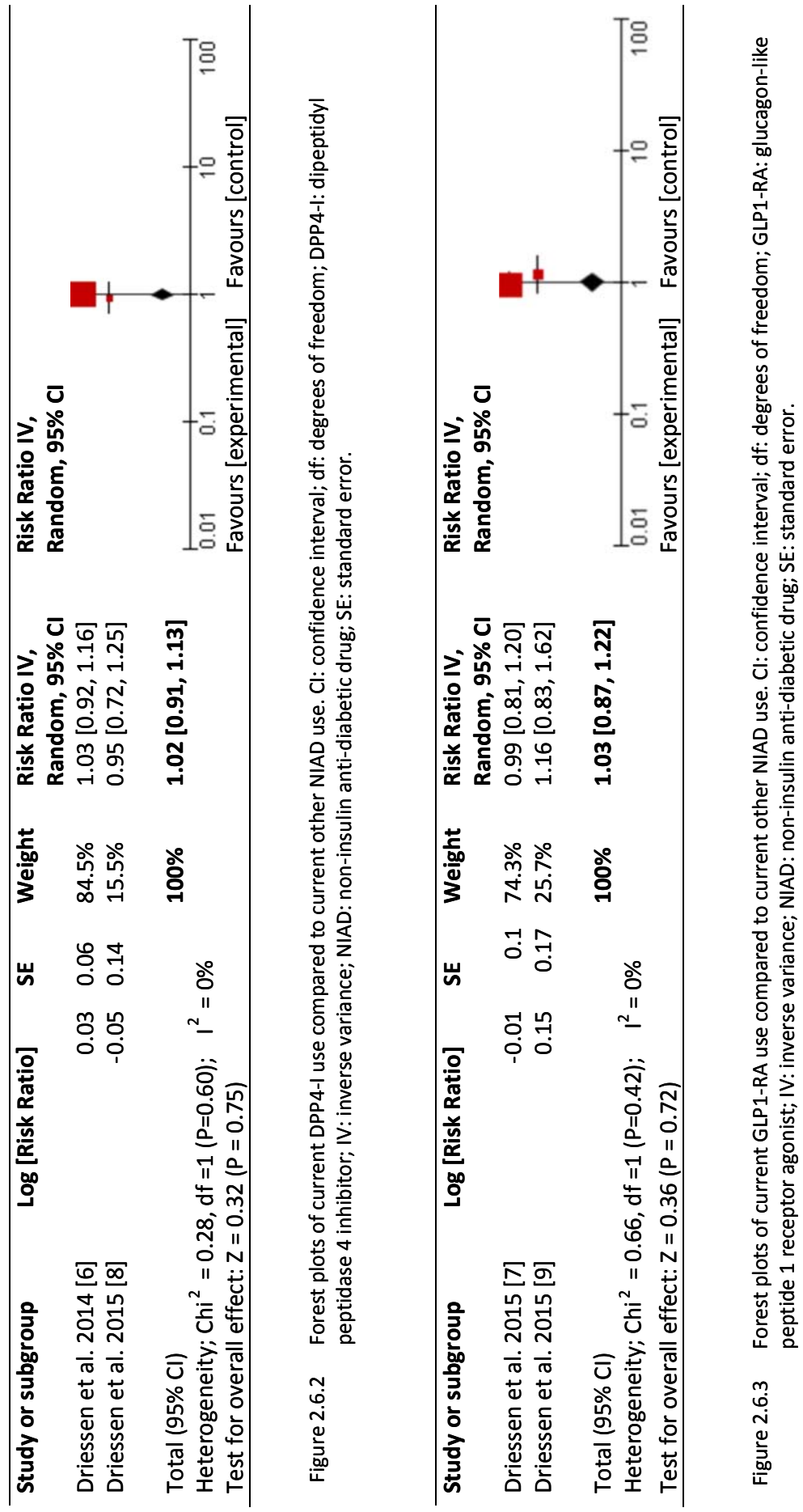


Table 2.6.2 Risk of fracture in DPP4-I and GLP1-RA users compared with NIAD users, by age, sex, cumulative exposure and average daily dose.

\begin{tabular}{|c|c|c|c|}
\hline \multicolumn{2}{|c|}{ DPP4-I } & \multicolumn{2}{|c|}{ GLP1-RA } \\
\hline & Pooled RR (95\% Cl) & & Pooled RR $(95 \% \mathrm{CI})$ \\
\hline Risk of any fracture & & Risk of any fracture & \\
\hline $\begin{array}{l}\text { Current NIAD use } \\
\text { excl. incretin use }\end{array}$ & Reference & $\begin{array}{l}\text { Current NIAD use } \\
\text { excl. incretin use }\end{array}$ & Reference \\
\hline Current DPP4-I use & $1.02(0.91-1.13)$ & Current GLP1-RA use & $1.03(0.87-1.22)$ \\
\hline By sex & & By sex & \\
\hline Males & $1.01(0.86-1.17)$ & Males & $1.00(0.79-1.27)$ \\
\hline Females & $0.99(0.80-1.23)$ & Females & $1.11(0.76-1.61)$ \\
\hline By age & & By age & \\
\hline$<50$ years & $0.82(0.56-1.20)$ & $<50$ years & $0.86(0.58-1.27)$ \\
\hline 50 - 59 years & $1.18(0.95-1.47)$ & 50 - 59 years & $0.84(0.62-1.15)$ \\
\hline $60-69$ years & $1.01(0.85-1.20)$ & $60-69$ years & $1.35(1.06-1.73)^{*}$ \\
\hline $70-79$ years & $1.08(0.86-1.37)$ & $70+$ years & $0.77(0.49-1.22)$ \\
\hline $80+$ years & $0.98(0.76-1.25)$ & & \\
\hline By cumulative exposure $^{a}$ & & By cumulative exposure ${ }^{b}$ & \\
\hline $0-9.1 \mathrm{~g}$ & $0.98(0.79-1.22)$ & $0-1.3 \mathrm{mg}$ & $1.02(0.75-1.37)$ \\
\hline $9.2-18.2 \mathrm{~g}$ & $1.06(0.84-1.33)$ & $1.4-2.6 \mathrm{mg}$ & $1.18(0.79-1.76)$ \\
\hline $18.3-36.4 \mathrm{~g}$ & $0.93(0.75-1.16)$ & $2.7-5.4 \mathrm{mg}$ & $1.60(1.04-2.47)^{*}$ \\
\hline$\geq 36.5 \mathrm{~g}$ & $1.01(0.85-1.20)$ & $\geq 5.5 \mathrm{mg}$ & $0.94(0.59-1.51)$ \\
\hline By average daily dose $^{a}$ & & By average daily dose $e^{b}$ & \\
\hline$<100 \mathrm{mg} /$ day & $1.08(0.76-1.55)$ & $<15.0 \mathrm{mcg} /$ day & $1.05(0.80-1.37)$ \\
\hline $100-149 \mathrm{mg} /$ day & $0.92(0.79-1.06)$ & $15.0-22.4 \mathrm{mcg} / \mathrm{day}$ & $0.91(0.70-1.17)$ \\
\hline$\geq 150 \mathrm{mg} /$ day & $0.96(0.80-1.14)$ & $\geq 22.5 \mathrm{mcg} / \mathrm{day}$ & $1.63(1.11-2.41)^{*}$ \\
\hline
\end{tabular}

$\mathrm{Cl}$ : confidence interval; DPP4-I: dipeptidyl peptidase 4 inhibitor; GLP1-RA: glucagon-like peptide 1 receptor agonist; NIAD: non-insulin anti-diabetic drug; RR: relative risk. * Statistically significant, $p<0.05 .{ }^{a}$ In sitagliptin equivalents. ${ }^{b}$ In exenatide equivalents.

\section{Discussion}

The results of this meta-analysis on real-life population-based data demonstrate that, contrary to pooled RCT-data ${ }^{3,5}$, the current use of incretins (either DPP4-Is or GLP1-RAs) was not associated with a decreased fracture risk. Moreover, GLP1-RA use was associated with an increased risk of any fracture if the average daily dosage exceeded $22.5 \mathrm{mcg} /$ day. The present results were in line with a previous meta-analysis, showing no association between use of GLP1-RA and risk of fracture ${ }^{4}$. It is possible that the discrepancies between the pooled RCT-data and our real-life population-based data may be a result of selection bias due to the use of strict inclusion and exclusion criteria with RCTs and the fact that data on fractures in the RCT studies were not predefined outcomes and therefore not routinely systematically collected. Importantly, the notion that incretins may have skeletal effects stems from in vitro and experimental animal studies, possibly acting via osteoclast inhibition and modulation of thyroid C-cells, 
which express incretin receptors ${ }^{11,12}$; the translation of such observations to the human clinical situation must be viewed with caution.

A particular strength of this short report is, next to its analyses of real-life population-based data, its use of the same cumulative and average daily dose categories which allowed us to use the same definitions across the studies. When interpreting the results, a couple of limitations are worth mentioning. The number of fractures with current GLP1-RA use was relatively small, which limited the statistical power to detect associations, particularly when stratified by cumulative exposure, average daily dose and fracture type. In addition, only a small number of observational studies, all performed by us, could be included in the present meta-analysis. Another limitation is the relative short duration of incretin use (37 weeks to 1.7 years) ${ }^{6-9}$. In addition, the included studies adjusted for different sets of confounders, which may have biased our results. We nevertheless have tested the hypothesis that incretin use was associated with a decreased risk of fracture in multiple ways, and none of the analyses showed a decreased risk of fracture. Moreover we used data representative for the United Kingdom (2007-2012) and data on all fractures in Denmark between 2007 and 2011.

In short, this meta-analysis demonstrated that current use of incretin agents, either DPP4-Is or GLP1-RAs, was not associated with decreased fracture risk. Moreover, current GLP1-RA use was associated with an increased risk of any fracture when the average daily dosage exceeded $22.5 \mathrm{mcg} /$ day. Our findings show the value of representative real world populations, and the risks associated with suggesting benefits for medications on the basis of safety reporting in RCTs. An adequately powered trial with fracture as the primary endpoint will be required to properly demonstrate the skeletal efficacy or otherwise of incretins. 


\section{References}

1. Braithwaite RS, Col NF, Wong JB. Estimating hip fracture morbidity, mortality and costs. J Am Geriatr Soc. 2003;51(3):364-70.

2. Vestergaard P. Discrepancies in bone mineral density and fracture risk in patients with type 1 and type 2 diabetes - a meta-analysis. Osteoporos Int. 2007;18(4):427-44.

3. Monami M, Dicembrini I, Antenore A, Mannucci E. Dipeptidyl peptidase-4 inhibitors and bone fractures: a meta-analysis of randomized clinical trials. Diabetes Care. 2011;34(11):2474-6.

4. Mabilleau G, Mieczkowska A, Chappard D. Use of glucagon-like peptide-1 receptor agonists and bone fractures: a meta-analysis of randomized clinical trials. J Diabetes. 2014;6(3):260-6.

5. Su B, Sheng $H$, Zhang $M, B u L$, Yang $P$, Li L, et al. Risk of bone fractures associated with glucagon-like peptide-1 receptor agonists' treatment: a meta-analysis of randomized controlled trials. Endocrine. 2015;48(1):10715.

6. Driessen $\mathrm{JH}$, van Onzenoort $\mathrm{HA}$, Henry RM, Lalmohamed A, van den Bergh JP, Neef C, et al. Use of dipeptidyl peptidase-4 inhibitors for type 2 diabetes mellitus and risk of fracture. Bone. 2014;68:124-30.

7. Driessen $\mathrm{JH}$, Henry RM, van Onzenoort $H A$, Lalmohamed A, Burden AM, Prieto-Alhambra $D$, et al. Bone fracture risk is not associated with the use of glucagon-like peptide-1 receptor agonists: a population-based cohort analysis. Calcif Tissue Int. 2015;97(2):104-12.

8. Driessen JH, van Onzenoort HA, Starup-Linde J, Henry R, Neef C, van den Bergh J, et al. Use of dipeptidyl peptidase 4 inhibitors and fracture risk compared to use of other antihyperglycemic drugs. Pharmacoepidemiol Drug Saf. 2015;24(10):1017-25.

9. Driessen JH, van Onzenoort HA, Starup-Linde J, Henry R, Burden AM, Neef C, et al. Use of Glucagon-Like-Peptide 1 Receptor Agonists and Risk of Fracture as Compared to Use of Other Anti-hyperglycemic Drugs. Calcif Tissue Int. 2015;97(5):506-15.

10. Sutton AJ, Duval SJ, Tweedie RL, Abrams KR, Jones DR. Empirical assessment of effect of publication bias on meta-analyses. BMJ. 2000; 320(7249):1574-7.

11. Zhong $Q$, Itokawa $T$, Sridhar S, Ding $K H$, Xie D, Kang B, et al. Effects of glucose-dependent insulinotropic peptide on osteoclast function. Am J Physiol Endocrinol Metab. 2007;292(2):E543-8.

12. Yamada C, Yamada Y, Tsukiyama K, Yamada K, Udagawa N, Takahashi $\mathrm{N}$, et al. The murine glucagon-like peptide-1 receptor is essential for control of bone resorption. Endocrinology. 2008;149(2):574-9. 


\section{Chapter}

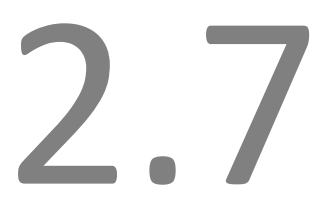

Long-term use of dipeptidyl peptidase 4 inhibitors and risk of fracture; a retrospective populationbased cohort study

JHM Driessen, JPW van den Bergh, HAW van Onzenoort, RMA Henry, HGM Leufkens, F de Vries

Diabetes Obes and Metabolism, 2017;19(3):421-428 


\section{Abstract}

\section{Introduction}

Patients with type 2 diabetes mellitus (T2DM) have an increased risk of fracture as compared to patients without T2DM. It has been suggested based on clinical trial data that use of dipeptidyl peptidase 4 inhibitors (DPP4-Is), an anti-hyperglycaemic drug, is associated with a decreased risk of fracture as compared to patients with and without T2DM. However, observational studies have failed to show this association, which might be due to the short duration of use. Therefore, the aim of the present study was to investigate the association between long-term DPP4-I use and risk of fracture.

\section{Methods}

A retrospective population-based cohort study, using data from the Clinical Practice Research Datalink (CPRD) database (2007-2015), was conducted. All patients $(n=328,254)$ with at least one prescription for a non-insulin anti-diabetic drug (NIAD), aged 18+ during data collection, were included. Cox proportional hazards models were used to estimate the hazard ratio of any, osteoporotic and hip fracture in DPP4-I users versus other NIAD users. Analyses were stratified by continuous duration of DPP4-I use. Time-dependent adjustments were made for age, sex, lifestyle, comorbidity and concomitant drug use.

\section{Results}

Current use of DPP4-Is was not associated with risk of any fracture (adjusted (adj.) hazard ratio (HR): 0.99 (95\% confidence interval (Cl) 0.93-1.06)) as compared to current other NIAD use. Current use of DPP4-Is was also not associated with risk of osteoporotic or hip fracture. After stratification by continuous duration of DPP4-I use the highest category was not associated with any (>4.0-8.5 years of DPP4-I use; adj. HR: 0.99 (0.70-1.41)), osteoporotic (>3.0-8.5 years of DPP4-I use; adj. HR: 0.75 (0.52-1.09)), or hip (>2.0-8.5 years of DPP4-I use; adj. HR: 1.24 (0.85-1.79)) fracture.

\section{Conclusion}

Continuous long-term DPP4-I use (defined as $>4.0-8.5$ years of DPP4-I use for any fracture, $>3.0-8.5$ years for osteoporotic fracture and $>2.0-8.5$ years for hip fracture, respectively) was not associated with risk of any, osteoporotic, or hip fracture. These findings may be of value for clinical decisions regarding treatment of T2DM patients, especially those at high fracture risk. 


\section{Introduction}

Worldwide, about 422 million people suffer from type 2 diabetes mellitus (T2DM) ${ }^{1}$. Besides other complications T2DM has been associated with an increased risk of fracture compared to subjects without T2DM ${ }^{2}$. Explanations for this increased fracture risk include an increased risk of falling ${ }^{3}$, the pathophysiology of diabetes itself on bone quality $^{4}$ as well as the effect of anti-hyperglycaemic drugs used in T2DM ${ }^{5}$. Dipeptidyl peptidase 4 inhibitors (DPP4-Is), are a relatively new type of anti-hyperglycaemic drugs which have been marketed since $2006^{6}$.

It has been suggested that DPP4-Is might influence bone metabolism and thereby potentially reduce fracture risk $^{5}$. A first meta-analysis of randomised controlled trials (RCTs) indeed showed a reduced risk of fracture with use of DPP4-Is ${ }^{7}$. Recently, we have performed the first observational studies investigating the association between use of DPP4-Is and risk of fracture ${ }^{8,9}$. In contrast to the result of the meta-analysis, we found no association between use of DPP4-Is and fracture risk. One of the explanations might be the fact that the meta-analysis was based on a small number of fractures, which needed to be reported as severe adverse outcomes. In contrast, the observational studies used routinely collected data on fractures. Recently, another observational study was published which compared current use of metformin and DPP4-Is to non-use. Non-use was defined as insufficient exposure to diabetes medication (i.e., a medication possession ratio $(\mathrm{MPR})<20 \%)^{10}$. This study showed no association with fracture risk when a DPP4-I was added to metformin.

A major limitation of both the observational studies as well as the meta-analysis was the median actual duration of DPP4-I use. For the observational studies it ranged between 47 weeks $^{9}$ and 1.04 years ${ }^{8}$ and for the meta-analysis the median duration of the included trials was 24 weeks $^{7}$.

Based on these findings, the limited duration of DPP4-I use might have been too short to show an association between use of DPP4-Is and fracture risk. Therefore, in the present study we aimed to investigate the association between long-term use of DPP4-Is and risk of fracture.

\section{Methods}

Data for this study were obtained from the Clinical Practice Research Datalink (CPRD) in the United Kingdom, previously known as the General Practice Research Database (GPRD) [www.CPRD.com]. The CPRD contains computerized medical records of 674 primary care practices in the United Kingdom, representing $6.9 \%$ of the population ${ }^{11}$. The data recorded in the CPRD include demographic information, prescription details, clinical events, preventive care provided, specialist referrals, hospital admissions, and major outcomes since 1987. Previous studies using CPRD data have shown to be highly valid, with for example for hip fractures over $90 \%$ confirmed diagnoses ${ }^{12}$. 
We conducted a retrospective population-based cohort study. The study population consisted of all patients with at least one prescription for a non-insulin anti-diabetic drug (NIAD) and who were aged 18+ during the period of valid CPRD data collection. For this study, data collection started on June 13, 2007, the date of the first ever prescription of a DPP4-I in CPRD, and ended December 31, 2015. The index date was defined as the date of the first NIAD prescription since the start of the study period (i.e. the study population was a mix of incident and prevalent NIAD users). This study obtained approval from the independent scientific advisory committee of the CPRD (protocol number: 12_161R).

\section{Exposure}

The follow-up time of the NIAD users was divided into fixed intervals of 30 days. When there was a prescription of a NIAD in the 90 days before the start of an interval, the interval was classified as current NIAD use, otherwise the interval was classified as past NIAD use. Patients were allowed to move between current and past NIAD use. All DPP4-I exposed intervals were classified, according to the time since the most recent prescription, as current (1-90 days), recent (91-180 days), or past (over 180 days) use.

Continuous duration of use was determined at the start of every interval. The prescribed quantity and the written dosage instruction were used to estimate the duration of each DPP4-I prescription. Continuous duration of use was defined as the time from the first continuous prescription until the start of an interval, allowing a gap of 30 days $^{13}$ between the estimated end date of a prescription and the start of the next prescription.

\section{Outcome}

Patients were followed up from the index date to either the end of data collection, the date of transfer of the patient out of the practice area, the patient's death, or the fracture type of interest, whichever came first. Fractures were classified by use of read codes $^{14}$. We used the following categories to classify fractures: any, hip, and osteoporotic fracture. An osteoporotic fracture was defined as a fracture of the hip, vertebrae, radius/ulna or humerus according to the WHO definition ${ }^{15}$.

\section{Potential confounders}

The presence of risk factors was assessed by reviewing the computerized medical records for any record of a risk factor prior to the start of an interval. The following potential confounders were determined at baseline: sex, body mass index (BMI), smoking status and alcohol use. All other risk factors that were considered in this study were determined time-dependently (i.e. at the start of each interval). We considered the following potential confounders: age, most recent glycosylated hemoglobin A1c 
(HbA1c) measurement in the year prior the start of an interval, falls in 7-12 months before the start of an interval, a history of chronic obstructive pulmonary disease, previous fracture, rheumatoid arthritis, hypothyroidism, hyperthyroidism, cancer, retinopathy, neuropathy, congestive heart failure and secondary osteoporosis (hypogonadism or premature menopause). In addition, the following drug prescriptions in the 6 months prior to the start of an interval were considered as a potential confounder: oral glucocorticoids, cholesterol modifying drugs, antidepressants, anxiolytics or hypnotics, antipsychotics, anti-Parkinson drugs, antihypertensives (betablockers, thiazide diuretics, renin angiotensin aldosteron system inhibitors, calcium channel blockers, loop diuretics), antiarrhythmics, opposed hormone replacement therapy, calcium, bisphosphonates, vitamin $\mathrm{D}$, raloxifene, strontium ranelate, calcitonin and parathyroid hormone.

\section{Statistical analyses}

Regression analysis with Cox proportional hazards models (SAS 9.4, PHREG procedure) was used to estimate the fracture rate of current DPP4-I users compared to other NIAD users, excluding glucagon-like peptide 1 receptor agonist (GLP1-RA) users. GLP1-RA use was taken into account as a separate exposure group as it has been associated with a decreased risk of fracture ${ }^{16}$. In further analyses we stratified current DPP4-I use by categories of continuous duration of use. In all analyses potential confounders were included if they independently changed the beta-coefficient for current DPP4-I exposure by at least $5 \%$, or when consensus about inclusion existed within the team of researchers, supported by clinical evidence from literature. For confounder data with missing values (BMI, HbA1c, alcohol use and smoking status) a missing indicator variable was added.

\section{Sensitivity analyses}

As a sensitivity analysis the gap used to determine continuous duration of use was changed to 60 and 90 days. In a second sensitivity analysis we performed a new-user design in which all NIAD users with a NIAD prescription before the start of the study were excluded from the analyses. Additionally, we performed a sensitivity analysis in which all patients with a history of a fracture before the index date were excluded. A fourth sensitivity analysis was performed in which we adjusted the main analyses for current use of thiazolidinediones and current use of sulfonylurea derivatives, as they have been associated with fracture risk, respectively ${ }^{17,18}$. 


\section{Results}

In total 328,254 NIAD users were included, of which 46,355 were DPP4-I users. The baseline characteristics are shown in Table 2.7.1. The median actual duration of DPP4-I use was 1.6 years and the mean duration of follow-up was 6.3 and 5.6 years for the DPP4-I users and the NIAD users, respectively. DPP4-I users were less often women and slightly younger, had a higher $\mathrm{HbA} 1 \mathrm{c}$ and $\mathrm{BMI}$ at index date as compared to other NIAD users (HbA1c: 8.8 versus 8.0 and BMI: 32.6 versus 31.4). History of retinopathy, use of statins and use of antihypertensives was higher in DPP4-I users at baseline as compared to other NIAD users.

Table 2.7.1 Baseline characteristics of current DPP4-I users and other NIAD users.

\begin{tabular}{|c|c|c|}
\hline Characteristic & $\begin{array}{l}\text { DPP4-I users } \\
\mathrm{N}=46,355\end{array}$ & $\begin{array}{c}\text { Other NIAD users } \\
\mathrm{N}=281,899\end{array}$ \\
\hline Mean follow-up time (years, SD) & $6.3(2.5)$ & $5.6(2.8)$ \\
\hline Median actual duration of DPP4-use, [IQR] & $1.6[0.7-3.1]$ & $\mathrm{n} / \mathrm{a}$ \\
\hline Females & 19,428 (41.9) & $114,467(48.6)$ \\
\hline \multicolumn{3}{|l|}{ Age } \\
\hline Mean age at index date (years, SD) & $59.7(12.4)$ & $61.5(16.1)$ \\
\hline $18-49$ years & $9,883(21.3)$ & $53,131(22.6)$ \\
\hline 50 - 59 years & $12,550(27.1)$ & $44,660(19.0)$ \\
\hline $60-69$ years & $13,448(29.0)$ & $56,812(24.1)$ \\
\hline $70-79$ years & $8,065(17.4)$ & $50,561(21.5)$ \\
\hline $80+$ years & $2,409(5.2)$ & $30,380(12.9)$ \\
\hline \multicolumn{3}{|l|}{ BMI } \\
\hline Mean $\mathrm{BMI}$ at index date $\left(\mathrm{kg} / \mathrm{m}^{2}, \mathrm{SD}\right)$ & $32.6(6.7)$ & $31.4(6.8)$ \\
\hline$<20.0 \mathrm{~kg} / \mathrm{m}^{2}$ & $273(0.6)$ & $3,646(1.5)$ \\
\hline $20.0-24.9 \mathrm{~kg} / \mathrm{m}^{2}$ & $4,044(8.7)$ & $30,956(13.1)$ \\
\hline $25.0-29.9 \mathrm{~kg} / \mathrm{m}^{2}$ & $13,270(28.6)$ & $71,599(30.4)$ \\
\hline $30.0-34.9 \mathrm{~kg} / \mathrm{m}^{2}$ & $14,059(30.3)$ & $63,347(26.9)$ \\
\hline$\geq 35.0 \mathrm{~kg} / \mathrm{m}^{2}$ & $14,023(30.3)$ & $57,971(24.6)$ \\
\hline Missing & $686(1.5)$ & $8,025(3.4)$ \\
\hline \multicolumn{3}{|l|}{$\mathrm{HbA1c}$} \\
\hline Mean $\mathrm{HbA1c}(\%, \mathrm{SD})$ & $8.8(1.5)$ & $8(1.8)$ \\
\hline$<6 \%$ & $394(0.8)$ & $8,550(3.6)$ \\
\hline $6.0-6.9 \%$ & $2,807(6.1)$ & $35,868(15.2)$ \\
\hline $7.0-7.9 \%$ & $10,418(22.5)$ & $42,017(17.8)$ \\
\hline $8.0-8.9 \%$ & $12,217(26.4)$ & $22,598(9.6)$ \\
\hline$\geq 9.0 \%$ & $15,720(33.9)$ & $31,355(13.3)$ \\
\hline Missing & $4,799(10.4)$ & $95,156(40.4)$ \\
\hline \multicolumn{3}{|l|}{ Smoking status } \\
\hline Never & $14,839(32.0)$ & $77,335(32.8)$ \\
\hline Current & $8,015(17.3)$ & $40,256(17.1)$ \\
\hline Ex & $23,334(50.3)$ & $116,180(49.3)$ \\
\hline Missing & $167(0.4)$ & $1,773(0.8)$ \\
\hline \multicolumn{3}{|l|}{ Alcohol use } \\
\hline No & $14,349(31.0)$ & $74,826(31.8)$ \\
\hline Yes & $30,416(65.6)$ & $145,609(61.8)$ \\
\hline Missing & $1,590(3.4)$ & $15,109(6.4)$ \\
\hline Falls ( 6 - 12 months before index date) & $477(1.0)$ & 2,427 (1.0) \\
\hline
\end{tabular}


Table 2.7.1 (continued)

\begin{tabular}{lcc}
\hline & DPP4-I users & Other NIAD users \\
Characteristic & $\mathrm{N}=46,355$ & $\mathrm{~N}=281,899$ \\
\hline History of diseases & & \\
Fracture & $9,575(20.7)$ & $49,438(21.0)$ \\
Hyperthyroidism & $535(1.2)$ & $2,315(1.0)$ \\
Hypothyroidism & $4,180(9.0)$ & $18,997(8.1)$ \\
COPD & $2,765(6.0)$ & $12,559(5.3)$ \\
Congestive heart failure & $1,929(4.2)$ & $9,119(3.9)$ \\
Cancer & $11,491(24.8)$ & $51,587(21.9)$ \\
Rheumatoid arthritis & $726(1.6)$ & $3,621(1.5)$ \\
Retinopathy & $12,976(28.0)$ & $31,532(13.4)$ \\
Secondary osteoporosis & $3,774(8.1)$ & $19,655(8.3)$ \\
Neuropathy & $3,090(6.7)$ & $10,506(4.5)$ \\
Drug use within six months prior to index date & & \\
Glucocorticoids & $9,160(19.8)$ & $40,683(17.3)$ \\
Statins & $34,574(74.6)$ & $118,488(50.3)$ \\
Antiarrhythmics & $641(1.4)$ & $3,464(1.5)$ \\
Antidepressants & $9,688(20.9)$ & $38,909(16.5)$ \\
Anti-Parkinson drugs & $259(0.6)$ & $1,235(0.5)$ \\
Antipsychotics & $997(2.2)$ & $5,794(2.5)$ \\
Anxiolytics/hypnotics & $3,133(6.8)$ & $16,402(7.0)$ \\
Antihypertensives & $32,411(69.9)$ & $129,584(55.0)$ \\
Bisphosphonates & $1,032(2.2)$ & $6,399(2.7)$ \\
Raloxifene & $14(0.0)$ & $282(0.1)$ \\
Calcium/vitamin D & $2,393(5.2)$ & $10,574(4.5)$ \\
Strontium & $16(0.0)$ & $126(0.1)$ \\
Parathyroid hormone/calcitonin & $<6(0.0)$ & $820(0.3)$ \\
Hormone replacement therapy & $178(0.4)$ & \\
\hline
\end{tabular}

Data are presented as number (\%), unless stated otherwise. BMI: body mass index; DPP4-I: dipeptidyl peptidase 4 inhibitor; HbA1c: glycosylated hemoglobin A1c; IQR: inter quartile range; n/a: not applicable; NIAD: non-insulin anti-diabetic drug; SD: standard deviation

Table 2.7.2 shows that any DPP4-I use was associated with a decreased risk of any fracture (adjusted (adj.) hazard ratio (HR): 0.93 (95\% confidence interval (Cl) 0.88-0.94)). Current use of DPP4-Is was not associated with risk of any fracture (adj. HR: 0.99 (95\% Cl: 0.93-1.06)) as compared to current other NIAD use. Recent DPP4-I use was not associated with risk of fracture either, whereas, past DPP4-I use was associated with a decreased risk of fracture (adj. HR: 0.83 (95\% Cl: 0.75-0.91)). NIAD past use was associated with a $60 \%$ reduced risk of any fracture (adj. HR: 0.40 (95\% Cl: $0.38-0.43)$ ). The fully adjusted model including all potential confounders showed an HR of 0.95 (95\% $\mathrm{Cl}$ : 0.89-1.01) with current use of DPP4-I and risk of any fracture. Stratification by continuous duration of use resulted in an increased risk of fracture for patients who continuously used DPP4-I for 2.0-2.9 years (adj. HR: 1.23 (95\% Cl: 1.03-1.48)). Other categories showed no association with continuous duration of DPP4-I use, all Table 2.7.2. 
Table 2.7.2 Use of DPP4-Is and risk of any fracture stratified by continuous duration of use.

\begin{tabular}{|c|c|c|c|c|}
\hline & $\begin{array}{c}\text { Number of } \\
\text { fractures } \\
N=16,572^{a}\end{array}$ & $\begin{array}{l}\text { IR / } 1000 \\
\text { PY }\end{array}$ & $\begin{array}{l}\text { Age/gender adjusted } \\
\text { HR }(95 \% \mathrm{Cl})\end{array}$ & Adjusted HR $(95 \% \mathrm{Cl})^{\mathrm{b}}$ \\
\hline Current NIAD excl. incretins & 12,575 & 14.3 & Reference & Reference \\
\hline Past NIAD & 1,923 & 3.3 & $0.23(0.22-0.24)^{*}$ & $0.40(0.38-0.43)^{*}$ \\
\hline Any DPP4-I & 1,700 & 10.3 & $0.88(0.83-0.92)^{*}$ & $0.93(0.88-0.94)^{*}$ \\
\hline \multicolumn{5}{|l|}{ By recency } \\
\hline Past DPP4-I & 479 & 7.6 & $0.65(0.59-0.72)^{*}$ & $0.83(0.75-0.91)^{*}$ \\
\hline Recent DPP4-I & 93 & 9.9 & $0.84(0.68-1.03)$ & $0.83(0.67-1.02)$ \\
\hline Current DPP4-I & 1,128 & 12.2 & $1.02(0.96-1.08)$ & $0.99(0.93-1.06)$ \\
\hline \multicolumn{5}{|l|}{ By continuous duration of use } \\
\hline No continuous duration of use & 275 & 12.0 & $1.00(0.89-1.13)$ & $0.97(0.86-1.09)$ \\
\hline$\leq 0.5$ year & 311 & 12.2 & $1.01(0.90-1.13)$ & $1.00(0.89-1.12)$ \\
\hline $0.6-0.9$ year & 162 & 11.6 & $0.96(0.82-1.12)$ & $0.93(0.80-1.09)$ \\
\hline 1.0 - 1.9 years & 192 & 12.4 & $1.02(0.88-1.18)$ & $1.00(0.87-1.16)$ \\
\hline $2.0-2.9$ years & 117 & 14.9 & $1.25(1.04-1.50)^{*, c}$ & $1.23(1.03-1.48)^{*, c}$ \\
\hline 3.0 - 3.9 years & 40 & 9.9 & $0.86(0.63-1.17)$ & $0.84(0.62-1.15)$ \\
\hline $4.0-8.5$ years & 31 & 11.0 & $1.02(0.72-1.45)$ & $0.99(0.70-1.41)$ \\
\hline
\end{tabular}

DPP4-I: dipeptidyl peptidase 4 inhibitor; GLP1-RA: glucagon-like peptide 1 receptor agonist; HbA1c: glycosylated hemoglobin A1c; HR: hazard ratio; IR: incidence rate; NIAD: non-insulin anti-diabetic drug; py: person years. Current NIAD use: most recent NIAD prescription within 90 days before start of an interval. Past NIAD use: most recent prescription over 90 days before start of an interval. Past DPP4-I use: most recent prescription over 180 days before start of an interval. Recent DPP4-I use: most recent prescription within 91-180 before start of an interval. Current DPP4-I use: most recent prescription within 90 before start of an interval. * Statistically significant ( $p$-value <0.05). ${ }^{a}$ GLP1-RA use not shown, therefore the total numbers of fractures do not add up to the total number of fractures. ${ }^{b}$ Adjusted for: age, gender, body mass index, smoking status, HbA1c, use of antipsychotics, glucocorticoids, statins, anti-depressants, anti-hypertensives, anxiolytics/hypnotics, calcium/vitamin $d$, anti-osteoporotic drugs ${ }^{d}$, history of fracture, falls, secondary osteoporosis, retinopathy and neuropathy. ${ }^{\mathrm{C}}$ Statistically significant difference compared with no continuous duration of use, 0.5-1 year of continuous duration of use and 3-4 years of continuous duration of use, using Wald-test $(p<0.05){ }^{d}$ Use of bisphosphonates, raloxifene, strontium ranelate or parathyroid hormone/ calcitonin.

Any DPP4-I use was associated with a decreased risk of osteoporotic fracture but not with hip fracture (adj. HR osteoporotic fracture: 0.91 (95\% Cl: 0.84-0.98); hip fracture: 0.92 (95\% Cl: 0.79-1.06)). Current use of DPP4-Is was not associated with risk of osteoporotic (adj. HR: 0.96 (95\% Cl: 0.87-1.05)) or hip fracture (adj. HR: 0.96 (95\% Cl: 0.81-1.15)), Table 2.7.3. Both recent and past DPP4-I use showed a decreased risk of osteoporotic fracture (adj. HR recent DPP4-I use: 0.72 (95\% Cl: 0.52-0.99), past DPP4-I use: 0.84 (95\% Cl: 0.73-0.96)). Recent and past DPP4-I use were not associated with risk of hip fracture. Past NIAD use was associated with a reduced risk of major osteoporotic fracture and hip fracture. Current use of DPP4-Is stratified by continuous duration of use was not associated with risk of osteoporotic fracture nor with risk of hip fracture. 


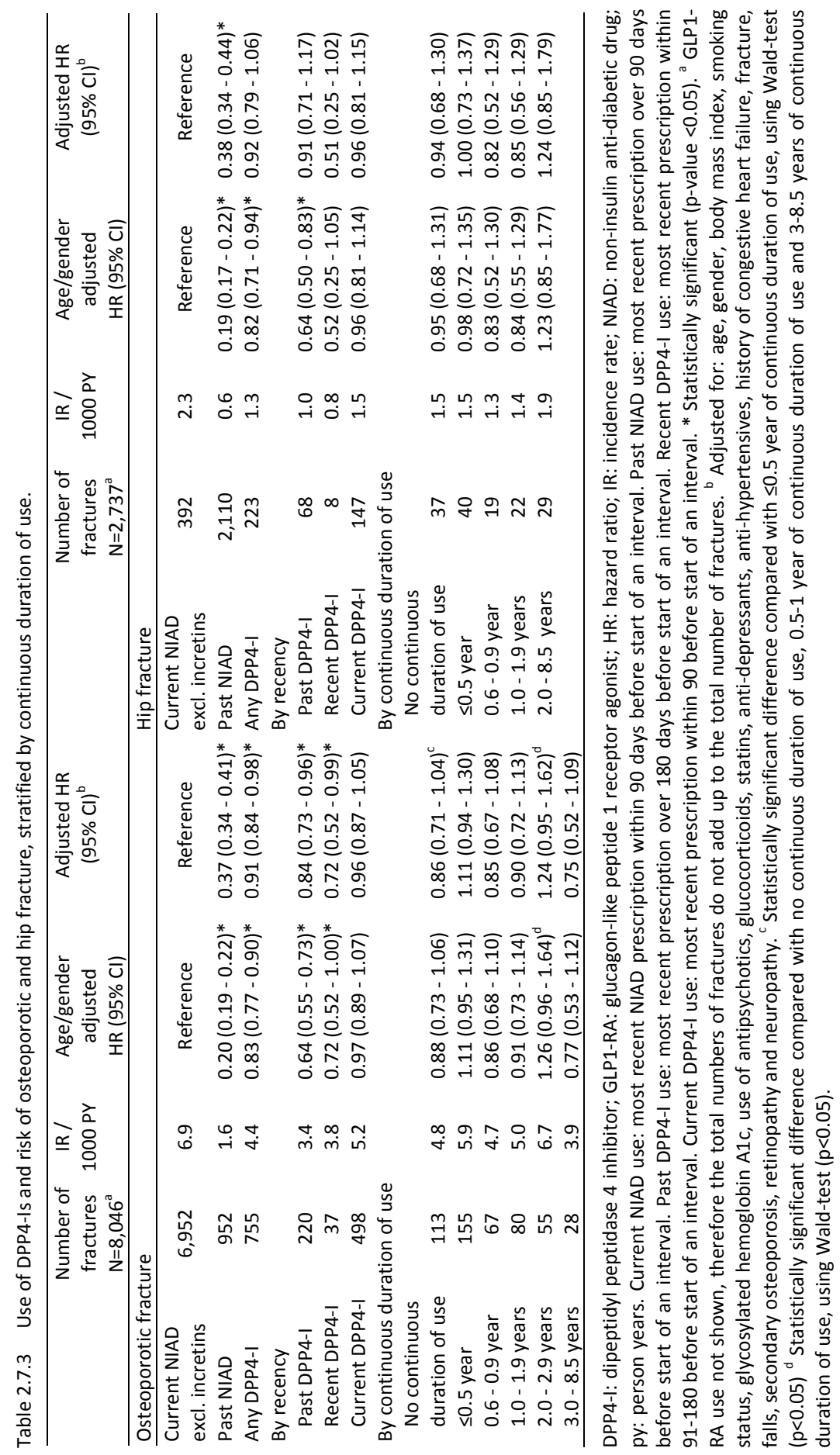


In the first sensitivity analysis we extended the gap between the expected end date of a prescription and the start of the next prescription to 60 and 90 days, respectively. When the gap was set to 60 days the results for risk of any, osteoporotic or hip fracture did not substantially change except for continuous duration of DPP4-I use of 2.0-2.9 years and risk of any fracture, which was not significant anymore (adj. HR: 1.04 ( $95 \% \mathrm{Cl}$ : $0.87-1.24)$ ). When the gap was set to 90 days similar results were seen: no materially altered results for risk of any, osteoporotic or hip fracture except with 2.0-2.9 years of DPP4-I use and risk of any fracture, which was not significantly any more (adj. HR: 1.04 (95\% Cl: 0.88-1.24)).

In a second sensitivity analysis the study population was restricted to new users of NIADs. Current DPP4-I use stratified by continuous duration of use categories was not associated with risk of any fracture. Additional adjustment for diabetes duration did not materially alter the results. In a third sensitivity analysis we excluded all patients with a history of a fracture. Current use of DPP4-Is stratified by continuous duration of use was not associated with risk of any fracture. Additional adjustments for current use of thiazolidinediones and sulfonylurea derivatives resulted in a significantly decreased risk of any fracture with current DPP4-I (adj. HR: 0.94 (95\% Cl: 0.88-1.00)).

\section{Discussion}

The present study showed that current use of DPP4-Is was not associated with risk of any, osteoporotic or hip fracture. After stratification by continuous duration of use we showed no association between the highest continuous duration of use category with any (>4.0-8.5 years of DPP4-I use), osteoporotic (>3.0-8.5 years of use) or hip (>2.0-8.5 years of use) fracture. Different sensitivity analyses confirmed the results of no association between current use of DPP4-Is and risk of any fracture.

Our results are in line with the results of two recently performed meta-analyses, which included 51 and 62 RCTs, respectively, comparing DPP4-Is to placebo or an active comparator $^{19,20}$. Both meta-analyses showed no association between use of DPP4-I and risk of fracture. The adverse events fracture data of a large clinical trial $(n=16,492)$ comparing saxagliptin, a DPP4-I, to placebo have been analysed in more depth and showed a relative risk of $1^{21}$. The present results are also supported by the results of an analysis on the fracture data of a cardiovascular trial comparing sitagliptin, a DPP4-I, to placebo in patients with T2DM $(n=14,671)$ which showed no association with risk of fracture $^{22}$.

The present results are also in keeping with our previous observational studies comparing current use of DPP4-Is to other NIADs ${ }^{8,9}$, with a meta-analysis of the observational studies ${ }^{23}$ and with an observational study comparing use of metformin and DPP4-I to non-use ${ }^{10}$. The present results are not in line with a meta-analysis including 28 RCTs comparing DPP4-Is to placebo or active treatment which showed a 
$40 \%$ reduced risk $^{7}$. However, the two updated meta-analyses showed no reduced risk of fracture with use of DPP4- ${ }^{19,20}$, suggesting that the large reduction of fracture risk found in the first meta-analysis might have been a consequence of the small number of included trials and the small number of reported fractures.

DPP4-Is increase the concentration of incretin hormones glucagon-like peptide 1 (GLP1) and gastric inhibitory polypeptide $(\mathrm{GIP})^{5}$. In vitro research has shown that GIP stimulates osteoblast differentiation ${ }^{24}$. Treatment with GLP1 has been associated with an increase in bone density in rodent models with osteopenia ${ }^{25,26}$. It was therefore hypothesized that DPP4-Is may reduce fracture risk. However in the current study we did not show a decreased risk of fracture with use of DPP4-Is. One of the explanations might be that DPP4-Is are still not used long enough to establish this reduced risk of fracture. However, a small group of patients used DPP4-Is continuously for more than four years, when studying risk of any fracture. Anti-hyperglycaemic drugs that have been associated with an unintended effect on bone, such as thiazolidinediones, showed this already after two years of use $\mathrm{e}^{27,28}$. In addition, bisphosphonates, used to prevent fractures, have shown a reduction in fracture risk after 18 months of use ${ }^{29,30}$. GIP and GLP1 have shown to be reduced in patients with T2DM ${ }^{31}$. It might be that due to the use of DPP4-Is the levels of GIP and GLP1 increase to the normal level, but not to higher levels required to have an effect on bone metabolism and in the end on fracture risk.

Current use of DPP4-Is was associated with an increased risk of any fracture when patients used it continuously for 2.0-2.9 years. Longer use was not associated with an increased fracture risk, which would be expected if DPP4-I use would increase fracture risk. In addition, in all sensitivity analyses this increased risk disappeared, suggesting that this increased risk was a chance finding. Unexpectedly, past NIAD use was associated with a $60 \%$ reduced risk of any fracture, which is hard to explain and should be interpreted with caution. Past NIAD use includes patients who are switched to insulin use. However, this has been associated with an increased and not a decreased risk of fracture ${ }^{32}$.

Strengths of this study include its large sample size as well as the representativeness of the used CPRD data for the general population of the United Kingdom. In addition, we were able to adjust for many potential important confounders in a time-dependent manner. We also had data on important life-style factors such as BMI and we had data on $\mathrm{HbA} 1 \mathrm{c}$. Moreover, we were able to investigate the association between current use of DPP4-Is for $>4.0-8.5$ years and risk of any fracture. Additionally, it has been shown that the CPRD fracture data has a high validity ${ }^{12}$.

Our study had also some limitations. For osteoporotic and hip fracture we had to lump the highest categories of continuous duration of use into $>3.0-8.5$ years and $>2.0-8.5$ years, respectively. Another limitation is that despite the fact that the followup period was extended with almost 3.5 years as compared to the previous observational studies ${ }^{8,9}$, the median duration of actual DPP4-I use only increased with 0.6 year. Future work could be beneficial to properly evaluate the associated between 
long duration of DPP4-I use and the effects on fracture risk, once the duration data has had sufficient time to mature. Moreover, although we were able to adjust for many confounders, residual confounding may be present.

We showed that current use of DPP4-Is was not associated with risk of any, osteoporotic, or hip fracture. Moreover, we showed that, when stratified by continuous duration of use, current use of DPP4-Is was not associated with a decreased risk of any (>4.0-8.5 years of DPP4-I use), osteoporotic (>3.0-8.5 years of DPP4-I use), or hip (>2.0-8.5 years of DPP4-I use) fracture. These findings may be of value for clinical decisions regarding treatment of T2DM patients, especially those at high fracture risk. 


\section{References}

1. Global report on diabetes. World Health Organization, Geneva, 2016.

2. Vestergaard P. Discrepancies in bone mineral density and fracture risk in patients with type 1 and type 2 diabetes--a meta-analysis. Osteoporos Int. 2007;18(4):427-44.

3. de Waard EA, van Geel TA, Savelberg $\mathrm{HH}$, Koster A, Geusens PP, van den Bergh JP. Increased fracture risk in patients with type 2 diabetes mellitus: an overview of the underlying mechanisms and the usefulness of imaging modalities and fracture risk assessment tools. Maturitas. 2014;79(3):26574.

4. Carnevale V, Romagnoli E, D’Erasmo E. Skeletal involvement in patients with diabetes mellitus. Diabetes Metab Res Rev 2004;20:196-204.

5. Mannucci E, Dicembrini I. Drugs for type 2 diabetes: role in the regulation of bone metabolism. Clin Cases Miner Bone Metab. 2015;12(2):130-4.

6. Dicker D. DPP-4 inhibitors: impact on glycemic control and cardiovascular risk factors. Diabetes Care. 2011;34:S276-8.

7. Monami M, Dicembrini I, Antenore A, Mannucci E. Dipeptidyl peptidase-4 inhibitors and bone fractures: a meta-analysis of randomized clinical trials. Diabetes Care. 2011;34(11):2474-6.

8. Driessen $\mathrm{JH}$, van Onzenoort $\mathrm{HA}$, Henry RM, Lalmohamed A, van den Bergh JP, Neef C, et al. Use of dipeptidyl peptidase-4 inhibitors for type 2 diabetes mellitus and risk of fracture. Bone. 2014;68:124-30.

9. Driessen JH, van Onzenoort HA, Starup-Linde J, Henry R, Neef C, van den Bergh J, et al. Use of dipeptidyl peptidase 4 inhibitors and fracture risk compared to use of other antihyperglycemic drugs. Pharmacoepidemiol Drug Saf. 2015;24(10):1017-25.

10. Choi HJ, Park C, Lee YK, Ha YC, Jang S, Shin CS. Risk of fractures and diabetes medications: a nationwide cohort study. Osteoporos Int. 2016 ;27(9):2709-15.

11. Herrett E, Gallagher AM, Bhaskaran K, Forbes $\mathrm{H}$, Mathur R, van Staa T, et al. Data Resource Profile: Clinical Practice Research Datalink (CPRD). Int J Epidemiol. 2015;44(3):827-36.

12. Van Staa TP, Abenhaim L, Cooper C, Zhang B, Leufkens HG. The use of a large pharmacoepidemiological database to study exposure to oral corticosteroids and risk of fractures: validation of study population and results. Pharmacoepidemiol Drug Saf. 2000;9(5):359-66.

13. Van Wijk BL, Klungel $\mathrm{OH}$, Heerdink ER, de Boer A. The association between compliance with antihypertensive drugs and modification of antihypertensive drug regimen. J Hypertens. 2004;22(9):1831-7.

14. Health and Social Care Information Centre: UK terminology centre-readcodes. http://systems. hscic.gov.uk/data/uktc/readcodes/index_html. Assessed: 20-7-2016.

15. FRAX. WHO Fracture Risk Assessment Tool. 2001. shef.ac.uk. www.shef.ac.uk/FRAX/ index.aspx. Assessed: 20-7-2016.

16. Su $B$, Sheng $H$, Zhang $M, B u L$, Yang $P$, $L i ~ L$, et al. Risk of bone fractures associated with glucagon-like peptide-1 receptor agonists' treatment: a meta-analysis of randomized controlled trials. Endocrine. 2015;48(1):10715.

17. Bazelier MT, Gallagher AM, van Staa TP, Cooper C, Leufkens HG, Vestergaard P et al. Use of Thiazolidinediones and risk of osteoporotic fracture: Disease or drugs? Pharmacoepidemiol Drug Saf. 2012;21(5):50714.

18. Vestergaard P, Rejnmark L, Mosekilde L. Relative fracture risk in patients with diabetes mellitus, and the impact of insulin and oral antidiabetic medication on relative fracture risk. Diabetologia. 2005;48(7):1292-9.

19. Mamza J, Marlin C, Wang C, Chokkalingam K, Idris I. DPP-4 inhibitor therapy and bone fractures in people with Type 2 diabetes - A systematic review and meta-analysis. Diabetes Res Clin Pract. 2016;116:288-98.

20. Fu J, Zhu J, Hao Y, Guo C, Zhou Z. Dipeptidyl peptidase- 4 inhibitors and fracture risk: an updated meta-analysis of randomized clinical trials. Sci Rep. 2016;6:29104.

21. Mosenzon O, Wei C, Davidson J, Scirica BM, Yanuv I, Rozenberg A, et al. Incidence of Fractures in Patients With Type 2 Diabetes in the SAVOR-TIMI 53 Trial. Diabetes Care. 2015;38(11):2142-50.

22. Josse RG, Majumdar SR, Zheng $Y$, Adler A, Bethel MA, Buse JB, et al. Sitagliptin and risk of fractures in type 2 diabetes: Results from the 
TECOS trial. Diabetes Obes Metab. 2017;19(1):78-86.

23. Driessen $\mathrm{JH}$, de Vries $\mathrm{F}$, van Onzenoort $\mathrm{HA}$, Harvey $\mathrm{HC}$, Neef $C$, van den Bergh JP, et al. The use of incretins and fractures - a meta-analysis on population-based real life data. $\mathrm{Br} J$ Clin Pharmacol. 2016. Epub ahead of print.

24. Bollag RJ, Zhong Q, Phillips $P$, et al. Osteoblastderived cells express functional glucosedependent insulinotropic peptide receptors. Endocrinology. 2000;141:1228-35.

25. Nuche-Berenguer B, Moreno P, Portal-Nuñez $S$, et al. Exendin-4 exerts osteogenic actions in insulin-resistant and type 2 diabetic states. Regul Pept. 2010;159:61-6.

26. Nuche-Berenguer $B$, Lozano D, Gutiérrez-Rojas I, et al. GLP-1 and exendin-4 can reverse hyperlipidic-related osteopenia. J Endocrinol. 2011;209:203-10.

27. Bazelier MT, Vestergaard P, Gallagher AM, van Staa TP, Cooper C, Leufkens HG et al. Risk of fracture with thiazolidinediones: disease or drugs? Calcif Tissue Int. 2012;26(9):2271-9.

28. Kahn S, Zinman B, Lachin JM, Haffner SM, Herman WH, Holman RR, et al. Diabetes
Outcome Progression Trial (ADOPT) Study Group. Rosiglitazone-associated fractures in type 2 diabetes: an Analysis from A Diabetes Outcome Progression Trial (ADOPT). Diabetes Care. 2008;31(5):845-51.

29. Black DM, Delmas PD, Eastell R, Reid IR, Boonen S, Cauley JA, et al. Once-yearly zoledronic acid for treatment of postmenopausal osteoporosis. N Engl J Med. 2007;356(18):1809-22.

30. McClung MR, Geusens P, Miller PD, Zippel H, Bensen WG, Roux C, et al. Effect of risedronate on the risk of hip fracture in elderly women. $\mathrm{N}$ Engl J Med. 2001;344(5):333-40.

31. Vilsboll T, Holst JJ. Incretins, insulin secretion and type-2 diabetes mellitus. Diabetologia. 2004;47:357-66.

32. Carnevale V, Romagnoli E, D'Erasmo E. Skeletal involvement in patients with diabetes mellitus. Diabetes Metab Res Rev. 2004;20(3):196-204. 



\section{Chapter 3}

Anti-hyperglycaemic drug use within the Maastricht Study population and potential unintended effects 


\section{Chapter}

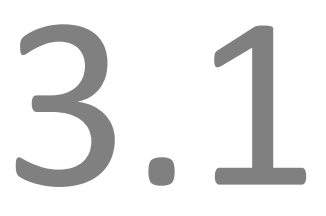

\section{Drug utilisation in the Maastricht Study: a comparison with nationwide data}

JHM Driessen, JTH Nielen, PC Dagnelie, A Boonen, B van den Bemt, HAW van Onzenoort, C Neef, RMA Henry, A Burden, SJS Sep, CJ van der Kallen, MT Schram, NC Schaper, CDA Stehouwer, JPW van den Bergh, L Smits, F de Vries

Submitted 


\section{Abstract}

\section{Introduction}

Within the southern region of the Netherlands, the Maastricht Study is an ongoing observational prospective population-based cohort study that focuses on the aetiology of type 2 diabetes mellitus (T2DM). Representativeness of the participating population is a crucial but often unknown factor in population-based cohort studies such as the Maastricht Study. Therefore the objective of the study was to assess the representativeness of the study population by comparing drug utilisation of the participants of the Maastricht Study with the general population of the Netherlands.

\section{Methods}

Since T2DM patients were oversampled in the Maastricht Study, a sampling method was applied in order to ensure a similar distribution of T2DM over the study population. Drug use in the study population was compared to drug use in the population of the Netherlands, using a Z-test test to compare two independent proportions.

\section{Results}

In general, drug use in the Maastricht Study was similar compared to national data. However, in patients aged 65-74 years total drug use was lower in the study population (833/1000 persons) versus nationwide data $(882 / 1000$ persons). The use of pulmonary medications was lower (104/1000 persons vs $141 / 1000$ persons) and the use of hypnotics/anxiolytics was higher (90/1000 persons vs 36/1000 persons) in the Maastricht Study as compared to national data.

\section{Conclusion}

Drug use in the Maastricht Study is largely comparable to that in the total Dutch population. Therefore, data on drug utilisation by participants in the Maastricht Study are useful for the assessment of drug utilisation or the association of drug use with outcomes. 


\section{Introduction}

In 2013 on average 677 out of 1000 inhabitants of the Netherlands received at least one drug prescription. This equals approximately 11.6 million inhabitants, which is $\sim 70 \%$ of the national population. It has been estimated that this has led to 4.3 billion euro nationwide annual costs for drugs in $2013^{1,2}$. In $2011,6.5 \%$ and $16.1 \%$ of the population aged 45-64 and 65-74 respectively have been diagnosed with type 2 diabetes mellitus (T2DM) ${ }^{3}$.

Interestingly, in the southern region of the Netherlands (Zuid-Limburg), drug use is higher as compared to the national average. Drug utilisation in this area in 2013 is estimated to be 720 users per 1000 insured inhabitants ${ }^{1}$. Within this region, the Maastricht Study is an on-going observational prospective population-based cohort study including individuals aged between 40 and 75 years living in the southern region of the Netherlands. Details regarding this study have been reported elsewhere ${ }^{4}$.

Representativeness of the participating population is a crucial but often unknown factor in population-based cohort studies such as the Maastricht Study. In order to extrapolate findings from this type of studies to the general population it is important to assess the representativeness of the study population and to be aware of deviations. More specifically, in order to compare results of drug outcome studies in studies such as the Maastricht Study to outcome studies in the general population drug use should be similar in these populations. Therefore, the objective of this study was to assess the representativeness of drug use of the Maastricht Study by comparing drug utilisation of the participants with the general population of the Netherlands.

\section{Methods}

\section{Data sources}

Data from the Maastricht Study and the Drug Information System of the National Health Care Institute ("Genees- en hulpmiddelen Informatie Project") were used ${ }^{2}$. The Maastricht Study is an observational prospective population-based cohort study. The study focuses on the aetiology, pathophysiology, complications and comorbidities of T2DM and is characterized by an extensive phenotyping approach. Eligible for participation were all individuals aged between 40 and 75 years and living in the southern part of the Netherlands. Participants were recruited through mass media campaigns and from the municipal registries and the regional Diabetes Patient Registry via mailings. Recruitment was stratified according to known T2DM status, with an oversampling of individuals with T2DM, for reasons of efficiency. The present report includes cross-sectional data from the first 3,451 participants, who completed the baseline survey between November 2010 and September 2013. The examinations of each participant were performed within a time window of three months. The study has 
been approved by the institutional medical ethical committee (NL31329.068.10) and the Minister of Health, Welfare and Sports of the Netherlands (Permit 131088-105234PG). All participants gave written informed consent. Information regarding drug use was available from electronic dispensing records obtained from community pharmacies. Aggregated national data on drug use per 1000 insured inhabitants of the Netherlands were available from the Drug Information System of the National Health Care Institute ("Genees- en hulpmiddelen Informatie Project").

\section{Study population}

This study was conducted in Maastricht Study participants who were included between 2011 and 2013. Participants younger than 45 and older than 74 years at the date of inclusion (index date) were excluded from the analyses, because aggregated national data were not available on drug use for these age categories. If no informed consent was given for the collection of pharmacy data, participants were excluded. Participants with a diagnosis of type 1 diabetes mellitus (T1DM) were excluded because they were clinically aberrant compared to both T2DM and other non-T2DM participants, Figure 3.1.1.

Two methods were applied in order to achieve a study population with $6.5 \%$ and 16.1\% T2DM patients aged $45-64$ and $65-74$ respectively $^{3}$. First, by randomly excluding patients with T2DM. Second, by randomly selecting non-T2DM patients with replacement in the selection pool. The age categories were selected based on the availability of national reference data.

\section{Random exclusion}

For the main analyses, T2DM patients were randomly excluded from the study population in order to achieve a distribution of T2DM representative for the general Dutch population. Consequently, the study population consisted of all participants without T2DM and a random sample of T2DM participants, Figure 3.1.1 (left panel). Sensitivity analyses were conducted in order to take into account age distribution within the previously specified categories. In these analyses, overrepresented age categories were reduced in order to achieve a population comparable with the national age distribution.

\section{Random selection}

In additional analyses all T2DM patients were retained and non-T2DM patients were randomly selected, with replacement in the selection pool. Non-T2DM patients may therefore have been included more than once in this population, while no data was lost by excluding T2DM patients, Figure 3.1.1 (right panel). 


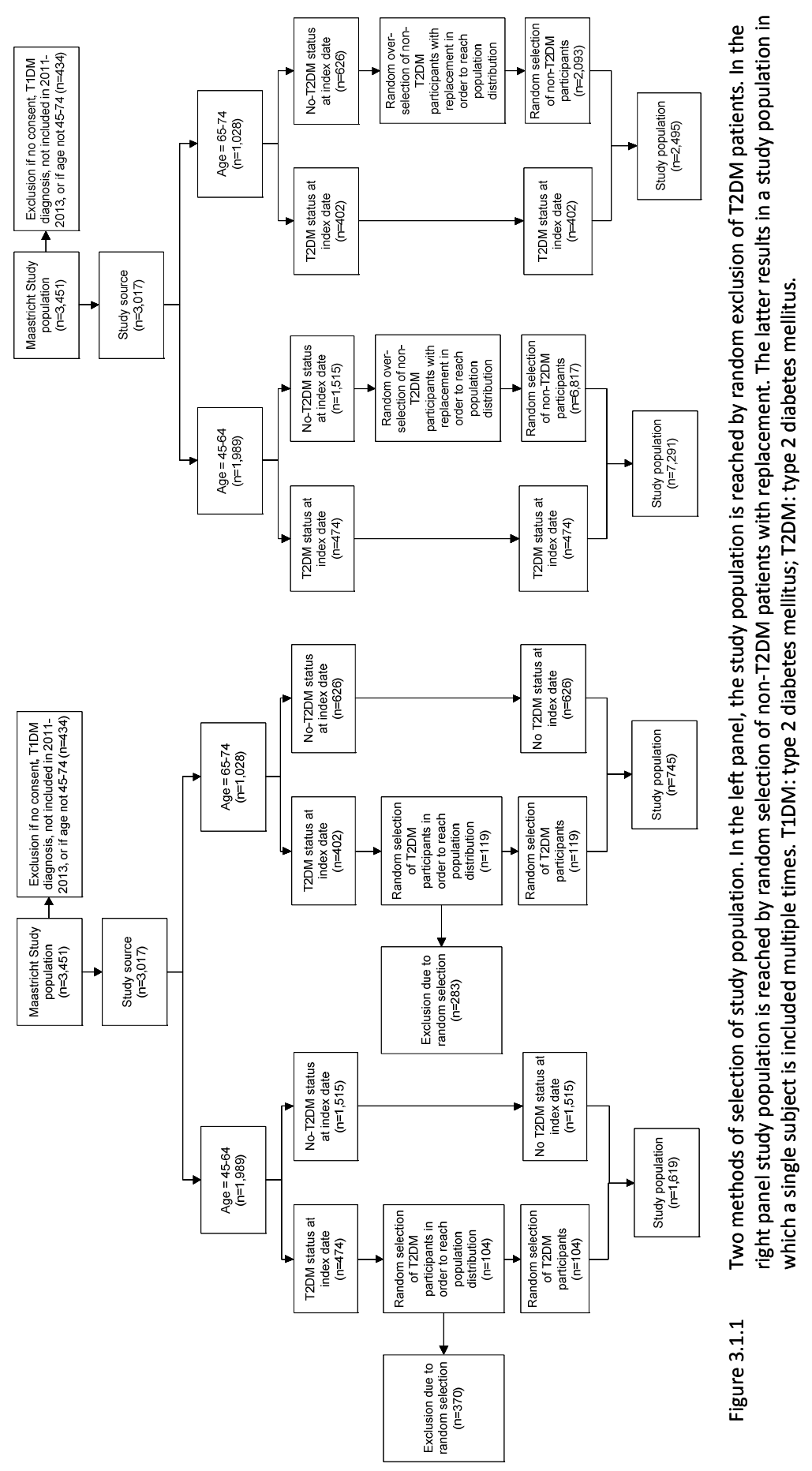




\section{Diabetes Mellitus status and drug exposure}

T2DM status was determined by an oral glucose tolerance test (OGTT). Participants with a fasting plasma glucose level of $\geq 7.0 \mathrm{mmol} / \mathrm{l}(126 \mathrm{mg} / \mathrm{dl})$ or a two hour plasma glucose level $\geq 11.1 \mathrm{mmol} / \mathrm{l}(200 \mathrm{mg} / \mathrm{dl})$ were defined as T2DM according to the World Health Organisation (WHO) guidelines. Others were defined as non-T2DM. Drug use in the year prior to index date was determined by at least one drug dispensing according to community pharmacy data. We calculated drug use per 1000 participants of the study population. Drug use in the year prior to index date took into account potential variability in seasonal prescription patterns. In order to deal with regulatory or guideline changes throughout the study period, patients contributed to drug exposure in two years, Supplementary Figure S3.1.1. The proportion contributing to a specific year depended on the index date. If the index date was July $1^{\text {st }} 2012$, a dispensing in the year prior contributed for $50 \%$ to 2012 and for $50 \%$ to 2011 . Consequently if the index date was April $1^{\text {st }} 2012$, a dispensing contributed for $25 \%$ to 2012 and for $75 \%$ to 2011. Drugs were classified according to the WHO's Anatomical Therapeutic Chemical classification (ATC) ${ }^{5}$. Drug use was categorized into the following groups (ATC codes): H2-receptor antagonists and PPIs (A02), lipid modifying drugs (C10), antihyperglycaemic drugs (A10), asthma/chronic obstructive pulmonary disease (COPD) (R03, R05CB), antidepressants (N06A), antipsychotics (N05A), and hypnotics/anxiolytics (N05BA, N05CD, N05CF).

\section{Statistical analysis}

We compared drug use in the study population in 2013 to nationwide drug use in the same year, using a Z-test test to compare two independent proportions. The Z-test allows an overlap of not more than $10 \%$ of the total population ${ }^{6}$.

\section{Results}

\section{Random exclusion}

Baseline characteristics of the national and the study populations are depicted in Table 3.1.1. On average, when compared to the national population, the study population aged $45-64$ years were older ( 56.5 years versus 54.6 years), while age was comparable for participants aged $65-74$ years ( 68.5 years versus 68.9 years). More specifically, there was an underrepresentation for the age categories 45-49 years, 50-54 years and 70-74 years in the study populations, and an overrepresentation among categories 55-59 years, 60-64 years and 65-69 years, when compared to the national population. Furthermore, among those aged 45-64 years, there were more females in the study population (55.8\%) compared to the national population (49.8\%), yet the opposite was observed for the 65-74 years category (study population: $44.0 \%$, national: $51.1 \%$ ). 
Table 3.1.2 presents the total drug use in the study population and the national population among those aged 45-64 years of age. For the year 2013, we identified that the total drug use was comparable between the study population $(687.0 / 1000$ persons 95\% [Confidence Interval ( $\mathrm{Cl}): 624.0-750.0 / 1000$ persons]) and the national population (718.8/1000 persons). The use of hypnotics/anxiolytics was significantly higher in the study population, as compared to the national population, while use of asthma/chronic obstructive pulmonary disease and H2-receptor antagonists and PPIs tended to be lower in the study population. However, only asthma/COPD use was significantly lower. All other medication use was similar between the two groups.

In the study population aged 65-74 years, Table 3.1.3, total drug use $(833.3 / 1000$ persons [95\% Cl: 758.5-908.2/1000 persons]) was significantly lower compared to the national population (881.8/1000 persons). Similar to the 45-64 age group, the use of hypnotics/anxiolytics was significantly higher, while the use of asthma/COPD and $\mathrm{H} 2$-receptor antagonists and PPIs was lower in the study population. Notably, there was no use of antipsychotic drugs in the study population aged 65-74.

Sensitivity analyses accounting for age distribution within the pre-specified age categories revealed similar results to our primary analysis, Table 3.1.4. In contrast to the primary analysis, among those aged 45-64 years, the use of lipid modifying medications was significantly higher, while the use of antipsychotics was significantly lower in the study population, as compared to the national population. In the analyses of the population aged 65-74 years, trends by specific drug remained consistent with our primary analysis; however, the total drug use was no longer significantly lower in the study population ( 865.9 [95\% Cl: $787.16-944.63 / 1000$ persons]) when compared to the national population (881.8/1000 persons).

\section{Random selection}

The study population consisting of all participants with T2DM, and a selection with replacement of participants without T2DM, Supplementary Table S3.1.1, showed similar baseline characteristics to the primary analysis (Table 3.1.1, i.e. study population of all participants without T2DM and a random exclusion of T2DM patients). In the population aged 45-64 years, the total drug use in the study population aged 45-64 years was comparable with drug use in the national population, Supplementary Table S3.1.2. Among the study population, the use of lipid modifying drugs (182.5/1000 persons [95\% Cl: 152.8-212.1/1000 persons]) and hypnotics/anxiolytics (67.9 95\% Cl: 48.6-87.1/1000) was significantly higher than among the national population (146.9/1000 persons and 31.2/1000 persons, respectively), while asthma/COPD drug use was significantly lower $(61.5 / 1000$ persons [95\% Cl: $43.1-80 / 1000$ persons] in the study population versus $97.6 / 1000$ persons in the national population). 


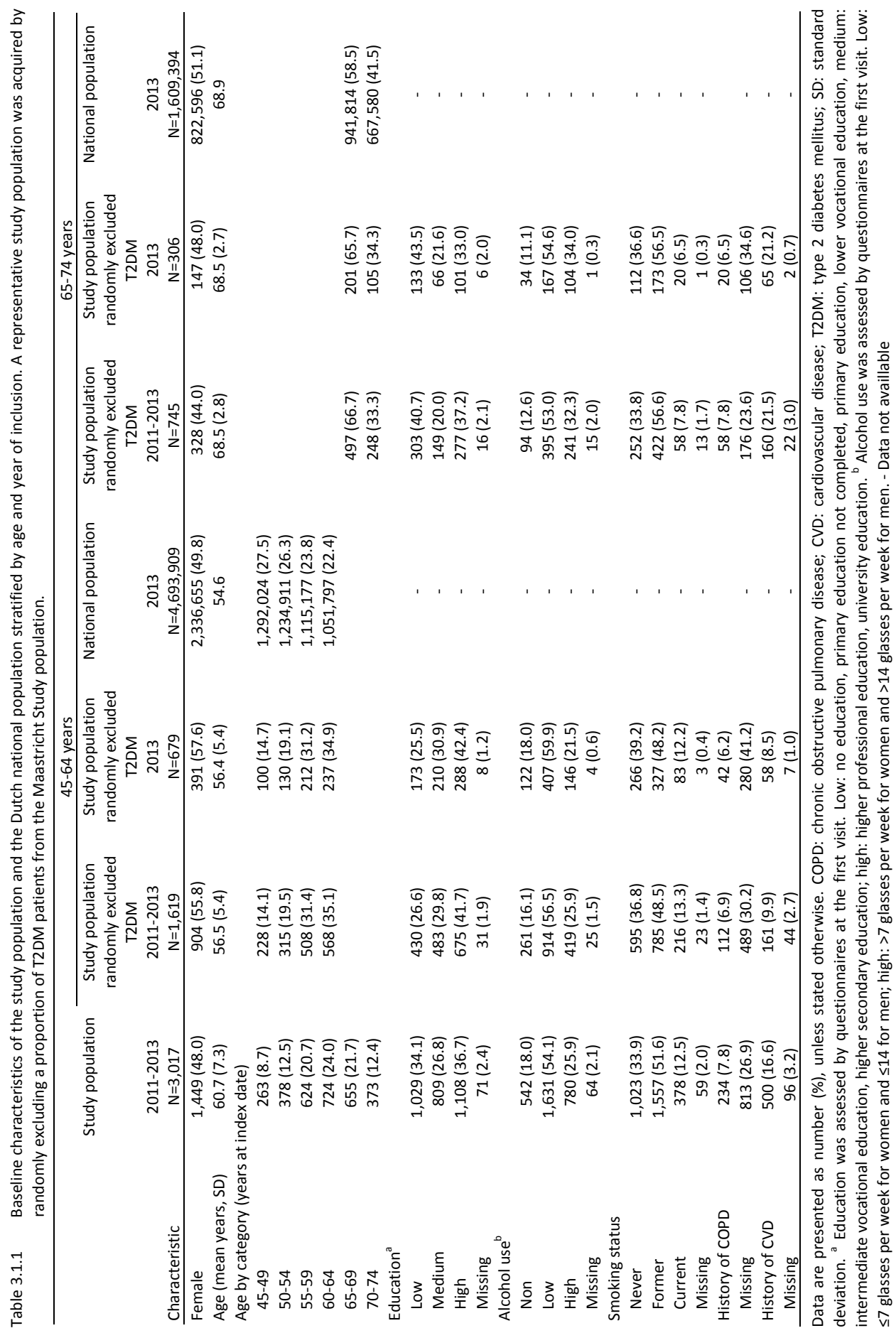



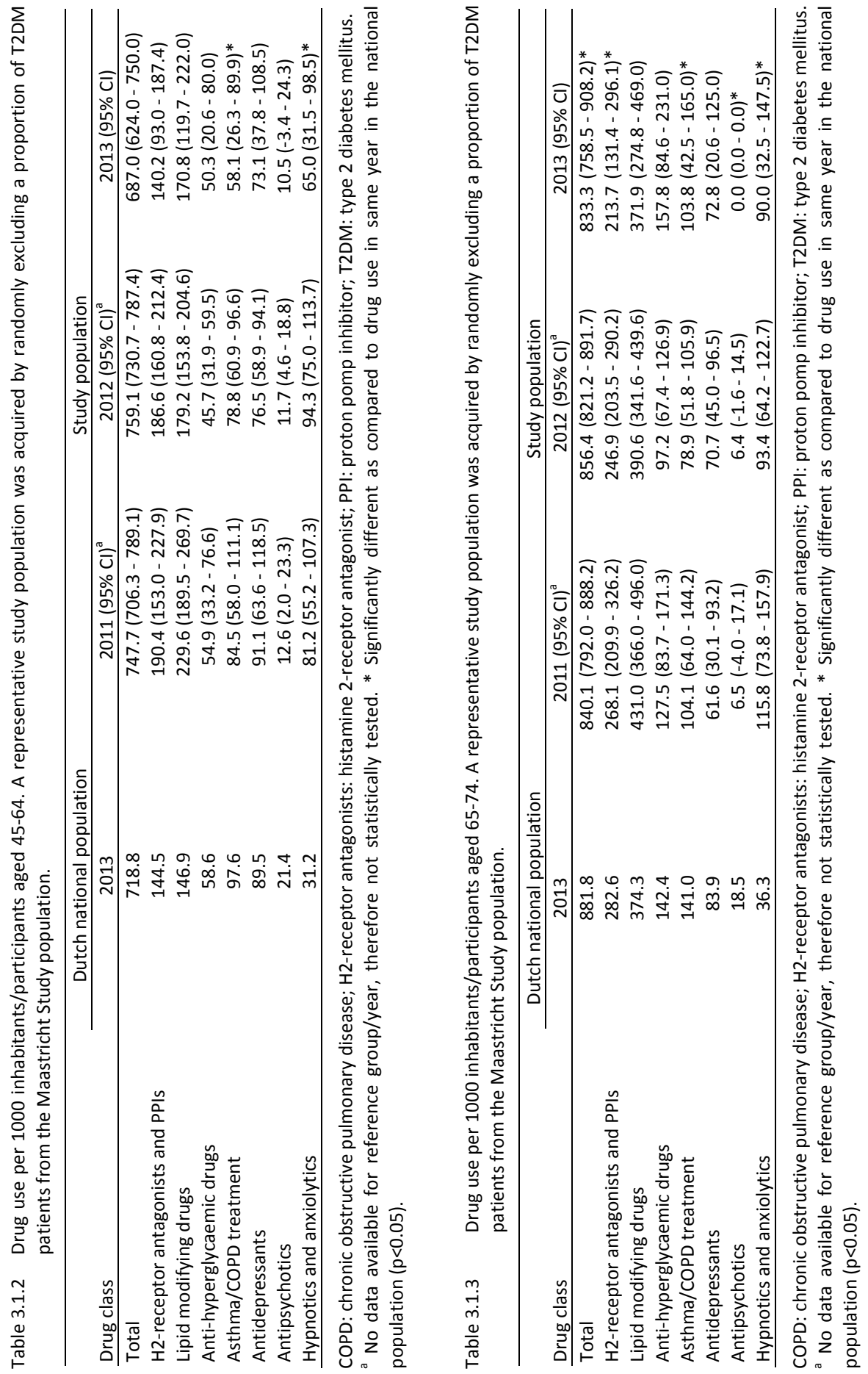


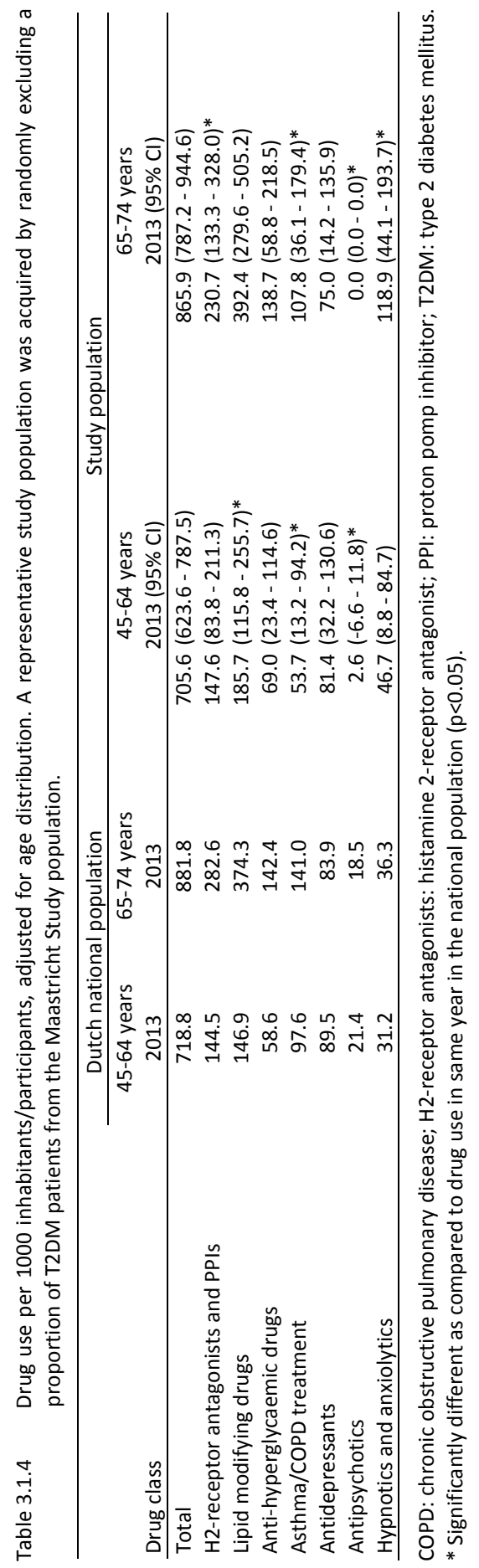


In the study population aged 65-74 years, total drug use was significantly lower (846.5/1000 persons [95\% Cl: 798.8-894.2/1000 persons]), when compared to the national population (881.8/1000 persons), Supplementary Table S3.1.3. Only the use of anti-depressants was comparable between the study population and the national population, while all other drugs showed significant differences. In particular, the study population showed higher use of anti-hyperglycaemic, lipid modifying, and hypnotics/anxiolytics medications, yet had lower use of asthma/COPD and H2-receptor antagonists and PPIs.

\section{Discussion}

\section{Random exclusion}

We identified that drug use in the study population was similar to national data. However, differences in drug use were present in some drug classes and across age groups. In all groups, our results suggest that the use of anti-hyperglycaemic drugs and lipid modifying drugs was similar, while there are significant differences for the use of pulmonary medications and the use of hypnotics/anxiolytics between the study population and the national population.

The use of anti-hyperglycaemic and lipid modifying drugs was similar between the study population and the national population. This is reassuring as we randomly sampled the Maastricht Study population in order to create a study population with $6.5 \%$ and $16.1 \%$ T2DM patients aged 45-64 and 65-74, respectively. Furthermore, lipid modifying drugs are commonly prescribed to patients with $\mathrm{T}_{2} \mathrm{DM}^{7,8}$. Therefore, similar use of this co-prescribed drug class is to be expected.

In order to evaluate differences and similarities in drug use between a populationbased study, such as the Maastricht Study, and the general population it is important to consider potential determinants for (non-)participation. Several factors that may be involved include the distance to a research facility ${ }^{9}$, medical history ${ }^{10,11}$, age ${ }^{11-13}$, $\operatorname{sex}^{12,14}$, race ${ }^{9,13}$, and education or income ${ }^{9,10,15}$.

Previous studies have identified an underrepresentation of age extremes in studies that depend on active recruitment. It has been suggested that the time required to participate may be problematic for those at working age or those of advanced age ${ }^{11-13}$. In our study we identified an underrepresentation of participants in the oldest age category (70-74 years). Since older patients are more likely to use a higher number of drugs, this may have caused the lower total drug use identified among the participants aged $65-74$ years $^{16}$.

Differential participation rates of patients with, and without, an extended medical history have been reported previously ${ }^{10,11}$. It is generally thought that an increased presence of comorbidities is associated with a decline in functional status, which may 
reduce participation rates ${ }^{11}$. Participation may especially be problematic for patients with pulmonary morbidities. This is consistent with the results in this study.

The increased rates of hypnotic/anxiolytic drug use may be caused by a regional effect and by differences in health perception. The use of these drugs is estimated at $27.6 / 1000$ inhabitants in the Zuid-Limburg area compared to $23.4 / 1000$ persons in the national population ${ }^{1}$. However, this does not fully explain the more than doubled rates found in this study. It may, however, be associated with the assumption that a generally healthier, but care seeking population is more likely to participate in a study, such as the Maastricht Study ${ }^{15}$. Individuals from this population are concerned about their health and may therefore visit their general practitioner for unexplained complaints.

Sensitivity analyses that accounted for age distribution showed only minor differences with the primary analyses. In the population aged 45-64 this procedure mainly resulted in the exclusion of a proportion of participants between 55-64 years. It was expected this would result in a reduction of drug utilisation compared to the primary analyses. Surprisingly the opposite was true. This may be explained by the fact that by reducing the proportion of participants, while retaining a population with $6.5 \%$ T2DM, predominantly healthier participants were excluded. This effect was less pronounced in the population aged 65-74 years. This is possibly due to smaller differences in drug utilisation between participants aged 65-69 and participants aged 70-74 years.

\section{Random selection}

In comparison with the random exclusion population, analyses using the randomly selected population resulted in more significant differences between the study population and the national population, especially in the population aged 65-74 years. This is most likely due to a larger sample size, consequently leading to smaller confidence intervals. However, this method may be less valid. By randomly selecting participants with replacement in the selection pool the study population will have less variation than expected when the same sample size is achieved by including new subjects in the study.

\section{Strengths and limitations}

The major strength of this study was the availability of detailed dispensing data of the Maastricht Study participants, not only on the index date but also up to several years prior to index date. This enabled us to take drug dispensings that were no longer active at index date into account.

A limitation of this study was the restricted availability of regional drug use data. Drug use in the Zuid-Limburg area is generally higher than the national drug utilisation ${ }^{1}$. However, in this study we identified drug use that is largely comparable to national 
rates. Consequently, there appeared to be an overall participation bias towards a relatively healthy or health-conscious study population. As described previously, this is a known phenomenon in studies such as the Maastricht Study ${ }^{10,11}$. The relatively low drug utilisation may also be explained by misclassification of participants with T2DM. In this study they were classified based on an OGTT. However, T2DM is known to be undetected and untreated in a considerable proportion of the population. We may have therefore categorized participants as T2DM patients, while this may have been unknown to their general practitioner. Consequently, these patients did not receive pharmacological treatment as would have been expected for a T2DM patient. Arguably they should therefore have been classified as non-T2DM. However, in the population aged 45-64 approximately $0.4-1.0 \%$ was newly diagnosed based on the OGTT, and in the population aged $65-74$ this was the case for $1.3-1.7 \%$. We therefore expect this misclassification would not have affected the results.

Due to limited availability of national drug use data we were only able to compare drug use in 2013. However, we expect that results would have been comparable in other years, since recruitment methods were similar across the years. Furthermore, we were unable to compare other drug classes, such as drugs used for cardiovascular diseases. This would have been interesting, but not essential for the objective of this study. The statistical procedure used to compare the study populations may also have its limitations. The Z-test is partly affected by the absolute difference between the populations. Therefore in the case of small numbers a factor 2 difference may result in a non-significant difference, whereas a factor 1.1 may trigger a significant difference in the case of higher numbers.

\section{Conclusion}

Drug use in the Maastricht Study appears to be largely representative for drug use in the national population. Therefore, data from this study could be used to assess drug utilisation or when studying the relative risk of specific outcomes associated with drug use. However, care should be taken when examining outcomes associated with the use of pulmonary drugs since functional impairment may have biased participation. In general, when conducting drug use studies using a cohort study, such as the Maastricht Study, it is important to assess representativeness of drug use and to be aware of deviating drug classes. 


\section{References}

1. GIP: Genees- en hulpmiddelen Informatie Project (Zorginstituut Nederland) accessible through: http://www.zorgatlas.nl/zorg/ genees- en-hulpmiddelen/geneesmiddelengebruik/gebruikers-geneesmiddelen-perzorgkantoorregio/\#breadcrumb. Assessed: 176-2015.

2. Genees- en hulpmiddelen Informatie Project, GIPeiling 2013,2014;35:46-52.

3. NIVEL. accessible through: http://www.nivel.nl/nl/incidentie-enprevalentiecijfers-in-de-huisartsenpraktijk Assessed: 3-2-2016.

4. Schram MT, Sep SJ, van der Kallen CJ, Dagnelie PC, Koster A, Schaper N, et al. The Maastricht Study: an extensive phenotyping study on determinants of type 2 diabetes, its complications and its comorbidities. Eur J Epidemiol. 2014;29(6):439-51.

5. WHO's ATC/DDD index 2016, accessible through: http://www.whocc.no/atc_ddd_ index/ (5th April 2016).

6. Hayes LJ, Berry G. Comparing the part with the whole: should overlap be ignored in public health measures? J Public Health (Oxf). 2006;28(3):278-82.

7. Wijnands $\mathrm{JM}$, van Durme $\mathrm{CM}$, Driessen $\mathrm{JH}$, Boonen A, Klop C, Leufkens B, et al. Individuals With Type 2 Diabetes Mellitus Are at an Increased Risk of Gout But This Is Not Due to Diabetes: A Population-Based Cohort Study. Medicine (Baltimore). 2015;94(32):e1358.

8. Knapen LM, van Dalem J, Keulemans YC, van Erp NP, Bazelier MT, De Bruin ML, et al. Use of incretin agents and risk of pancreatic cancer: a population-based cohort study. Diabetes Obes Metab. 2016;18(3):258-65.
9. Linne A, Leander K, Lindström D, Törnberg S, Hultgren R. Reasons for non-participation in population-based abdominal aortic aneurysm screening. Br J Surg. 2014;101(5):481-7.

10. Jackson R, Chambless LE, Yang K, Byrne T, Watson $R$, Folsom $A$, et al. Differences between respondents and nonrespondents in a multicenter community-based study vary by gender ethnicity. The Atherosclerosis Risk in Communities (ARIC) Study Investigators. J Clin Epidemiol. 1996;49(12):1441-46.

11. Jacobsen SJ, Mahoney DW, Redfield MM, Bailey KR, Burnett JC Jr, Rodeheffer RJ. Participation bias in a population-based echocardiography study. Ann Epidemiol. 2004;14(8):579-84.

12. Slattery ML, Edwards SL, Caan BJ, Kerber RA, Potter JD. Response rates among control subjects in case-control studies. Ann Epidemiol. 1995;5(3):245-9.

13. Moorman PG, Newman B, Millikan RC, Tse CK, Sandler DP. Participation rates in a casecontrol study: the impact of age, race, and race of interviewer. Ann Epidemiol. 1999;9(3):18895.

14. Olson SH. Reported participation in casecontrol studies: changes over time. Am J Epidemiol. 2001:15;154(6):574-81.

15. Lorant V, Demarest S, Miermans PJ, Van Oyen $\mathrm{H}$. Survey error in measuring socio-economic risk factors of health status: a comparison of a survey and a census. Int J Epidemiol. 2007;36(6):1292-9.

16. Statline, Centraal bureau voor de Statistiek http://statline.cbs.nl/Statweb/publication/. Table with number of persons with a certain drug prescribed stratified by age and sex. Assessed: 18-3-2016. 


\section{Supplementary material}

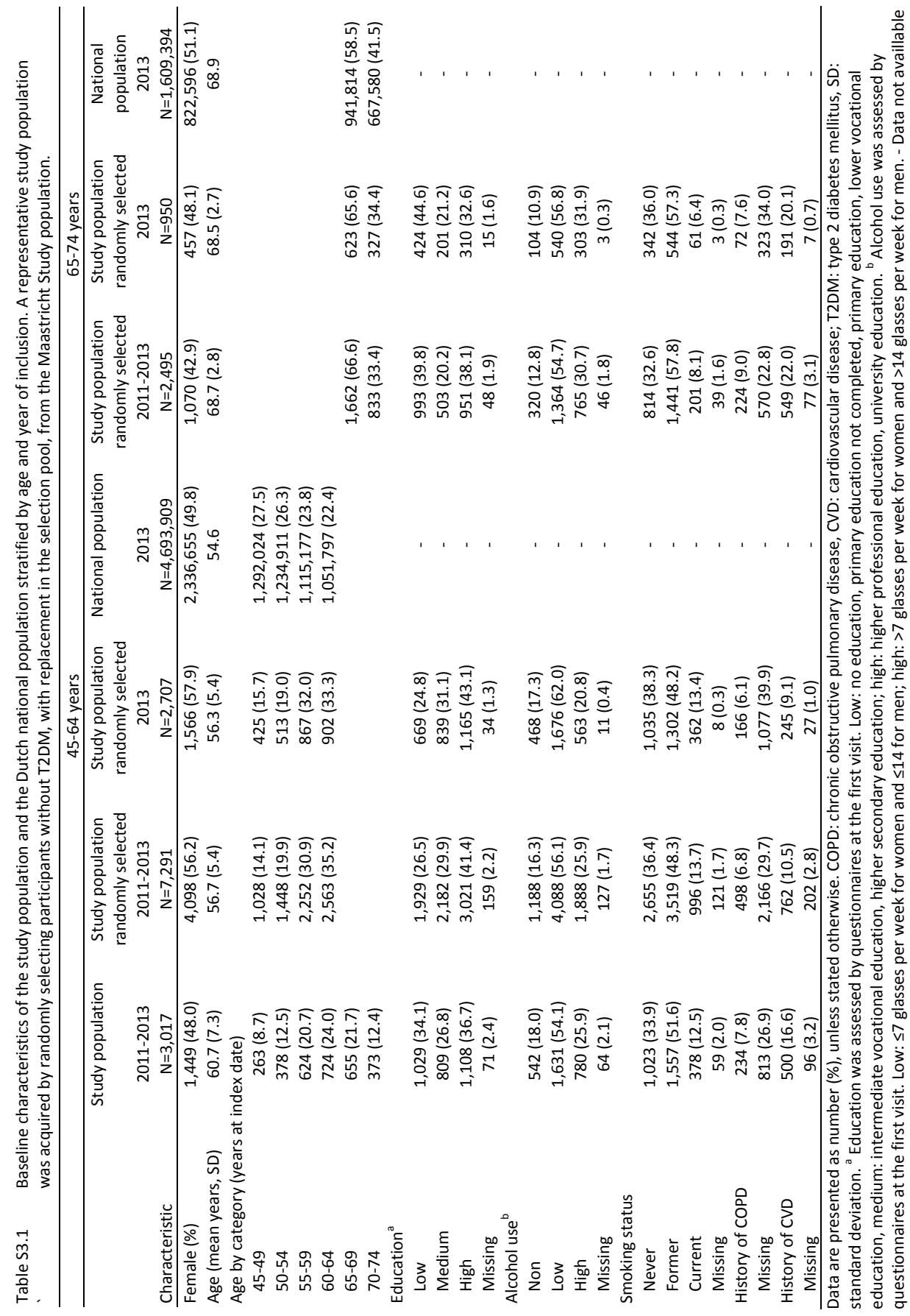


Table S3.1.2 Drug use per 1000 inhabitants/participants aged 45-64. A representative study population was acquired by randomly selecting participants without T2DM, with replacement in the selection pool, from the Maastricht Study population.

\begin{tabular}{lcccc}
\hline \multicolumn{4}{c}{$\begin{array}{c}\text { Dutch national } \\
\text { population }\end{array}$} & \multicolumn{3}{c}{ Study population } \\
\cline { 2 - 5 } Drug class & 2013 & $2011(95 \% \mathrm{Cl})^{\mathrm{a}}$ & $2012(95 \% \mathrm{Cl})^{\mathrm{a}}$ & $2013(95 \% \mathrm{Cl})$ \\
\hline Total & 718.8 & $755.0(734.2-775.8)$ & $760.7(745.7-775.7)$ & $699.0(663.8-734.2)$ \\
H2-receptor antagonists and PPIs & 144.5 & $184.3(165.5-203.0)$ & $189.4(175.6-203.1)$ & $147.2(120.0-174.3)$ \\
Lipid modifying drugs & 146.9 & $246.5(225.7-267.4)$ & $190.7(176.9-204.5)$ & $182.5(152.8-212.1)^{*}$ \\
Anti-hyperglycaemic drugs & 58.6 & $64.7(52.8-76.6)$ & $53.9(46.0-61.9)$ & $68.7(49.3-88.1)$ \\
Asthma/COPD treatment & 97.6 & $95.3(81.1-109.5)$ & $74.6(65.4-83.8)$ & $61.5(43.1-80.0)^{*}$ \\
Antidepressants & 89.5 & $97.7(83.3-112.0)$ & $78.7(69.2-88.1)$ & $77.0(56.6-97.5)$ \\
Antipsychotics & 21.4 & $14.0(8.3-19.7)$ & $10.0(6.5-13.5)$ & $7.7(1.0-14.4)^{*}$ \\
Hypnotics and anxiolytics & 31.2 & $71.6(59.2-84.1)$ & $91.2(81.1-101.4)$ & $67.9(48.6-87.1)^{*}$ \\
\hline
\end{tabular}

COPD: chronic obstructive pulmonary disease; H2-receptor antagonists: histamine 2-receptor antagonist; PPI: proton pomp inhibitor; T2DM: type 2 diabetes mellitus. ${ }^{a}$ No data available for reference group/year, therefore not statistically tested.

* Significantly different as compared to drug use in same year in the national population $(p<0.05)$.

Table S3.1.3 Drug use per 1000 inhabitants/participants aged 65-74. A representative study population was acquired by randomly selecting participants without T2DM, with replacement in the selection pool, from the Maastricht Study population.

Dutch national

\begin{tabular}{lcccc}
\multicolumn{4}{c}{$\begin{array}{c}\text { Dutch national } \\
\text { population }\end{array}$} & \multicolumn{3}{c}{ Study population } \\
\cline { 2 - 5 } Drug class & 2013 & $2011(95 \% \mathrm{Cl})^{\mathrm{a}}$ & $2012(95 \% \mathrm{Cl})^{\mathrm{a}}$ & $2013(95 \% \mathrm{Cl})$ \\
\hline Total & 881.8 & $834.5(804.6-864.4)$ & $846.0(823.0-869.0)$ & $846.5(798.8-894.2)^{*}$ \\
H2-receptor antagonists and PPIs & 282.6 & $274.0(238.1-309.9)$ & $233.6(206.6-260.6)$ & $216.0(161.5-270.4)^{*}$ \\
Lipid modifying drugs & 374.3 & $445.4(405.4-485.4)$ & $409.9(378.5-441.3)$ & $423.7(358.3-489.1)^{*}$ \\
Anti-hyperglycaemic drugs & 142.4 & $171.9(141.5-202.2)$ & $144.3(121.9-166.7)$ & $223.5(168.3-278.6)^{*}$ \\
Asthma/COPD treatment & 141.0 & $123.1(96.7-149.5)$ & $75.4(58.6-92.3)$ & $104.7(64.2-145.3)^{*}$ \\
Antidepressants & 83.9 & $47.6(30.4-64.7)$ & $70.6(54.3-87.0)$ & $64.3(31.8-96.8)$ \\
Antipsychotics & 18.5 & $4.0(-1.1-9.2)$ & $4.8(0.4-9.2)$ & $0.0(0.0-0.0)^{*}$ \\
Hypnotics and anxiolytics & 36.3 & $104.2(79.7-128.8)$ & $98.4(79.4-117.4)$ & $90.1(52.2-128.1)^{*}$ \\
\hline
\end{tabular}

COPD: chronic obstructive pulmonary disease; $\mathrm{H} 2$-receptor antagonists: histamine 2-receptor antagonist; PPI: proton pomp inhibitor; T2DM: type 2 diabetes mellitus. ${ }^{a}$ No data available for reference group/year, therefore not statistically tested. * Significantly different as compared to drug use in same year in the national population $(p<0.05)$.

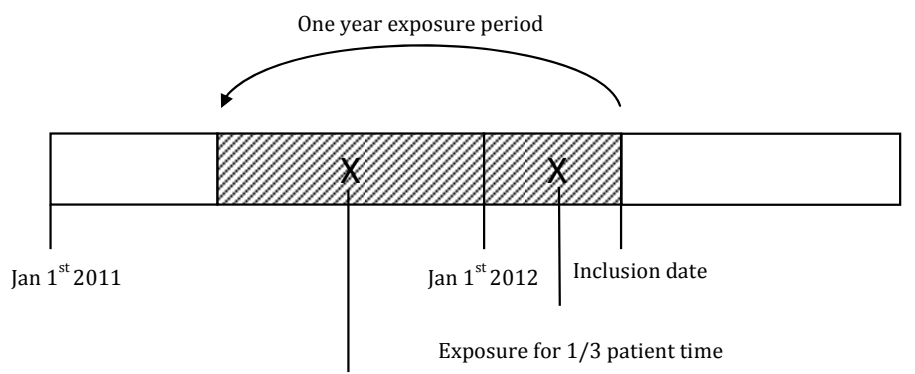

Exposure for $2 / 3$ patient time

Figure S3.1.1 Exposure definition ( $\mathrm{X}=$ dispensing). 


\section{Chapter}

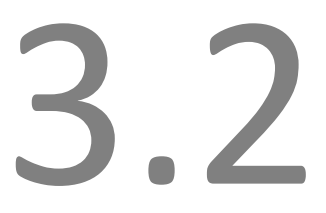

The association between insulin use and

volumetric bone mineral density, bone microarchitecture and bone strength of the distal radius in patients with T2DM - the Maastricht Study

JHM Driessen, EAC de Waard, JJA de Jong, TACM van Geel, RMA Henry, HAW van Onzenoort, MT Schram, PC Dagnelie, CJ van der Kallen, SJS Sep, CDA Stehouwer, NC Schaper, A Koster, HHCM Savelberg, C Neef, F de Vries, JPW van den Bergh

Pending Revisions 


\section{Abstract}

\section{Introduction}

Type 2 diabetes mellitus (T2DM) has been associated with an increased risk of fractures, despite normal to increased bone mineral density (BMD). Insulin use is one of the factors associated with this increased fracture risk. However, direct negative effects of insulin on bone quality are not expected since insulin is thought to be anabolic to bone. In this study we examined the association between insulin use and volumetric BMD (VBMD), bone micro-architecture and strength, as measured with high-resolution peripheral quantitative computed tomography (HRpQCT).

\section{Methods}

In this cross-sectional study, data was used from 51 participants of the Maastricht Study (mean age 62 (SD 7.5) years, 44\% women). These participants had a diagnosis of T2DM based on an oral glucose tolerance test, medication history at baseline and/or a dispensing of an antihyperglycaemic drug in the six months prior to the HR-pQCT scan. Participants were classified as insulin user $(n=13)$ or non-insulin user $(n=38)$ based on dispensing data. Multivariable linear regression analysis was used to estimate the association between current insulin use and HRPQCT derived parameters.

\section{Results}

After adjustment for age, sex, body mass index, glycosylated hemoglobin A1c and T2DM duration, current insulin use was associated with a lower total VBMD (B: -100.75 (95\% Cl: -155.01 - -46.48)), trabecular vBMD (B: -57.55 (95\% Cl: -83.77 - -31.33)), cortical vBMD (B: -63.23 (95\% Cl: $-126.16--0.31))$, trabecular thickness (B: $-0.02(95 \% \mathrm{Cl}-0.02--0.01))$, cortical thickness $(-0.24$ (95\% Cl: $-0.43--0.06))$, log cortical pore volume (B: $-0.45(95 \% \mathrm{Cl}:-0.77--0.13))$, bone stiffness (B: -23.58 (95\% Cl: $-36.79--10.36)$ ) and failure load (B: -1069.87 (95\% Cl: $-1673.03--466.71)$ ) when compared to the non-insulin users. Current insulin use was not associated with trabecular number, trabecular separation, cortical porosity and cortical pore diameter.

\section{Conclusion}

Current insulin use was associated with compromised VBMD, bone micro-architecture and strength. This is the first study indicating that insulin use is negatively associated with bone micro-architectural and bone strength parameters. These findings may partly explain the previously observed increased fracture risk in insulin users. However, there may be confounding by disease severity and therefore replication of our findings in larger and prospective studies is needed. 


\section{Introduction}

Type 2 diabetes mellitus (T2DM) is a highly prevalent chronic disease and is well known for its classic complications such as neuropathy, retinopathy and nephropathy ${ }^{1}$. More recently, T2DM has been associated with an increased risk of fractures, despite a normal to increased bone mineral density $(B M D)^{2,3}$. The mechanisms leading to this increased fracture risk are not completely elucidated, but it is hypothesized that the increased fracture risk is the consequence of an increased falling frequency and increased bone fragility ${ }^{4}$. Some previous studies indeed showed that T2DM is associated with unfavorable changes in bone micro-architecture and bone strength, which may result in increased bone fragility ${ }^{5,6}$.

Most T2DM patients are treated with anti-hyperglycaemic drugs to reach a normoglycemic state. Oral anti-hyperglycaemic drugs are not associated with an increased fracture risk, except for thiazolidinediones ${ }^{7,8}$. In addition, insulin use has been associated with an increased fracture risk ${ }^{9}$. Since previous studies showed that insulin may be anabolic to bone ${ }^{10}$, it has been hypothesized that the increased fracture risk in insulin users is not caused by the drug itself, but is due to an increased falling frequency and to long-term negative effects of hyperglycaemia on bone quality, as insulin is most often used in patients with long disease duration.

The association between hyperinsulinemia and areal BMD, as measured with dual Xray absorptiometry (DXA), in nondiabetic participants has been examined in several studies. These studies showed a positive association between hyperinsulinemia and areal $\mathrm{BMD}^{11-13}$. Up to this date, only two small studies examined the association between insulin therapy and BMD in patients with T2DM, and showed a positive correlation between insulin dose and $\mathrm{BMD}^{14,15}$. The effect of insulin therapy on bone volumetric BMD (vBMD), micro-architecture and strength is currently unknown.

High-resolution peripheral quantitative computed tomography (HR-pQCT) is a relatively new technique which can be used to measure $\mathrm{VBMD}$, micro-architecture and bone strength ${ }^{16,17}$. The association between insulin use and bone mechanic parameters measured by HR-pQCT has not been studied before ${ }^{8}$. Therefore, the aim of this study was to examine the association between the insulin use, and VBMD, bone microarchitecture and bone strength in participants with T2DM. It is hypothesized that insulin use will be positively associated with HR-pQCT derived parameters when compared to non-insulin use.

\section{Methods}

\section{Source population}

Data from the Maastricht Study, an ongoing observational prospective populationbased cohort study was used in the present study. The rationale and methodology have 
been described previously ${ }^{18}$. In brief, the study focuses on the etiology, pathophysiology, complications and comorbidities of T2DM and is characterized by an extensive phenotyping approach. Eligible for participation were all individuals aged between 40 and 75 years and living in the southern part of the Netherlands. Participants were recruited through mass media campaigns and from the municipal registries and the regional Diabetes Patient Registry via mailings. Recruitment was stratified according to known T2DM status, with an oversampling of individuals with T2DM, for reasons of efficiency.

To determine glucose metabolism status, all participants, except those who used insulin, underwent a standardized 2-h $75 \mathrm{~g}$ oral glucose tolerance test (OGTT) after an overnight fast. For safety reasons, participants with a fasting glucose level $>11.0 \mathrm{mmol} / \mathrm{l}$ (>200.0 mg/dl), as determined by a capillary blood glucose measurement, did not undergo the OGTT. Fasting glucose level, 2-h plasma glucose level and information about diabetes medication were used to determine glucose metabolism status. Participants were classified as having T2DM when they had a fasting plasma glucose level $\geq 7.0 \mathrm{mmol} / \mathrm{l}(\geq 126 \mathrm{mg} / \mathrm{dl})$ or a two hour plasma glucose level $\geq 11.1 \mathrm{mmol} / \mathrm{l}$ $\left(\geq 200 \mathrm{mg} / \mathrm{dl}\right.$ ) as specified by the World Health Organization guidelines ${ }^{19}$ or if they used anti-hyperglycaemic drugs at baseline. Individuals without type 1 diabetes mellitus who used anti-hyperglycaemic drugs were classified as having T2DM. Participants who were not classified as T2DM, but did use an anti-hyperglycaemic drug in the six months prior to the date of the HR-pQCT scan (based on their pharmacy dispensing data) were also included.

The present study includes cross-sectional data from participants with T2DM, who completed the baseline survey between November 2010 and September 2013 and returned to the research centre between March 2015 and February 2016 for the HRpQCT scan of the distal radius. Dispensing records were collected at the pharmacy for all participants who gave written informed consent for the collection of their drug dispensing history. Dispensing data was available from January $1^{\text {st }} 1991$ up to the date of the HR-pQCT scan and contained the product name, the anatomical therapeutical chemical (ATC) $\operatorname{code}^{20}$, the dispensed quantity, the dispensing date and the prescribed daily dose ${ }^{21}$.

The study has been approved by the institutional medical ethical committee (NL31329.068.10) and the Minister of Health, Welfare and Sports of the Netherlands (Permit 131088-105234-PG) and the Netherlands Health Council under the Dutch Law for Population Studies (Permit: I-1227-13/LvR/bp/894-A47). All participants gave written informed consent.

\section{Study population}

When a participant had a dispensing for insulin (ATC code A10A) in the six months before the date of the HR-pQCT scan, the participant was classified as current insulin 
user. All other T2DM participants were classified as non-insulin users. The mean time since first insulin dispensing was calculated from the pharmacy data. Participants with a diagnosis of type 1 diabetes mellitus were excluded from the analyses.

\section{HR-pQCT imaging}

The non-dominant radius was scanned on a HR-pQCT scanner (Xtreme-CT; Scanco Medical AG, Brüttisellen, Switzerland) using the standard in vivo protocol as described in literature ${ }^{22,23}$. In case of a history of a distal radius fracture at the non-dominant site, the dominant site was scanned. The forearm was placed into a carbon fiber cast. An anteroposterior scout projection of the scan site was acquired for positioning of the tomographic acquisition. A reference line was placed on the radial joint surface. The scan volume spanned $9.02 \mathrm{~mm}$ in length and started $9.5 \mathrm{~mm}$ from the reference line in the proximal direction. Images were reconstructed using an isotropic voxelsize of 82 $\mu \mathrm{m}$, thus resulting in 110 consecutive slices. Total scan time was 2.8 minutes, with each acquisition resulting in an effective dose of approximately $3 \mu \mathrm{Sv}$. All scans were graded with regard to motion, and scans with quality 4 or 5 were repeated once ${ }^{24}$. Only scans with quality 1 to 3 (grade 1: no motion artifacts, grade 2: minor motion artifacts, grade 3: moderate motion artifacts) were used for subsequent image analysis ${ }^{25}$.

\section{Image analysis of HR-pQCT scans}

All scans were evaluated using the standard patient evaluation protocol that was provided by the manufacturer and that has been described previously in detail ${ }^{26-28}$. First, the periosteal contour was automatically derived and manually modified when contours visually deviated from the periosteal boundary ${ }^{29}$. The images were automatically segmented and the following bone density parameters were calculated from the images: total VBMD, trabecular VBMD and cortical VBMD. In the trabecular region, the micro-architectural parameters trabecular number, trabecular thickness and trabecular separation were calculated. For the cortical region, cortical thickness was calculated. In addition extended analysis of the cortical compartment was performed to obtain cortical pore volume, cortical porosity and mean cortical pore diameter ${ }^{30}$.

Micro-finite element analysis was performed by creating micro-finite element models directly from the segmented HR-pQCT images as described previously ${ }^{31,32}$. In short, all voxels representing bone tissue were converted into brick elements of the same size. A Young modulus of $10 \mathrm{GPa}$ and a Possion ratio of 0.3 was assigned to every element. Compression stiffness and estimated failure load were determined by applying a virtual "high-friction' compression test in the axial direction ${ }^{31}$. 


\section{Covariates}

Weight and height were measured without shoes and wearing light clothing using a scale and stadiometer to the nearest 0.5 kilogram or 0.1 centimetre (Seca, Hamburg, Germany). Body mass index (BMI) was calculated by dividing weight in kilogram by height in metres squared. Glycosylated hemoglobin A1c (HbA1c) level was determined as described elsewhere ${ }^{18}$. Alcohol use, smoking status and T2DM duration were questioned at the baseline visit ${ }^{18}$. For the current study the time between the baseline visit and the date of the HR-pQCT scan was added to the T2DM duration at baseline. If T2DM duration was not available, it was estimated by the time between the first antihyperglycaemic dispensing and the date of the HR-pQCT scan. Use of other antihyperglycaemic drugs in the six months before the date of the HR-pQCT scan was based on the pharamcy data using ATC codes: metformin (ATC code A10BA02, A10BD02, -03, $05,-07,-08,-10,-11,-13-18$ ), sulfonylurea derivate (ATC code A10BB, A10BD01, $A 10 B D 02)$, dipeptidyl peptidase-4 inhibitor (ATC code $A 10 B H)$, thiazolidinedione (A10BG) or other blood glucose lowering drugs (A10BX).

\section{Statistical analysis}

The mean HR-pQCT derived bone parameters and standard deviations were calculated for the insulin and non-insulin users and compared for statistically significant differences with a student's t-test. Multiple linear regression analysis was used to estimate the association between current use of insulin and HR-pQCT derived parameters as compared to the non-insulin users. Log-transformation was performed if variables showed a skewed distribution. The same models were used for all regression analyses; model 1 was adjusted for age and sex, model 2 was additionally adjusted for $\mathrm{BMI}, \mathrm{HbA} 1 \mathrm{c}$ and duration of diabetes. A p-value $<0.05$ was considered statistically significant and analyses were conducted using SAS 9.4 (SAS Institute Inc., Cary, NC, USA).

\section{Results}

In total, data from 59 T2DM participants that had a HR-pQCT scan and had pharmacy dispensing data available was retrieved. Data of 8 participants were excluded due to extreme motion artifacts of the HR-pQCT scan (grade 5: n=2, grade 4: $n=6$ ). From the 51 included participants, 13 were classified as insulin user and 38 were classified as noninsulin user.

The general characteristics of the study population are shown in Table 3.2.1. The non-insulin users were slightly older, had a shorter time since first hyperglycaemic dispensing, a shorter duration of diabetes and lower mean $\mathrm{HbA1c}$ levels. 
Table 3.2.1 General characteristics of the study population.

\begin{tabular}{lcc}
\hline Characteristic & $\begin{array}{c}\text { Non-insulin users } \\
(\mathrm{N}=38)\end{array}$ & $\begin{array}{c}\text { Insulin users } \\
(\mathrm{N}=13)\end{array}$ \\
\hline Age, years & $62.1(7.5)$ & $60.4(5.9)$ \\
Female & $16(42.1)$ & $6(46.2)$ \\
BMI, kg/m & $30.3(4.9)$ & $30.9(5.4)$ \\
Smoking status & & \\
Current & $6(15.8)$ & $0(-)$ \\
Former & $18(47.4)$ & $10(76.9)$ \\
Never & $13(34.2)$ & $2(15.4)$ \\
Missing & $1(2.6)$ & $1(7.7)$ \\
Alcohol use & & \\
None & $6(15.8)$ & $5(38.4)$ \\
Low & $21(55.3)$ & $4(30.8)$ \\
High & $10(26.3)$ & $3(23.1)$ \\
Missing & $1(2.6)$ & $1(7.7)$ \\
Median time since first anti-hyperglycaemic dispensing $[I Q R], y e a r s ~$ & $4.1[5.0]$ & $8.5[8.3]$ \\
Median time since first insulin dispensing [IQR], years & $\mathrm{n} / \mathrm{a}$ & $7.0[4.7]$ \\
Use of anti-hyperglycaemic drugs & & \\
Metformin & $27(71.1)$ & $8(61.5)$ \\
Sulfonylurea derivatives & $6(15.8)$ & $0(0)$ \\
Dipeptidyl peptidase-4 inhibitors & $0(-)$ & $2(15.4)$ \\
Thiazolidinediones & $0(-)$ & $0(-)$ \\
Other anti-hyperglycaemic drugs & $0(-)$ & $0(-)$ \\
Median duration of T2DM [IQR], years & $4.2[3.2]$ & $14.7[6.0]$ \\
HbA1c, \% & $6.6(0.7)$ & $7.7(0.8)$ \\
Quality HR-pQCT scan & & $3(23.1)$ \\
Grade 1 (no motion artifacts) & $8(21.1)$ & $6(46.2)$ \\
Grade 2 (minor motion artifacts) & $21(55.3)$ & $4(30.8)$ \\
Grade 3 (moderate motion artifacts) & $9(23.7)$ & \\
\hline
\end{tabular}

Continues variables are presented as mean (SD), categorical variables as number of participants (\%). BMI: body mass index; HbA1c: glycosylated hemoglobin A1c; HR-pQCT: high-resolution peripheral quantitative computed tomography; IQR: inter quartile range; n/a: not applicable; T2DM: type 2 diabetes mellitus.

The mean HR-pQCT derived bone parameters of the non-insulin and the insulin users are shown in Table 3.2.2. Mean total VBMD, trabecular VBMD, trabecular thickness, cortical thickness and bone stiffness were significantly lower in the insulin users, when compared to the non-insulin users. There were no statistically significant differences in cortical vBMD, trabecular number, trabecular separation, cortical porosity and failure load between the groups.

The association between insulin use and HR-pQCT derived bone parameters is shown in Table 3.2.3. After adjustment for age, sex, BMI, HbA1c and diabetes duration (model 2), current insulin use was associated with lower total VBMD, trabecular vBMD, cortical vBMD, trabecular thickness, cortical thickness, cortical pore volume, bone stiffness and failure load as compared to the non-insulin users. Current insulin use was not associated with trabecular number, trabecular separation, cortical porosity and cortical pore diameter. 
Table 3.2.2 HR-pQCT derived bone parameters in participants with and without insulin use.

\begin{tabular}{|c|c|c|c|}
\hline & $\begin{array}{c}\text { Non-insulin users } \\
(\mathrm{N}=38)\end{array}$ & $\begin{array}{l}\text { Insulin users } \\
(\mathrm{N}=13)\end{array}$ & P-value \\
\hline \multicolumn{4}{|l|}{ Bone mineral density } \\
\hline Total vBMD (mg/cm $\left.{ }^{3}\right)$ & 327.32 (74.89) & $258.62(61.00)$ & $<0.001$ \\
\hline Trabecular vBMD $\left(\mathrm{mg} / \mathrm{cm}^{3}\right)$ & $173.71(43.70)$ & $142.86(32.77)$ & 0.02 \\
\hline Cortical vBMD $\left(\mathrm{mg} / \mathrm{cm}^{3}\right)$ & $854.90(81.98)$ & 799.85 (95.48) & 0.05 \\
\hline \multicolumn{4}{|l|}{ Bone micro-architecture } \\
\hline Trabecular number $\left(\mathrm{mm}^{-1}\right)$ & $1.95(0.36)$ & $1.95(0.35)$ & 0.99 \\
\hline Trabecular thickness (mm) & $0.07(0.01)$ & $0.06(0.01)$ & $<0.001$ \\
\hline Trabecular separation (mm) & $0.47(0.17)$ & $0.47(0.10)$ & 0.96 \\
\hline Cortical thickness (mm) & $0.84(0.26)$ & $0.64(0.24)$ & 0.02 \\
\hline Cortical pore volume $\left(\mathrm{mm}^{3}\right)$ & $19.10(8.76)$ & $13.30(5.79)$ & 0.03 \\
\hline Cortical porosity (\%) & $3.36(1.21)$ & $2.98(1.64)$ & 0.38 \\
\hline Cortical pore diameter $(\mathrm{mm})$ & $0.18(0.02)$ & $0.17(0.02)$ & 0.08 \\
\hline \multicolumn{4}{|l|}{ Bone strength } \\
\hline Bone stiffness (kN/mm) & $100.02(27.45)$ & $82.14(23.28)$ & 0.04 \\
\hline Failure load (N) & $4770.26(1290.68)$ & $3981.08(1101.46)$ & 0.05 \\
\hline
\end{tabular}

Data are presented as mean (standard deviation). HR-pQCT: high-resolution peripheral quantitative computed tomography; T2DM: type 2 diabetes mellitus; vBMD: volumetric bone mineral density.

Table 3.2.3 The association between insulin use and HR-pQCT derived parameters.

\begin{tabular}{|c|c|c|c|}
\hline & \multirow[t]{3}{*}{$\begin{array}{l}\text { Non-insulin } \\
\text { users }(\mathrm{N}=38)\end{array}$} & \multicolumn{2}{|c|}{$\begin{array}{c}\text { Insulin } \\
\text { users }(\mathrm{N}=13)\end{array}$} \\
\hline & & Model 1 & Model 2 \\
\hline & & $\mathrm{B}(95 \% \mathrm{Cl})$ & $\mathrm{B}(95 \% \mathrm{Cl})$ \\
\hline \multicolumn{4}{|l|}{ Bone mineral density } \\
\hline Total vBMD $\left(\mathrm{mg} / \mathrm{cm}^{3}\right)$ & Reference & $-69.89(-115.78--23.99)^{*}$ & $-100.75(-155.01--46.48)^{*}$ \\
\hline Trabecular vBMD $\left(\mathrm{mg} / \mathrm{cm}^{3}\right)$ & Reference & $-29.86(-54.48--5.24)^{*}$ & $-57.55(-83.77--31.33)^{*}$ \\
\hline Cortical vBMD (mg/cm $\left.{ }^{3}\right)$ & Reference & $-62.73(-113.91--11.55)^{*}$ & $-63.23(-126.16--0.31)^{*}$ \\
\hline \multicolumn{4}{|l|}{ Bone micro-architecture } \\
\hline Trabecular number $\left(\mathrm{mm}^{-1}\right)$ & Reference & $-0.01(-0.22-0.21)$ & $-0.23(-0.46-0.00)$ \\
\hline Trabecular thickness (mm) & Reference & $-0.01(-0.02--0.00)^{*}$ & $-0.02(-0.02--0.01)^{*}$ \\
\hline Trabecular separation (mm) & Reference & $0.01(-0.09-0.10)$ & $0.08(-0.02-0.19)$ \\
\hline Cortical thickness (mm) & Reference & $-0.21(-0.36--0.05)^{*}$ & $-0.24(-0.43--0.06)^{*}$ \\
\hline Cortical pore volume $\left(\mathrm{mm}^{3}\right)$ & Reference & $-0.30(-0.55--0.05)^{*}$ & $-0.45(-0.77--0.13)^{*}$ \\
\hline Cortical porosity (\%) & Reference & $-0.23(-0.96-0.50)$ & $-0.58(-1.53-0.36)$ \\
\hline Cortical pore diameter (mm) & Reference & $-0.01(-0.02-0.00)$ & $-0.01(-0.03-0.00)$ \\
\hline \multicolumn{4}{|l|}{ Bone strength } \\
\hline Bone stiffness (kN/mm) & Reference & $-16.85(-28.16--5.54)^{*}$ & $-23.58(-36.79--10.36)^{*}$ \\
\hline Failure load $(\mathrm{N})$ & Reference & $-742.52(-1260.19--224.85)^{*}$ & $-1069.87(-1673.03--466.71)^{*}$ \\
\hline
\end{tabular}

$\mathrm{Cl}$ : confidence interval; HR-pQCT: high-resolution peripheral quantitative computed tomography; vBMD: volumetric bone mineral density. Model 1: adjusted for age and sex. Model 2: model $1+$ body mass index, glycosylated hemoglobin A1c and duration of diabetes. Cortical pore volume is log transformed. * Statistically significant, $\mathrm{p}<0.05$. 


\section{Discussion}

In the present study the association between current insulin use and HR-pQCT derived bone parameters in patients with T2DM was examined. In contrast to our hypothesis, after adjustment for potential confounders, current insulin use was associated with lower total VBMD, trabecular VBMD, cortical VBMD, trabecular thickness, cortical thickness, cortical pore volume, bone stiffness and failure load as compared to noninsulin users.

Literature on the association between insulin therapy and BMD in T2DM patients is scarce. Up to this date, only two small studies examined the association between insulin dose and BMD, and found a positive association ${ }^{14,15}$. This is in contrast to our study, where a negative association between insulin use and BMD was observed.

There are no studies available that investigated the effects of insulin therapy on bone micro-architecture or bone strength. We found a negative association between insulin use and bone micro-architectural properties and calculated bone strength. Based on our findings, one might speculate that insulin has a negative effect on bone mass and bone quality. The total amount of trabecular bone is higher than the total amount of cortical bone, one might therefore argue that trabecular bone will be more affected. In this study, the association between insulin use and trabecular bone parameters was indeed more pronounced than the association between insulin use and cortical bone parameters. Since both trabecular and cortical parameters are negatively associated with insulin, it is not surprising that stiffness and failure load were also inversely associated.

Previous studies showed that insulin use is associated with an increased fracture risk in T2DM patients ${ }^{6}$. The mechanisms leading to this increased fracture risk are not completely understood, but a direct negative effect of insulin use of bone was thought to be unlikely because in-vitro studies showed that insulin is an anabolic bone agent ${ }^{7}$. It was proposed that insulin use may be a surrogate for disease severity and duration of the disease as insulin is most often used by T2DM patients with long disease duration and that the observed increased fracture risk in insulin users may therefore be due to factors associated with the disease itself. For example, complications of T2DM and risk factors for falling such as diabetic neuropathy and retinopathy are more common in patients with a longer disease duration, and one of the proposed mechanisms of the increased fracture risk in insulin users was therefore an increased frequency of falling. Additionally, insulin users are generally more insulin resistant than non-insulin users. Insulin resistance may result in impaired insulin signalling in osteoblasts, which leads to impaired bone quality due to deteriorated osteoblast proliferation, differentiation and survival $^{33}$. Insulin resistance may therefore be another mechanism leading to the observed increased fracture risk in insulin users. Furthermore, the cumulative effect of chronic hyperglycaemia will be larger in insulin users than in non-insulin users. Longterm hyperglycaemia may have several negative effects on bone quality, such as an 
increased formation and accumulation of advanced glycation end products, which result in impaired bone collagen quality and thereby a decreased bone strength ${ }^{34}$. Elevated blood glucose levels also lead to hypercalcuria ${ }^{35}$, which may influence bone mineralization. Finally, insulin users may be more often sarcopenic than non-insulin users $^{36}$. As muscle strength influences bone strength, this may be another mechanism resulting in an increased fracture risk.

This study has several strengths: diabetes status was objectively determined, using an oral glucose tolerance test, the medication history and prescription data. Furthermore, insulin use was objectively determined using pharmacy dispensing data. Finally, this is the first study that focuses on the association between insulin use and bone quality.

Our study also has some limitations. First, cross-sectional HR-pQCT data were, for this manuscript, only available for a relatively small number of participants since this measurement was started later due to the need of special clearance for radiological examinations within the Maastricht Study by the Dutch Ministry of Health. This resulted in reduced power of the study which may have led to over- or underestimation of the associations ${ }^{37}$. The present results should therefore be interpreted with caution. Additionally, HR-pQCT scans of the distal tibia were only recently allowed within the Maastricht Study and therefore these scans were not available in our study population. Since the distal tibia is a weight bearing bone, in contrast to the distal radius, the association between insulin use and HR-pQCT derived bone parameters at the distal tibia may be different and is subject for future analyses.

Furthermore, no DXA scans of the participants were available and as such no BMD data at other sites could be compared between insulin and non-insulin users. Due to the small number of participants we were not able to adjust for potential confounders such as use of glucocorticoids, a history of a fracture above the age of 50, and a parental history of hip fracture. Within the non-insulin user group there were some users of glucocorticoids, and use of it has been associated with increased fracture risk ${ }^{38}$ and this might have confounded the investigated association.

In this study, we were not able to distinguish between negative effects of the disease itself on bone parameters or effects of insulin. Insulin use may be a surrogate for severity or duration of T2DM, as it is most often used in patients with long disease duration. Although the results in this study were adjusted for $\mathrm{HbA1c}$ and disease duration, which were used as proxies for T2DM severity, there may still be residual confounding by disease severity present. Further information regarding disease severity such as the presence of micro- and macrovascular complications will be very useful to take into account, but for this study we did not have this information. Larger studies and prospective studies are needed to investigate the effects of insulin use on bone and in case that detrimental effects of insulin use will be confirmed, underlying mechanisms should be further investigated. 
Finally, we used an automatic instead of a semi-automatic algorithm to calculate cortical bone parameters. Currently, there is much discussion about determination of the cortical region, since the transition from cortical to trabecular bone is gradual ${ }^{39}$. It has been hypothesized that on top of a trabecular and cortical region, a transitional zone (the region between the trabecular and cortical region) should be identified ${ }^{40}$. In this manuscript, the endocortical contour was not manually adjusted to prevent intraoperator variability, and this may have resulted in over- or underestimation of the cortical bone parameters if the automatic contours were not correct.

In this cross-sectional study, insulin use was negatively associated with bone mineral density, bone micro-architectural and bone strength parameters as measured with HR-pQCT in T2DM participants. Therefore, the previously observed increased fracture risk in insulin users might be partly due to bone fragility. However, results may be confounded by disease severity. Replication of these findings in a larger number of T2DM patients is needed, as well as further research including longitudinal studies to investigate the effect of insulin use on bone micro-architectural and bone strength parameters and its potential clinical implications. 


\section{References}

1. Danaei G, Finucane MM, Lu Y, Singh GM, Cowan MJ, Paciorek $\mathrm{CJ}$, et al. National, regional, and global trends in fasting plasma glucose and diabetes prevalence since 1980: systematic analysis of health examination surveys and epidemiological studies with 370 country-years and 2.7 million participants. Lancet 2011;378(9785):31-40.

2. Schwartz AV, Sellmeyer DE, Ensrud KE, Cauley JA, Tabor HK, Schreiner PJ, et al; Study of Osteoporotic Features Research Group. Older women with diabetes have an increased risk of fracture: a prospective study. J Clin Endocrinol Metab. 2001;86(1):32-8.

3. Vestergaard P. Discrepancies in bone mineral density and fracture risk in patients with type 1 and type 2 diabetes--a meta-analysis Osteoporos Int 2007;18(4):427-44.

4. de Waard EA, van Geel TA, Savelberg $H H$, Koster A, Geusens PP, van den Bergh JP. Increased fracture risk in patients with type 2 diabetes mellitus: an overview of the underlying mechanisms and the usefulness of imaging modalities and fracture risk assessment tools. Maturitas 2014;79(3):26574.

5. Paccou J, Ward KA, Jameson KA, Denisson EM, Cooper C, Edwards $\mathrm{MH}$. Bone microarchitecture in men and women with diabetes: the importance of cortical porosity. Calcif Tissue Int 2016;98(5):465-73.

6. Yu EW, Putman MS, Derrico N, AbrishamanianGarcia G, Finkelstein JS, Bouxsein ML. Defects in cortical microarchitecture among AfricanAmerican women with type 2 diabetes. Osteoporosis Int 2015;26(2):673-9.

7. Palermo A, D'Onofrio L, Eastell R, Schwartz AV, Pozzili P, Napoli N. Oral antidiabetic drugs and fracture risk, cut to the bone: safe or dangerous? A narrative review. Osteoporosis Int 2015;26(8):2073-89.

8. Gilbert MP, Pratley E. The impact of diabetes and diabetes medications on bone health. Endocr Rev 2015;36(2):194-213.

9. Starup-Linde J, Frost $M$, Vestergaard $P$, Abrahamsen B. Epidemioloy of fractures in diabetes. Calcif Tissue Int 2016. Epub ahead of print.

10. Thrailkill KM, Lumpkin CK Jr., Bunn RC, Kemp SF, Fowlkes JL. Is insulin an anabolic agent in bone? Dissecting the diabetic bone for clues.
Am J Physiol Endocrinol Metab 2005;289(5):E735-45.

11. Stolk RP, van Daele PL, Pols HA, Burger $H$, Hofman A, Birkenhäger JC, et al. Hyperinsulinemia and bone mineral density in an elderly population: The Rotterdam Study. Bone 1996;18(6):545-9.

12. Barret-Conner E, Kritz-Silverstein D. Does hyperinsulinemia preserve bone? Diabetes Care 1996;19:1388-92.

13. Reid IR, Evans MC, Cooper GJS, Ames RW, Stapleton J. Circulating insulin levels are related to bone density in postmenopausal women. Am J Physiol Endocrinol Metab 1993;265:E655-9.

14. Fukunaga $Y$, Minamikawa J, Inoue D, Koshiyama $\mathrm{H}$. Does insulin use increase bone mineral density in patients with non-insulindependent diabetes mellitus? Arch Intern Med 1997;157:2668-69.

15. Weinstock RS, Goland RS, Shane E, Clemens TL, Lindsay R, Bilezikian JP. Bone mineral density in women with type II diabetes mellitus. J Bone Miner Res 1989;4:97-101.

16. Geusens P, Chapurlat R, Schett G, GhasemZadeh A, Seeman E, de Jong J, et al. Highresolution in vivo imaging of bone and joints: a window to microarchitecture. Nat Rev Rheumatol 2014 10(5):304-13.

17. MacNeil JA, Boyd SK. Accuracy of highresolution periph-eral quantitative computed tomography for measurement of bone quality. Med Eng Phys 2007;29(10):1096-105.

18. Schram MT, Sep SJ, van der Kallen CJ, Dagnelie PC, Koster A, Schaper N, et al. The Maastricht Study: an extensive phenotyping study on determinants of type 2 diabetes, its complications and its comorbidities. Eur J Epidemiol 2014;29(6):439-51.

19. World Health Organization (2006) Definition and diagnosis of diabetes mellitus and intermediate hyperglycemia: report of a WHO/IDF consultation. Geneva, Switzerland.

20. WHO's ATC/DDD index 2016, accessible through: http://www.whocc.no/atc_ddd_ index/

21. Nielen JT, JH Driessen, Dagnelie PC, Boonen A, van den Bemt B, van Onzenoort HA, et al. Drug utilisation in the Maastricht Study: a comparison with nationwide data. [Submitted]. 
22. Boutroy S, Bouxsein ML, Munoz F, Delmas PD. In vivo assessment of trabecular bone microarchitecture by high-resolution peripheral quantitative computed tomography. The Journal of clinical endocrinology and metabolism 2005;90(12):6508-15.

23. Khosla $S$, Riggs BL, Atkinson EJ, Oberg AL, McDaniel $L$, Holets $M$, et al. Effects of sex and age on bone microstructure at the ultradistal radius: a population-based noninvasive in vivo assessment. Journal of bone and mineral research : the official journal of the American Society for Bone and Mineral Research 2006;21(1):124-31.

24. Pialat JB, Burghardt AJ, Sode $M$, Link TM, Majumdar S. Visual grading of motion induced image degradation in high resolution peripheral computed tomography: impact of image quality on measures of bone density and micro-architecture. Bone 2012;50(1):1118.

25. Pauchard $Y$, Liphardt AM, Macdonald HM, Hanley DA, Boyd SK. Quality control for bone quality parameters affected by subject motion in high-resolution peripheral quantitative computed tomography. Bone 2012;50(6): 1304-10.

26. Laib A, Hauselmann HJ, Rüegsegger P. In vivo high resolution 3D-QCT of the human forearm. Technology and health care : official journal of the European Society for Engineering and Medicine 1998;6(5-6):329-37.

27. Laib A, Rüegsegger P. Comparison of structure extraction methods for in vivo trabecular bone measurements. Computerized medical imaging and graphics: the official journal of the Computerized Medical Imaging Society 1999;23(2):69-74.

28. Hildebrand T, Rüegsegger P. A new method for the model-independent assessment of thickness in three-dimensional images. Journal of Microscopy 1997;185(1):67-75.

29. Buie HR, Campbell GM, Klinck RJ, MacNeil JA, Boyd SK. Automatic segmentation of cortical and trabecular compartments based on a dual threshold technique for in vivo micro-CT bone analysis. Bone 2007;41(4):505-15.

30. Burghardt AJ, Buie HR, Laib A, Majumdar S, Boyd SK. Reproducibility of direct quantitative measures of cortical bone microarchitecture of the distal radius and tibia by HR-pQCT. Bone 2010;47(3):519-28.

31. Pistoia $W$, van Rietbergen $B$, Lochmüller EM, Lill CA, Eckstein F, Rüegsegger P. Estimation of distal radius failure load with micro-finite element analysis models based on threedimensional peripheral quantitative computed tomography images. Bone 2002;30(6):842-8.

32. Dalzell N, Kaptoge $S$, Morris $N$, Berthier A, Koller B, Braak L, et al. Bone microarchitecture and determinants of strength in the radius and tibia: age-related changes in a population-based study of normal adults measured with high-resolution pQCT. Osteoporos Int 2009;20(10):1683-94.

33. Pramojanee SN, Phimphilai M, Chattipakorn N, Chattipakorn SC. Possible role of insulin signaling in osteoblasts. Endocr Res 2014;39(4):144-51.

34. Goh SY, Cooper ME. Clinical review: The role of advanced glycation end products in progression and complications of diabetes. J Clin Endocrinol Metab 2008;93(4):1143-52.

35. Gregorio F, Cristallini S, Santeusanio F, Filipponi P, Fumelli P. Osteopenia associated with non-insulin-dependent diabetes mellitus: what are the causes? Diabetes Research and Clinical Practice 1994;23(1):43-54.

36. Beck TJ, Oreskovic TL, Stone KL, Ruff CB, Ensrud K, Nevitt MC, et al. Structural adaptation to changing skeletal load in the progression toward hip fragility: the study of osteoporotic fractures. J Bone Miner Res 2001;16(6):1108-19.

37. Button KS, loannidis JP, Mokrysz C, Nosek BA, Flint J, Robinson ES, et al. Power failure: why small sample size undermines the reliability of neuroscience. Nat Rev Neurosci. 2013;14(5):365-76.

38. van Staa TP, Leufkens HG, Abenhaim L, Zhang B, Cooper C. Use of oral corticosteroids and risk of fractures. J Bone Miner Res 2000;15:993-1000.

39. Zebaze R, Seeman E. Cortical bone: a challenging geography. J Bone Miner Res 2015;30(1):24-9.

40. Zebaze R, Ghasem-Zadeh A, M'bala A, Seeman E. A new method of segmentation of compact-appearing, transitional and trabecular compartments and quantification of cortical porosity from high resolution peripheral quantitative computed tomographic images. Bone 2013;54:8-20. 


\section{Chapter}

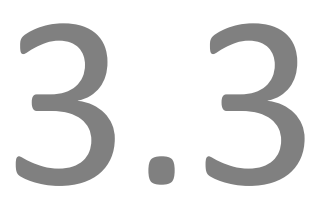

Metformin dosage and duration is not associated with aortic stiffness - the Maastricht Study

JHM Driessen, F de Vries, HAW van Onzenoort, MT Schram, P Dagnelie, CJ van der Kallen, SJS Sep, CDA Stehouwer, NC Schaper, AA Kroon, C Schalkwijk, JPW van den Bergh, RMA Henry 


\section{Abstract}

\section{Introduction}

Type 2 diabetes mellitus (T2DM) has been associated with cardiovascular disease (CVD) complications such as myocardial infarction and stroke. These complications are at least partially the consequence of diabetes-associated increased arterial stiffness. Metformin, an oral glucoselowering drug, is the first choice therapeutic agent in the treatment of T2DM. Metformin has been associated with potential cardio-protective effects. One of the hypothesized mechanisms includes a reduction of plasma advanced glycation end products (AGEs) which then might result in reduced arterial stiffness. However, there is no data on the association between real-life metformin use and arterial stiffness.

The objective was to study the association between metformin dosage and duration and arterial stiffness as determined by carotid-femoral pulse wave velocity (cfPWV) and to quantify the role of AGEs on any such an association.

\section{Methods}

We used data from the Maastricht Study, an ongoing observational prospective population-based cohort study $(n=3,451)$. All current metformin users, based on pharmacy records $(n=449,29.6 \%$ women, mean age 62.5 \pm 7.4 ), were included in the present study. Linear regression analyses were used to estimate the association between the duration and dosage of metformin and cfPWV, plasma AGEs $\mathrm{N}(\varepsilon)$-(carboxymethyl)lysine (CML), $\mathrm{N}(\varepsilon)$-(carboxyethyl)lysine (CEL) and pentosidine. In addition, the association between the duration and dosage of metformin and tissue accumulation of AGEs as measured by skin autofluorescence (SAF) was investigated. Current use of metformin was stratified according to cumulative dose, continuous duration of use, average daily dose and the time since the first dispensing.

\section{Results}

Linear regression showed that dosage and duration of metformin use were not associated with cfPWV (adjusted B for cumulative metformin dose 1024-3121 gram (95\% Cl): 0.0 (-0.04 - 0.05) and $\geq 3122$ gram: 0.03 (-0.02 - 0.07), as compared to <1024 gram metformin). Metformin dosage and duration were also not associated with SAF AGEs or plasma AGES CEL, CML and pentosidine except for continuous duration of use of $>554$ days which was associated with a decreased level of the plasma AGE CML (adjusted B -7.22 (-13.12 - -1.31)) as compared to a continuous duration of $<106$ days.

\section{Conclusion}

We showed that dosage and duration of metformin use were not associated with arterial stiffness as measured by cfPWV. There might be no beneficial effect of dosage and duration of metformin use on arterial stiffness in middle-aged patients with T2DM using metformin. 


\section{Introduction}

In the year 2030, worldwide 366 million individuals will suffer from type 2 diabetes mellitus (T2DM), which will be followed by an epidemic of related cardiovascular disease (CVD) complications such as myocardial infarction and stroke ${ }^{1}$. These complications are, at least partially, the consequence of diabetes associated increased arterial stiffness ${ }^{2-4}$, as increased arterial stiffness leads to increased systolic and decreased diastolic blood pressure, which in turn hampers coronary perfusion and increases the pulsatile pressure load upon the cerebral circulation ${ }^{5}$.

The oral glucose-lowering drug metformin is a first choice therapeutic agent in the treatment of $\mathrm{T}^{2} \mathrm{DM}^{6}$. Interestingly, it has been hypothesized that metformin may harbour cardio-protective effects as there is some data that its use reduces the incidence of arterial stiffness-related CVD complications ${ }^{7-12}$.

How metformin use may do so remains largely unclear. Proposed mechanisms involve direct interference with the formation of advanced glycation end-products (AGEs) such as pentosidine ${ }^{13}$. Pentosidine itself causes cross-linkages of the blood pressure load-bearing elements within the arterial wall ${ }^{2,14}$ and may thereby cause increased arterial stiffness. Alternatively, metformin may indirectly interfere via its ameliorating effects upon endothelial dysfunction, low-grade inflammation and/or oxidative stress $^{6}$, which by themselves are all involved in arterial stiffening ${ }^{15}$. Currently there is no data on the association between real-life metformin use in the population at large and arterial stiffness.

In view of the above we set out to investigate in a population-based sample of individuals with T2DM the association between the dosage and duration of metformin use and carotid-femoral pulse wave velocity (cfPWV) as a measure for arterial stiffness. In addition, we set out to quantify the role of AGEs (tissue accumulation as estimated by skin autofluorescence (SAF) and measured in plasma) on any such an association.

\section{Methods}

We used data from the Maastricht Study, an observational prospective populationbased cohort study. The rationale and methodology have been described previously ${ }^{16}$. In brief, the study focuses on the etiology, pathophysiology, complications and comorbidities of T2DM and is characterized by an extensive phenotyping approach. Eligible for participation were all individuals aged between 40 and 75 years and living in the southern part of the Netherlands. Participants were recruited through mass media campaigns and from the municipal registries and the regional Diabetes Patient Registry via mailings. Recruitment was stratified according to known T2DM status, with an oversampling of individuals with T2DM, for reasons of efficiency.

To investigate the association between dosage and duration of metformin use we only included participants with T2DM currently using metformin $(n=596)$ and enrolled 
between November 2010 and September 2013. Current metformin users were initially selected as having at least one metformin dispensing in six months prior to the first study visit according to pharmacy dispensing records (see below). The examinations of each participant were performed within a time window of three months. The study has been approved by the institutional medical ethical committee (NL31329.068.10) and the Minister of Health, Welfare and Sports of the Netherlands (Permit 131088-105234$P G)$. All participants gave written informed consent.

\section{Pharmacy dispensing records}

Dispensing records were collected at 25 loco-regional pharmacies for all participants who gave written informed consent for the collection of their drug dispensing history. Dispensing data (available from January $1^{\text {st }}, 1991$ ) contained product name, anatomical therapeutical chemical (ATC) $\operatorname{code}^{17}$, amount and date dispensed and, the prescribed dosage regimen.

For current metformin users all dispensings before the first study visit were extracted. For every dispensing the total amount of defined daily dosage (DDD) was calculated. If the DDD could not be calculated the median DDD was assigned $(0.07 \%$ of the dispensings). The cumulative dose was estimated by adding all prescribed doses of metformin (in DDDs). The average daily dose was determined as the cumulative amount of DDDs divided by the time between the first metformin dispensing and the date of the study visit. To determine the continuous duration of use we calculated the expected end date for every metformin dispensing by dividing the total number of prescribed tablets over the number of tablets prescribed per day and adding this to the dispensing date. When the expected end date could not be estimated the median duration was added to determine the expected end date. A gap of 30 days between the estimated end date of a dispensing and the date of the next dispensing was allowed for a dispensing to count as continuous use ${ }^{18}$. Continuous duration of use was then defined as the time between the first dispensing and the date of the first study visit.

\section{Arterial stiffness: pulse wave velocity}

cfPWV was determined according to recent guidelines ${ }^{19}$ with the use of applanation tonometry (SphygmoCor, Atcor Medical, Sydney, Australia). In brief, pressure waveforms were determined at the right common carotid and right common femoral arteries. The difference in the time of pulse arrival from the R-wave of the electrocardiogram (3-lead electrocardiogram) between the two sites (transit time) was determined with the intersecting tangents algorithm. The pulse wave travel distance was calculated as $80 \%$ of the direct straight distance (measured with an infantometer) between the two arterial sites. The median of three consecutive cfPWV recordings (defined as travelled distance/transit time) was used in the analyses. 
All measurements were done by trained vascular technicians unaware of the participants' clinical or diabetes status, in a dark, quiet, temperature controlled room $\left(21-23^{\circ} \mathrm{C}\right)$. Participants were asked to refrain from smoking and drinking coffee, tea or alcoholic beverages three hours prior to the study. Participants were allowed to have a light meal (breakfast and(or) lunch).

During the measurements brachial systolic, diastolic and mean arterial pressure (MAP) were determined with an oscillometric device (Accutorr Plus, Datascope Inc., Montvale, NJ, USA). The mean MAP of these measurements was used in the statistical analyses.

\section{Covariates}

Weight and height were measured without shoes and wearing light clothing using a scale and stadiometre to the nearest 0.5 kilogram or 0.1 centimetre (Seca, Hamburg, Germany). Body mass index (BMI) was calculated by dividing the weight in kilogram by the height in metres squared. CVD history and smoking status were assessed by questionnaire. Participants were regarded as having a history of CVD if they reported to have had a myocardial infarction, and/or cerebrovascular infarction or haemorrhage, and/or percutaneous artery angioplasty of/or vascular surgery on the coronary, abdominal, peripheral, or carotid arteries. Use of lipid-modifying and antihypertensive medication was assessed during a medication interview where generic name, dose, and frequency were registered. Glycosylated hemoglobin $\mathrm{A} 1 \mathrm{c}(\mathrm{HbA} 1 \mathrm{c})$, total and highdensity lipoprotein cholesterol and triglycerides were determined as described elsewhere ${ }^{16}$. Estimated glomerular filtration rate (eGFR) was estimated according to the CKD-EPI (Chronic Kidney Disease Epidemiology Collaboration) equation ${ }^{20}$. Office blood pressure was determined according to international standards ${ }^{21}$ using a non-invasive blood pressure measurement device (Omron 705IT, Omron, Japan).

\section{Advanced glycation end-products: skin autofluorescence}

SAF AGEs were measured with the AGE Reader (DiagnOptics Technologies BV) as described elsewhere ${ }^{22}$. In short, the AGE Reader is a desktop device that uses the characteristic fluorescent properties of certain AGEs to estimate the level of the accumulation of AGEs in the skin. Technical details have been described elsewhere ${ }^{23}$. In short, the AGE Reader illuminates a skin surface of $4 \mathrm{~cm}^{2}$ guarded against surrounding light, with an excitation wavelength range of 300-420 nm and a peak excitation of $370 \mathrm{~nm}$. SAF was calculated as the ratio between emission light from the skin in the wavelength range of 420-600 $\mathrm{nm}$ (fluorescence) and excitation light reflected by the skin (300-420 nm), multiplied by 100 (arbitrary units (AU)). Measurements with a mean reflectance below $6 \%$ were considered unreliable and not processed by the software. These participants were excluded from the analyses. In addition, (single) SAF values $>10 \mathrm{AU}$ were considered unreliable and therefore manually excluded from calculating 
any individual's SAF mean. For these participants the mean of the remaining two measurements were used in the statistical analyses.

\section{Advanced glycation end-products in plasma}

Plasma AGEs were measured in EDTA samples obtained from fasting venous blood, which were stored at $-80^{\circ} \mathrm{C}$ until analysis. Protein-bound pentosidine was quantified using high-performance liquid chromatography with fluorescence detection, as described in detail elsewhere ${ }^{23}$. Intra- and interassay coefficients of variation for pentosidine were 6.5 and $7.8 \%$, respectively. Protein-bound $N(\varepsilon)$-(carboxymethyl)lysine $(C M L), \quad N(\varepsilon)$-(carboxyethyl)lysine (CEL) and lysine were quantified using ultraperformance liquid chromatography tandem mass spectrometry, as described in detail elsewhere ${ }^{24}$. Intra- and interassay coefficients of variation were 4.5 and $6.7 \%$ for $\mathrm{CML}$, 6.2 and $10.3 \%$ for CEL, and 5.0 and $5.3 \%$ for lysine. Concentrations of protein-bound pentosidine, CML, and CEL were adjusted for levels of lysine and expressed as nanomoles per millimole lysine.

\section{Statistical analysis}

Linear regression analyses were used to estimate the association between metformin dosage and duration and cfPWV. cfPWV was log transformed because of a skewed distribution. Metformin use was stratified according to cumulative dose, continuous duration of use, average daily dose and time since first prescription. Model 1 was adjusted age and sex. In model 2 MAP was added, followed by BMI, smoking, history of cardiovascular disease, use of hypertension medication and use of lipid modifying drugs in model 3. Model 4 was additionally adjusted for HbA1c.

In a small subset of the sample we performed an additional set of linear regression analyses to estimate the association between metformin dosage and duration use and AGEs measured by SAF $(n=108)$ or in plasma $(n=110)$. A p-value $<0.05$ was considered statistically significant. All analyses were done with SAS 9.4 (SAS Institute Inc., Cary, NC, USA.).

\section{Results}

In total there were 596 current metformin users identified in the Maastricht Study pharmacy database. Due to missing values for different variables 147 patients were excluded, which resulted in a study population of 449 participants. In Table 3.3.1 the baseline characteristics are shown. The mean age of the study population was $62.5 \pm 7.4$ years and $29.6 \%$ were women. The majority of the study population had a prescription for a lipid modifying drug (83.1\%) or an antihypertensive drug $(73.9 \%)$ at the baseline visit. The mean HbA1c was 7.0 (standard deviation (SD) 1.0). 
Table 3.3.1 Baseline characteristics of current metformin users stratified by cumulative dose.

\begin{tabular}{|c|c|c|c|}
\hline Characteristic & $\begin{array}{c}\text { Low cumulative } \\
\text { dose } \\
0-1023 \mathrm{~g} \\
\text { metformin } \\
\mathrm{N}=149\end{array}$ & $\begin{array}{c}\text { Medium cumulative } \\
\text { dose } \\
1024-3121 \mathrm{~g} \\
\text { metformin } \\
\mathrm{N}=148 \\
\end{array}$ & $\begin{array}{c}\text { High cumulative } \\
\text { dose } \\
\geq 3122 \mathrm{~g} \\
\text { metformin } \\
\mathrm{N}=152 \\
\end{array}$ \\
\hline Age, years & $62.1 \pm 7.4$ & $62.3 \pm 7.7$ & $63.2 \pm 7.2$ \\
\hline Women & $53(35.6)$ & $43(29.1)$ & $37(24.3)$ \\
\hline Body mass index, $\mathrm{kg} / \mathrm{m}^{2}$ & $29.7 \pm 4.8$ & $29.1 \pm 4.7$ & $30.2 \pm 4.3$ \\
\hline$<25.0 \mathrm{~kg} / \mathrm{m}^{2}$ & $24(16.1)$ & $26(17.6)$ & $19(12.5)$ \\
\hline $25-29.9 \mathrm{~kg} / \mathrm{m}^{2}$ & $62(41.6)$ & $71(48.0)$ & $57(37.5)$ \\
\hline$\geq 30.0 \mathrm{~kg} / \mathrm{m}^{2}$ & $63(42.3)$ & $51(34.5)$ & $76(50.0)$ \\
\hline \multicolumn{4}{|l|}{ Smoking status } \\
\hline Never & $34(22.8)$ & $47(31.8)$ & $44(28.9)$ \\
\hline Former & $91(61.1)$ & $79(53.4)$ & $86(56.6)$ \\
\hline Current & $24(16.1)$ & $22(14.9)$ & $22(14.5)$ \\
\hline History of cardiovascular disease & $34(22.8)$ & $43(29.1)$ & $44(28.9)$ \\
\hline \multicolumn{4}{|l|}{ Drug use in six months before first visit } \\
\hline Use of lipid-modifying drugs & 119 (79.9) & $123(83.1)$ & $131(86.2)$ \\
\hline Use of antihypertensive drugs & $102(68.5)$ & $110(74.3)$ & $120(78.9)$ \\
\hline eGFR ${ }^{a}, \mathrm{ml} / \mathrm{min}$ per $1.73 \mathrm{~m}^{2}$ & $83.7 \pm 18.8$ & $85.5 \pm 19.5$ & $85.0 \pm 18.8$ \\
\hline Total cholesterol to HDL ratio & $3.7 \pm 1.2$ & $3.6 \pm 1.1$ & $3.4 \pm 1.0$ \\
\hline Triglycerides, mmol/l & $1.7 \pm 0.9$ & $1.7 \pm 0.8$ & $1.7 \pm 1.1$ \\
\hline $\mathrm{HbA} 1 \mathrm{c}, \%$ & $6.8 \pm 0.9$ & $7.1 \pm 1.1$ & $7.1 \pm 0.9$ \\
\hline Mean arterial pressure, $\mathrm{mm} \mathrm{Hg}$ & $98.0 \pm 9.2$ & $96.5 \pm 9.6$ & $96.3 \pm 8.5$ \\
\hline Office mean arterial pressure $\mathrm{mm} \mathrm{Hg}$ & $99.1 \pm 10.2$ & $98.8 \pm 10.6$ & $98.7 \pm 10.1$ \\
\hline Office systolic blood pressure, $\mathrm{mm} \mathrm{Hg}$ & $140.6 \pm 16.4$ & $143.2 \pm 17.6$ & $142.6 \pm 16.6$ \\
\hline Office diastolic blood pressure, $\mathrm{mm} \mathrm{Hg}$ & $78.3 \pm 9.4$ & $76.6 \pm 9.6$ & $76.7 \pm 9.4$ \\
\hline Office heart rate, bpm & $73.1 \pm 12.4$ & $71.0 \pm 11.6$ & $73.9 \pm 11.5$ \\
\hline $\mathrm{cfPWV} \mathrm{m/s}$ & $9.8 \pm 2.2$ & $9.9 \pm 2.4$ & $10.2 \pm 2.4$ \\
\hline Skin autofluorescence, $\mathrm{AU}$ & $2.9 \pm 0.5^{b}$ & $3.0 \pm 0.5^{b}$ & $3.0 \pm 0.6^{b}$ \\
\hline Pentosidine, $\mathrm{nmol} / \mathrm{mmol}$ lysine & $0.4 \pm 0.2^{c}$ & $0.5 \pm 0.2^{c}$ & $0.5 \pm 0.2^{c}$ \\
\hline CEL, $\mathrm{nmol} / \mathrm{mmol}$ lysine & $36.6 \pm 13.3^{c}$ & $34.4 \pm 9.3^{c}$ & $38.0 \pm 11.7^{c}$ \\
\hline $\mathrm{CML}, \mathrm{nmol} / \mathrm{mmol}$ lysine & $69.9 \pm 14.3^{c}$ & $72.0 \pm 12.9^{c}$ & $65.2 \pm 14.2^{c}$ \\
\hline
\end{tabular}

Data are presented as number (\%) or mean \pm SD. AU: arbitrary units; bpm: beats per minute; $C E L: N(\varepsilon)$ (carboxyethyl)lysine; cfPWV: carotid to femoral pulse wave velocity; CKD EPI: Chronic Kidney Disease Epidemiology Collaboration; CML: $\mathrm{N}(\varepsilon)$-(carboxymethyl)lysine; eGFR: estimated glomerular filtration rate; HbA1c: glycosylated hemoglobin (A1c); HDL: high density lipid; n/a: not available; SD: standard deviation. ${ }^{a}$ Based on the CKDEPI cys formula. ${ }^{b}$ Based on 108 observations in total (of whom 41 were exposed to a low, 38 to a medium and 29 to a high cumulative metformin dose). ${ }^{c}$ Based on 110 observations in total (of whom 41 were exposed to a low, 38 to a medium and 31 to a high cumulative metformin dose)

Linear regression showed that, after adjusting for age and sex (model 1) cumulative dosage of metformin use was not significantly associated with cfPWV. Age and sex adjusted linear regression showed a B for cumulative dose of $1024-3121$ gram $(95 \% \mathrm{Cl})$ of: 0.00 (-0.05-0.05); and a $B$ for a cumulative dose of $\geq 3122$ gram of: 0.02 (-0.03-0.07) as compared to $0-1023$ gram of metformin. Full adjustments slightly changed the betas to: $1024-3121$ gram: 0.00 (-0.04-0.05); $\geq 3122$ gram: 0.03 (-0.02-0.07), Table 3.3.2. 


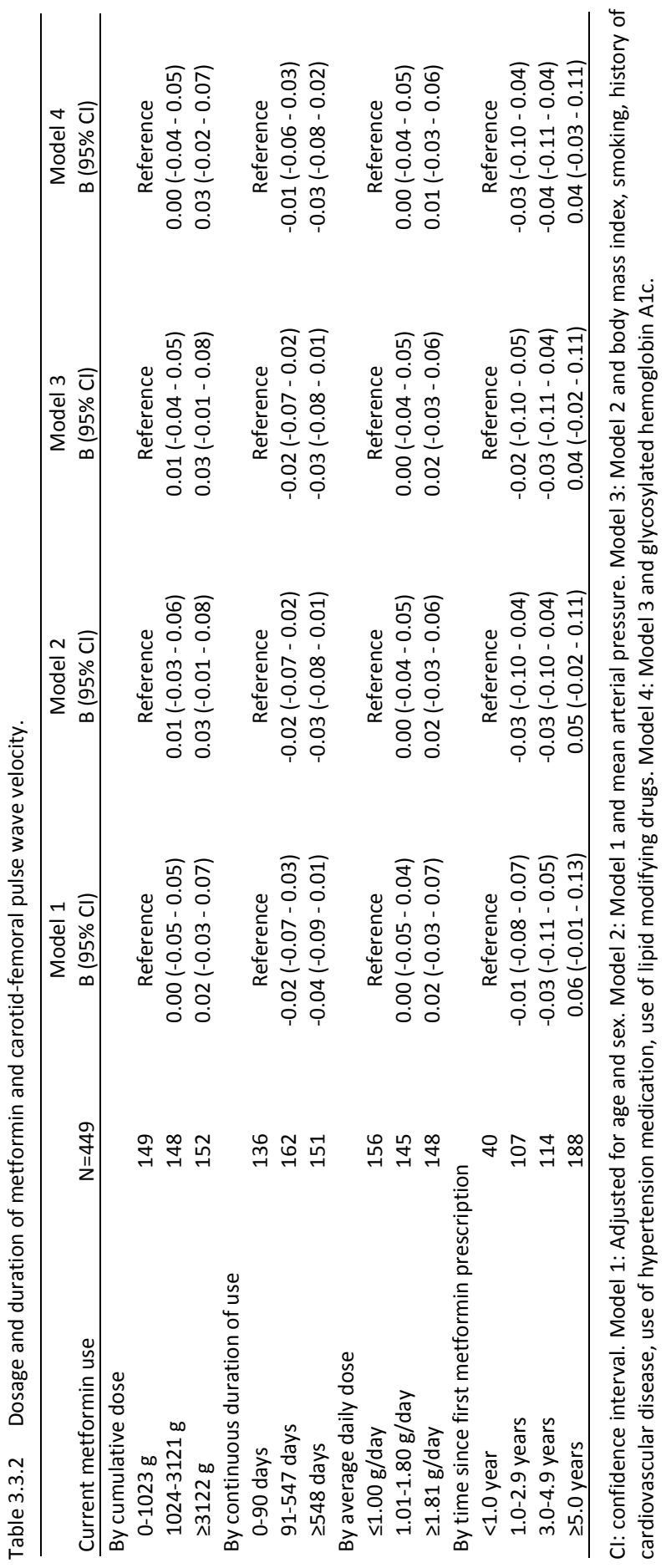


Continuous duration of metformin use was not significantly associated with cfPWV (B for metformin use between 91-547 days (95\% confidence interval): -0.02 (-0.07-0.03); B ( $\geq 548$ days): $-0.04(-0.09-0.01))$ as compared to continuous duration of $<91$ days). Further adjustments for MAP, BMI, smoking, history of cardiovascular disease, use of hypertension medication and lipid modifying drugs did not materially alter these results. After additional adjustments for $\mathrm{HbA1C}$ the $\mathrm{B}$ for metformin use between 91-547 days $(95 \% \mathrm{Cl})$ was: $-0.01(-0.06-0.03)$ and for $\geq 548$ days: $-0.03(-0.08-0.02)$. Metformin use stratified by average dose and time since first dispensing was not associated with cfPWV, Table 3.3.2.

In a small subset of the sample we investigated the association between current use of metformin and AGEs measured by SAF $(n=108)$ and in plasma $(n=110)$. The results showed that metformin use stratified according to cumulative dose, continuous duration of use, average daily dose or time since first dispensing was not associated with SAF AGEs.

With regard to the plasma AGEs, only $>554$ days of continuous use of metformin was associated with a decreased level of the plasma AGE CML (adjusted B -7.22 $(-13.12--1.31)$ ) as compared to a continuous duration of $<106$ days. The other stratifications (cumulative dose, average daily dose, and time since first dispensing) of current use of metformin were not associated with the level of CML measured in blood. Dosage and duration of metformin use was not associated with the plasma AGES CEL and pentosidine (data not shown).

\section{Discussion}

The results of the present study show that there is no significant association between current metformin use and cfPWV regardless of how metformin use itself was further defined (i.e., cumulative dose, continuous duration of use, average daily dose, time since first dispensing). Thereby the results of the present study do not support the hypothesis that metformin use protects against CVD by lowering arterial stiffness. In addition, a small subset analyses showed that dosage and duration of metformin use was not associated with AGEs as measured by skin auto fluorescence or measured in plasma.

Our results are in line with the results of a small clinical trial $(n=52)$ which showed no effect of 52 weeks of metformin use on arterial stiffness parameters ${ }^{25}$. Our results are also in line with a trial $(n=96)$ which investigated use of metformin for four months and plasma AGEs CEL and CML and showed no association ${ }^{26}$. Our results contrast a small study in newly diagnosed T2DM patients $(n=50)$, which showed a significant decrease in AGEs, and advanced oxidation protein products after 12 weeks of treatment with metformin in combination with life-style intervention ${ }^{27}$. Use of metformin has also been associated with a reduction in the AGE pentosidine after 
24 weeks of treatment ${ }^{13}$. However, these results were not adjusted for the change in $\mathrm{HbA1c}$. It has been suggested that not metformin but improved hyperglycaemic control might be the reason of the decreased level of plasma AGEs ${ }^{28}$.

Our T2DM study population was characterized by good glycaemic control (mean HbA1c 7.0) and normal blood pressure. The majority of the patients was treated with hypertension medication (73.9\%), which might have resulted in the near normal blood pressure levels seen in the study population. Increased blood pressure is an important determinant of arterial stiffness. The fact that our population was well treated for hypertension might be the reason that we underestimated the associations. An alternative explanation for the fact that we did not find an association between use of metformin and cfPWV might be selection bias. Study participation is voluntary, and it might therefore be that only more healthy patients with diabetes were willing to participate. However, despite the normal HbA1c and normal blood pressure, $26.7 \%$ of the participants had a history of CVD. Due to the relatively small number of included participants, we were not able to detect a small beneficial effect of metformin use, if there is such an effect. However, based on the present results it is unlikely that there is a large beneficial effect of metformin dosage or duration on aortic stiffness.

It has been hypothesized that metformin might decrease arterial stiffness. Hyperglycaemia plays an important role in the formation of $\mathrm{AGEs}^{2}$. Metformin lowers the blood-glucose level, by the inhibition of gluconeogenesis, and might thereby also reduce the formation of AGEs. Another potential mechanism by which metformin might reduce the AGEs is via its anti-oxidative properties. Metformin treatment (100, 250 and $500 \mu \mathrm{M})$ reduced intracellular reactive oxygen species in human aortic endothelial cells $^{29}$. Additionally, use of metformin $(60 \mathrm{mg} / \mathrm{kg} / \mathrm{day})$ has been associated with a reduced production of superoxide and a reduced level of $\mathrm{CML}$, one of the AGEs, in diabetic rats $^{30}$. Both studies investigated metformin concentrations which are not reached in clinical practice (peak concentration is about $15 \mu \mathrm{M}$ in humans ${ }^{31}$ ). This might be the reason that we were not able to show an association between use of metformin and AGEs.

The present results showed a negative association between the highest category of continuous duration of use and the level of plasma AGE CML. It might be hypothesized that metformin has a different effect on CML than on the other measured AGEs. However, the results for CML were not supported by results from the other analyses were current use of metformin was stratified according to cumulative dose, average dose and time since first prescription. Therefore, the results should be interpreted with caution as they may also be a chance finding, especially if one takes into account the small sample we were able to do these analyses on.

Strengths of this study include the availability of longitudinal data on metformin dispensings, which permitted us to reliably estimate the average and cumulative dose as well as the continuous duration of metformin use. Additionally, this made it possible to study long-term use of metformin and to test our hypothesis in different ways. We 
have been able to adjust for different important confounders. Unfortunately, we were only able to study the association between dosage and duration of metformin use and AGEs (measured via SAF or in plasma) in a small subgroup of the study population, which has resulted in less statistical power. Another limitation is the fact that cfPWV was only available cross-sectional, which makes it impossible to examine causal relationships.

We showed that dosage and duration of metformin were not associated with arterial stiffness as measured by cfPWV. Additionally, we showed that dosage and duration of metformin use were not associated with AGEs measured by SAF and also not with the plasma AGEs pentosidine, CEL and CML, except for continuous duration of use. The present results showed no beneficial effect of metformin dosage or duration on arterial stiffness in middle-aged patients with T2DM using metformin. 


\section{References}

1. Wild S, Roglic G, Green A, Sicree R, King H. Global prevalence of diabetes: estimates for the year 2000 and projections for 2030. Diabetes Care. 2004;27(5):1047-53.

2. Aronson D. Cross-linking of glycated collagen in the pathogenesis of arterial and myocardial stiffening of aging and diabetes. J Hypertens. 2003;21(1):3-12.

3. Stehouwer CD, Henry RM, Ferreira I. Arterial stiffness in diabetes and the metabolic syndrome: a pathway to cardiovascular disease. Diabetologia. 2008;51(4):527-39.

4. Prenner SB, Chirinos JA. Arterial stiffness in diabetes mellitus. Atherosclerosis. 2015;238(2):370-9.

5. Laurent $S$, Cockcroft J, Van Bortel L, Boutouyrie P, Giannattasio C, Hayoz D, et al. European Network for Non-invasive Investigation of Large Arteries.Expert consensus document on arterial stiffness: methodological issues and clinical applications. Eur Heart J. 2006;27(21):2588-605.

6. Kinaan $M$, Ding $H$, Triggle CR. Metformin: An Old Drug for the Treatment of Diabetes but a New Drug for the Protection of the Endothelium. Med Princ Pract. 2015;24(5):40115.

7. UK Prospective Diabetes Study Group: Tight blood pressure control and risk of macrovascular and microvascular complications in type 2 diabetes (UKPDS 38). Br Med J 1998;317:703-13.

8. Abbasi F, Chu JW, McLaughlin T, Lamendola C, Leary ET, Reaven GM. Effect of metformin treatment on multiple cardiovascular disease risk factors in patients with type 2 diabetes mellitus. Metabolism 2004;53:159-64.

9. Mather KJ, Verma S, Anderson TJ: Improved endothelial function with metformin in type 2 diabetes mellitus. J Am Coll Cardiol 2001;37:1344-50.

10. Arunachalam G, Samuel SM, Marei I, Ding H, Triggle CR. Metformin modulates hyperglycaemia-induced endothelial senescence and apoptosis through SIRT1. Br J Pharmacol. 2014;171:523-35.

11. Kooy A, de Jager J, Lehert $P$, Bets $D$, Wulffelé $M G$, Donker AJ, et al. Long-term effects of metformin on metabolism and microvascular and macrovascular disease in patients with type 2 diabetes mellitus. Arch Intern Med. 2009;169(6):616-25.
12. Lamanna C, Monami M, Marchionni N, Mannucci E. Effect of metformin on cardiovascular events and mortality: a metaanalysis of randomized clinical trials. Diabetes Obes Metab. 2011;13(3):221-8.

13. Chakraborty A, Chowdhury S, Bhattacharyya M. Effect of metformin on oxidative stress, nitrosative stress and inflammatory biomarkers in type 2 diabetes patients. Diabetes Res Clin Pract. 2011;93(1):56-62.

14. Yoshida N, Okumura K, Aso Y. High serum pentosidine concentrations are associated with increased arterial stiffness and thickness in patients with type 2 diabetes. Metabolism. 2005;54(3):345-50.

15. van Bussel BC, Schouten F, Henry RM, Schalkwijk CG, de Boer MR, Ferreira I, et al. Endothelial dysfunction and low-grade inflammation are associated with greater arterial stiffness over a 6-year period. Hypertension. 2011;58(4):588-95.

16. Schram M, Sep SJ, Kallen van der CJ, Dagnelie PC, Koster A, Schaper N, et al. The Maastricht Study: An Extensive Phenotyping Study on Determinants of Type 2 Diabetes, its Complications and its Comorbidities. Eur J Epidemiol. 2014;29(6):439-51.

17. WHO's ATC/DDD index 2016, accessible through: http://www.whocc.no/ atc_ddd_ index/

18. Van Wijk BL, Klungel $\mathrm{OH}$, Heerdink ER, de Boer A. The association between compliance with antihypertensive drugs and modification of antihypertensive drug regimen. J Hypertens. 2004;22(9):1831-7.

19. Van Bortel LM, Laurent $S$, Boutouyrie $P$, Chowienczyk P, Cruickshank JK, De Backer T, et al. Expert consensus document on the measurement of aortic stiffness in daily practice using carotid-femoral pulse wave velocity. Journal of hypertension. 2012;30(3):445-8.

20. Levey AS, Stevens LA, Schmid CH, Zhang YL, Castro AF 3rd, Feldman $\mathrm{HI}$, et al. A new equation to estimate glomerular filtration rate. Ann Intern Med. 2009;150:604-12.

21. Mancia G, Fagard R, Narkiewicz K, Redon J, Zanchetti A, Böhm M et al. 2013 ESH/ESC guidelines for the management of arterial hypertension: the Task Force for the Management of Arterial Hypertension of the European Society of Hypertension (ESH) and of 
the European Society of Cardiology (ESC). Eur Heart J. 2013;34(28):2159-219.

22. Spauwen PJ, van Eupen MG, Köhler $\mathrm{S}$, Stehouwer CD, Verhey FR, van der Kallen CJ, et al. Associations of advanced glycation endproducts with cognitive functions in individuals with and without type 2 diabetes: the maastricht study. J Clin Endocrinol Metab. 2015;100(3):951-60.

23. Scheijen JL, van de Waarenburg MP, Stehouwer CD, Schalkwijk CG. Measurement of pentosidine in human plasma protein by a single-column high-performance liquid chromatography method with fluorescence detection. J Chromatogr B Analyt Technol Biomed Life Sci. 2009;877:610-4.

24. Hanssen NM, Engelen L, Ferreira I, Scheijen JL, Huijberts MS, van Greevenbroek MM, et al. Plasma levels of advanced glycation endproducts $\mathrm{N} \varepsilon$-(carboxymethyl)lysine, $\mathrm{N} \varepsilon$ (carboxyethyl)lysine, and pentosidine are not independently associated with cardiovascular disease in individuals with or without type 2 diabetes: the Hoorn and CODAM studies. J Clin Endocrinol Metab. 2013;98(8):E1369-73.

25. Kiyici S, Ersoy C, Kaderli A, Fazlioglu M, Budak $F$, Duran C, et al. Effect of rosiglitazone, metformin and medical nutrition treatment on arterial stiffness, serum MMP-9 and MCP-1 levels in drug naive type 2 diabetic patients. Diabetes Res Clin Pract. 2009;86(1):44-50.

26. Lund SS, Tarnow L, Stehouwer CD, Schalkwijk CG, Teerlink T, Gram J, et al. Impact of metformin versus repaglinide on nonglycaemic cardiovascular risk markers related to inflammation and endothelial dysfunction in non-obese patients with type 2 diabetes. Eur J Endocrinol. 2008;158(5):631-41.

27. Esteghamati A, Eskandari D, Mirmiranpour $\mathrm{H}$, Noshad S, Mousavizadeh M, Hedayati M, et al. Effects of metformin on markers of oxidative stress and antioxidant reserve in patients with newly diagnosed type 2 diabetes: a randomized clinical trial. Clin Nutr. 2013;32(2):179-85.

28. Engelen L, Lund SS, Ferreira I, Tarnow L, Parving $\mathrm{HH}$, Gram J, et al. Improved glycemic control induced by both metformin and repaglinide is associated with a reduction in blood levels of 3-deoxyglucosone in nonobese patients with type 2 diabetes. Eur J Endocrinol. 2011;164(3):371-9

29. Hou X, Song J, Li XN, Zhang L, Wang X, Chen L, et al. Metformin reduces intracellular reactive oxygen species levels by upregulating expression of the antioxidant thioredoxin via the AMPK-FOXO3 pathway. Biochem Biophys Res Commun. 2010:28;396(2):199-205.

30. Sena CM, Matafome P, Louro T, Nunes E, Fernandes R, Seiça RM. Metformin restores endothelial function in aorta of diabetic rats. Br J Pharmacol. 2011;163(2):424-37.

31. Tucker GT, Casey C, Phillips PJ, Connor H, Ward JD, Woods HF. Metformin kinetics in healthy subjects and in patients with diabetes mellitus. Br J Clin Pharmacol. 1981;12(2):235-46. 

Chapter 4

Methodological Aspects 


\section{Chapter 4.1}

Evaluation of different missing data strategies in propensity score analyses

JHM Driessen, EJ Williamson, JR Carpenter, F de Vries 


\section{Abstract}

\section{Introduction}

Large databases containing routinely collected data, are very useful to study associations between drug exposure and outcomes. However, these data often suffer from missing data. Missing data can be handled by different approaches, including complete case analysis, adding an indicator and multiple imputation (MI). In contrast to multivariable regression, not much research has been done comparing these different missing data approaches when performing a propensity score (PS) analysis. Therefore the aim of our study was to assess the robustness of an estimated association when using a range of approaches to handle missing data within a PS analysis, and to contrast this with traditional multivariable regression.

\section{Methods}

In order to study this we evaluated the association between use of statins and risk of hip fracture as observational studies have shown contrasting results as compared to randomised controlled trials. One of the hypothesizes included the way how missing data on important confounders, such as smoking and body mass index (BMI), were handled in the observational studies.

A retrospective population-based cohort study, using data from the Clinical Practice Research Datalink (CPRD) database (1991-2014), was conducted. All patients with at least one prescription for a statin and who were aged 50 years or older were included. Statin users were matched to one non-user by year of birth, sex and practice, using incidence density sampling. Cox regression analysis was used to estimate the hazard ratio (HR) of hip fracture risk with use of statin as compared to non-statin use applying a complete case analysis, adding an indicator and performing MI. First all potential confounders were added in the multivariable Cox regression models to adjust for confounding. Second, the PSs were estimated by a logistic regression for statin use and weighted Cox regression was applied using the inverse of the PS as weight.

\section{Results}

Data on BMI was missing in $33.3 \%$ and $53.3 \%$ and smoking status in $7.9 \%$ and $10.1 \%$ of the statin and non-statin users, respectively. The adjusted HR for risk of fracture with statin use applying a complete case analysis was 1.09 (95\% confidence interval (Cl): 0.99-1.20); adding an indicator resulted in a HR of 1.01 (95\% Cl: 0.95-1.08); and performing $\mathrm{MI}$ in an $\mathrm{HR}$ of 1.04 (95\% Cl: 0.99-1.09). The PS adjusted HR was 0.96 (95\% Cl: 0.91-1.01) for the complete case analyses; 0.96 (95\% Cl: 0.92-0.99) when adding and indicator and after $\mathrm{Ml}$ the $\mathrm{HR}$ was 1.07 (95\% $\mathrm{Cl}: 1.03-1.11)$.

\section{Conclusion}

This study using a case-study showed that when compared to multivariable adjusted analyses, propensity score analyses show quite similar results when combined with different missing data strategies in time-fixed analyses. However, more research is needed to investigate whether this also applies to time-dependent time-to-event analyses. 


\section{Introduction}

Large databases containing routinely collected data, like the Clinical Practice Research Datalink (CPRD), are very useful to study associations between drug exposure and outcomes, and in particular adverse events. These databases are increasingly used to study unintended effects of drugs. However, these data suffer from missing data, predominantly data of potential confounders is missing.

When performing observational studies potential confounding factors have to be taken into account. This can be done by, amongst other techniques, multivariable regression analyses or propensity scores (PSs). PS methods deal with observed confounding by balancing the observed potential confounders across exposure groups being compared ${ }^{1}$. This is achieved by estimating each patient's propensity to be exposed and stratifying, matching, or weighting the sample using the estimated propensities $^{1}$. The weighting approaches are particularly attractive, since they extend naturally to situations where confounding is time-dependent, which will often be the case in studies drawing data from large observational databases.

There are a number of approaches which can be used to handle missing confounder data. Examples include performing a complete case analysis in which all records with one or more missing confounder values are deleted. Another method is the missing indicator method where separate categories are created for the missing observations ${ }^{2}$. Missing data can also be handled by use of an imputation approach ${ }^{3}$.

Much research has been done comparing these different missing data approaches when performing a multivariable regression analysis. Conducting a complete case analysis is an easy solution, however it may result in the exclusion of a substantial amount of observations which leads to reduced power and precision and can introduce bias under some circumstances ${ }^{3}$. When an indicator is added to handle the missing confounder data in a multivariable regression this results in biased estimates. As a result of adding an indicator, the missing data category is a mix of values of all different categories. In addition, the correlation between variables is ignored which may also result in bias $^{3,4}$. Nowadays, multiple imputation (MI) is increasingly used to handle missing data ${ }^{3}$. By use of $\mathrm{MI}$, different complete datasets are created in which missing values are replaced by imputed values. The observed data is used to impute the missing data taking into account the correlations between all variables used in the imputation model. This procedure is replicated multiple times to account for the uncertainty around the imputed values. Standard statistical methods are applied on the different imputed datasets and the results are then averaged by use of Rubin's rules ${ }^{5}$ to get an overall unbiased estimate under the assumption that the missing data are missing at random (MAR) ${ }^{3}$.

However, less research has been done on whether these missing data methods lead to consistent estimators when used in conjunction with a PS analysis. And if so, under what assumptions. Therefore the aim of our study is to assess the robustness of an 
estimated association when using a range of approaches to handle missing data within a PS analysis, and to contrast this with traditional multivariable regression. In order to study this we will evaluate the association between use of statins and risk of hip fracture and compare our results to the results of a large randomised controlled trial (RCT) which investigated the same research question ${ }^{6}$.

\section{Methods}

In order to evaluate the effect of different missing data strategies within a PS analysis, and to contrast this with traditional multivariable regression we studied the association between use of statins and hip fracture risk. Observational studies have shown a decreased risk of hip and any fracture with use of statins ${ }^{6-10}$, however, large RCTs were not able to confirm this decreased risk of fracture with use of statins ${ }^{11}$. Body mass index (BMI) and smoking are, amongst others, important potential confounders when examining the association between statin use and fracture risk and they are often incomplete. Bias introduced by the observational data being analysed in ways that do not properly account for this missing data might explain the differences between the results of the RCTs and the observational studies.

Data for this study were obtained from the CPRD in the United Kingdom, previously known as the General Practice Research Database (GPRD) [www.CPRD.com]. The CPRD contains computerized medical records of 674 primary care practices in the United Kingdom, representing $6.9 \%$ of the population ${ }^{12}$. The data recorded in the CPRD include demographic information, prescription details, clinical events, preventive care provided, specialist referrals, hospital admissions, and major outcomes since 1987. Previous studies using CPRD data have shown to be highly valid, with for example for hip fractures over $90 \%$ confirmed diagnoses ${ }^{13}$.

We conducted a retrospective population-based cohort study. The study population consisted of all patients with at least one prescription for a statin and who were aged 50 years or older during the period of valid CPRD data collection. For this study, data collection started on January $1^{\text {st }} 1991$, and ended on December $31^{\text {st }}, 2014$. The index date was defined as the date of the first statin prescription since the start of the study period (i.e. the study population was a mix of incident and prevalent statin users). A random selection of 400,000 statin users was made to keep the study population of a reasonable size. Statin users were matched to one non-user by year of birth, sex and practice, using incidence density sampling. The index date of the controls was set to the index date of the matched statin user.

\section{Exposure}

Non-users with a history of statin use before the index date were excluded. Additionally, we excluded all patients with a history of familiar hypercholesterolemia at 
index date. Patients who were prescribed a non-statin cholesterol lowering drug (cholestyramine, clofibrate, colestipol, gemfibrozil, niacin, probucol, fenofibrate and niacinamide) during the study period were excluded. Finally, patients with a history of hip or unspecified femur fracture were excluded as well as all patients with a hip fracture on the index date. Matched statin-users or non-users from excluded patients were excluded as well.

We first performed a series of multivariable adjusted analyses in combination with three methods to handle missing data being complete case analysis, adding an indicator and multiple imputation. Thereafter the same methods to handle missing data were combined with PSs to adjust for confounding.

\section{Outcome}

Patients were followed up from the index date to either the end of data collection, the date of the patient's transfer out of the practice area, the patient's death, the date of the hip fracture, or until the date when the exposure status changed (a first prescription for non-statin users or discontinuation for statin users), whichever came first. To determine discontinuation, the expected end date of each statin prescription was estimated and statin users were censored at the expected end date of the prescription when there was no new prescription within the following 90 days after the expected end date.

\section{Potential confounders}

The presence of potential confounders was assessed by reviewing the computerized medical records at the index date. Potential confounders that were determined were age, gender, smoking status (non-smoker, current smoker, former smoker or missing), the most recent $\mathrm{BMI}$ within three years before index date ${ }^{14}$ and alcohol consumption (yes/no). In addition, a history of any fracture (excluding hip/unspecified femur fracture), rheumatoid arthritis, chronic obstructive pulmonary disease, hyperthyroidism, congestive heart failure, or coronary artery disease were assessed. The following drug prescriptions within the six months prior to the index date were considered as potential confounders: anticonvulsants, non-steroidal anti-inflammatory drugs, methotrexate, hormone replacement therapy, thiazide diuretics, anxiolytics/ hypnotics, anti-psychotics, antidepressants, anti-parkinson drugs, corticosteroids (systemic and inhaled), bronchodilators, anti-diabetic drugs, and anti-hypertensive drugs.

The following auxiliary variables were used in the imputation model but not in the analysis model: The number of general practitioner visits year prior to the index date, calendar year, years of valid data collection within CPRD. 


\section{Statistical analyses}

Regression analysis with Cox proportional hazards models (SAS 9.4, PHREG procedure) was used to estimate the hip fracture rate for statin users compared to non-statin users. First, all potential confounders were added in the multivariable Cox regression analyses to adjust for confounding. Second, the PSs were estimated by a logistic regression for statin use, including all confounders listed above as explanatory variables. Then the inverse of the treatment probability was calculated by 1 divided by the predicted value for statin users and by $1 /$ (1-predicted value) for non-statin users. Thereafter a weighted Cox model was applied (including only the treatment variable) to estimate the hazard ratio for hip fracture between statin users and non-users.

For the complete case analyses all patients with a missing value for one of the confounders were excluded from the analyses. For the missing indicator approach a missingness indicator was added for all confounders with missing data (BMI, smoking and alcohol use). Multiple imputation was performed separately for the cases and controls using a fully conditional specification for the multiple imputation model: log BMI was modelled by linear regression, smoking status by a discriminant function and alcohol use by logistic regression. All potential confounders, the outcome variable, the auxiliary variables and the Nelson-Aalen estimator were included in the imputation model. The imputation was done five times. Each dataset was analysed separately where after the results were combined by use of Rubin's rules. For the PS analyses, the PSs and the weighted Cox model were performed separately for each imputed dataset, where after the results were combined.

\section{Results}

After exclusions the final study populations consisted of 551,444 patients, of whom 275,722 were statin users and the same number were non-statin users, Figure 4.1.1. The mean age of both statin users and non-statin users was 65.9 years, and $46.5 \%$ of the population was women. There was no BMI recorded in the three years prior to the index date for $33.3 \%$ of the statin users and $53.3 \%$ of the non-statin users. Smoking was missing in $7.9 \%$ and $10.1 \%$ and alcohol in $14.9 \%$ and $19.0 \%$ of the statin, and non-statin users, respectively, Table 4.1.1.

For the complete case analysis all observations with a missing value for BMI, smoking or alcohol were deleted (47.5\%) resulting in a population of 289,330 patients: 168,891 statin users and 120,439 non-statin users. The hazard ratio (HR) for risk of fracture with statin use applying a multivariable adjusted complete case analysis was 1.09 (95\% confidence interval (CI): 0.99-1.20). Applying an indicator analyses resulted in a multivariable adjusted $\mathrm{HR}$ of 1.01 (95\% Cl: 0.95-1.08). After applying multiple imputation of the missing variables the estimated HR of fracture risk with statin use was 1.04 (95\% Cl: 0.99-1.09), Table 4.1.2. 


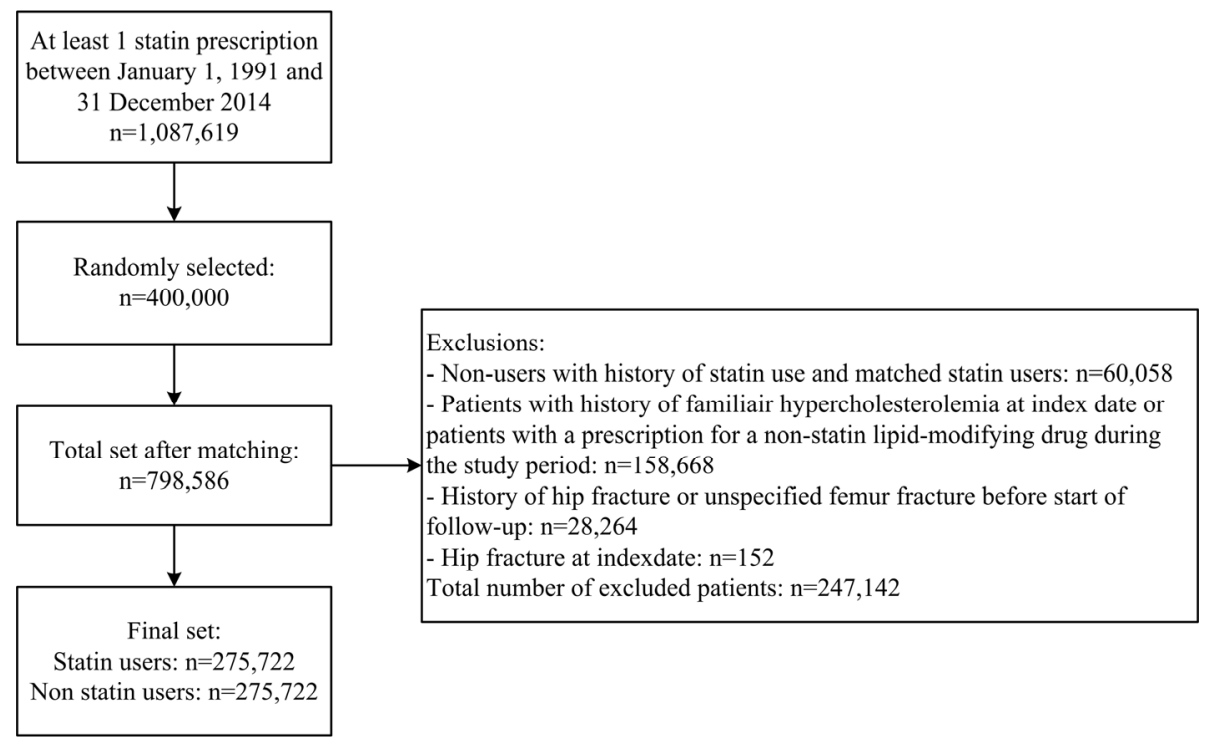

Figure 4.1.1 Flowchart.

Table 4.1.1 Baseline characteristics.

\begin{tabular}{lcc}
\hline Characteristic & $\begin{array}{c}\text { Statin users } \\
(\mathrm{N}=275,722)\end{array}$ & $\begin{array}{c}\text { Non-statin users } \\
(\mathrm{N}=275,722)\end{array}$ \\
\hline Mean follow-up time (years, SD) & $3.8(3.7)$ & $5.7(4.1)$ \\
Females & $128,263(46.5)$ & $128,263(46.5)$ \\
Age & & \\
Mean age at index date (years, SD) & $65.9(10.5)$ & $65.9(10.5)$ \\
$50-59$ years & $86,157(31.2)$ & $86,157(31.2)$ \\
$60-69$ years & $91,284(33.1)$ & $91,284(33.1)$ \\
$70-79$ years & $65,663(23.8)$ & $65,663(23.8)$ \\
$80-89$ years & $28,987(10.5)$ & $28,987(10.5)$ \\
$90+$ & $3,631(1.3)$ & $3,631(1.3)$ \\
BMI & & \\
Mean BMI at index date $\left(\mathrm{kg} / \mathrm{m}^{2}, \mathrm{SD}\right)$ & $28.8(5.6)$ & $27.5(5.4)$ \\
$<25 \mathrm{~kg} / \mathrm{m}^{2}$ & $45,576(16.5)$ & $43,097(15.6)$ \\
$25.0-29.9 \mathrm{~kg} / \mathrm{m}^{2}$ & $73,210(26.6)$ & $50,618(18.4)$ \\
$30.0-34.9 \mathrm{~kg} / \mathrm{m}^{2}$ & $42,179(15.3)$ & $23,898(8.7)$ \\
$\geq 35.0 \mathrm{~kg} / \mathrm{m}^{2}$ & $23,066(8.4)$ & $11,141(4.0)$ \\
Missing & $91,691(33.3)$ & $146,968(53.3)$ \\
Smoking status & & \\
Never & $116,609(42.3)$ & $128,578(46.6)$ \\
Current & $66,770(24.2)$ & $60,283(21.9)$ \\
Ex & $70,595(25.6)$ & $59,115(21.4)$ \\
Missing & $21,748(7.9)$ & $27,746(10.1)$ \\
\hline
\end{tabular}


Table 4.1.1 (continued)

\begin{tabular}{lrr}
\hline & \multicolumn{1}{c}{$\begin{array}{c}\text { Statin users } \\
\text { Characteristic }\end{array}$} & \multicolumn{1}{c}{$\begin{array}{c}\text { Non-statin users } \\
(\mathrm{N}=275,722)\end{array}$} \\
\hline Alcohol use & & \\
No & $53,358(19.4)$ & $44,512(16.1)$ \\
Yes & $181,314(65.8)$ & $178,759(64.8)$ \\
Missing & $41,050(14.9)$ & $52,451(19.0)$ \\
History of diseases & & \\
Fracture (excluding hip / unspecified femur) & $52,065(18.9)$ & $50,558(18.3)$ \\
Hyperthyroidism & $2,296(0.8)$ & $1,838(0.7)$ \\
Coronary artery disease & $67,580(24.5)$ & $20,774(7.5)$ \\
COPD & $14,211(5.2)$ & $12,447(4.5)$ \\
Congestive heart failure & $10,073(3.7)$ & $5,329(1.9)$ \\
Rheumatoid arthritis & $4,469(1.6)$ & $4,068(1.5)$ \\
Drug use within past six months & & \\
Antidepressants & $33,955(12.3)$ & $8,530(3.1)$ \\
Anxiolytics/hypnotics & $19,744(7.2)$ & $5,511(2.0)$ \\
Antipsychotics & $3,443(1.2)$ & $1,063(0.4)$ \\
Antihypertensives & $143,967(52.2)$ & $24,507(8.9)$ \\
Anti-parkinson drugs & $1,095(0.4)$ & $498(0.2)$ \\
Hormone replacement therapy & $3,073(1.1)$ & $1,549(0.6)$ \\
NSAIDs & $39,249(14.2)$ & $11,497(4.2)$ \\
Anti-convulsants & $7,697(2.8)$ & $1,777(0.6)$ \\
Methotrexate & $1,367(0.5)$ & $466(0.2)$ \\
Systemic glucocorticoids & $27,322(9.9)$ & $7,960(2.9)$ \\
Thiazide diuretics & $50,344(18.3)$ & $7,889(2.9)$ \\
Bronchodilators & $28,039(10.2)$ & $2,291(0.8)$ \\
Anti-hyperglycaemic drugs & $32,931(11.9)$ & \\
\hline
\end{tabular}

Data presented as number (\%), unless stated otherwise. BMI: body mass index, COPD: chronic obstructive pulmonary disease; NSAID: non-steroidal anti-inflammatory drugs; SD: standard deviation.

Table 4.1.2 Risk of hip fracture with statin use based on time-fixed analyses combined with three different methods to handle missing data.

\begin{tabular}{lccc}
\hline Missing data method & $\begin{array}{c}\text { Age/sex adjusted HR } \\
(95 \% \mathrm{Cl})\end{array}$ & $\begin{array}{c}\text { Multivariate adjusted } \\
\mathrm{HR}(95 \% \mathrm{Cl})\end{array}$ & $\begin{array}{c}\text { Propensity score analyses } \\
\mathrm{HR}(95 \% \mathrm{Cl})\end{array}$ \\
\hline Complete case & $1.31(1.21-1.41)$ & $1.09(0.99-1.20)$ & $0.96(0.91-1.01)$ \\
Indicator method & $1.25(1.19-1.32)$ & $1.01(0.95-1.08)$ & $0.96(0.92-0.99)^{*}$ \\
Multiple imputation & $\mathrm{n} / \mathrm{a}^{\mathrm{a}}$ & $1.04(0.99-1.09)$ & $1.07(1.03-1.11)^{*}$ \\
\hline
\end{tabular}

$\mathrm{Cl}$ : confidence interval; HR: hazard ratio, n/a: not applicable. ${ }^{a}$ Only exposure, age and sex were used in this analyses without missing data, therefore multiple imputation is not applicable. ${ }^{*}$ Statistically significant, $p$ value $<0.05$.

The density of the PSs stratified by statin use and non-statin use for the different methods to handle missing data are shown in Figure 4.1.2. After inverse probability weighting the density curves were overlapping. The PS complete case analysis showed a $\mathrm{HR}$ of 0.96 (95\% Cl: 0.91-1.01). The PS adjusted indicator analyses resulted in an HR 
for risk of hip fracture with statin use of 0.96 (95\% Cl: 0.92-0.99). Multiple imputation in combination with PS adjustments showed a HR of 1.07 (95\% Cl:1.03-1.11), Table 4.1.2.
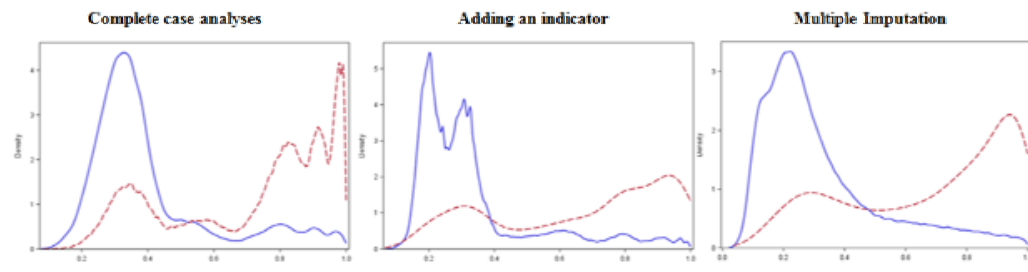

Blue: Non-statin use

Red: Statin use

Figure 4.1.2 Density plots of the propensity scores for the statin users and non-statin users by method used to handle missing data.

\section{Discussion}

In this study we evaluated the effect of combining different methods to handle missing data and performing PS analyses in time-fixed analyses. The effect estimates in the PS analyses were quite comparable to the results from the multivariable adjusted analyses.

PSs have shown to give similar results to multivariate adjustments ${ }^{15,16}$, which is in line with our results. A review, comparing multivariate adjustment effect estimates to PS effect estimates, showed that multivariable models sometimes show a significant result where corresponding PS analyses do not ${ }^{15}$. However, the opposite was not seen in the review ${ }^{15}$. This is in contrast to the present results, as we showed small significant results with the PS analysis in opposite directions while this was not seen with in the corresponding multivariable adjusted analyses.

It is known that when the missingness is related to the outcome and a complete case analyses is performed this will result in biased estimates. When the missingness is not related to the outcome a complete case analysis can give unbiased exposure estimates, although precision and power is lost due to the exclusion of observations. Applying an indicator method in combination with multivariable analyses often gives biased results, even when the data are missing completely at random (MCAR) ${ }^{17}$. In contrast, multiple imputation gives unbiased estimates when missing data are $M A R^{3}$.

$\mathrm{BMI}$ is not thought to be MCAR as it is often collected opportunistically and it has been shown that BMI completeness varies across different diseases and patient characteristics $^{14}$. Missing BMI values may be MAR. A study using data from The Health Improvement Network (THIN), a British primary care database, showed that after MI, data on height and weight were comparable to external data ${ }^{18}$. These results suggest 
that it may be possible to account for missing BMI data applying MI using data from clinical primary care databases ${ }^{18}$. By using clinical information on diseases and medication use we aimed to predict BMI and satisfy the MAR assumption.

For alcohol use and smoking it has been shown that after $\mathrm{Ml}$ the results were not comparable to external data, investigating the first year after a patients registration, suggesting that these data are missing not at random ${ }^{18}$. However it was also suggested that when the available data covers longer periods of time $\mathrm{MI}$ may be valid ${ }^{18}$. In the present study we had data on a longer period available to determine alcohol consumption and smoking status at baseline which might have led to better results when performing $\mathrm{MI}$.

In the present study we did not find large differences between the effect estimate when applying a complete case analysis, adding an indicator or performing multiple imputation to handle missing data in combination with multivariate adjustments, perhaps suggesting that the bias due to the indicator method and the complete case method was rather small in the multivariable adjusted analyses.

Strengths of this study include the large sample size, longitudinal data and extensive information on potential confounders which could be used to estimate the PS and which were used to predict the confounders with missing data when performing MI. However, we only performed time-fixed analyses, which limits the generalizability of our results.

This study using a case-study showed that when compared to multivariable adjusted analyses, propensity score analyses show quite similar results when combined with different missing data strategies in time-fixed analyses. However, more research is needed to investigate whether this also applies to time-dependent time-to-event analyses. 


\section{References}

1. Williamson EJ, Forbes A. Introduction to propensity scores. Respirology. 2014;19(5):625-35.

2. Vach $W$, Blettner M. Biased estimation of the odds ratio in case-control studies due to the use of ad hoc methods of correcting for missing values for confounding variables. Am J Epidemiol. 1991;134:895-907.

3. Sterne JA, White IR, Carlin JB, Spratt $M$, Royston $\mathrm{P}$, Kenward $\mathrm{MG}$, et al. Multiple imputation for missing data in epidemiological and clinical research: potential and pitfalls. BMJ. 2009:29;338:b2393.

4. Qu Y, Lipkovich I. Propensity score estimation with missing values using a multiple imputation missingness pattern (MIMP) approach. Stat Med. 2009 28(9):1402-14.

5. Rubin D. Multiple imputation for nonresponse in surveys. New York: Wiley, 1987.

6. Chan KA, Andrade SE, Boles M, Buist DS, Chase GA, Donahue JG, et al. Inhibitors of hydroxymethylglutaryl-coenzyme $A$ reductase and risk of fracture among older women. Lancet. 2000;355(9222):2185-8.

7. Scranton RE, Young M, Lawler E, Solomon D, Gagnon D, Gaziano JM. Statin use and fracture risk: study of a US veterans population. Arch Intern Med. 2005;165(17):2007-12.

8. Wang PS, Solomon DH, Mogun $\mathrm{H}$, Avorn J. HMG-CoA reductase inhibitors and the risk of hip fractures in elderly patients. JAMA. 2000;283(24):3211-16.

9. Meier CR, Schlienger RG, Kraenzlin ME, Schlegel B, Jick H. HMG-CoA reductase inhibitors and the risk of fractures. JAMA. 2000;283(24):3205-10.

10. Helin-Salmivaara A, Korhonen MJ, Lehenkari $P$, Junnila SY, Neuvonen PJ, Ruokoniemi P, et al. Statins and hip fracture prevention-a population based cohort study in women. PLoS One. 2012;7(10):e48095.

11. Peña JM, Aspberg S, MacFadyen J, Glynn RJ, Solomon DH, Ridker PM. Statin therapy and risk of fracture: results from the JUPITER randomized clinical trial. JAMA Intern Med. 2015;175(2):171-7.

12. Herrett E, Gallagher AM, Bhaskaran K, Forbes $H$, Mathur R, van Staa $T$, et al. Data Resource Profile: Clinical Practice Research Datalink (CPRD). Int J Epidemiol. 2015;44(3):827-36.

13. Van Staa TP, Abenhaim L, Cooper C, Zhang B, Leufkens HG. The use of a large pharmacoepidemiological database to study exposure to oral corticosteroids and risk of fractures: validation of study population and results. Pharmacoepidemiol Drug Saf. 2000;9(5):359-66.

14. Bhaskaran K, Forbes HJ, Douglas I, Leon DA, Smeeth L. Representativeness and optimal use of body mass index (BMI) in the UK Clinical Practice Research Datalink (CPRD). BMJ Open. 2013;3(9):e003389.

15. Shah BR, Laupacis A, Hux JE, Austin PC. Propensity score methods gave similar results to traditional regression modeling in observational studies: a systematic review. J Clin Epidemiol. 2005;58(6):550-9.

16. Stürmer T, Wyss R, Glynn RJ, Brookhart MA. Propensity scores for confounder adjustment when assessing the effects of medical interventions using nonexperimental study designs. J Intern Med. 2014;275(6):570-80.

17. Donders AR, van der Heijden GJ, Stijnen $T$, Moons KG. Review: a gentle introduction to imputation of missing values. J Clin Epidemiol. 2006;59(10):1087-91.

18. Marston L, Carpenter JR, Walters KR, Morris RW, Nazareth I, Petersen I. Issues in multiple imputation of missing data for large general practice clinical databases. Pharmacoepidemiol Drug Saf. 2010;19(6):61826. 



\section{Chapter}

General Discussion 
This thesis evaluated several unintended effects of various classes of antihyperglycaemic drugs in population-based cohorts. In Chapter 2 we evaluated the association between use of incretin agents, both dipeptidyl peptidase 4 inhibitors (DPP4-Is) and glucagon-like peptide 1 receptor agonists (GLP1-RAs), and risk of fracture. Thereafter we assessed whether data from the Maastricht Study could be used to evaluate unintended effects of diabetes medication (Chapter 3 ). Finally, we studied the robustness of an estimated association when using a range of approaches to handle missing data within a propensity score analyses. In this final chapter the main findings and the clinical implications will be discussed. This is then followed by a discussion of methodological considerations and future perspectives. This thesis will conclude with clinical and methodological recommendations based on the results of this thesis.

\section{Main findings}

The aim of Chapter 2 was to investigate the association between the use of incretin agents and fracture risk. We did not find an association between short-term use of DPP4-Is or GLP1-RAs and risk of fracture using data representative for the United Kingdom (UK) as well as data representative for Denmark. Additionally, we did not find an association between use of these incretin agents after meta-analysing our results. Moreover, long-term use ( $>4$ years) of DPP4-Is was not associated with risk of fracture either. These findings are in line with the results from a large clinical trial $(n=16,492)$, demonstrating no association with fracture risk when comparing DPP4-I use to placebo $^{1,2}$. Two recent meta-analyses of 51 and 62 randomised controlled trials (RCTs), respectively, comparing DPP4-Is to an active comparator or placebo also showed no association $^{3,4}$. Data from RCTs comparing GLP1-RAs to active comparator or placebo have also been meta-analysed. No overall effect has been found ${ }^{5,6}$. However, when GLP1-RAs were stratified by type, a reduced risk of fracture was reported with liraglutide while users of exenatide had an elevated risk ${ }^{6}$.

Based on the data presented in this thesis and together with data from literature it can be concluded that there is no beneficial effect of incretin agents on fracture risk. Hence, these findings may be of value for clinical decisions regarding treatment of patients with T2DM, especially those at high fracture risk.

The aim of Chapter 3 was to assess the usefulness of the Maastricht Study data to evaluate unintended effects of diabetes medication (Chapter 3). After evaluating the representativeness of the data we first explored the association between use of insulin as compared to non-insulin use and bone micro-architecture and strength parameters. Secondly, we studied the association between use of metformin and carotid-femoral pulse wave velocity (cfPWV), as a measure for arterial stiffness.

Participants visit the Maastricht Study four to five times for the extensive assessment of various measurements ${ }^{7}$. This might have resulted in a selected 
population as only patients who were able and willing to undergo this extensive procedure were included. The first published studies showed indeed that participants of the Maastricht Study were on average younger, had a higher level of education and were healthier than the source population ${ }^{8-10}$. However, it was unknown whether this was also present with respect to the dispensing data of the Maastricht Study participants. Therefore we compared the dispensing data of the Maastricht Study to drug reimbursement data of the total Dutch population.

For most of the investigated drugs we found similar results between the national data and the Maastricht Study data, except for respiratory prescriptions and hypnotics/anxiolytics. One of the hypotheses for this decreased number of respiratory prescriptions is the fact that these drugs are often prescribed for asthma and/or chronic obstructive pulmonary disease (COPD). Guidelines recommend that patients with severe asthma or COPD needs to be followed-up frequently ${ }^{11,12}$. Patients with severe asthma or COPD might therefore be less willing or able to participate in the Maastricht Study. This then could partially explain the lower number of respiratory prescriptions.

The use of hypnotics/anxiolytics was significantly higher in the study population, as compared to the national population. One of the hypothesis is that the participants of the Maastricht Study are in general healthier but also more care seeking as compared to the Dutch population ${ }^{13}$.

Anti-hyperglycaemic drug use was comparable between the national data and the Maastricht Study data. However, a report on national prescription data showed that the average number of citizens who had at least one drug prescription was higher in the South-Limburg region as compared to national average in 2013 (720 vs. 677 per 1000 insured citizens, respectively) ${ }^{14}$. This was not reflected in the Maastricht Study dispensing data, which is in agreement with earlier results suggesting that participants of the Maastricht Study are relatively healthy ${ }^{8-10}$. An advantage of the selected Maastricht Study population is the fact that it enables the study of potential unintended effects in patients with a relatively short duration of T2DM and with only a few comorbidities.

As a consequence of the relatively healthy Maastricht Study population the studied associations may be underestimated as patients with more severe T2DM are less likely to be present in the Maastricht Study. However, it can also be hypothesized that the associations are overestimated. A case-control study investigating the association between stroke and risk of fracture showed that risk of fracture was greatest in younger patients ${ }^{15}$. It was hypothesized that older patients have multiple risk factors increasing fracture risk, whereas this is less the case in younger patients resulting in a relatively larger contribution of stroke to fracture risk in the younger patients.

Then two different pharmacoepidemiological studies using data from the Maastricht Study were performed. Chapter 3.2 was a small explorative study investigating the potential association between use of insulin compared to non-insulin 
use and bone micro-architecture and strength parameters. A larger number of patients is needed before we can draw definite conclusions about the potential association. Nevertheless, the explorative results showed that use of insulin was negatively associated with bone micro-architectural and bone strength parameters.

Based on the results from Chapter 3.3 we concluded that metformin dosage and duration was not associated with a beneficial effect on arterial stiffness, as measured by cfPWV. However, the relatively healthy population may be an alternative explanation for the fact that we did not find an association. Additionally, we concluded that, although investigated in a small population, metformin was not associated with plasma advanced glycation end products (AGEs) or AGEs measured by skin autofluorescence. This is in line with the results of a RCT, which investigated whether metformin may have beneficial effects on AGEs ${ }^{16}$. This led to the hypothesis that not metformin itself but its anti-hyperglycaemic effect reduces the level of plasma AGEs.

The studies presented in Chapter 3.2 and 3.3 showed that it is possible to perform pharmacoepidemiological research using data from the Maastricht Study. Examples of the extensive phenotyping in the Maastricht Study include the measurement of the bone architectural and bone strength parameters as well as the measurement of arterial stiffness via cfPWV. These measurements are generally not present in electronic healthcare databases (EHDs). Moreover there is longitudinal dispensing data available in the Maastricht Study which makes it an unique database to perform pharmacoepidemiological research. The results from Chapter 3.2 and 3.3 cannot be translated into clinical implications yet, as larger number of patients and longitudinal data is needed before definite conclusion can be drawn.

The last aim of this thesis was to investigate the effect on treatment estimates when different methods to handle missing data are combined with propensity score analysis. From the case study in Chapter 4.1 it can be concluded that combining propensity scores with different methods to handle missing data may result in similar treatment estimates as compared to multivariable adjusted estimated when performing time-fixed time-to-event analyses. Further, more research is needed whether this also applies to time-dependent time-to-event analyses.

\section{Methodological considerations of the work presented in this thesis}

Although the studies presented in this thesis had different strengths, including the use of population-based data and large sample sizes, the results also need to be viewed in the light of some methodological considerations. When interpreting the results of the studies presented in this thesis some potential sources of bias need to be taken into account. 
Bias is defined as a systematic error in the design of the study or as a systematic error in the collection, analysis, interpretation, reporting, or review of the data, which leads to results which are systematically different from the truth ${ }^{17}$. Most biases can be classified as either information bias, selection bias or confounding. Information bias occurs when there is incorrect information on exposure, outcome or confounding variables. Selection bias happens when study participants are not representative for the outcome or exposure in the source population due to selective recruitment. Confounding is the result of an imbalance of covariates between the different compared groups which results in a biased estimate of the effect measure ${ }^{18}$.

Bias might seriously distort the estimated effect measures and should therefore be avoided as much as possible. It is not possible to correct analyses for bias. The only way to minimize bias is by a proper study design ${ }^{19}$. The results of the studies presented in this thesis will now be considered in light of some potential sources of bias.

\section{Information bias}

\section{Misclassification bias}

Data on dispensed prescriptions is often used to determine drug exposure in pharmacoepidemiological studies. However, this does not necessary reflect whether patients actually took the drug or not. Therefore, this may result in misclassification bias as patients are classified as exposed while they actually were not exposed ${ }^{18}$. When this occurs equally between the studied groups, or when the misclassification is independent of the outcome or exposure it is said to be non-differential ${ }^{18}$. If the exposure is dichotomous this non-differential misclassification bias results in an effect towards the null. However, when there are more than two exposure categories the direction of the bias can be either towards or away from the null, depending on the exposure categories in which the misclassification occurs ${ }^{20-22}$. Non-differential misclassification bias might have occurred in all studies (except Chapter 2.1) in this thesis. It is hard to determine the direction of the bias as there were often more than two exposure categories in the presented studies.

Differential misclassification occurs when the misclassification is not independent of the outcome or exposure. This bias can seriously distort the effect estimates. Multiple examples are discussed below as well as the likeliness of the occurrence in the presented studies in this thesis and the potential effects of these biases.

\section{Immortal time bias}

This bias occurs when there is a period of follow-up or observation time during which death cannot occur. This might happen for instance when patients need to have at least 
a number of prescriptions before they enter the cohort and when this time is not properly taken into account (e.g. classified as exposed instead of unexposed) ${ }^{23}$. This form of immortal time bias might also occur when patients are classified based on a prescription they will get in the future. The time until the prescription is then immortal and is classified as exposed while patients are actually unexposed. Such a misclassification might then result in a lower relative risk of the studied drug $^{24}$.

Immortal time bias can only occur in cohort studies and may therefore only be an issue in Chapter 2.2, 2.4 and 2.7. Since patients were followed from the first prescription and all time between the start of follow-up and the first prescription for the drug of interest (either DPP4-I or GLP1-RA) was classified as unexposed, these studies do not suffer from this bias.

\section{Recall bias}

Recall bias is defined as a bias due to differences between what cases and controls remember about for instance exposure or events in the past ${ }^{25}$. One of the advantages of the use of EHDs is that data is collected prospectively and it often does not use selfreported data which excludes the possibility of recall bias. Therefore this has likely not been a problem in the studies presented in Chapter 2. However, potential confounders such as falls may have suffered from recall bias as these can only be registered after questioning the patients. We were only able to adjust for falls in the cohort studies (Chapter 2.2, 2.4 and 2.7). Consequently, information on falls was collected before the fracture occurred and this may have reduced the potential for recall bias.

Another variable which may be effected by recall bias is body mass index (BMI). It is possible that weight is based on self-reported weight by the patients instead of being measured by the general practitioner (GP) every time. This may then result in an underestimated BMI. However, when this occurred equally between the different exposure groups this results in a bias towards the null. If BMI was more underreported in the incretin exposure groups this may have masked a potential protective association between the incretin agents (either DPP4-Is or GLP1-RAs) and fracture risk.

Part of the Maastricht Study data is based on questionnaires and therefore recall bias might be an issue in the studies presented in Chapter 3. Chapter 3.1 is only based on collected pharmacy data, so recall bias is not an issue there. Chapter 3.2 only used self-reported data on the duration of disease. This may have been more accurately recorded in patients using metformin as the time since diagnoses of T2DM is likely to be shorter as compared to participants with T2DM using insulin. When insulin users underestimate the duration of disease this might result in an estimate which is not fully adjusted for disease duration. Disease duration is associated with poorer bone quality. Not fully adjusting for disease duration might therefore result in an effect away from the null. In contrast, when insulin users overestimate the disease duration over- 
adjusting may occur, resulting in an effect towards the null. In Chapter 3.3 only metformin users were investigated, and therefore recall bias is not expected.

\section{Prothopatic bias}

This can arise when an underlying outcome (not yet diagnosed) causes the studied exposure $^{26}$. A potential association where this could occur is when use of incretin agents and risk of pancreatic cancer is studied. Undiagnosed pancreatic cancer may result in T2DM or T2DM-like symptoms, which will lead to treatment with antihyperglycaemic drugs. Due to the pancreatic cancer the glycaemic control might worsen quite quickly resulting in the prescription of second-line treatment, such as incretin agents ${ }^{27}$. Then pancreatic cancer will be diagnosed. As a consequence, a falsepositive result might be found, suggesting that these drugs increase the risk of pancreatic cancer. This is an example of reverse causality because the outcome of interest is actually causing the exposure (the prescription of incretin agents). A study investigating use of incretin agents and risk of pancreatic cancer showed a rapid increase in the risk of pancreatic cancer with only a small number of incretin prescriptions. The risk of pancreatic cancer declined with longer-term incretin use. One of the explanations for this increased risk with short-term use was prothopatic bias ${ }^{28}$.

Prothopatic bias often arises if there is a long time between the onset of the disease and the time of diagnosis. When studying fracture as an outcome this will likely not be an issue except for vertebral fracture. It is estimated that only one third to one fourth of the vertebral fractures come to clinical attention ${ }^{29,30}$. Though, it is unlikely that a vertebral fracture will lead to prescription of anti-hyperglycaemic drugs. Additionally, we did not find an increased risk of vertebral fracture with current use of DPP4-Is or GLP1-RAs. It is unlikely that prothopatic bias has occurred in Chapter 3.2 and 3.3. To be an issue, worse bone quality, reduced bone strength or increased cfPWV should have caused an increase of the prescription of the investigated drugs.

\section{Immeasurable time bias}

Immeasurable time bias is a form of bias which occurs when an exposure is not measureable for a certain period of time due to for instance hospitalizations ${ }^{31}$. When this is different between exposed and unexposed groups or between cases and controls this will lead to bias. In a case-control study this might happen when outcomes like mortality are studied. It has been estimated that 53\% of the patients in England dies in the hospital ${ }^{32}$. EHDs, such as the clinical practice research datalink (CPRD), only contain data on prescriptions prescribed by the GP. People who die are more often hospitalized in the period before, and during this hospitalization period the exposure is immeasurable. In cohort studies immeasurable time bias can occur when patients with a chronic disease, and consequently many hospitalizations, are compared to patients without the disease and a lower number of hospitalizations. Again the exposure is 
immeasurable and this than might result in a virtual protective effect of the studied exposure.

There is no reason to suspect that patients are often hospitalized just before a fracture, so this will not influence the results of the case-control studies in Chapter 2.3 and 2.5. However, this type of bias might also have occurred when the date of fracture is not correctly recorded which will then result in immeasurable time. For the casecontrol studies presented in Chapter 2.3 and 2.5 we used Danish hospital data including the admission date ${ }^{33}$. Therefore it is expected that the date of fracture is accurate.

Additionally, in our cohort studies we compared person time of patients with the same disease and thereby limited the immeasurable time window bias in Chapter 2.2, 2.4 and $2.7^{31}$. For the studies presented in Chapter 3, pharmacy dispensing records were collected. We might have missed dispensings due to hospitalizations. However, this is not expected to be differential between the studied groups, and therefore immeasurable time bias is probably not an issue in these studies.

\section{Time window bias}

When the opportunity for exposure is different between cases and controls (in a casecontrol study), time window bias can occur ${ }^{34}$. This was shown in a study investigating the association between use of statins and lung cancer ${ }^{35}$. The end of study was determined by the date of the cancer diagnosis for the cases. For the controls it was set to the end of the study period. Consequently, the average observation period was longer for controls as for cases. The exposure was determined as having at least one statin prescription. This resulted in a higher chance of exposure for the controls and finally an artificial $40 \%$ reduced risk of lung cancer with use of statins.

In our case-control studies the index date for the controls was set to the date of fracture of the cases, avoiding this form of time window bias. Additionally, the mean duration of treatment with incretin agents, was similar for cases and controls, suggesting that they have had the same opportunity of exposure (Chapter 2.3 and 2.5$)^{34}$.

\section{Missing data}

The way missing data are handled may also result in bias. When the missingness is related to the outcome performing a complete-case analyses will result in a biased estimates. However, when the missingness is unrelated to the outcome a completecase analyses will not result in biased estimates for the investigated exposure although a complete-case analyses will result in lower power and less precision due to the excluded observations. Another method to deal with missing data is by adding an indicator for the missingness to the analysis. This will always result in biased results as the correlation between the variables is ignored ${ }^{36,37}$. 
The studies using the Danish national health services register (NHSR) data did not suffer from missing data. For the CPRD data we had missing data for some lifestyle variables (BMI, alcohol use and smoking) and glycosylated hemoglobin A1c (HbA1c). For these analyses, we applied the indicator method, which might have resulted in a biased effect estimate. Since the results were comparable to the results from Chapter 2.3 and 2.5 , this suggests that the amount of bias might have been limited. In addition, in Chapter 4.1 we showed that the different methods to handle missing data (completecase analysis, adding an indicator or performing $\mathrm{MI}$ ) resulted in comparable effect estimates in time-fixed analyses when combined with multivariate adjustments. However, it needs to be taken into account that these results were based on time-fixed analyses, while most studies in this thesis were analysed by use of a time-dependent approach.

In both Chapter 3.2 and 3.3 we have applied the complete-case analysis method which, under the assumption that the missingness is not related to the outcome, results in unbiased estimates. When the missingness was related to the outcome this may have resulted in biased results. In Chapter 3.3 most of the cases were excluded due to missing cfPWV data, which was mainly missing due to logistic reasons, and therefore not expected to cause bias.

\section{Selection bias}

\section{Immortal time bias}

When immortal time is excluded from the analyses, it is classified as selection bias ${ }^{38}$. An example includes a study in which unexposed person time was excluded from the analyses ${ }^{39,40}$. As a consequence, patients who experienced an event in that period were not taken into account in the analyses at all, and this resulted in biased estimates. It has been shown that such an exclusion may result in an artificial reduced risk ${ }^{24}$.

This form of immortal time bias was not an issue in the cohort studies presented in this thesis (Chapter 2.2, 2.4 and 2.7), as the cohort entry was equal to the date of the first anti-hyperglycaemic prescription since start of the study. Additionally patients were classified as unexposed to the drug under study (DPP4-I/GLP1-RA) until their first prescription and this time was taken into account as unexposed and not excluded. As immortal time bias can only occur in cohort studies this was not an issue in the other presented studies in this thesis.

\section{Depletion of susceptibles}

Depletion of susceptibles can occur when prevalent users are compared to incident users and an acute unintended-effect is studied ${ }^{27,41}$. The prevalent users might have a 
different risk for the adverse event than the first-time users, and this causes biased results. It is therefore important to compare new-users of such a drug with a potential acute adverse effect with new-users of the comparison drug.

Bone is continuously remodelled, the process of remodelling takes about 3-6 months. It has been shown that drugs which increase bone mineral density need to be taken for at least 6-12 months to prevent vertebral fractures ${ }^{42}$ and more than 18 months to prevent other fractures including hip fractures ${ }^{42,43}$. It is therefore not expected that the effect of incretins on fracture risk is acute, and depletion of susceptibles based on this theory is therefore not an issue in Chapter 2.

Patients could also have an increased fracture risk just after they have started a certain type of anti-hyperglycaemic agents due to an increased fall risk. This is highly likely when patients start with insulin. However, this is unlikely with incretin agents, as they very rarely cause hypoglycaemic events ${ }^{44}$. In Chapter 2.7 a sensitivity analyses was performed only including new anti-hyperglycaemic drug users and this did not materially change the results. Chapter 3.2 and 3.3 used cross-sectional outcome data, therefore depletion of susceptibles was not an issue.

\section{Time lag bias}

Time lag bias occurs when patients with a certain disease are compared to patients with a different stage of the same disease ${ }^{45}$. When disease duration is associated with the outcome this results in bias. This bias may have occurred in the studies presented in Chapter 2.2-2.7 as we compared current use of incretin agents to use of other antihyperglycaemic drugs.

Duration of diabetes is positively associated with fracture risk ${ }^{46}$. The average disease duration is expected to be higher for current DPP4-I or GLP1-RA users than the users in the comparison group. Therefore, this might have masked a protective association between use of DPP4-Is or GLP1-RAs and risk of fracture. However, it has been hypothesized that duration of diabetes via increased complications of diabetes is associated with an increased risk of fracture ${ }^{46}$. We have adjusted the analyses of Chapter 2.2-2.7 for neuropathy and retinopathy and HbA1c (Chapter 2.2, 2.4 and 2.7) and this may have limited the bias by diabetes duration.

The results of the study in Chapter 3.2 may suffer from time-lag bias as well. We compared users of insulin to non-insulin users. The underlying disease severity may therefore be an alternative explanation for the results indicating that insulin users have worse bone micro-architecture and bone strength.

Another type of time lag bias occurs when the studied outcome has a long latency period $^{45}$. Due to this long latency period an outcome will be more often detected in later stages of the disease, which makes it difficult to study the potential association between for instance first-line anti-hyperglycaemic treatment and risk of cancer as the latency period for cancer is long. 
This form of time lag bias might have also played a role when studying fracture as an outcome. Incretin agents are second or sometimes even third-line (especially GLP1RAs) treatment options. As a consequence the potential beneficial effect of incretin agents might have been shifted towards the null. However, there was no difference in the results between GLP1-RAs and DPP4-Is, while GLP1-RAs are more used as third than as second-line treatment.

\section{Confounding by indication and channelling bias}

Confounding by indication occurs when there is an extraneous determinant of the outcome parameters which is also associated with whether the drug of interest is prescribed or not ${ }^{47}$. This might for instance occur when the severity or the prognosis of the disease influences the choice of the prescribed drug. A large observational cohort study evaluating use of inhaled corticosteroids and risk of fracture showed that the initially found doubled fracture risk disappeared after adjusting for disease severity ${ }^{48}$. After adjustments the results in Chapter 2 changed only slightly, suggesting that confounding by indication might not have been a large issue. However, channelling bias may have been an issue.

Channelling bias is a form of bias which is specific to new drugs. When new drugs have claimed certain advantages, these new drugs might be selectively prescribed to patients with for instance a certain comorbidity ${ }^{49,50}$. The disease may than be attributed to the prescribed drug. When incretin agents entered the market it was hypothesized that they were associated with a decreased risk of fracture. Therefore incretins may have been preferably prescribed to patients with an increased fracture risk which then may have masked the reduced risk of fracture. However, in Chapter 2.7 a comparable study was performed with a longer follow-up, which reduced the potential for channelling bias. These results were similar to the results of the earlier studies, suggesting that channelling bias was not a large issue.

\section{Confounding}

Confounding plays a role in every observational study. When a study is not properly adjusted for confounding factors the estimated effect measures will be distorted. We were not able to adjust our results for life-style factors such as BMI, smoking and alcohol use in Chapter 2.3 and 2.5 as these were not available. Additionally we could not adjust the results for lab measurements, such as HbA1c. This might have resulted in confounded results. However, the results were similar to the results from Chapter 2.2, 2.4 and 2.7 were we used CPRD data including data on life-style variables and HbA1c.

Another confounding factor in the studies presented in Chapter 2.2-2.7 might be the fact that people who suffer from alcoholism are preferably prescribed incretin 
agents as opposed to sulfonylurea derivatives (SUs). SUs in combination with alcohol increase the risk of hypoglycaemia, while this is less of an issue with incretin agents. Use of alcohol has also been associated with an increased risk of fracture ${ }^{51}$. Alcoholism is not very well captured in the used databases, and this might therefore have masked a potential beneficial effect.

Our studies may have suffered from time-dependent confounding, which occurs when potential confounders are affected by previous exposure. This happens for instance when the association between use of statins and cognition is investigated ${ }^{52}$. Cholesterol level is an indicator for statin use, which itself influences the cholesterol level. Cholesterol level is associated with both future cognitive status and future statin use. Cholesterol level is also a mediator as statin use affects the cholesterol level which then may influence future cognition. The cohort studies presented in Chapter 2.2, 2.4 and 2.7 may have suffered from this form of bias as we adjusted for HbA1c. HbA1c is often used in practice to decide to change or not change the current treatment for T2DM. In addition, HbA1c is influenced by the used anti-hyperglycaemic treatment.

The results of the studies presented in Chapter 3.2 and 3.3 are also prone to confounding. This is especially true for the results in Chapter 3.2 as the small sample size limited the possibility to adjust the results for confounding. The results might therefore be the consequence of confounding. Additional to these potential sources of confounding, observational studies always suffer from residual confounding, due to factors that are not present in the databases, or not known to cause confounding. Residual confounding may be less of an issue when using data from the Maastricht Study as extensive phenotype data are available for all participants, which might reduce residual confounding.

Another form of selection bias may have occurred due to the fact that especially in the UK, GLP1-RAs are only recommended in patients with a $\mathrm{BMI} \geq 35^{53}$. High $\mathrm{BMI}$ has been associated with a decreased risk of hip, osteoporotic and radius/ulna fracture ${ }^{54}$. When we would have found a decreased risk of fracture this may have also been the consequence of confounding by BMI. However, we did not find a decreased risk of fracture. Moreover, this selective prescribing of GLP1-RAs to patients with a BMI $\geq 35$ is not an issue when using the Danish NHSR data, as there is no such an restriction on BMI in the Danish guidelines ${ }^{55,56}$. The results from the Danish data and the CRPD data regarding the association between use of GLP1-RAs and risk of fracture were comparable, suggesting that this restrictive prescribing in the UK has not influenced our results.

\section{Overall implications \& future perspectives}

The results of the studies presented in Chapter 2 showed no association between the use of incretin agents and risk of fracture. Additionally, long-term use of DPP4-Is was 
also not associated with fracture risk. These findings may be of value for clinical decisions regarding treatment of T2DM patients and incretin agents might therefore even be preferred in patients with a high fracture risk over other anti-hyperglycaemic drugs. However, these data were limited to a median duration of 1.6 years of actual DPP4-I use. As patients with T2DM often have to use anti-hyperglycaemic drugs the rest of their life, this is still an area that needs further investigation, including both DPP4-Is and GLP1-RAs.

Additionally, more research studying the potential association between use of GLP1-RAs and fracture needs to be performed, as the number of patients and certain types of fractures were low in the studies presented in this thesis. Therefore we may have failed to show an association just because the power in our study was too low. Furthermore, research investigating whether there is indeed a difference between liraglutide and exenatide and fracture risk is required. Another way to study the potential effect of liraglutide and exenatide on fracture risk is by investigating the association between use of these drugs and bone mechanical parameters, which can be done within the Maastricht Study.

It can be concluded from the results of Chapter 3.1 that the data from the Maastricht Study could be used in studies assessing drug utilisation or studies assessing the relative risk of specific outcomes associated with drug use. Most of the collected data in the Maastricht Study is not present in EHDs as this extensive phenotyping does not occur in practice. The Maastricht Study data thereby enables the study of unique potential associations between drug use and potential unintended effects. However, care should be taken when examining outcomes associated with the use of respiratory medications since functional impairment may have biased participation of these subjects. To make optimal use of the Maastricht Study data and the large number of included participants (>7000 currently included, 10,000 intended to be included) the prescription data needs to be updated and needs to be collected for all participants.

The results from the small explorative study in Chapter 3.2 are of interest but need to be replicated in larger cohorts as well as in longitudinal studies before definite conclusions can be drawn. In addition, bone micro-architecture and strength parameters need to be compared to patients without diabetes and the clinical relevance of the architectural and strength parameters and the relationship with fracture risk in T2DM needs to be determined.

The trabecular bone score (TBS) is a novel texture parameter reflecting pixel graylevel variations in dual X-ray absorptiometry (DXA) images ${ }^{57}$. It has also been related to bone micro-architecture ${ }^{57}$. A first study comparing T2DM patients to controls showed that part of the increased fracture risk seen in patients with T2DM is captured in the lumbar spine $\mathrm{TBS}^{58}$. However, more research is needed to investigate whether these bone scores can be used to predict fracture risk, especially in T2DM. DXA data will be available in the near future within the Maastricht Study and this could be used to 
investigate the association between the TBS and bone microarchitecture parameters measured by the HR-pQCT scan.

Based on the results from Chapter 3.3 we concluded that dosage and duration of metformin was not associated with cfPWV. Longitudinal data on cfPWV is needed to fully elucidate whether dosage and duration of metformin is associated with a potential beneficial effect on arterial stiffness.

Based on the results from our case study in Chapter 4.1 we concluded that applying propensity scores to time-fixed time-to-event analyses may give similar results as multivariable adjusted analyses. Replications are needed as well as more research evaluating time-dependent time-to-event analyses.

Missing data are an issue in almost every research, including the Maastricht Study. Currently almost all studies using data from the Maastricht Study perform a completecase analysis resulting in the exclusion of a large amount of participants (almost 25\% in Chapter 3.3). More research on how to make as optimal as possible use of the collected data is needed.

\section{Final conclusion}

In conclusion, we showed that both short-term and long-term use of DPP4-Is use was not associated with fracture risk in patients with T2DM. Also, short-term use of GLP1-RAs was not associated with fracture risk. These findings may be of value for clinical decisions regarding treatment of T2DM patients, especially those at high fracture risk.

We demonstrated that the dispensing data of the Maastricht Study was representative as compared to national drug reimbursement data. With use of these data we showed that use of insulin was associated with deteriorating effects on microarchitectural and bone strength parameters. In addition, we reported that dosage and duration of metformin was not associated with aortic stiffness as measured by cfPWV in middle-aged patients with T2DM.

From a methodological point of view it can be concluded that PSs combined with different methods to handle missing data in time-fixed analyses may give similar effect estimates as compared to multivariable adjusted analyses. In addition, when performing pharmacoepidemiological studies it is important to think thoroughly about the study design and choose the optimal design for the research question and to avoid potential (time-related) biases as much as possible. 


\section{References}

1. Scirica BM, Bhatt DL, Braunwald E, Steg PG, Davidson J, Hirshberg B et al. Saxagliptin and cardiovascular outcomes in patients with type 2 diabetes mellitus. N Engl J Med. 2013;3;369(14):1317-26.

2. Mosenzon O, Wei C, Davidson J, Scirica BM, Yanuv I, Rozenberg $A$, et al. Incidence of Fractures in Patients With Type 2 Diabetes in the SAVOR-TIMI 53 Trial. Diabetes Care. 2015;38(11):2142-50.

3. Mamza J, Marlin C, Wang C, Chokkalingam K, Idris I. DPP-4 inhibitor therapy and bone fractures in people with Type 2 diabetes - A systematic review and meta-analysis. Diabetes Res Clin Pract. 2016;116:288-98.

4. Fu J, Zhu J, Hao Y, Guo C, Zhou Z. Dipeptidyl peptidase-4 inhibitors and fracture risk: an updated meta-analysis of randomized clinical trials. Sci Rep. 2016;6:29104.

5. Mabilleau G, Mieczkowska A, Chappard D. Use of glucagon-like peptide-1 receptor agonists and bone fractures: a meta-analysis of randomized clinical trials. J Diabetes. 2014;6(3):260-6.

6. Su B, Sheng $H$, Zhang $M$, Bu L, Yang $P$, Li L, et al. Risk of bone fractures associated with glucagon-like peptide-1 receptor agonists' treatment: a meta-analysis of randomized controlled trials. Endocrine. 2015;48(1):10715.

7. Schram MT, Sep SJ, van der Kallen CJ, Dagnelie PC, Koster A, Schaper N, et al. The Maastricht Study: an extensive phenotyping study on determinants of type 2 diabetes, its complications and its comorbidities. Eur J Epidemiol. 2014;29(6):439-51.

8. Van Dooren F (2015). Diabetes and depression exploring the interface between pathophysiological and psychological factors. (Unpublished doctoral thesis). University of Maastricht, The Netherlands.

9. Van Bussel F.C (2016). Advanced MRI in diabetes cerebral biomarkers of cognitive decrements. (Unpublished doctoral thesis). University of Maastricht, The Netherlands.

10. van Dooren FE, Pouwer F, Schalkwijk CG, Sep SJ, Stehouwer CD, Henry RM, et al. Advanced glycation end product (AGE) accumulation in the skin is associated with depression: The Maastricht Study. Depress Anxiety. 2017;34(1):59-67.
11. Roche N, Morel H, Martel P, Godard P. Clinical practice guidelines: medical follow-up of patients with asthma-adults and adolescents. Respir Med, 2005;99(7):793-815.

12. Vestbo J, Hurd SS, Agustí AG, Jones PW, Vogelmeier C, Anzueto A et al. Global strategy for the diagnosis, management, and prevention of chronic obstructive pulmonary disease: GOLD executive summary. Am J Respir Crit Care Med. 2013;187(4):347-65.

13. Lorant V, Demarest S, Miermans PJ, Van Oyen $H$. Survey error in measuring socio-economic risk factors of health status: a comparison of a survey and a census. Int J Epidemiol. 2007;36(6):1292-9.

14. http://www.zorgatlas.nl/zorg/genees-enhulp middelen/geneesmiddelengebruik/gebruikersgeneesmiddelen-per-zorgkantoorregio/. Assessed: 29-6-2016.

15. Pouwels S, Lalmohamed A, Leufkens B, de Boer A, Cooper C, van Staa T, et al. Risk of hip/femur fracture after stroke: a population-based casecontrol study. Stroke. 2009;40(10):3281-5.

16. Engelen L, Lund SS, Ferreira I, Tarnow L, Parving HH, Gram J, et al. Improved glycemic control induced by both metformin and repaglinide is associated with a reduction in blood levels of 3-deoxyglucosone in nonobese patients with type 2 diabetes. Eur J Endocrinol. 2011;164(3):371-9.

17. Porta M. (2008). A Dictionary of Epidemiology. 5th Edition. New York, NY: Oxford University Press.

18. The European Network of Centres for Pharmacoepidemiology and Pharmaco vigilance (ENCePP). Guide on Methodological Standards in Pharmacoepidemiology (Revision 4). EMA/95098/2010. Available at http://www. encepp.eu/standards_and_guidances. Assessed: 1-6-2016.

19. Strom BL, Kimmel SE, Hennessy S (2012). Pharmacoepidemiology, 5th Edition. Chichester: Wiley-Blackwell.

20. Dosemeci M, Wacholder S, Lubin JH. Does nondifferential misclassification of exposure always bias a true effect toward the null value? Am J Epidemiol. 1990;132(4):746-8.

21. Correa-Villaseñor A, Stewart WF, FrancoMarina F, Seacat $H$. Bias from nondifferential misclassification in case-control studies with three exposure levels. Epidemiology. 1995;6(3):276-81. 
22. Rothman, KJ, Greenland, S, \& Lash, TL (2008). Modern Epidemiology, 3rd Edition. Philadelphia, PA: Lippincott, Williams \& Wilkins.

23. Suissa S. Immortal time bias in pharmacoepidemiology. Am J Epidemiol. 2008;167(4):492-9.

24. Lalmohamed $A$, van Staa TP, Vestergaard $P$, Leufkens HG, de Boer A, Emans P, et al. Statins and Risk of Lower Limb Revision Surgery: The Influence of Differences in Study Design Using Electronic Health Records From the United Kingdom and Denmark. Am J Epidemiol 2016;184(1):58-66.

25. Coughlin SS. Recall bias in epidemiologic studies. J Clin Epidemiol. 1990;43(1):87-91.

26. Gerhard T. Bias: considerations for research practice. Am J Health Syst Pharm. 2008 15;65(22):2159-68.

27. Azoulay L, Filion KB, Platt RW, Dahl $M$, Dormuth CR, Clemens KK, et al. Incretin based drugs and the risk of pancreatic cancer: international multicentre cohort study. BMJ. 2016;352:i581.

28. Knapen LM, van Dalem J, Keulemans YC, van Erp NP, Bazelier MT, De Bruin ML, et al. Use of incretin agents and risk of pancreatic cancer: a population-based cohort study. Diabetes Obes Metab. 2016;18(3):258-65.

29. Cooper C, Atkinson EJ, O'Fallon WM, Melton LJ $3^{\text {rd }}$. Incidence of clinically diagnosed vertebral fractures: a population-based study in Rochester, Minnesota, 1985 - 1989. J Bone Miner Res. 1992;7:221-7.

30. Fink HA, Milavetz DL, Palermo L, Nevitt MC, Cauley JA, Genant HK, et al. Fracture Intervention Trial Research Group. What proportion of incident radiographic vertebral deformities is clinically diagnosed and vice versa? J Bone Miner Res 2005;20:1216-22.

31. Suissa S. Immeasurable time bias in observational studies of drug effects on mortality. Am J Epidemiol. 2008;168(3):32935.

32. https://www.mariecurie.org.uk/globalassets/ media/documents/policy/policypublications/february-2013/death-and-dyingunderstanding-the-data.pdf. Assessed: 15-72016.

33. Andersen TF, Madsen M, Jørgensen J, Mellemkjoer L, Olsen JH. The Danish National Hospital Register. A valuable source of data for modern health sciences. Dan Med Bull. 1999;46(3):263-8.
34. Suissa S, Dell'aniello S, Vahey S, Renoux C. Time-window bias in case-control studies: statins and lung cancer. Epidemiology. 2011;22(2):228-31.

35. Khurana V, Bejjanki HR, Caldito G, Owens MW. Statins reduce the risk of lung cancer in humans: a large case-control study of US veterans. Chest. 2007;131(5):1282-8.

36. Vach $\mathbf{W}$, Blettner $M$. Biased estimation of the odds ratio in case-control studies due to the use of ad hoc methods of correcting for missing values for confounding variables. Am J Epidemiol. 1991;134:895-907.

37. Qu Y, Lipkovich I. Propensity score estimation with missing values using a multiple imputation missingness pattern (MIMP) approach. Stat Med. 2009 30;28(9):1402-14.

38. Suissa S. Immortal time bias in observational studies of drug effects. Pharmacoepidemiol Drug Saf. 2007;16(3):241-9.

39. Kiri VA, Pride NB, Soriano JB, Vestbo J. Inhaled corticosteroids in chronic obstructive pulmonary disease: results from two observational designs free of immortal time bias. Am J Respir Crit Care Med. 2005;172(4):460-4.

40. Suissa S. Observational studies of inhaled corticosteroids in chronic obstructive pulmonary disease: misconstrued immortal time bias. Am J Respir Crit Care Med. 2006;173(4):464; author reply 464-5.

41. Moride Y, Abenhaim L. Evidence of the depletion of susceptibles effect in nonexperimental pharmacoepidemiologic research. J Clin Epidemiol. 1994;47(7):731-7.

42. Black DM, Delmas PD, Eastell R, Reid IR, Boonen S, Cauley JA, et al. Once-yearly zoledronic acid for treatment of postmenopausal osteoporosis. N Engl J Med. 2007;356(18):1809-22.

43. McClung MR, Geusens $P$, Miller PD, Zippel H, Bensen WG, Roux $C$, et al. N Engl J Med. 2001;344(5):333-40. Effect of risedronate on the risk of hip fracture in elderly women.

44. Sportiello L, Rafaniello C, Scavone C, Vitale C, Rossi F, Capuano A. The importance of Pharmacovigilance for the drug safety: Focus on cardiovascular profile of incretin-based therapy. Int J Cardiol. 2016;202:731-5.

45. Suissa S, Azoulay L. Metformin and the risk of cancer: time-related biases in observational studies. Diabetes Care. 2012;35(12):2665-73.

46. Leslie WD, Lix LM, Prior HJ, Derksen S, Metge C, O'Neil J. Biphasic fracture risk in diabetes: a 
population-based study. Bone. 2007;40(6):1595-601.

47. Miettinen OS. Theoretical epidemiology: principles of occurrence research in medicine. New York, NY: John Wiley \& Sons, 1985:321-2

48. de Vries F, van Staa TP, Bracke MS, Cooper C, Leufkens HG, Lammers JW. Severity of obstructive airway disease and risk of osteoporotic fracture. Eur Respir J. 2005;25(5):879-84.

49. Petri $H$, Urquhart J. Channeling bias in the interpretation of drug effects. Stat Med. 1991;10(4):577-81.

50. MacDonald TM, Morant SV, Goldstein JL, Burke TA, Pettitt D. Channelling bias and the incidence of gastrointestinal haemorrhage in users of meloxicam, coxibs, and older, nonspecific non-steroidal anti-inflammatory drugs. Gut. 2003;52(9):1265-70.

51. Kanis JA, Johnell $O$, Oden A, Johansson $H$, McCloskey E. FRAX and the assessment of fracture probability in men and women from the uk. Osteoporos Int. 2008;19(4):385-97.

52. Power MC, Weuve J, Sharrett AR, Blacker D, Gottesman RF. Statins, cognition, and dementia-systematic review and methodological commentary. Nat Rev Neurol. 2015;11(4):220-9.
53. Type 2 diabetes in adults: managment, NICE guideline NG28 (December 2015)

54. Johansson $H$, Kanis JA, Odén A, McCloskey $E$, Chapurlat RD, Christiansen C, et al. A metaanalysis of the association of fracture risk and body mass index in women. J Bone Miner Res. 2014;29(1):223-33.

55. Järvinen S, Laine MK, Eriksson JG. Ann Med. 2016;48(3):162-8. Comparison of use of diabetic medication and clinical guidelines in four Nordic countries.

56. http://www.endocrinology.dk/PDF/Farmakolo giskbehandlingDM2rev2014.pdf. Assessed: 76-2016.

57. Pothuaud L, Carceller P, Hans D. Correlations between grey-level variations in 2D projection images (TBS) and 3D microarchitecture: applications in the study of human trabecular bone microarchitecture. Bone. 2008;42:77587.

58. Leslie WD, Aubry-Rozier B, Lamy O, Hans D; Manitoba Bone Density Program. TBS (trabecular bone score) and diabetes-related fracture risk. J Clin Endocrinol Metab. 2013;98(2):602-9. 



\section{Appendices}

Summary

Samenvatting

Valorisation Addendum

Dankwoord

Curriculum Vitae 


\section{Summary}

Osteoporosis is defined as a systematic bone disease characterized by low bone mass and deterioration of the microarchitecture of the bone, leading to bone fragility and propensity to fracture. It is estimated that 22 million women and 3.5 million men suffered from osteoporosis in Europe in 2010. In particular, hip fracture has been associated with an increased risk of morbidity and mortality.

Diabetes is a chronic disease characterized by high blood glucose levels. The estimated total number of patients with diabetes (all types) world-wide was 171 million in 2000. Projections indicate that the number of patients will increase to 366 million in 2030. The estimated prevalence of diabetes in the Netherlands was 61.8 per 1000 women and 66.1 per 1000 men in 2014. About $90 \%$ of the patients with diabetes have type 2 diabetes mellitus (T2DM) which is characterized by insulin resistance and/or abnormal insulin secretion. The majority of patients with T2DM need anti-hyperglycaemic drugs to control their blood glucose levels.

Patients with T2DM have an increased risk of fracture as compared to patients without T2DM despite the fact that they often have a normal, or even increased, bone mass. It is therefore hypothesized that T2DM patients will have decreased bone quality and/or bone strength. In addition, an increased risk of falling and the use of certain anti-hyperglycaemic drugs (thizolidinediones) have also been associated with an increased risk for fracture.

Pharmacoepidemiology is the study of the use and effects of medications in large numbers of people. It frequently utilizes large "real-world" electronic healthcare databases (EHDs) that contains longitudinal data on patient characteristics, medical diagnoses, drug use and occasionally life-style variables such as body mass index (BMI), smoking status and alcohol use. These EHDs can be used to study rare adverse events which cannot be studied in randomised controlled trials (RCTs) due to the often restricted number of included patients.

Besides EHDs, prospective cohort studies can also be used to study potential adverse events. The Maastricht Study is a large observational prospective population-based cohort study which focuses on the aetiology, pathophysiology, complications and comorbidities of T2DM. Data on patients with and without T2DM is collected. In this thesis we used data on arterial stiffness, bone quality and bone strength.

When performing observational research one often has to deal with the following issues: missing data and confounding. Standard statistical techniques cannot handle missing data and delete all observations with missing values. Multiple imputation (MI) is a statistical technique which can be used to deal with missing data, by replacing the missing data with imputed values based on the observed data. Confounding occurs when there is a third factor which is associated with both the exposure and the outcome of interest, and distorts the potential association between the exposure and the 
outcome. Adding this confounding factor to the analysis is a commonly used method to correct for confounding. Another way to deal with confounding is by use of propensity scores (PSs).

The overall objective of this thesis was to study the unintended effects of antihyperglycaemic drugs in population-based cohorts. This thesis consists of three main parts: 1) evaluation of the association between use of incretin agents, both dipeptidyl peptidase 4 inhibitors (DPP4-Is) and glucagon-like peptide 1 receptor agonists (GLP1-RAs), and risk of fracture; 2) an assessment of the usefulness of Maastricht Study data to evaluate unintended effects of diabetes medication, in particular of bone strength parameters and 3) to investigate the effect on treatment estimates when combining different techniques to handle missing data with PS analyses.

\section{Chapter 2: Fracture risk and use of anti-hyperglycaemic drugs}

In Chapter 2.1 the fracture incidence in Denmark in 2011 was studied and compared with estimations based on imputed data. The results showed that there were 80,760 incident fractures in 2011, of which $56.2 \%$ in women. The majority of the fractures occurred in the population aged 50 years and older $(50,470)$ and the incidence rates of most fracture sites increased with age. The numbers of any and hip fracture were lower than the previously imputed estimates, whereas the number of forearm fractures was higher. Future research should therefore focus on how to improve those imputations as not all countries have nationwide registry data.

New anti-hyperglycaemic drugs, the incretin agents, have been marketed since 2007. They include DPP4-Is and GLP1-RAs. Both GLP1-RAs and DPP4-Is lower the blood glucose level by stimulation of the insulin secretion. GLP1-RAs do this directly by binding to a glucagon-like peptide-1 (GLP1) receptor which results into more insulin secretion. DPP4-Is bind to the enzyme which degrades GLP1, which leads to more available GLP1 and results indirectly in more insulin secretion.

A first meta-analysis of adverse events data of RCTs showed a $40 \%$ reduced risk of fractures with use of DPP4-Is. However, this meta-analysis only included a few RCTs and the total number of fractures was low. RCTs often apply strong in- and exclusion criteria which consequently result in a selected population which might give biased results. The potential association between use of incretins and fracture risk can also be investigated by performing a pharmacoepidemiological study. In such studies the use of drugs, in this case incretin agents, can then be studied in a larger group of patients. This is done in Chapter 2.2-2.7.

In both Chapter 2.2 and 2.3 the association between use of DPP4-Is and fracture risk was studied. In Chapter 2.2 data from Clinical Practice Research Datalink (CPRD) was used, which represents $6.9 \%$ of the United Kingdom population. In Chapter 2.3 we used 
data from a Danish EHD. This EHD contains data on medical diagnoses as well as drug prescriptions of the Danish population. In contrast to the earlier published results we reported no association between use of DPP4-Is and fracture risk. In Chapter 2.4 and 2.5 use of GLP1-RAs and fracture risk was studied. We did not find an association between use of GLP1-RAs and fracture risk when using the CPRD data (Chapter 2.4) or using the Danish data (Chapter 2.5).

In Chapter 2.6 the results of Chapter 2.2-2.5 were combined using meta-analytic methods. After combining the results we did not identify an association between use of DPP4-Is or GLP1-RAs and fracture risk. In Chapter 2.7 the study period from Chapter 2.2 (2007-2012) was extended to 2007-2015 to investigate if the short duration of actual DPP4-I use, a limitation of the study in Chapter 2.2, was the reason we did not find an association. However, even with the longer duration of DPP4-I use the association between use of DPP4-Is and risk of fracture was not significant.

\section{Chapter 3: Anti-hyperglycaemic drug use within the Maastricht Study population and potential unintended effects}

In Chapter 3 we studied potential associations between use of anti-hyperglycaemic drugs and different outcomes measured within the Maastricht Study. We first investigated whether drug use in the Maastricht Study population was representative for the Dutch population (Chapter 3.1). This was studied by comparing drug use within the Maastricht Study to national data. Different drug classes were compared and the number of prescriptions per 1000 persons was comparable to national data, including for anti-hyperglycaemic drugs. However, the number of respiratory prescriptions was lower in the Maastricht Study population. In contrast, hypnotics and anxiolytics were higher in the Maastricht Study population as compared to national data. We concluded that drug use within the Maastricht Study was largely comparable to national data, and that the Maastricht Study data could be used to study drug - outcome associations.

In Chapter 3.2 bone quality and bone strength, as measured with high-resolution peripheral quantitative computed tomography, was compared between patient with T2DM who used and did not use insulin. Within the Maastricht Study HR-pQCT is used to study the micro-architecture of the distal radius, which can be used to estimate bone strength. The micro-architecture parameters, bone mineral density and bone strength were lower in insulin users, as compared to non-insulin users. This result remained even after correction for age, gender, body mass index, glycosylated hemoglobin A1c and duration of diabetes. Insulin use is most often used in a later stage of T2DM. Therefore it might be expected that patients using insulin have T2DM for a longer period or have a more severe form of T2DM than non-insulin users. Consequently, the results may be the consequence of the difference in disease duration, and severity, between the insulin users and the non-insulin users. 
In Chapter 3.3 the association between dosage and duration of metformin use (an anti-hyperglycaemic drug) and arterial stiffness was investigated. Within the Maastricht Study, different measurements of arterial stiffness are performed as this is an important risk factor for cardiovascular diseases. One of the arterial stiffness measurements is the carotid to femoral pulse wave velocity (cfPWV). The cfPWV is determined by measuring the pressure waveforms between the carotid and femoral arteries. The higher the cfPWV, the stiffer the arteries. Previous studies suggested that metformin may have a beneficial effect on arterial stiffness. However, in this study we did not show an association between dosage and duration of metformin use and arterial stiffness as measured by cfPWV, in middle-aged patients with T2DM.

\section{Chapter 4: Methodological Aspects}

In Chapter 4.1 the effect on the treatment estimates was investigated when different techniques to handle missing data were combined with PSs. The results from our casestudy showed that the estimates were quite similar when the different techniques were combined. However, we only investigated this in time-fixed analyses, in which the study period is seen as a whole. In pharmacoepidemiological studies, the study period is often split in short-time intervals to study the exposure in more detail (time-dependent analysis). Therefore, more research is needed to investigate the effect on treatment estimates, when different techniques to handle missing data are combined with PSs in time-dependent analyses.

\section{General Discussion}

In Chapter 5 the results of the different studies presented in this thesis are placed into a broader context. In addition, different forms of bias and confounding which may have occurred were discussed as well as the potential effects on the identified associations. This chapter concludes with a discussion of the clinical implications and prospects for future research.

\section{Conclusion}

In conclusion, we showed that both short-term and long-term use of DPP4-Is use was not associated with fracture risk in patients with T2DM. Also, short-term use of GLP1RAs was not associated with fracture risk. These findings may be of value for clinical decisions regarding treatment of T2DM patients, especially those at high fracture risk.

We demonstrated that the dispensing data of the Maastricht Study was representative as compared to national drug reimbursement data. With use of these data we showed that use of insulin was associated with deteriorating effects on microarchitectural and bone strength parameters. In addition, we reported that dosage and 
duration of metformin was not associated with aortic stiffness as measured by cfPWV in middle-aged patients with T2DM.

From a methodological point of view it can be concluded that PSs combined with different methods to handle missing data in time-fixed analyses may give similar effect estimates as compared to multivariable adjusted analyses. 


\section{Samenvatting}

Osteoporose is een systemische botaandoening die gekarakteriseerd wordt door een lage bot massa en een verslechtering van de micro-architectuur van het bot wat resulteert in fragielere botten en een grotere kans op fracturen. Geschat wordt dat in 2010 ongeveer 22 miljoen vrouwen en 5.5 miljoen mannen osteoporose hadden in Europa. Met name heupfracturen zijn geassocieerd met een verhoogde kans op morbiditeit en sterfte.

Diabetes Mellitus is een chronische ziekte die gekenmerkt wordt door een verhoogde bloedglucose spiegel. Het geschatte aantal mensen met diabetes (alle types) wereldwijd was 171 miljoen in 2000 en de verwachting is dat dit stijgt naar 366 miljoen in 2030. De geschatte prevalentie van type 2 diabetes mellitus (T2DM) in 2014 was 61.8 per 1000 vrouwen en 66.1 per 1000 mannen in Nederland. Ongeveer 90\% van de mensen met diabetes heeft T2DM, wat gekarakteriseerd wordt door insuline resistentie en/of abnormale insuline secretie. Het merendeel van de patiënten met T2DM wordt behandeld met bloedglucoseverlagende middelen om zo de bloedglucose spiegel zoveel mogelijk onder controle te houden.

Mensen met T2DM hebben een groter risico op het krijgen van een fractuur dan mensen zonder T2DM ondanks het feit dat ze vaak een normale of zelfs hogere botmassa hebben. Er wordt dan ook gedacht dat de kwaliteit en sterkte van het bot mogelijk verminderd is in patiënten met T2DM. Andere verklaringen zijn een verhoogd valrisico en ook het gebruik een bepaalde groep bloedglucoseverlagende middelen (thiazolidinediones) is geassocieerd met een toegenomen fractuur risico.

Farmacoepidemiologie bestudeert het gebruik en effect van medicijnen in grote aantallen mensen. Vaak worden hiervoor grote elektronische gezondheidszorg databases gebruikt die informatie bevatten over patiënt karakteristieken, medische diagnoses, medicatiegebruik en soms ook overige gegevens zoals lichaamsgewicht, roken en alcohol gebruik. Met deze grote gezondheidszorg databases is het onder andere mogelijk om bijwerkingen en effecten van medicijnen te onderzoeken die niet onderzocht kunnen worden in gerandomiseerde studies. Het aantal mensen dat geïncludeerd wordt in gerandomiseerde studies is vaak relatief laag waardoor bijwerkingen die minder vaak voorkomen niet/moeilijk onderzocht kunnen worden. Dit is echter wel mogelijk in observationele farmacoepidemiologische studies.

Naast het gebruik van grote gezondheidszorg databases kunnen ook prospectieve cohort studies gebruikt worden om mogelijke bijwerkingen van medicatie te onderzoeken. De Maastricht Studie is een groot prospectief cohort onderzoek dat zich met name op het ontstaan, complicaties en co-morbiditeiten van T2DM richt. Er worden zeer veel gegevens verzameld van gezonde personen en patiënten met T2DM. In dit proefschrift is gebruik gemaakt van gegevens over bijvoorbeeld vaatstijfheid en de botkwaliteit en -sterkte. 
Bij het doen van onderzoek komt men vaak de volgende problemen tegen: hoe om te gaan met ontbrekende gegevens en wat te doen met factoren die het resultaat onbedoeld kunnen verstoren ('confounding'). Standaard statistische technieken kunnen niet omgaan met ontbrekende waarden en verwijderen dan ook alle observaties met ontbrekende waarden, waardoor veel gegevens verloren kunnen gaan. Een van de manieren om hiermee om te gaan is door het toepassen van 'Multiple Imputation', waarbij de ontbrekende gegevens geschat worden op basis van de aanwezige gegevens en zo alsnog alle observaties meegenomen kunnen worden in de analyses.

'Confounding' ontstaat wanneer er een derde factor is die zowel met de te onderzoeken determinant als de uitkomst is geassocieerd en de relatie tussen de determinant en de uitkomst verstoord. Het toevoegen van de mogelijk verstorende factor aan de analyse is de veel gebruikte manier om voor 'confounding' te corrigeren. Daarnaast kunnen ook 'propensity scores' gebruikt worden om te corrigeren voor 'confounding'. Er wordt dan per patiënt een 'propensity score' berekend die meegenomen wordt in de analyse.

Het doel van dit proefschrift is het bestuderen van onbedoelde effecten van bloedglucoseverlagende medicijnen in grote cohorten. Het proefschrift bestaat uit drie verschillende onderdelen:

1) Het bestuderen van de associatie tussen incretines, een bepaalde groep orale bloedglucoseverlagende medicatie, en het risico op een fractuur; 2) het onderzoeken van de bruikbaarheid van gegevens uit de Maastricht Studie om farmacoepidemiologisch onderzoek uit te voeren en 3 ) het onderzoeken van het effect op de puntschattingen wanneer verschillende technieken voor het omgaan met ontbrekende gegevens gecombineerd worden met 'propensity scores'.

\section{Hoofdstuk 2: Fractuur risico en het gebruik van bloedglucose-verlagende medicijnen}

In Hoofdstuk 2.1 is de fractuurincidentie in Denemarken in 2011 onderzocht en vergeleken met schattingen op basis van geïmputeerde gegevens. De resultaten lieten zien dat er 80,760 nieuwe fracturen waren in 2011 , waarvan $56.2 \%$ in vrouwen. De meerderheid van de fracturen werd gezien bij personen die 50 jaar of ouder waren $(50,470)$ en de incidentie nam voor de meeste fractuur typen toe met de leeftijd. Het totaal aantal fracturen en het aantal heupfracturen was lager terwijl het aantal onderarmfracturen hoger was vergeleken met de geïmputeerde gegevens. Toekomstig onderzoek zou zich daarom moeten richten op het verbeteren van het imputeren van gegevens aangezien niet alle landen de beschikking hebben over grote gezondheidszorg gegevens om zelf incidenties te berekenen.

Sinds 2007 is er een nieuwe groep bloedglucoseverlagende middelen, genaamd incretines, beschikbaar gekomen. Binnen de incretines zijn er twee typen te onderscheiden, de dipeptidyl peptidase-4 remmers (DPP4-remmers) en de glucagon- 
like peptide 1 receptor agonisten (GLP1-RAs). Zowel de GLP1-RAs als de DPP4-remmers zorgen voor verlaging van de bloedglucose door de afgifte van insuline te stimuleren. GLP1-RAs doen dit direct door aan de 'glucagon-like peptide -1' (GLP1) receptor te binden wat zorgt voor meer insuline afgifte. DPP4-remmers binden aan het enzym dat GLP1 afbreekt en zorgen er zo indirect voor dat er meer GLP-1 beschikbaar blijft wat vervolgens resulteert in een toename van insuline afgifte.

Een eerste meta-analyse, van bijwerkingen gerapporteerd in gerandomiseerde studies, liet een $40 \%$ lager risico op fracturen zien met het gebruik van DPP4-remmers. Echter, deze meta-analyse bevatte maar een beperkt aantal gerandomiseerde studies en totaal aantal fracturen. Gerandomiseerde studies vaak uitgevoerd in geselecteerde populaties wat kan leiden tot een vertekening van de resultaten. Een andere manier om de mogelijke associatie tussen het gebruik van incretines en fractuur risico te onderzoeken is door het uitvoeren van observationele farmacoepidemiologische studies. In zulke studies kan het gebruik van, in dit geval incretines, in een grotere groep gebruikers worden onderzocht. Dit is toegepast in Hoofdstuk 2.2-2.7.

In zowel Hoofdstuk 2.2 als Hoofdstuk 2.3 werd de associatie tussen het gebruik van DPP4-remmers en fractuurrisico bestudeerd. In Hoofdstuk 2.2 zijn gegevens van een grote huisartsen database, de 'Clinical Practice Research Datalink' (CPRD), representatief voor 6,9\% van de Britse bevolking, onderzocht. In Hoofdstuk 2.3 zijn gegevens uit een Deense database bestudeerd. Deze Deense database bevat onder andere medische gegevens en medicatie gegevens van de gehele Deense bevolking. In tegenstelling tot hetgeen in eerdere onderzoeken werd gerapporteerd, toonden beide studies in dit proefschrift geen associatie tussen het gebruik van DPP4-remmers en fracturen aan. In Hoofdstuk 2.4 en 2.5 werd de relatie tussen het gebruik van GLP1-RAs en fracturen bestudeerd. Ook bij het gebruik van GLP1-RAs werd geen relatie gevonden op basis van de CPRD (Hoofdstuk 2.4) en de Deense database (Hoofdstuk 2.5).

In Hoofdstuk 2.6 zijn de resultaten van Hoofdstuk 2.2-2.5 samengevoegd door middel van een meta-analyse. Ook na het samenvoegen van de resultaten was er geen associatie tussen het gebruik van DPP4-remmers of GLP1-RAs en fractuurrisico. Vervolgens is in Hoofdstuk 2.7 de gebruikte studie periode uit Hoofdstuk 2.2 (20072012) verder uitgebreid naar 2007-2015 om te kijken of één van de beperkingen van de studie in Hoofdstuk 2.2, de korte duur van het gebruik van DPP4-remmers, de reden was dat we geen associatie vonden. Echter ook in de uitgebreide studie met langduriger gebruik van DPP4-remmers kon geen associatie tussen het gebruik van DPP4-remmers en fractuurrisico worden aangetoond.

\section{Hoofdstuk 3: Bloedglucoseverlagend medicijn gebruik binnen de Maastricht Studie populatie en mogelijke onbedoelde effecten}

In Hoofdstuk 3 zijn mogelijke associaties onderzocht tussen het gebruik van bloedglucoseverlagende medicijnen en verschillende uitkomsten gemeten in de 
Maastricht Studie. In eerste instantie is onderzocht of het geneesmiddelgebruik in de Maastricht Studie populatie representatief was voor de Nederlandse populatie (Hoofdstuk 3.1). Dit is onderzocht door het medicijngebruik in de Maastricht Studie te vergelijken met nationale gegevens. Verschillende groepen medicijnen zijn vergeleken en voor de meeste groepen was het aantal prescripties per 1000 personen gelijk aan de nationale gegevens, inclusief de bloedglucoseverlagende middelen. Het aantal prescripties voor astma en chronische obstructieve longziekte was lager in de Maastricht Studie populatie. Daarentegen was het aantal prescripties voor slaap- en kalmeringsmiddelen juist hoger ten opzichte van landelijke gegevens. We concludeerden dat medicatie gebruik in de Maastricht Studie grotendeels representatief is voor de nationale populatie en dat Maastricht Studie gegevens gebruikt kunnen worden om mogelijke medicatie - uitkomst associaties te onderzoeken.

In Hoofdstuk 3.2 is de botkwaliteit en botsterkte, gemeten met behulp van 'highresolution peripheral quantitative computed tomography' (HR-pQCT), vergeleken tussen patiënten met T2DM die wel en geen insuline gebruikten. Binnen de Maastricht Studie wordt met HR-pQCT gedetailleerd gekeken naar de micro-architectuur van het bot in de distale radius en kan onder andere de botsterkte berekend worden.

Zowel de micro-architectuur parameters als botdichtheid en botsterkte waren lager in de insuline gebruikers ten opzichte van de niet-insuline gebruikers, ook na correctie voor leeftijd, geslacht, 'body mass index', geglycosyleerd hemoglobine A1c en diabetes duur. Aangezien insuline gebruik bij patiënten met T2DM vaak de laatste stap in het behandelproces is, is te verwachten dat insuline gebruikers langer en mogelijk ook een ernstigere vorm van T2DM hebben dan niet-insuline gebruikers. De gevonden verschillen tussen de insuline en niet-insuline gebruikers in botkwaliteit kunnen het gevolg zijn van insuline gebruik maar kunnen mogelijk ook veroorzaakt zijn door het verschil in duur en ziekte-ernst (waarvoor niet goed kan worden gecorrigeerd in deze studie) tussen deze twee groepen gebruikers.

In Hoofdstuk 3.3 is de associatie tussen duur en dosis van metformine gebruik (een bloedglucoseverlagende medicijn), en arteriële stijfheid onderzocht. Binnen de Maastricht Studie wordt onderzoek gedaan naar verschillende maten van vaatstijfheid aangezien dit een belangrijke risicofactor is voor het ontstaan van hart- en vaatziekten. Als maat voor vaatstijfheid wordt onder andere gekeken naar de snelheid waarmee de drukgolf zich verplaatst over het traject van de halsslagader naar de liesslagader, de zogenoemde 'polsgolfsnelheid'. Hoe hoger deze snelheid hoe stijver de bloedvaten zijn. In eerdere studies werd gesuggereerd dat metformine een gunstig effect zou hebben op vaatstijfheid (metformine zou de arteriële stijfheid verlagen). Echter in de studie in dit proefschrift werd geen associatie gevonden tussen de dosis en duur van metformine gebruik en arteriële stijfheid, gemeten via de polsgolfsnelheid, in patiënten met T2DM van middelbare leeftijd. 


\section{Hoofdstuk 4: Methodologische aspecten}

In Hoofdstuk 4.1 is het effect op de puntschatting onderzocht wanneer verschillende technieken om met ontbrekende waarden om te gaan gecombineerd worden met 'propensity scores'. Uit de resultaten van onze 'case-study' bleek dat er weinig verschil zat in de puntschattingen wanneer de verschillende technieken werden gecombineerd. We hebben dit echter alleen getest in een analyse waarbij we de studie periode als één geheel hebben gezien ('time-fixed analyses'). In farmacoepidemiologische studies wordt de studie periode vaak opgesplitst in kortere periodes om zo een nauwkeuriger beeld van de blootstelling te krijgen ('time-dependent analyses'). Er is daarom meer onderzoek nodig naar wat er gebeurd met de puntschatting wanneer technieken om met ontbrekende gegevens om te gaan gecombineerd worden met 'propensity scores' in deze 'time-dependent analyses'.

\section{Algemene discussie}

In Hoofdstuk 5 zijn de resultaten van de verschillende studies in een breder perspectief geplaatst. Daarnaast zijn er verschillende vormen van vertekening en verstoring ('bias' en 'confounding') besproken die mogelijk plaats hebben gevonden evenals het mogelijke effect op de gevonden associaties. Ook zijn de klinische implicaties van het onderzoek in dit proefschrift besproken, net als de mogelijkheden voor toekomstig onderzoek.

\section{Conclusie}

Op basis van dit proefschrift kan geconcludeerd worden dat zowel kort- als langdurig gebruik van DPP4-remmers niet geassocieerd is met fractuurrisico in patiënten met T2DM. Ook kortdurend gebruik van GLP1-RAs is niet geassocieerd met fractuurrisico. Deze bevindingen zijn mogelijk van belang bij het nemen van de beslissingen die betrekking hebben op de behandeling van patiënten met T2DM, en dan met name voor T2DM patiënten met een hoog fractuur risico.

Uit de onderzoeken binnen de Maastricht Studie kan geconcludeerd worden dat de medicatie gegevens van de Maastricht Studie representatief zijn ten opzichte van de nationale medicatie gegevens. Daarnaast werd een associatie gevonden tussen insuline gebruik en een verminderde botsterkte en -kwaliteit. De dosis en duur van metformine gebruik bleek niet geassocieerd te zijn met vaatstijfheid in patiënten van middelbare leeftijd met T2DM in de Maastricht Studie.

Ten slotte kan er vanuit een methodologisch perspectief geconcludeerd worden dat wanneer 'propensity scores' gecombineerd worden met verschillende technieken om met ontbrekende gegevens om te gaan in 'time-fixed analyses', dit vergelijkbare resultaten geeft ten op zichte van multivariabele gecorrigeerde analyses. 


\section{Valorisation Addendum}

Knowledge valorisation refers to the "process of creating value from knowledge, by making knowledge suitable and/or available for social (and/or economic) use and by making knowledge suitable for translation into competitive products, services, processes, and new commercial activities" (adapted definition based on the National Valorisation Committee 2011:8). In this addendum the societal relevance of the results presented in this thesis will be discussed as well as the possibilities for valorisation of our results.

\section{Healthcare problem}

Osteoporosis is defined as a systematic bone disease characterized by low bone mass and deterioration of the microarchitecture of the bone, leading to bone fragility and propensity to fracture. It has been estimated that about 22 million women and 3.5 million men suffered from osteoporosis in Europe in 2010. The worldwide annual estimated costs of hip fractures, both direct and indirect, were $\$ 34.8$ billion in 1990 and are expected to increase to $\$ 131$ billion in $2020^{2}$.

Type 2 diabetes mellitus (T2DM) is a chronic disease characterised by high blood glucose levels. Estimations showed that about 422 million people suffered from diabetes (all types) in $2014^{3}$. Patients with T2DM have to take anti-hyperglycaemic drugs to control their blood glucose levels, often for the rest of their lives. This has a huge impact on patient's lives as well as on healthcare costs.

T2DM has been associated with an increased risk of fracture. Different mechanisms have been proposed which partly explain this increased risk, including an increased risk of falling, reduced bone strength or quality and the use of anti-hyperglycaemic drugs. However, the effect of recently introduced anti-hyperglycaemic drugs, the incretin agents, on fracture risk in the population at large was unclear.

\section{Investigational approach}

In this thesis the potential association between newly marketed drugs and fracture risk was investigated using "real-life" data. The class of incretin agents includes two different drug types, dipeptidyl peptidase 4 inhibitors (DPP4-Is) and glucagon-like peptide 1 receptor agonists (GLP1-RAs). The association between incretin agents and fracture risk was studied separately for the two types of incretins. In addition, the association was studied using two separate databases, one representative for the UK population and one representative for the Danish population. Thereafter the results were combined to further investigate the potential association between use of incretin agents and risk of fracture. This was followed by a study investigating long-term DPP4-I use (up to 8.5 years) and risk of fracture using the UK database. 


\section{Main findings}

In contrast to the first results of a meta-analysis of adverse events data ${ }^{4}$ we were not able to show an association between use of incretin agents, either DPP4-I or GLP1-RA, and risk of fracture in the population at large. In the different individual studies we did not found a reduced risk of fracture, with use of DPP4-Is or GLP1-RAs. In addition, when the results were combined in a meta-analysis, we were also not able to show a reduced risk of fracture. Moreover, when the duration of follow-up was extended we were still not able to show a reduced risk of fracture with long-term use (up to 8.5 years) of DPP4-Is.

\section{Target population}

The results of this thesis are important for general practitioners (GPs) making clinical decisions regarding treatment of T2DM patients, especially those at high fracture risk. Use of thiazolidinediones, another type of anti-hyperglycaemic drugs, has been associated with an increased risk of fracture. In patients at a high fracture risk those drugs are therefore not preferred. In this thesis it was shown that use of incretin agents was not associated with fracture risk. They may therefore be prescribed in patients with T2DM at high fracture risk, without increasing their fracture risk even further.

Based on the results of a first meta-analysis of adverse events data of clinical trials a $40 \%$ reduction of fracture risk with use of DPP4-Is was shown ${ }^{4}$. This may have led to the preferred prescribing of DPP4-Is as compared to other second-line treatment for T2DM patients. However, only a small number of studies were included and the total number of fractures was only 63. Based on the results from the presented pharmacoepidemiological studies in this thesis it can be concluded that there is no association between use of DPP4-Is or GLP1-RAs and risk of fracture. There is therefore no reason to preferably prescribe DPP4-Is or GLP1-RAs to patients with T2DM based on the potential protective effect on fracture risk with these incretin agents.

Recently, updated meta-analyses, including a larger number of trials, have been published and reported no association between use of DPP4-Is and fracture risk ${ }^{5,6}$. This shows that a meta-analysis of adverse events data with only a small number of trials included could lead to biased results and should therefore be interpreted with caution.

When interpreting the results of pharmacoepidemiological studies potential sources of bias and confounding need to be considered, as these may have a large influence on the final results. However, when performed well, pharmacoepidemiological studies are relatively cheap option to study drug-outcome associations which can be used to prevent unnecessary expensive clinical trials investigating the same drug-outcome associations. In addition, with pharmacoepidemiological studies it is possible to investigate associations using data from real-life patients, which is expected to better represent clinical practice than the data of patients included in randomised controlled trials. 


\section{Innovation and future research}

Although we showed that use of DPP4-Is and GLP1-RAs was not associated with fracture risk, more research is still needed. Especially the potential association between use of GLP1-RAs and fracture needs to be further studied. Long-term GLP1-RA use needs to be investigated as well as research investigating whether there is indeed a different association between the different GLP1-RA types (liraglutide and exenatide), and fracture risk.

With the studies in Chapter 3 we showed that drug dispensing data in combination with Maastricht Study data can be used to perform pharmacoepidemiological studies, with new unique parameters, such as bone strength and bone micro-architecture, which are often not available in electronic health care databases. This makes the Maastricht Study a very unique cohort and gives many opportunities for future research and valorisation of the results. For instance, data from the Maastricht study could be used to study the potential effects of anti-hyperglycaemic drugs on bone mechanical parameters.

Another option for future studies with use of data from the Maastricht Study is investigating the association between different bone strength and micro-architecture parameters and the trabecular bone score (TBS). This bone score is a novel texture parameter reflecting pixel gray-level variations in dual X-ray absorptiometry (DXA) images. DXA data will be available in the near future in the Maastricht Study which then could be studied in combination with bone strength and micro-architecture parameters as well as in combination with the use of different anti-hyperglycaemic drugs. 


\section{References}

1. Svedbom A, Hernlund $E$, Ivergård $M$, Compston $J$, Cooper C, Stenmark J, et al; EU Review Panel of IOF. Osteoporosis in the European Union: a compendium of country-specific reports. Arch Osteoporos. 2013;8:137.

2. Johnell $O$. The socioeconomic burden of fractures: today and in the 21st century. Am J Med. 1997;103(2A):20S-25S; discussion 25S-26S.

3. World Health Organization. WHO Global report on diabetes. 2016. http://apps.who.int/iris/bit stream/10665/204871/1/9789241565257_eng.p df. Assessed: 13-12-2016.
4. Monami M, Dicembrini I, Antenore A, Mannucci E. Dipeptidyl peptidase-4 inhibitors and bone fractures: a meta-analysis of randomized clinical trials. Diabetes Care. 2011;34(11):2474-6.

5. Mamza J, Marlin C, Wang C, Chokkalingam K, Idris I. DPP-4 inhibitor therapy and bone fractures in people with Type 2 diabetes - A systematic review and meta-analysis. Diabetes Res Clin Pract. 2016;116:288-98.

6. Fu J, Zhu J, Hao Y, Guo C, Zhou Z. Dipeptidyl peptidase-4 inhibitors and fracture risk: an updated meta-analysis of randomized clinical trials. Sci Rep. 2016;6:29104. 


\section{Dankwoord}

Het moment van het afronden van mijn promotieonderzoek is bijna daar. Na het schrijven van dit laatste hoofdstuk rest alleen nog de verdediging. Dit "boekje" was niet tot stand gekomen zonder de hulp van velen. ledereen, collega's, co-auteurs, de beoordelingscommissie, vrienden en familie, die op wat voor wijze dan ook hebben bijgedragen aan de totstandkoming van dit proefschrift, wil ik hierbij dan ook hartelijk danken. Een aantal mensen wil ik in het bijzonder bedanken.

Frank, bedankt voor de fijne samenwerking en begeleiding gedurende mijn promotieonderzoek. Ik heb veel van je geleerd over het efficiënt opschrijven en publiceren van studies, het programmeren in SAS en natuurlijk over het uitvoeren van farmacoepidemiologisch onderzoek. Daarnaast heb ik ook erg genoten van de verschillende methodologische discussies over "study designs" en mogelijke "biases".

Joop, bedankt voor de fijne samenwerking en klinische input. Ondanks dat je niet altijd in Maastricht aanwezig was, was je wel erg betrokken bij mijn onderzoek. Daarnaast kon ik altijd rekenen op snelle reacties op emails en kritische blikken op mijn manuscripten, bedankt hiervoor.

Ronald, bedankt voor de leerzame en ondertussen bekende "schrijfsessies", waarin ik een hoop geleerd heb over het schrijven van een artikel.

Hein, bedankt voor de fijne samenwerking, de feedback op mijn manuscripten en je klinische input als ziekenhuis apotheker.

Abby, mede door jou ben ik pas echt gaan motorrijden :). Heel fijn om af en toe even lekker te ontspannen op de motor en o.a. Zuid-Limburg, de Eiffel en Ardennen per motor te verkennen. Ook de avondjes in onze "stamkroeg" waren erg gezellig en zorgde voor de nodige afleiding tijdens het afronden van mijn proefschrift.

Yannick, na mijn eerste maanden als enige fulltime PhD student in de apotheek kwam jij me vergezellen. Het was erg fijn om zowel werk-gerelateerde als niet werkgerelateerde zaken met je te kunnen delen. Heel veel succes met het afronden van je eigen promotieonderzoek. 


\section{Curriculum Vitae}

Annemariek Driessen was born on November $7^{\text {th }}, 1988$ in Naarden, The Netherlands. She graduated from secondary school at Sint Vitus College Bussum in 2007. In August 2010 she obtained her Bachelor's degree in Biomedical Sciences at Leiden University. Hereafter she studied statistical sciences for the life and behavioral Sciences and obtained her Master's degree in Mathematics at Leiden University, September 2012.

In November 2012 Annemariek started her PhD research at the Department of Clinical Pharmacy and Toxicology of the Maastricht University Medical Centre+, within the School for Public Health and Primary Care (CAPHRI) at Maastricht University. This research was supervised by prof. dr. J.P.W. van den Bergh, dr. F de Vries, dr. R.M.A. Henry, and dr. H.A.W. van Onzenoort. During her PhD Annemariek also worked at the research center of the Maastricht Study were she participated in data collection.

Annemariek has been awarded with two young investigator awards during her PhD, and she has given several talks at international conferences. Currently she is appointed as a postdoctoral research fellow at Maastricht University within CAPHRI and the School of Nutrition and Translational Research in Metabolism (NUTRIM). 
